UNITED STATES

DEPARTMENT OF THE INTERIOR

GEOLOGICAL SURVEY

\title{
EMPIRICAL TRANSFER FUNCTIONS FOR \\ STATIONS IN THE CENTRAL CALIFORNIA
}

SEISMOLOGICAL NETWORK

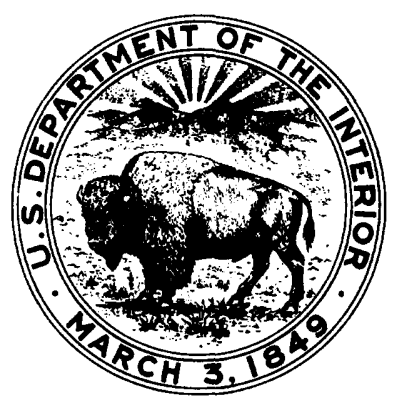

OPEN-FILE REPORT 76-259

This report is preliminary and has not been edited or reviewed for conformity with Geological Survey standards and nomenclature 
Empirical Transfer Functions for Stations in the

central Cal ifornia Seismographic Network

by

William H. Bakun and Jay Dratler, Jr.

\section{ABSTRACT}

A sequence of calibration signals composed of a station identification code, a transient from the release of the seismometer mass at rest from a known displacement from the equilibrium position, and a transient from a known step in voltage to the amplifier input are generated by the automatic daily calibration system (ADCS) now operational in the U.S. Geological Survey central California seismographic network. Documentation of a sequence of interactive programs to compute, from the calibration data, the complex transfer functions for the seismographic system (ground motion through digitizer), the electronics (amplifier through digitizer), and the seismometer alone are presented. The analysis utilizes the Fourier transform technique originally suggested by Espinosa et al. (1962).

Section I is a general description of seismographic calibration. Section II contrasts the "Fourier transform" and the "least-squares" techniques for analyzing transient calibration signals. Theoretical considerations for the Fourier transform technique used here are described in Section III. Section IV is a detailed description of the sequence of calibration signals generated by the ADCS. Section $V$ is a brief "cookbook description" of the calibration programs; Section VI contains a detailed sample program execution. Section VII suggests the uses of the resultant empirical transfer functions. Supplemental interactive programs by which smooth response functions, suitable for reducing seismic data to ground motion, are also documented in Section VII. Appendices A and B contain complete listings of the Fortran source codes while Appendix $C$ is an updatecontaining preliminary results obtained from an analysis of some of the calibration signals from stations in the seismographic network near Oroville, California. 
I. Introduction

II. Techniques for Analysis of Transient Calibration Signals . . 4 III. Theoretical Considerations . . . . . . . . . . . . 7

A. Linear Systems Analysis . . . . . . . . . 7

B. The Input $I(f)$ for the Calibration Transients . . . 9

1. The Mass Release Calibration Transients . . . 9

2. The Electronics Step Calibration Transient . . 9

C. The Output $O(f)$ from the Calibration Transient . . 10

D. The Response of the Seismometer . . . . . . 13

E. Response at High Frequency . . . . . . . . 15

IV. Calibration Data . • . . . . . . . . . . . 17

V. Using the Calibration Programs . . . . . . . . . . 21

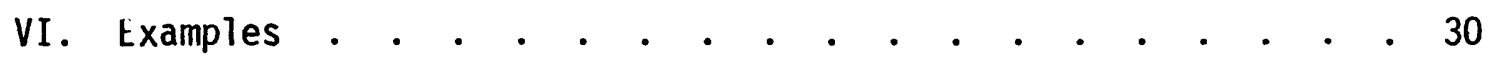

A. Preparation for Program CALIB . . . . . . 30

B. A Typical Case . . . . . . . . . . . . . 31

C. A Noisy Calibration Sequence . . . . . . . 35

VII. Using the Response Functions . . . . . . . . . 38

A. Obtaining the Input Ground Motion . . . . . . 38

B. Obtaining a Smooth System Response from the Empirical Response Functions . . . . . . . . . . . 39

C. Monitoring Temporal Variations in the System . . . 43

Appendix A. Program CALIB . . . . . . . . . . . . 44

Appendix B. Program CALSMO . . . . . . . . . . . . 69

Appendix C. Further Results from the Oroville Net . . . . . 73

References . . . . . . . . . . . . . . . . 76

Start of Figures . . . . . . . . . . . . . . . 77 


\section{INTRODUCTION}

Any seismological study which depends on the amplitude or frequency content of seismic signals requires a calibrated seismographic system. In addition to providing a means of obtaining ground motions from the seismogram and/or obtaining theoretical seismograms for computed ground motions, an automatic daily calibration system yields a number of other valuable bonuses, particularly in a large network. Visual inspection of the daily calibration signal during routine scanning of the seismograms provides a quick check that the system is still operating - and that it is operating with approximately the characteristics desired. If the operation is judged unsatisfactory, the calibration signal can provide diagnostics of what component in the total system is malfunctioning - and how. Calibration signals may be utilized to pinpoint deficiencies in an operating system that otherwise might escape detection.

In order to take full advantage of these potential benefits, the calibration signals should be: (1) scanned daily when arrival times are read to detect gross system malfunctions, (2) analyzed on a routine, if infrequent, basis to detect subtle changes in the system, and (3) analyzed to determine the system response whenever the ground motion for a particular event is desired.

There are several ways of empirically obtaining a transfer function, or system response. The steady-state approach often used on the lab bench is to drive the system sequentially with many harmonic inputs of known amplitude and to plot the normalized amplitudes of the harmonic output. Since relatively lengthy calibration time (downtime for both the system and the person doing the calibrating) is required, this approach 
is not attractive for automatic, daily calibrations. In addition, relatively complicated and expensive circuitry is required to generate a sequence of harmonic inputs for automatic remote calibration. A more practical approach involves the use of transient input signals, such as steps, which have significant and known frequency content over a fairly large band width.

Calibration using transient signals has several advantages when compared with the steady-state approach. The transient technique is quite general and only requires input signals which are known and have finite duration. If the system has zero dc response (as does the velocity transducer seismograph), the duration of the output transient is relatively short so that the amount of system down time for calibration purposes need not be burdensome. Finally, it is relatively easy to design simple circuits to create step inputs for automatic transient calibration of remote seismographic stations.

Such electronic circuits have been designed and built for the short-period seismographic stations in the Central California Seismographic Network operated by the U. S. Geological Survey. Collectively called the automatic daily calibration system (ADCS), the circuits are designed for reliable and continuous low-power operation in the field. One automatic daily calibration unit ( $A D C U$ ) is to be installed at each seismometer site along with the $J 302$ preamplifier-VCO unit and the seismometer itself. At present, about $1 / 4$ of the central California stations have ADCU's installed. Detailed descriptions of the design and operation of the ACDS are available in internally published reports by Jerry Eaton and John Van Schaak.

In the present report, we describe theoretical techniques and a 
collection of interactive graphical computer programs for viewing and analyzing the numerous output signals produced by the ADCS in a large network. The essence of our technique is the use of fast-Fourier transform (FFT) to calculate for each station the response of (1) the entire seismographic system, from ground to digitizer output, (2) the electronic systems, from preamplifier input to digitizer output, and (3) the seismometer alone. With this technique, an empirical response function for each of a large number of stations over nearly the entire band width of seismological interest is obtained from transient signals of short duration. 
Methods for calculating response functions from transient signals may be divided into two categories: Fourier-transform techniques or least-squares techniques. The Fourier-transform technique is an empirical approach, which considers the system as a "black-box", with a response equal to the Fourier transform of its output signal divided by the Fourier transform of its known input signal. For example, the transient resulting from the release of a seismometer mass from rest in a displaced position corresponds to the integral of impulse response of the system to acceleration (Espinosa et al., 1962). A similar empirical approach, which uses a pseudo-random binary sequence generator as input to the system, has been employed for routine calibration of the LASA (Wood and Guillette, 1966; Ziolkowski, 1972). In the least-squares approach an analytical form of the response function is assumed, and the values of parameters in this assumed form are calculated by making a least-squares fit of the theoretical output to the actual transient signal (Mitchel1 and Landisman, 1969; Jorasch and Curtis, 1973).

Both approaches to calibration using transients have advantages and deficiencies. The least-squares approach is flexible enough to permit preferential weighting of the fit at times when the transient signal has a good signal-to-noise ratio. In contrast, the Fourier transform approach is restricted to equal weighting over the duration of the transient output. Since additive noise is presumably time-invariant and the signal strength is concentrated near the beginning of the transient, the Fourier transform technique is thus more prone to signal-to-noise problems than is the least-squares technique. In fact, the spectral content of a step input is inversely proportional to frequency while 
that of the system noise is pseudo-white, i.e., having amplitude approximately constant with frequency. Thus, the Fourier transform in practice tends to become noisy at higher frequencies. The Fourier transform calibration procedures described in this report, which are designed for use with the ADCS of Eaton and Van Schaack, have significant noise at frequencies greater than about $15 \mathrm{~Hz}$. The leastsquares approach, on the other hand, may be used to estimate system parameters from which the system response at all frequencies (for which the assumed analytical response function is valid) can be calculated. The disadvantage of the least-squares approach is that it requires an assumption of the analytical form of the system response. For particular elements in the system, such as the seismometer, specification of the analytical form of the response presents little problem. However, what is desired is the total system response, including the amplifiers, the voltage controlled oscillator ( $V C O)$, the transmission link (which often includes commercial telephone lines), the tape recording unit, the tape playback unit, the discriminator and its filters, and the digitizer. If, as is often the case (Dratler, 1975), the theoretical response of any of these elements is unknown or loosely approximated, the leastsquares approach will fit the transient with an incorrect function. The resultant system response will have the assumed form, but will not correctly described the system behavior. In contrast, the Fourier transform approach assumes nothing about the seismographic system except that it is linear, causal, and time-invariant. The system is a "black-box" with an unspecified response, and the Fourier transform technique produces a set of numbers that describes the system response - whatever it might be. For simple systems known to be operating correctly, the least-squares 
approach has clear advantages. For more complicated systems with elements poorly controlled and/or subject to malfunction, the Fourier transform approach is more reliable. For many systems, the two approaches are complementary. A reconnaissance using the Fourier transform approach can check to see that the system is operating in the expected fashion and produce corrections to remove the system response from the data; the least-squares approach may then be used if an analytical response function is required and/or the response in a frequency band not available using the Fourier transform technique is desired. Thus, the two approaches have different roles. The Fourier transform technique can detect and pinpoint malfunctions in the system - for example, an unknown tape recorder resonance or an overdriven (non-linear) amplifier, while the least-squares approach can identify the particular system parameter to change in order to achieve a desired system response shape. However, it should be emphasized that the Fourier transform technique is a truly empirical method of calibration, which requires no assumption about the form or level of the system response. 


\section{A. Linear systems analysis}

The transfer function or response $T(f)$ of a linear system is defined as the complex ratio of the output $O(f)$ in response to a steady-state harmonic input $I(f)$. The terms "transfer function" and "response" are used interchangeably in this report. The definition is shown schematically in figure 3.1. As long as the system is linear, causal, and time invariant, the transfer function completely describes its properties (e.g., see Papoulis, 1962, p. 81-83). $T(f)$ is conveniently expressed as $|T(f)| e^{i \phi(f)}$ where $|T(f)|$ is the amplitude or modulus response and $\phi(f)$ the phase response of the system. If $T(f)=a+i b$, $|T(f)| \equiv\left[a^{2}+b^{2}\right]^{\frac{1}{2}}$ and $\phi \equiv \tan ^{-1}(b / a)$.

Once the transfer function or system response is known, it can be removed from the system output to obtain the desired input using $I(f)=$ $\frac{0(f)}{T(f)}$. Equivalently the system impulse response $I(t)$ may be obtained by Fourier transforming the transfer function; then the impulse response may be removed from the data by convolution in the time domain. The time domain and frequency domain computations are mathematically equivalent. However, use of the Fast Fourier Transform (FFT) algorithm results in a significantly faster (and hence less expensive) computation in the frequency domain.

The Fourier transform $\mathscr{H}(f)$ of a time signal $x(t)$ is defined to be:

$$
\mu^{\prime}[x(t)]=\int_{-\infty}^{\infty} x\left(t^{\prime}\right) e^{-2 \pi f t^{\prime}} d t^{\prime},
$$

where $f$ is frequency in Hertz.

The inverse Fourier transform $f^{-1}(t)$ is:

$$
g^{-1}[S(f)]=\int_{-\infty}^{\infty} S(f) e^{i 2 \pi f t} d f .
$$




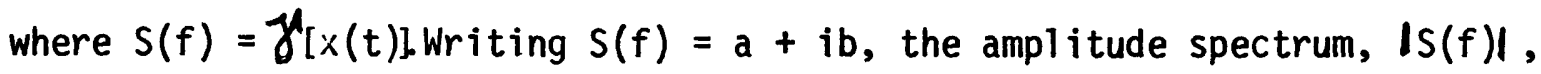
and the phase spectrum, $\phi(f)$, are defined as above:

$$
\begin{aligned}
& |S(f)| \equiv\left[a^{2}+b^{2}\right]^{\frac{3}{2}}, \\
& \phi(f)=\tan ^{-1}(b / a) .
\end{aligned}
$$

The system shown in figure 3.1 may represent a cascade of linear, causal, time invariant systems (see figure 3.2 ). The transfer function of the total system is the product of the transfer functions of the component systems. If one can construct the transfer function appropriate for each of the $N$ components in the system, then the total transfer function is easily obtained by multiplication. Alternatively, if means are available to determine the overall transfer function $T(f)$ and also the transfer functions $T_{j}(f)$ of $J$ of the system components, then the product of the transfer functions of the remaining $\mathrm{N}-\mathrm{J}$ components can be calculated as $T(f) /\left[T_{1}(f) \cdot T_{2}(f) \ldots T_{J-1}(f) T_{J}(f)\right]$.

For example, in the Central California Seismographic Network, the mass-release calibration signal provides a means of estimating the transfer function of the total system, $T(f)$, between the motion of a seismometer frame, and the digitized seismogram.

The total system thus includes the seismometer, amplifiers, VCO, transmission links, tape recorder, tape playback unit, discriminator, filters, and digitizer. Each of these components is described by a transfer function, $T_{j}(f)$. We also have a means, in the calibration signal resulting from the voltage step to the first stage of the amplifier, of estimating the product of the entire system less the seismometer; i.e., $T_{2}(f) \ldots T_{n}(f)$. The transfer function of the seismometer, $T_{2}(f)$, is then $T(f) /\left[T_{2}(f) \ldots T_{n}(f)\right]$. This is an important result since we have a good idea of what the seismometer response should be and no means of computing that response directly from 
the calibration signals available. Agreement between the expected response and the response obtained using the ratio scheme outlined above provides assurance that our calibration results are reliable. B. The input $I(f)$ for the calibration transients

1. The mass release calibration transient

In the ADCS used for calibration of the Central California Seismographic Network, a system calibration is obtained from the so-called "mass-release" transient. To produce this transient, the sensing coil of the seismometer is used as a motor to displace the seismometer mass and hold it at rest for the mass release. During this displacement, the seismometer is disconnected from the preamplifier. The sensing coil is driven with a known constant current $I$, so the coil exerts a force $G_{L} \cdot I$, where $G_{L}$ is the seismometer motor constant, against the restoring spring. When the current $I$ is switched off, and the seismometer reconnected to the preamplifier, the spring exerts a step in force $=G_{L} \cdot I$. The step in force is equivalent to a step in acceleration, $a=\frac{G_{L} \cdot I}{M}$, where $M$ is the seismometer mass. Thus, $a(t)=\frac{G_{L} \cdot I}{M} H(t)$, where $H(t)=\left\{\begin{array}{ll}1, & t>0 \\ \frac{1}{2}, & t=0 \\ 0, & t<0\end{array}\right.$, is the Heaviside step function. The Fourier transform of a Heaviside function is $\frac{1}{2} \delta(f)-i /(2 \pi f)$, or $\frac{1}{2 \pi f} e^{i_{3} \pi / 2}$ for $f>0$ (Bracewell, 1965). Thus, the input for the mass release transient is $I_{M-R}(f)=a(f)=\frac{G_{L} \cdot I}{2 \pi f M} e^{i \frac{3 \pi}{2}}$, for $f>0$.

\section{The electronics step calibration transient}

In order to measure the response of the system electronics, excluding the seismometer, a voltage step is applied directly to the preamplifier input, producing a second transient. The voltage step $E(t)$ to the amplifier can be expressed as $E \cdot H(t)$, where $H(t)$ is again the Heaviside 
function. From the preceding section, it follows that the input for the electronics step transient is

$$
I_{e-s}(f)=E /(2 \pi f) e^{i_{3} \pi / 2}
$$

C. The output $O(f)$ from the calibration transients

The spectra of the calibration transients are computed using a fast Fourier transform (FFT) algorithm. Before transforming via the FFT, several preliminary operations are necessary. If the sampling rate during digitization is $x \quad$ samples per second (sps), then the sample interval is $\Delta t=1 / x$. Letting $t=0$ at the onset of the calibration transient, the transient signal can be written as $s_{i}$ where $s_{1}=s(0)$, $S_{2}=S(\Delta t), \ldots, S_{n}=S(n-1) \Delta t=S(T) . T$ is called the signal length or window length.

In practice, the sampling rate for seismic signals digitized at NCER is a minimum of 100 sps. We recommend digitization rates of 200 sps so that the Nyquist or folding frequency $=\frac{1}{2 \Delta t}=100 \mathrm{~Hz}$. Since all discriminators used with the Central California Seismic Network have multipole lowpass output filters with a real time cutoff frequency of $30 \mathrm{~Hz}$, there is little danger of contamination from al iasing across the $100 \mathrm{~Hz}$ Nyquist frequency.

Terminating a time signal after $T$ seconds is mathematically equivalent to multiplying the signal by a rectangular or "boxcar" window of length $T$. The boxcar function $\equiv\left\{\begin{array}{llll}0, & t \leq 0 \text { or } t>T \\ 1, & t=0 & \text { or } t & t \\ 1, & 0<t< & <\end{array}\right.$

The boxcar window is sometimes referred to as the "do nothing window" since truncating a transient after $T$ seconds superficially appears to do nothing to the signal. The Fourier transform of a boxcar window of length $T$ is $\operatorname{sinc}(f T) \equiv \sin \frac{(\pi f T)}{\pi f T}$. It is a fundamental theorem of 
Fourier transform theory that multiplication of two functions is equivalent to convolution of their transforms. Thus, the Fourier transform of a truncated transient is the transform of the transient convolved with sinc $(f T)$. The spectrum of the windowed transient at frequency $f_{0}$ is thus a weighted average of the "actual" spectrum at frequencies near $f_{0}$. An examination of the weighting function, sinc (fT), shows that most of the contribution to the spectrum at frequency $f_{0}$ comes from the band $f_{0}-1 / T \leq f \leq f_{0}+1 / T$, since $\mid$ sinc $(f T) \mid$ is small for $f T>1$. We say that the resolution of the spectrum is $1 / T$. For a sampling frequency of $100 \mathrm{~Hz}$, the window length $\mathrm{T}$ is of order 10 seconds for both the mass release transient and the electronics step transient, so the resolution is about $0.1 \mathrm{~Hz}$. It is important to note that the sidelobes in the sinc function can cause "sidelobe contamination" at frequencies $f$ from a large spectral peak at $f_{0}$, where $\left|f-f_{0}\right|<\frac{1}{T}$. To avoid "sidelobe contamination", it is a common practice to "prewhiten" or to remove spectral peaks prior to spectral analysis. One serious problem for sidelobe contamination in the spectral analyses of the calibration transients is the presence of a large dc ( $\equiv$ zero frequency) component. Since velocity transducers have zero dc response, the presence of any dc component is due to drift in the $\mathrm{VCO}$ or discriminator center frequency. In the absence of additive noise, the average amplitude or dc component equals the signal amplitude preceding the transient onset. Thus, the dc component has no meaning for calibration, and it is therefore removed by subtracting $S_{1}$, the amplitude of the transient at $t=0$, from the entire calibration signal. Any significant remaining dc component indicates too short a window length $T$ (i.e., we have not considered a window length long enough to encompass the response of the system to the input). Truncating the calibration 
too soon (i.e., T too small) results in degradation of the spectrum and should be avoided.

FFT algorithms require input signals with certain specified numbers of points. The particular FFT routine used here requires $2^{\mathrm{N}}$ points, where $\mathrm{N}$ is a positive integer. In practice, we select the window length $\mathrm{T}$ for seismological reasons so that the number of points rarely equals $2^{N}$. The FFT routines used here automatically append a number of samples with zero value to the end of the time series (i.e., pads out the series with zeroes) so that the total number of points is equal to $2^{11}=2048$ points. (If the number of points is already larger than 2048, the series is truncated to 2048 points.) Since the sample rate is the same for the mass release transient and the electronics step transient, this insures that the window lengths of the padded out transients are the same. For 200 samples $/ \mathrm{sec}, T=(2047)(.005)=10.24$ seconds. (Window lengths of 10.24 seconds are sufficient to encompass the calibration transients satisfactorily so that the dc component in the spectrum of the transient is smal1.) FFT routines calculate the Fourier series of the time signal; i.e., spectral points are computed at harmonics of $1 / T$, up to and including the Nyquist frequency. Note that "padding out the time series with zeroes" artificially increases the resolution in the sense that the resolution is really the reciprocal of the window length of the unpadded series, while spectral values are calculated for frequency intervals less than the resolution.

By insuring that the frequencies for which spectra are calculated are the same for the two calibration transients, the computation of the response of the seismometer alone is greatly facilitated, since the 
seismometer response is the ratio of the system response to the electronics response. The amplitude of the seismometer response is just the ratio of the system and electronicsvresponses, while its phase is the difference between the system phase response and the electronics phase response. Since all components in seismographic systems are causal, the phase responses are continuous. The FFT algorithm calculates the phase by taking an inverse tangent. Since the inverse tangent is a multiple-valued function, the calculated phase angles are for the - $\pi$ to $\pi$ radians branch. The continuous phase spectrum is reconstructed by removing the $2 \pi$ phase discontinuities in the calculated phase spectrum. The phase response of the seismometer is then the difference between the reconstructed continuous phase responses.

D. Response of the seismometer

The seismometer used in the central California net is essentially a mass suspended by a spring. The magnetic damping is viscous. Referring to the schematic representation of the seismometer shown in figure 3.3 , the equation of motion can easily be shown to be:

$$
\ddot{z}+2 \rho \Omega \dot{z}+\Omega^{2} z=-\ddot{x},
$$

where $y=B / 2 \sqrt{K M}$ is the damping factor and $\Omega=\sqrt{K / M}$ is the angular resonant frequency. $\quad \ddot{-x}$ is the forcing acceleration. Letting $Z(s)=L[z]$ and $X(s)=$ $L[x]$ where $L$ represents the Laplace transform, the equation of motion for the seismometer is:

$$
\begin{aligned}
& s^{2} Z(s)-s z(0)-\dot{z}(0)+2 \rho \Omega s Z(s)-2 j \Omega z(0)+\Omega^{2} Z(s)= \\
& -s^{-} x(s)-s x(0)-\dot{x}(0)
\end{aligned}
$$

Rewriting, we have:

$$
z(s)=\tilde{I}(s) \cdot x(s)-\frac{\mathcal{Z}(s)}{s}[z(0)-x(0)]-\frac{\sigma(s)}{s^{2}}[\dot{z}(0)-\dot{x}(0)+2 \rho \Omega z(0)] \text {, }
$$

where $f(s)=-s^{2} /\left(s^{2}+2 g \Omega s+\Omega^{2}\right)$. For a steady state input, $Z(s)=\sigma_{j}^{\prime}(s) \cdot X(s)$ 
Converting the Laplace transform to a Fourier transform in the usual way by letting $s=i_{\omega}$, we have:

$$
\widetilde{F}(\omega)=\omega^{2} /\left(\Omega^{2}+2 \rho \Omega i \omega-\omega^{2}\right)
$$

Since the voltage out of a coil-magnet transducer is $v=G \dot{z}$ where $G$ is the generator constant, we have

$$
T(\omega)=G i \omega^{3} /\left(\Omega^{2}+2 \rho \Omega i \omega-\omega^{2}\right) .
$$

$T(\omega)$ is the complex transfer function or response of the velocity transducer seismometer in units of volts/ground displacement. The amplitude and phase response of the seismometer (displacement sensitivity) are plotted for damping factors of $\rho=1$ (critical damping) and $f=.7$ in figures 3.4 and 3.5 .

The seismometer response expressed in terms of input ground acceleration (i.e., the acceleration sensitivity) is $\mathrm{T}_{\text {ACCEL }}$ $(\omega)=T(\omega) /(i \omega)^{2}$ Normalizing the angular frequency $\omega$ to the angular resonant frequency $\Omega$, we can write the seismometer amplitude response to ground acceleration as:

$$
\left|T_{\text {acce } 1}{ }^{\left(\omega^{-}\right)}\right|=\frac{G}{\Omega}\left[\left(\omega^{-}-\frac{1}{\omega^{-}}\right)^{2}+(2 \rho)^{2}\right]^{-\frac{1}{2}}
$$

and the seismometer phase response to ground acceleration as:

where $\omega^{-}=\omega / \Omega$.

$$
\phi\left(\omega^{-}\right)=\tan ^{-1}\left(\frac{1 / \omega^{-}-\omega^{-}}{2 \xi}\right)
$$

The seismometer amplitude and phase response to ground acceleration for a range of damping factors are plotted in figures 3.6 and 3.7. An examination of the expression for $\left|T_{A C C E L}\left(\omega^{-}\right)\right|$indicates that the acceleration sensitivity is symmetric about and maximum at the seismometer resonant frequency. The response at low frequency $(\omega \ll \Omega)$ and high frequency ( $\omega>>\Omega$ ) are proportional to $\omega$ and $\omega^{-1}$ respectively. On a $\log -\log$ plot, the damping factor $\rho$ can be easily determined; it is the distance from the maximum response to the intersection of the highand low- frequency response asymptotes. 


\section{E. Response at high frequency}

At frequencies greater than about $10 \mathrm{~Hz}$, the empirical response functions for "normal" calibration signals are jittery. As noted in sections IIIB and IIIC, the inputs have the form of steps or Heaviside functions with Fourier transforms proportional to $\frac{1}{\omega} e^{i_{3} \pi / 2}$. The system noise is "pseudo-white." (By pseudo-white, we mean the amplitude of the noise spectrum is nearly constant over the passband of the system.) Some of the noise is non-white in the sense that the character of the noise spectrum is repeatable; i.e., certain peaks in the noise spectrum are reproducible from noise sample to noise sample ano often can be identified with specific physically identifiable non-ideal system responses (e.g., tape drive resonances). However, the general level of the noise is flat with frequency. Since the signal amplitude spectrum is proportional to $1 / \omega$ and the noise amplitude spectrum is flat, the signal-to-noise $(S / N)$ ratio decreases with increasing frequency. The character of the response functions begins to be jittery at the frequency for which the $S / N$ ratio approaches unity.

The response functions obtained using the Fourier transform techniques described in this report are valid only in the frequency band for which the signal is not seriously contaminated by system noise. The breakdown of the Fourier transform calibration procedures at the high frequencies is fundamental and is the result of using an input signal with sparse high-frequency content. The band of valid response can be extended to higher frequencies by differentiating the calibration transient and reducing the window length. Since the high rate of change is concentrated at the transients' onsets, a 1.56 second window length is sufficient to encompass the differentiated transients (see figures 3.8 and 3.9 ). 
Differentiating and transforming the transient with a shorter window length conserves the signal yet reduces the amplitude of the contaminating noise spectrum. Tests with a typical calibration signal (see figure 6.2) indicate that differentiating and using a reduced window length extends the range of valid high frequency response about one octave. Of course, the response at low frequency cannot be obtained accurately from signals of 1 to 2 seconds length. For this reason, the low frequency response is obtained from the transient ( $T=10.24$ seconds) and the high frequency response from the differentiated transient ( $T=1.56$ seconds). The two parts of the response are automatically patched together at an intermediate frequency which is selected interactively by the user (e.g., see figure $6.13)$.

For typical calibration signals, selection of an intermediate frequency $=5 \mathrm{~Hz}$ is satisfactory. Tests with very noisy calibration signals (e.g., figure 6.29) indicate that only marginal improvement in the high frequency response can be obtained from the differentiated transients.

It should be pointed out that use of a $1.56 \mathrm{sec}$ window implies a resolution $=0.78 \mathrm{~Hz}$. Although it appears possible to reduce the window length to $0.1 \mathrm{sec}$ for the differentiated electronics step transient (see figure 3.9 ), the resultant poor resolution $=10 \mathrm{~Hz}$ would effectively mask real - and unpredicted - response charactertics, such as tape resonances, etc.

Additional programs (CALFIX in appendix B) to obtain smooth response functions at high frequency from the jittery empirical responses are described in detail in section VIIA. 
The series of computer programs described in this report are desianed for interactive graphical analysis of data produced by the automatic daily calibration system (ADCS) developed for the California Seismographic Network by John Van Schaack and Wayne Jackson. Once each day, the ADCS interrupts the stream of seismic data from a given seismometer and generates a sequence of identification and calibration signals. These signals are: a slow-speed digital pulse code for identification of the station, a record of system electronics noise, a mass-release signal for calibration of the seismometer system, and an electronic step signal for calibration of the station, telemetry and recording electronics. Once they are recorded at Menlo Park along with seismic data, these signals provide a permanent and timely record of the identity, quality of data, and overall response of a given station.

Several models of the calibrator circuitry exist at present, and detailed descriptions of the systems are available in internally published notes by Jerry Eaton and John Van Schaack. We limit our description here to those points necessary to understand the methods and problems in the present analysis schemes.

Figure 6.2 shows a typical sequence of calibration signals, telemetered to Menlo Park from the ADCS at network station BGG. Seismic noise from the seismometer is interrupted by a quiet section of $1 \mathrm{sec}$ duration, 
followed by a series of 12 clear pulses constituting the ID code. Except for the first, which is $250 \mathrm{msec}$ wide, the positive-going pulses are each $200 \mathrm{msec}$ wide; and all are separated by $200 \mathrm{msec}$. Measured from the level of the quiet section, each ID pulse is either $0.4 V$ or $0.7 V$ in amplitude, depending on whether it represents a zero bit or a unity bit in the Station ID. The ID itself is the decimal equivalent of the binary number represented by the pulse train, with the first pulse representing the least significant bit. Figure 4.1 shows a typical structure of the ID code.

After the ID code is completed, the input of the seismic amplifier is terminated with an impedance equivalent to that of the seismometer and L-pad. The result is a record of system noise lasting about 2.7 seconds. This record includes noise from all electronic circuits from the preamplifier to the computer. At the end of this period the seismometer coil is released, producing a calibration signal for the seismographic station. During this "mass-release" calibration, the seismometer output is attenuated by an amount dependent on the calibrator model to keep the transients on scale. This signal is allowed to die away for about $8 \mathrm{sec}$; then a voltage step is applied to the input of the seismic preamplifier (J302). After the resulting transient is allowed to die away for $16 \mathrm{sec}$, the ADCS returns the station to its normal operating condition.

Certain features of the ADCS design present problems in data analysis. The start time of the calibration sequence and the timing of the ID code and system noise test are determined by a CMOS crystal oscillator with a specified drift rate of about $10^{-5} /$ day. If several stations are initially set to undergo automatic calibration at the same time of day, 
usually 2300 GMT, their calibration times will drift apart about 0.86 sec per day. Over a period of a year, the onset times may drift apart by as much as 5 minutes. Although this scatter makes it unlikely that a significant portion of the Central California Seismic Network will be down during a single event, it makes more difficult the digitization and reduction of calibration data from several stations simultaneously. While the overall start time and ID code timing are determined by a crystal oscillator, the timing of the mass-release calibration and the amplifier step test is determined by RC time constants. Both the onset time (relative to the ID code) and the duration of the calibration signals are therefore subject to as much as $15 \%$ variation from station to station. In the present analysis scheme, this uncertainty is handled with a combination of generous tolerances, pulse-locating subroutines, and human interaction.

Calibration data telemetered from field stations to the Menlo Park facility are recorded and reproduced by the same techniques used in the analysis of seismic data. Data are stored on magnetic tape as bundles of 8 multiplexed FM tones, one bundle per tape track. For computer analysis, the data must be played back, discriminated, and digitized. Fortunately, the NCER Data Processing Center has well-established procedures for digitizing seismic data on 7-track computer-compatible

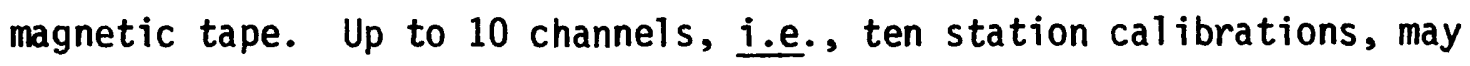
be digitized and multiplexed at rates up to $40 \mathrm{~K}$ total samples per second. Normally, a sampling rate of $200 \mathrm{~Hz}$ per channel is sufficient for analysis of the calibration data, so any number of stations from 1 to 10 can be digitized simultaneously. Digitized data are multiplexed and recorded on tape with 12 bit resolution (including sign), i.e., as integers with 
a range of \pm 2048 counts, in blocks of 1000 points. The digitizer sensitivity is normally set so that $\pm 2.5 \mathrm{~V}$ at a discriminator output corresponds to \pm 2048 counts.

To analyze calibration data from a given set of stations, the following steps are necessary. First, library or data tapes of the desired instruments for the desired day are searched for the desired calibration records and the records are digitized onto 7-track tape. The digital tape is then sent to the Lawrence Berkeley Laboratory computer center for inclusion in the LBL operating library. Finally, the data are called up and reduced interactively via the Tektronix 4010 CRT terminal at Menlo Park. Through interactive control in the analysis program, the user can: unpack and demultiplex the data; plot and view the calibration sequences and their various parts; decode the ID code; view and modify the tables of station constants; and calculate and plot the noise spectrum, system response, electronics response, and seismometer response. In addition, the program provides estimates of the free period and damping for each station from the calibration data; and the response functions may be written to a common disk file for use by other programs at LBL.

The present set of calibration analysis programs provides a streamlined procedure for obtaining the response functions for a particular instrument on a particular day with a minimum of trouble. For a given set of 10 stations, location and digitization of the calibration data requires about 1 afternoon. (The calibration transients often will be digitized at the same time as the seismic data for which the calibration is needed.) If the digitized tape is sent to LBL overnight, reduction of data via the interactive programs may take place the next afternoon. 
Thus, we anticipate that experimental calibration of 10 instruments, with plots of system and seismometer response in practical units, will require typically less than two days using the present program. V USING THE CALIBRATION PROGRAMS

The present programs have been designed for the user unacquainted with the LBL computer systems. In fact, little knowledge of computers in general is required to operate the programs successfully. However, before the user can analyze calibration data, he must supply the LBL system with a tape of digitized data. The standard procedures of the USGS Data Processing Center will suffice to produce this tape, but there are a few caveats. The maximum number of points per channel which the unpacking program can accept if 12,000 . Although it may be possible to use lower digitization rates, we recommend a sample rate per channel of $200 \mathrm{~Hz}$. At this sample rate, the longest time series which can be accommodated is $60 \mathrm{sec}$. Since the calibration sequence is about $30 \mathrm{sec}$ long, stations whose calibration onset times differ by more than $30 \mathrm{sec}$ should not be digitized together. If they are digitized together, the sequence of programs may have to be rerun for each channel. In general, we recommend making hard copies of the calibration data before digitizing and choosing the digitizer start time as close as possible to the onsets of the calibration sequences. If onset times for different stations differ by more than $30 \mathrm{sec}$, those stations should be digitized separately.

When a digitized tape is sent to LBL, its paper tag is returned with an "assigned LBL number." Once the user has this number, he may run the calibration programs by following five simple steps: 
1. Create a common file of calibration data from the digital tape (eg., see Figure 6.0). Note that this step does not require a Tektronix CRT terminal and may be run at any time prior to the execution of the calibration program (steps 2 through 5 ).

2. Log onto the LBL system, on the same machine, B or C, used in step 1. (Our experience is that a minimum of $150_{8}$ CPU should be allowed for each channel (i.e., seismographic station) to be analyzed.)

3. $\uparrow L O A D, C A L I B$, JDRAT

4. $\quad$ RUN

5. Enter data requested by programs.

Figure 6.1 shows the sequence for logging on, and running the programs as well as the initial interaction. Most of the data entry requests are self-explanatory. The "common file" referred to is the file created in step 1.

The entry of the NUMBER OF SCANS TO BE SKIPPED allows for those cases in which digitization is begun well before the start of the calibration sequence. A "scan" is simply a digitizer sequence of one sample per channel. Thus, if 1000 scans are skipped, unpacking of data will begin 1000 samples (on each channel) after the start of digitizing. Hard copy records of calibration data made during digitization are useful for calculating this entry when necessary.

The next entry, of CHANNEL NUMBERS OF SELECTED CHANNELS, IN ORDER determines which channels are unpacked from the copy on disk of the digitized tape. If calibration data for more than one instrument are to 
be analyzed at a given sitting, the corresponding digitizer channels should be entered in order. If only one digitizer channel is of interest, the single channel number may be entered. At the end of the spectral analysis program, reduction of data from a new instrument can be begun by choosing the option "J=6 PICK NEW DATA TRACE" (see below). In order to use this option, however, the digitizer channel number corresponding to the desired trace must have been included in the list of SELECTED CHANNELS.

With the next entry of DIGITIZER CHANNEL FOR TRACE TO BE DISPLAYED," the program which decodes the ID code and separates the calibration record into its components begins. The user enters the number of the digitizer channel corresponding to desired calibration. If the trace selected was not included in the "SELECTED CHANNELS", a diagnostic is sent to the terminal and the user is forced to pick another channel.

After the digitizer rate is entered, graphical interaction begins. First, the entire calibration record is plotted on the screen as shown in Figure 6.2 and the user is asked whether the ID code is present. (As is true of all plots in this series of programs, the user must enter any chararacter (followed by a carriage return) to return from the plotting routines. This pause allows the CRT screen to be copied. A plot is complete if a line of identifying text is at the top and the light pointer is in the upper left corner of the CRT screen.) If the user indicates that the ID code is present, he is asked to pick the start of the code. Using the dials at the right of the terminal, he places the vertical cursor somewhere in the quiet interval before the ID code and types any character, without a carriage return. This puts the $X$-position of the cursor in memory; the Y-position, determined by the horizontal cursor, is not used. 
If the code is not present, or if it is too noisy to be interpreted, the user indicates by entering a 2 . The program then asks the user to enter the station ID. The proper ID number is crucial, as it is used to find the proper instrument parameters in the constant table (see below). After entering the ID, or picking the start of the ID code, the user is asked to pick the start of the system noise record. He does this by using the vertical cursor as described above. For best results, the beginning of the noise record should be chosen close to the end of the ID code. With the noise onset chosen, the program reports the station ID obtained either by decoding the ID code or from the user entry. The line "ENTER ANY CHAR TO CONTINUE" is then printed, allowing the CRT screen to be copied. Entry of any character, followed by a carriage return, causes the program to continue.

Now begins separation of the data record into three time series: the system noise record, the seismometer release test, and the amplifier step test. Each of these records is selected by computer algorithms, and the user has the option of viewing, editing, and/or writing on a disk file, each individually. The start of the noise series is determined by the cursor entry discussed above, and its original length is $1.5 \mathrm{sec}$. The beginnings of the seismometer release test and amplifier step test are selected by computer algorithms which pick the peak of each transient, find a point on the initial rise with half the absolute value of the peak, and space backward a predetermined amount to the beginning of the transient. These algorithms are thus simplified routines to find the point of maximum slope of the transient, which is the most easily identified point in time. The point half-way up the peak is an approximation to the point of maximum slope, and the initial point is determined by subtracting a given time 
interval from this half-way point. Of course, if the shape of the tran(i.e. standard Central California) sients are grossly different from normal, these algorithms will not work, and the starting points for the transients must be picked by the user (see below). To insure that DC drift in the telemetry does not affect the selection of the starting points, an average of 100 values from the system noise series is subtracted from the decimated calibration series used to pick the transients. The seismometer release signal and electronics step signal chosen by the computer routines are 7.0 and $15.5 \mathrm{sec}$ long, respectively.

Beginning with the system noise record, the user is offered the following options for each time series: "1=PLOT ALL", "2=PLOT START", "3=CHANGE", and "4=CONTINUE." The first option creates a plot of the entire series as it exists at the time the option is entered. The ordinate of the plot is digitizer counts from -2000 to 2000 , slightly less than the full scale of \pm 2048 , while the abscissa is the sample step. Unlike the plot of the entire calibration sequence (Figure 6.2), which is decimated to a sample interval of $20 \mathrm{msec}$, plots of the individual time series are undecimated; so the sample interval is the reciprocal of the digitizer rate. The initial sample (number 1 ) is the sample 1 sec prior to the beginning of the noise record, allowing the noise record to be extended backward if necessary. The option "2=PLOT START" creates a similar graph to that of "PLOT ALL", but only the first 100 points of the data series are plotted. This allows the onset of the calibration signals to be inspected carefully.

If the plots of the entire time series and of its beginning are satisfactory, the option " $4=C O N T I N U E "$ is used to write the time series to a disk file read by the spectral analysis program. Otherwise, the option "CHANGE" may be used to change the start and/or end points. New 
points are selected by entering the sample number, using the abscissa labels on the previous plot as a guide, or by using the cursor, at user option. After new start and/or end points(s) are chosen, the user may write the series to a disk with option 4 or may check the changes with options 1 or 2. Option 4 may be used at any time, even before the first plot of a given time series is viewed. However, it is usually wise to inspect all three time series before continuing to the seismometer constant program.

After option 4 is used for the last time series (the electronics step test), a new program is loaded and executed. Using the station ID as an index, this program finds the necessary mechanical and electronic parameters for the seismometer station in a table of constants stored in the Program Storage System (data cell) at Berkeley. The constants are written to the CRT screen in the format shown in figure 6.9 , and a dummy entry is required to allow the screen to be copied. Next, the user is given the option of altering the table of constants, including the name of the station.

Alterations to the constant table are necessary to reflect the introduction of new stations and modifications in old stations, or to permit reduction of calibration data using constants from prior modifications. Whenever the option to alter is exercised, the date ("update") at the top of the constant table is automatically set to the current date. The new constants may be written on the data cell upon normal termination of the final program in the sequence (eg., see Figure 6.44). 
Alterations in the station name and/or constants are made as indicated in figure 6.9. When alteration is discontinued by entering a zero, the screen is cleared and the new lists of constants is printed. At this point, or after the option to alter is declined, certain station parameters are calculated from the list of constants according to formulas obtained from circuit analysis of the calibrator unit. These parameters are calculated exactly, using the specified values of circuit and attenuator resistance determined by the particular model of the calibrator and the attenuator setting recorded in the station log. The parameter values are printed on the CRT screen, as shown in figure 6.9, after a dummy entry for copying. After the calculated parameters are listed, there is another dummy entry for copying, following which the altered constants and calculated parameters are written to disk files and the constants program is terminated. At this point, all the required time series and instrumental parameters are stored on disc files, and the final program "CALTEM" is loaded and executed.

This program computes the Fourier transforms of the calibration transients and the response functions of the total seismograph system, the electronics, and the seismometer alone. The program is logically organized so that the user selects one of seven possible options (e.g., see figure 6.28). At the completion of option $1,2,3,4$, or 5 , the program requests the selection of another of the 7 options. Options may be repeated. Option $6, " \mathrm{~J}=6$ PICK NEW DATA TRACE", allows the user to examine the calibration transients for other selected channels. Option 7, " $\mathrm{J}=7$ TERMINATE" is the only way to terminate the pnogram normally. During execution of options $1,2,3,4$, or 5 , the user can view additional plots by selecting options listed on the CRT screen; e.g., 
"WHAT NEXT?

$$
1=\text { CONTINUE } 2 \text { = REPLOT WITH Y MAX" }
$$

or "WHAT NEXT?

$$
1=\text { CONTINUE } 2 \text { = PLOT PHASE RESPONSE" }
$$

or

"OUTPUT TO A DISC FILE?

$$
1=\text { YES } 2 \text { = NO" }
$$

Inadvertently entering a character other than 1 or 2 does not terminate the program. The program also pauses to display the results of the series of calculations necessary to obtain the response functions from the calibration transients (e.g., see section IIIC and figures 6.10 and 6.13). To continue, the user responds to the message "ENTER ANY CHAR TO CONTINUE." by typing any character and a carriage return.

Normal program termination is via option 7 , "J = 7 TERMINATE"

Non-normal termination is known to occur in two instances:

1. The allotted CPU time has been exceeded. To check the remaining time, enter "دCU." If the result is 15 CUS remaining, the user is out of time. The system automatically doles out a few more CUS so that files created by the job can be made common, copied to the data cell, etc.

2. The user has manually selected window lengths that are of insufficient length. The response functions already written to the 
sys tem common file "RESP" are not affected by non-normal program termination. Updates to the seismometer constants table (residing on the disc file "CONSTS") may be written to the seismometer constants table on the data cell only after normal program termination. To rewrite the data cell seismometer constants table after non-normal program termination, execute the following control card

"LIBRITE, JDRAT, CONSTS/RB ,CONSTS, 50, W=DRATLER." 
A. Preparation for program CALIB

For demonstration purposes the calibration program was run on the calibration transients generated 10 June 75 at stations BGG (Boggs Mountain) and SWB (Swansons Bluff) in the Central California Seismic Network. For this particular test, unshielded coaxial cable was used to transmit the multiplexed signals the 50-odd feet from the output jacks of the phone line terminal to the input of the discriminators. This was done for the purpose of el iminating the system noise introduced by the magnetic tape recorder and playback machines. (Recent progress in increasing the dynamic range of the tape units to $48 \mathrm{db}$ by using both capstan servo control and subtractive tape speed compensation suggests that bypassing the present "noisy" tape unit configuration presents a more realistic picture of the signal-to-noise ratio achievable at NCER in the near future.) The calibration transients for BGG and SWB were digitized at 200 sps with 2 other channels - an IRIG time code and the calibration transient for station PNP (Pinion Peaks). (The results for PNP are comparable to those for BGG and will not be discussed further in this report. The multiplexed ( 4 channels) digitized signals were placed on the second file (file 1 = dummy file) of the digital tape. An examination of the paper plots made during digitization indicated that 6000 scans $(1$ scan $=$ 1 sample per channel) were digitized preceding the beginning of the digitized calibration sequence. The multiplexed digital tape was transported via courier to LBL and logged into the LBL tape 1ibrary. The LBL tape library number assigned was \#10963. The above underlined information (i.e., 200 sps, file 2 of LBL tape \#10963, 4 multiplexed channels, 6000 scans) are necessary input to the calibration programs. 


\section{B. A typical case}

In this section, a step-by-step example of a "typical" successful execution of the calibration programs is presented. Figures referred to are hard copies of the CRT screen at the various stages of execution. Note that the symbol "!" is a carriage return and follows those characters entered by the user. Figure 6.0 shows the preliminary commands necessary to create a common file from the digital tape. (Note that common files usually exist for several days.)

Figure 6.1 shows the initial commands and interactive entries. The initial interactive entries are discussed in general in Section III and for this example in particular in Section VI-A. Note that the user has verified the existence of the common file "RW10963" created before beginning of execution program CALIB. All 4 multiplexed channels have been selected for access; channel 2 was selected for display. (Channel 3 will be displayed later in Section VI-C, "a noisy calibration sequence.")

After digitization rate of $200 \mathrm{sps}$ is entered, the entire calibration record for channel 2 is displayed on the CRT screen (see figure 6.2 ). The sequence of calibration signals in the calibration record is described in detail in Section IV. After entering a character to continue, the user enters a "l" to indicate the presence of the ID code. The start of the ID code and the start of the system noise are selected by cursor. (Interactive entry via the cursor is described 
in section $V$ ). The algorithm for decoding the ID code indicates that multiplexed channel 2 is seismographic station \#2. It is strictly coincidence that the channel \# is the same as the station ID number.

At this point the system noise signal, the seismometer mass release transient and the amplifier (or electronics) step transient are serially displayed so that the user can check and, if desired, alter the time windowing automatically selected by the algorithms contained in program "PICK." The options for viewing and modifying the time windowing are described in section V. Figure 6.3 is the system noise signal; the user has approved the time window by entering a "4." The entire seismometer mass release transient is shown in figure 6.4. By entering a "2", the user has exercised the "PLOT START" option. The resulting display shown in figure 6.5 indicates the picking algorithm has selected the initial break 2 samples or $10 \mathrm{msec}$ early. The user approves the window for the seismometer mass release transient by entering a "4." The entire amplifier or step test transient is shown in figure 6.6. Noting that the picking algorithm has erred in including a portion of the transient resulting from the return of the station to normal operation, the user has elected to modify the time window by entering a "3." The start point is left unaltered by entering a " 3 ".

The new end point is selected by cursor as described in section $V$. By entering a "1", the user replots the entire "rewindowed" amplifier step test transient (see figure 6.7). By entering a "2", a "blowup" of the start is obtained (see figure 6.8). By next entering a "4", the user approves the "rewindowed" amplifier step test transient. 
At this point, the 3 calibration signals, with approved time windows, have been written onto local disc files. The seismometer constants table that resides permanently in the LBL system has been accessed and searched for the entry corresponding to ID code \#2; the results of the search are then displayed (see figure 6.9). Figure 6.9 indicates that the name of the seismographic station with ID code \#2 is "BGG, Boggs Mountain." Also listed are seismometer constants and the amplifier attenuation setting. The data of the last previous alteration of the BGG entry in the seismometer constants table - 12 Sept 75 - is also shown. By entering a "2", the user chooses to use the displayed tabulated constants. Certain parameters, e.g., the seismometer test current, calculated from the seismometer constants and the circuitry appropriate for the $\mathrm{C5}$ calibrator unit at $\mathrm{BGG}$ are also 7 isted.

The user is next presented the 7 options shown in figure 6.28. The user entered a "l" to examine the system noise spectrum. The results of the several operations discussed in section IIIC are shown in figure 6.10 and the system noise amplitude spectrum in figure 6.11 . Since the ordinate scale is satisfactory, the user enters a "l" to continue. (Note that the noise spectrum shown in figure 6.11 is seriously contaminated by the transient due to the termination of the ID code.) The user next opted to not save the noise spectrum by entering a "2" (see figure 6.12).

The user is again presented the options shown in figure 6.28. Noting that the programs are more efficient for option 5 than for options 2, 3, and 4 selected serially and wanting to see all, the user entered a " 5 ". The results of the operations described in sections IIIC and IIIE for the seismometer mass release transient are displayed in figure 6.13. Note that the user has elected to use the derivative of the transient to obtain the response at frequencies greater than $5 \mathrm{~Hz}$. The system amplitude 
response is then displayed (see figure 6.14). (N.B., for conversion of the system response to units of volts/micron ground displacement, 2047 digitizer counts $\equiv 2.5$ volts at the output of the discriminator.) Noting that the response is on scale, the user opts to display the system phase response by entering a "2" (see figures 6.15 and 6.16). The system response functions are saved by writing them to the common disc file "RESP" (see figure 6.17).

After displaying the results of the operations discussed in sections IIIC and IIIE for the electronics step test transient (see figure 6.18), the amplitude response of the electronics is displayed (see figure 6.19). Note that the response for frequencies greater than $7 \mathrm{~Hz}$ is from the transient derivative. The phase response of the electronics is also displayed (see figure 6.20). The response functions for the electronics are saved by writing them to the common disc file "RESP" (see figure 6.21).

The amplitude response of the seismometer to ground displacement is next displayed (see figure 6.22). Noting that the ordinate scale is unsatisfactory, the user has entered a "2" and then a " 1 " to replot the amplitude response with the new power for $\operatorname{YMAX}=1$ (see figure 6.23). The phase response of the seismometer to ground displacement is shown in figure 6.24. Note that at low frequencies, where the signal-to-noise ratio is large for both the seismometer mass release transient and the electronics step test transient, the experimental and theoretical seismometer response functions are in good agreement (compare figures 3.4 and 6.23 and figures 3.5 and 6.24 ). This suggests that the calibration is reliable and that the entire seismographic system at $B G G$ is functioning in the anticipated manner.

The option to display the response of the seismometer to ground acceleration has been exercised (see figure 6.25). (As described in 
section IIID, the seismometer response to ground acceleration is particularly useful for estimating the seismometer free period and damping.) The amplitude response of the seismometer to ground acceleration is shown in figure 6.26. After entering a "1" to continue, the user has placed the cursor crosshairs on the point of maximum response. The seismometer free period, two estimates of the damping factor and the response to acceleration at the free period are then displayed. Two estimates of the damping are given to indicate the imprecision of the algorithm used here to obtain the damping factor estimate. (The algorithm used obtains the intersection of the low- and high-frequency asymptotes as the response at the free period on the straight line with slope 1 through the lowest frequency available $(0.1 \mathrm{~Hz})$. The second damping estimate is determined in an analogous manner using the secondlowest frequency available.) The phase response of the seismometer to ground acceleration is shown in figure 6.27 .

C. A noisy calibration sequence

With the analysis of the calibration signals for seismographic station BBG satisfactorily completed, the user elects to display another of the multiplexed calibration signals by selecting option 6 (see figure 6.28). The calibration record for digitized channel 3 was selected for display to demonstrate the results that can be obtained from very noisy calibration records (see figure 6.29). Since the signal-to-noise ratio during the ID code is poor, the user has indicated that the ID code is not present by entering a "2." The user has entered the ID code \#25 after decoding the ID code by inspection and has al so selected the start of the system noise using the cursor. The system noise signal, the seismometer mass release transient, and the amplifier step test transient 
for channel \#3 selected by the algorithm in program "PICK" are shown in figures $6.30,6.37$, and 6.32 , respectively. It is obvious that the picking algorithm failed in selecting the window for the amplifier step test transient. The "rewindowed" amplifier step test transient is shown in figure 6.33 .

Figure 6.34 shows the constants from the seismometer constants table for the station with ID code \#25. The seismographic station name is SWB, Swanson's Bluff." The system noise amplitude spectrum is shown in figure 6.35. Note that the system noise at SWB is primarily at the higher frequencies $(f \tilde{>} \mathrm{Hz})$.

The system amplitude and phase response for station SWB is shown in figures 6.36 and 6.37 respectively. Note that the "high-frequency breakdown" occurs at a lower frequency $(\sim 7 \mathrm{~Hz})$ for the noisy system at SWB than for the "typical" system at BGG (compare with figure 6.14). (Use of the transient derivative does not significantly improve the high frequency response for this noisy signal.) Although the calibration signal is severely contaminated by noise, it is clear that a reliable estimate of the amplitude response for frequencies less than about $5 \mathrm{~Hz}$ can be obtained. Seismic information at frequencies greater than about $5 \mathrm{~Hz}$ would probably also be seriously contaminated by the system noise so that the results of the calibration are probably sufficient for any seismic data obtainable at SWB. The electronics amplitude and phase response for station SWB are shown in figures 6.38 and 6.39 , respectively. Again the "high-frequency breakdown" of the response functions occurs at a lower frequency for the noisy SWB system than for station BGG. As for the system response, the transient derivative is not used to obtain the high frequency response of the electronics. The SWB seismometer amplitude and phase response for 
displacement and for acceleration are shown in figures $6.40,6.41,6.42$, and 6.43 , respectively. The similarity of the empirical response functions for the seismometer at SWB with the theoretical response functions shown in figures 3.4 and 3.7 suggest that the system is basically operating satisfactorily, albeit very noisily.

The calibration for station SWB satisfactorily completed, the program was terminated by selecting option 7 (see figure 6.44 ). Since the system and the electronics responses for station SWB as well as for station BBG were written on the common file "RESP", a total of 4 files exist on "RESP." Upon normal termination, the user is returned to the "SESAME" system at LBL. Note that for permanent retention, the common file "RESP" must now be disposed or copied to a tape, a data cell, etc. since common files can reasonably be expected to exist for only about one or two days. 
A. Obtaining the input ground motion

The response functions are written on the COMMON FILE "RESP" via the fortran binary write statement:

WRITE(79) ((LTITL(I), I=1 ,8), (LTITL2(J), J=1,8), NSUM, (TEMP(K), AMP(K), $\operatorname{PHASE}(K), K=1$, NSUM)) \$ENDFILE79

79 is the logical unit assigned to file RESP in program CALTEM. Note that successive response functions are separated by file marks. Pertinent information such as identification and units are stored in the alphanumeric arrays LTITL(8) and LTITL2(8). NSUM is the integer number of frequencies for which the response is stored. $\operatorname{TEMP}(K), \operatorname{AMP}(K)$, AND $\operatorname{PHASE}(K)$ are the frequency, the amplitude response, and the phase response respectively.

The Fourier spectrum of ground motion $I(f)$, can be obtained from the Fourier spectrum of seismometer output, $O(f)$, by using the definition of the response function $T(f)$ : i.e., $I(f)=0(f) / T(f)$. Letting $T(f)=|T(f)| e^{i \phi(f)}, I(f)=|I(f)| e^{i \theta(f)}$, and $0(f)=|0(f)| e^{i \psi(f)}$. $|I(f)|=|O(f)| /|T(f)|$, and $\theta(f)=\psi(f)-\phi(f)$. I.E., I(f) $=$ $|0(f)| /|T(f)| e^{i[\psi(f)-\phi(f)]}$. The ground motion $I(t)$ is the $\mathcal{F}^{-1}[I(f)]$ where $\bar{f}^{1}$ is the inverse Fourier transform defined in section IIIA.

The input spectrum can be obtained only at those frequencies for which the response is defined or non-zero. The low-frequency limit of known response is $1 / T \simeq 0.1 \mathrm{~Hz}$. ( $T$ is the window length of the mass release calibration signal). The response is 1 imited at high frequencies by a low signal-to-noise ratio (jittery response.) In the following section, a program to obtain a smooth response function is demonstrated. 
B. Obtaining a smooth system response from the empirical response functions .

The system response functions obtained in section VI B are "jittery" for frequencies greater than about $5 \mathrm{~Hz}$; the jitter increases with frequency (see figures 6.14 and 6.16). In the 5 to $20 \mathrm{~Hz}$ band, the trend through the jittery responses approximates the expected system response. At frequencies greater than about $20 \mathrm{~Hz}$, the jitter, or noise, dominates the signal so that the calibration is not valid in this band. For the corresponding electronics response functions (see figures 6.19 and 6.20), a similar pattern with frequency occurs. For the electronics response, the trend through the jitter approximates the expected response for frequencies up to about $30 \mathrm{~Hz}$. In this section, we demonstrate an interactive program (CALSMO on library WBSOURCE) which operates on the empirical response functions (e.g., figures $6.14,6.16,6.19$ and 6.20 ) to produce a smooth system response. The smooth response functions are generated by interpolation along the trend through the jitter of the empirical response functions. (The system response and electronics response for station $B G G$, written onto common file RESP during execution of program CALIB - see section VI B. were subsequently stored on subset RESP of library WBSOURCE. It is assumed that the user can access analogous appropriate system and electronics responses that were generated during a prior execution of program CALIB.)

The initial commands and interactive entries are shown in figure 7.1 . Program CALSMO is loaded from library WBSOURCE and executed via an $\uparrow$ RUN command from the SESAME system at LBL. Line 4 of CALSMO (see listing in figure 7.1) loads subset RESP from data cell library WBSOURCE onto a 
local file named RESP. (The user must alter line 4 to load appropriate response functions onto local file RESP.) A listing of the fortran program, CALFIX, (load module SMLGO) which is executed by CALSMO is given in APPENDIX $B$.

The user indicates that the appropriate system response resides on the first file of local file RESP. (see figure 7.2). After examining the displayed contents of ARRAYS LTITL and LTITL 2 from the first file, the user verifies that the desired system response has been selected by entering an "s" (any char other than 777 ).

The system amplitude response is then displayed (see figure 7.3). After entering a " $7 "$ to indicate that the ordinate scale is satisfactory, the user places the cursor crosshairs on the response curve at the highest frequency with a non-jittery response. The frequency selected was $3.26 \mathrm{~Hz}$. The program assumes that the high frequency limit of smooth response selected is greater by at least an octave than the natural frequency of the seismometer $(\sim \mathrm{Hz}$ for the seismometers in the USGS central California network). The theoretical amplitude response of the seismometer, proportional to $\omega^{1}$, is "patched" onto the empirical system response for frequencies greater than $3.26 \mathrm{~Hz}$. The result is displayed in figure 7.4 .

The empirical system phase response is next displayed (see figure 7.5). (It is necessary to obtain a smooth phase response if ground motion is to be computed; a smooth amplitude response is sufficient only for computing the amplitude spectrum of ground motion.) The smooth phase response is obtained by a sequence of linear interpolations on the linear ordinate - log abscissa scale. The user controls the interpolation by interactively selecting, via the cursor, a sequence of points on the 
response curve for interpolation. In figure 7.5, the user has selected via the cursor a high frequency limit of smooth response equal to $3.05 \mathrm{~Hz}$. and higher frequency points for interpolation at $4.95 \mathrm{~Hz}, 7.76 \mathrm{~Hz}$ and $11.49 \mathrm{~Hz}$. By entering "2" prior to selecting the $11.49 \mathrm{~Hz}$ point, the user has indicated that $11.49 \mathrm{~Hz}$ is the maximum frequency of reliable response. After verifying that the appropriate electronics response was on the second file of RESP as entered by the user (see figure 7.7 ), the empirical electronics amplitude response is displayed in figure 7.8 . Proceeding as with the system phase response, the user selects via the cursor crosshairs points on the response curve for linear interpolation on the log-log scale. The maximum frequency of reliable electronics amplitude response is $36.43 \mathrm{~Hz}$. The results of the electronics amplitude response interpolations are displayed in figure 7.9. The electronics phase response is next displayed (see figure 7.10). Proceeding as before, the user selects points on the response curve for linear interpolation on the linear ordinate-log abscissa scale. The maximum frequency of reliable electronics phase response is $30.63 \mathrm{~Hz}$. The results of the electronics phase response interpolations is shown in figure 7.11 .

The "pseudo" system amplitude response (figure 7.4 ) is multiplied by the smooth electronics amplitude response for frequencies greater than $1 \mathrm{~Hz}$. Since the "pseudo" system amplitude response is the theoretical amplitude response of the velocity-transducer seismometer at higher frequency, multiplication by the smooth electronics amplitude response results in a smooth system amplitude response (see figure 7.12 ) over the entire band (i.e., 10 seconds to $36.43 \mathrm{~Hz}$ ). The smooth electronics phase response (see figure 7.11 ) is patched onto the smooth system phase response 
(see figure 7.6) for frequencies greater than the maximum frequency of reliable system phase response $(11.49 \mathrm{~Hz}$ in this example). Since the phase response of the seismometer is nearly constant for frequencies >> seismometer resonant frequency (see figure 3.5 ), the result is a smooth system phase response (see figure 7.13 ) over the entire band (i.e., 10 seconds to $30.63 \mathrm{~Hz}$ ). The smooth amplitude (array SYSAMP) and phase (array SYSPH) system responses are then written onto disc file SYSRESP (see figure 7.14) via the fortran statement:

WRITE(81) ( ( $\operatorname{LTITL}(I), I=1,8)$, NSUM, NSUMA, NSUMP, (FI (K), $\operatorname{SYAMP}(K), \operatorname{SYSPH}(K), K=1, N S U M))$ \$ENDFILE81

81 is the logical unit for disc file SYSRESP. NSUM, NSUMA, and NSUMP are total number of system responses written to SYSRESP, the number of reliable system amplitude response samples and the number of reliable system phase response samples respectively. $\mathrm{Fl}$ (NSUMA) $=36.43 \mathrm{~Hz}$ and $\mathrm{Fl}(\mathrm{NSUMP})=30.63 \mathrm{~Hz}$ in this example. 


\section{Monitoring temporal variations in the system}

From the amplitude response of the seismometer to ground acceleration (see section IIID); the voltage at the input to the preamplifier for gound acceleration is:

$$
\left|T_{\text {accel }}\left(\omega^{-}\right)\right|=\frac{\operatorname{Geff}}{\Omega}\left[\left(\omega^{-1}-1 / \omega^{-}\right)^{2}+(2 \rho)^{2}\right]^{-1 / 2}
$$

where $G_{\text {eff }}=G_{L} R_{11} / R_{\text {eff }}$ is the effective generator constant, $G_{L}$ is the generator constant of the seismometer coil-magnet transducer, $\Omega$ is the resonant frequency of the seismometer, $\omega^{-}=\omega / \Omega$, and $\rho$ is the damping factor. $R_{11}=S R_{A} /\left(R_{A}+S\right), R_{\text {eff }}=T+R_{C}+R_{11}$ and $\rho=\beta_{0}+G_{L}{ }^{2} / 2 M \Omega R_{\text {eff }}$, where $R_{A}$ is the preamplifier input impedance, $R_{C}$ is the coil resistance, $T$ and $S$ are the resistances in series and in parallel with the coil respectively, $\beta_{0}$ is the open circuit damping, and $M$ is the seismometer mass (see Dratler, 1975). The maximum response, $G_{\text {eff }} / 2 f \Omega={ }^{G} L^{R} 11 /\left(2 \Omega \beta_{0} R_{\text {eff }}\right.$ $\left.+G_{L}^{2} / M\right)$ occurs at $\omega=\Omega$.

The maximum response and the seismometer resonant frequency are easily obtained from the amplitude response to acceleration (e.g., see figures 6.26 and 6.42 ). Since $\Omega=\sqrt{\mathrm{K} / \mathrm{M}}$, variations in the resonant frequency reflect variations in $\sqrt{K}$, i.e., relaxation of the spring. Variations in the maximum response are not as easily ascribed to a single seismometer constant. The term $G_{L}{ }^{2} / M$ in the denominator represents $\beta_{1}$ so that it is usually about $2+$ times larger than the term $2 \Omega \beta_{0} R_{\text {eff }}$. Thus, the peak value is relatively insensitive to $G_{L}$ until $G_{L}$ decreases by some $50 \%$. Thereafter, the peak height decreases proportionately to decreases in $G_{L}$. Decrease in $G_{L}$ with time is a measure of the degradation of the seismometer magnet. 


\section{APPENDIX A. PROGRAM CALIB}

PROGRAY RA HOAT (TAPE TTY, TAPE $1=$ TAPETTY, CONTROL, TAPET = CONTRCL)

COMMUN/ JPLOT/XPLT(4), IPLT (15)

COMMON/GET/NEJJ

DIMENSION R $(8)$, IFET ( 3$)$

$\operatorname{IPLT}(15)=1$

CALL FET(5LTAPE 1 , IFET,8)

IFET $(2)=$ IFET $(2) .0 R .04000010000000000000 B$

IFET $(8)=\operatorname{IFET}(8) .0 R .4000$ UDOO 0000000000008

CALL FET(SLTAPE 1 , IFET, -8)

WRITE $(1,10)$ \$ CALL ENDFEC(1)

10 FORMATI(FENTER NAME OF CALIBRATION JATA COMMON FILE (FOKMAT AT)*I REAO (1.11) IIIA

11 FORMAT (AT)

REWIND 7

WRI TE $(7,13)$ I IIA, II IA

13 FORMAT (*RETURN,*,A7,*,*1*COMMON,*,A7,*,*))

WRI TE $(7,15)$ IIIA

15 FORMAT ( F FIN.* /* DELETE, LGOB.*

$*$ *INK, F $=U P L G O, F=$ KOL GO,B**

* *SFL $(100000) * 1 * L G 03, *, A 7, *$.*)

WRITE $(7,18)$

18 FORMAT $(* L I N K, F=P K L G O, F=N F L G O, F=T X L G O, B=P I K R \cdot * 1$

* *SFL $(105000) * 1 * P I K K$, TAPETTY, TAPETTY.*1

* * INK, $F=S C L G O, F=T X L G O, B=S P L G O . *$,

* * SPLGO, TAPETTY, TAPETTY.*I

$* * L I N K, F=C F L G O, F=N P L G O, F=T X L G O, U=C T L G O . * /$

* CTLGO, TAPETTY, TAPETTY.०*I

WRITE (7,20)

20 FORMAT (*CXIT, * /*TEXT, TAPETTY, (CXIT ERRUR).*/*PTSS (E)*/

* EXIT.*/*TEXT, TAPCTTY, IEXIT ERROR].*1*PTSS $(E 2 * 1 * F[N * * *$ *TSS $(L) * 1$

**EXIT.*1*TEXT, TAPETTY, (CU LIMIT LIKELY).*/*PTSS $(E) * / * E N O * *)$

REWINU 7

STOP

END

SUSROUTINE GET(R)

COMMON/JPLOT/XPLT (4), IPLT (15)

COMMON/GET/NE

DIMENSION $R(1), L(80)$

$L U=I P L T(15)$

12 READ(LJ, 9$) L$ \& $I=J=N E=0$

$6 \quad J=J+1 \& N=P=S=0 \quad \& \quad M=F=1$

$5 I=I+1$ \& IF(I.GT.8U)RETURN \& $D=L(I) \& K=4$

IF (D.EQ.3B)K=2 S IF (O.GE.27.A.O.LE.36)K=1

IF $(D . E Q .47) K=3 \& K=K+S ; G U$ TO $(1,2,3,5,1,4,3,4) K$

$1 N=N+10+0-27$

$2 M=-1$

\$ $S=4$ \$ $\$$ TO 5

3 IF (P.NE. O)GOTO 10 \$ $P=I \$ S=4$ GO TO $\$$

4 IF $(P, N \equiv .0) F=10 . *+(I-P-1) \& K(J)=N / F * M$ \& $N E=N L+1$ \&O TC 6

9 FORMAT $(80 R I)$

10 WRITE (LU,11) J GO TO 12

11 FORMATI*TWO DECI PAL POINTS IN ENTRY*,I5,*-FE-ENTER LINE*I END 
PROGRAY JNPACK TTAPE'+, TAPETTY, TAPEL = TADETTY, TAPEG,

* OAT1, JATC, OATS, UAT4, JATS, JAT6, UATT, JATS, JAT9, UAT 1L, TADE 11 = JAT1,

* TAPEL $L=3 A T 2$, TAPE $13=J A T 3, T A P E 14=0 A T+, T A P E 15=0 A T 5, T A D \equiv 16=0 A T 6$,

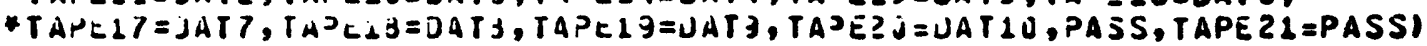

CUMYJ V/ JPLOT / XPLT (4), IPLT T (25)

COMMJN/JET/NE

ULMENSIUN IFET(O),ICHAN(11), NCHAN(16), R(1U),IAR(12000)

CAL. $F \equiv T(S L T A P E I, I F \equiv T, J)$

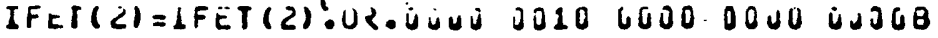

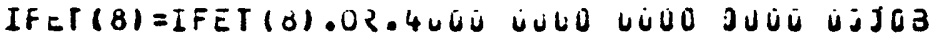

CALL FET(SLIAPEL, IFET, - d)

CALL FET(SLTAPEG,LFET, 3)

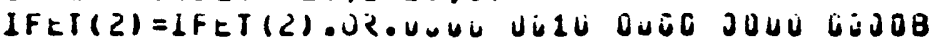

IFEI $(y)=[F E I(8) .02 .40 U U$ UUOO OUJU OUUU UOSJOB

CALL F $:$ T (5LTAPLE,IFET,-8)

IPLI $(15)=1$ \& $N L_{L}=1$

WKITE(1,1U) \$ CAL- $\cong V U R E C(1)$

10 FOKMAT (*ENTER NUMBER JF CHANNELS JIGITLLEJ*)

CALL $J E T R(R) ;: N J=I F L X(R(1))$

WKITE $(1,12)$ \& CAL- EVUKEL(1)

12 FUKMAT (*ENTER NUMBER OF SOANS TO $3 E S K[D D \equiv J * 1$

CALL BETK(R) औ NEEG $=I F \perp X(R(1))+1$

WKIIE $(1,15)$ \& $\angle A L L E V U R E C(1)$

15 FUKYATIFETER CHANNEL VUMAERS UF SELECTEJ GHANINELS, IN ORJER"

CALL OETR(र) $V$ VIS=NE

ICHAN $(V J+1)=Y$ B $N P T=1 \angle U O O$

Du $13 \quad I=1,16$

18 NCHAV $(I)=u$

UO LJO $I=1$, NuS

$N C H A V(I)=L S=\perp F I X(R(L))$ S $N L U=L S+10$

DU $20 J=1, N \mathrm{~J}$

$20 \operatorname{ICHAN}(J)=0$

ICHAV $(L S)=1$

30

UO 3u $<=1.12006$

$\operatorname{IAK}(<)=0$

KEMLVU 44

CALL RJTAPE (1,NFL,IZTAN, NOT, NBEG,IAR,IERR)

REWIVJ +4

KEWIVJ NLU

CALL AR3-K(VLU,LAR,1,120UÚ,SUU)

KENINU NLU

40 FUKMAT(1OI5)

100 CONTI VJE

REWiVJ 21

WKII $(21,120)($ VCHAVIS), $K=1,10)$ S CAL. EVJREC(2U)

12. F(KMAT (2UI7)

KEWIVO CI

STUP

ENI

SUURJJIANE JETR(K)

COMMJ V/ JPLUT/XPLT (4), I OLT (15)

CUMMJIN/GET/NE

$U I M=V S I \cup N R(1), L(30)$

$L U=I \supset-T(1.5)$

$12 \operatorname{KLAJ}(L J, \dot{J}) L \& I=J=V \equiv=0$

$6 J=J+1$; $N=P=S=U$ is $M=F=1$

$5 I=1+1$ b LF(L.GT. BU)RETJRN $\quad 0=-(I)$ \& $K=4$

IF (U.EZ2.38) K=L \& IF(U.GE. $27 . A . U . L E .35) K=1$

If $(U .0 .1 .47) K=3$ \& $S=K+S$ G $G J T J(1,2,3,5,1,4,3,1) K$

$1 N=N^{*}(U+j-27$

$S=4 \quad S 60$ T0 5 


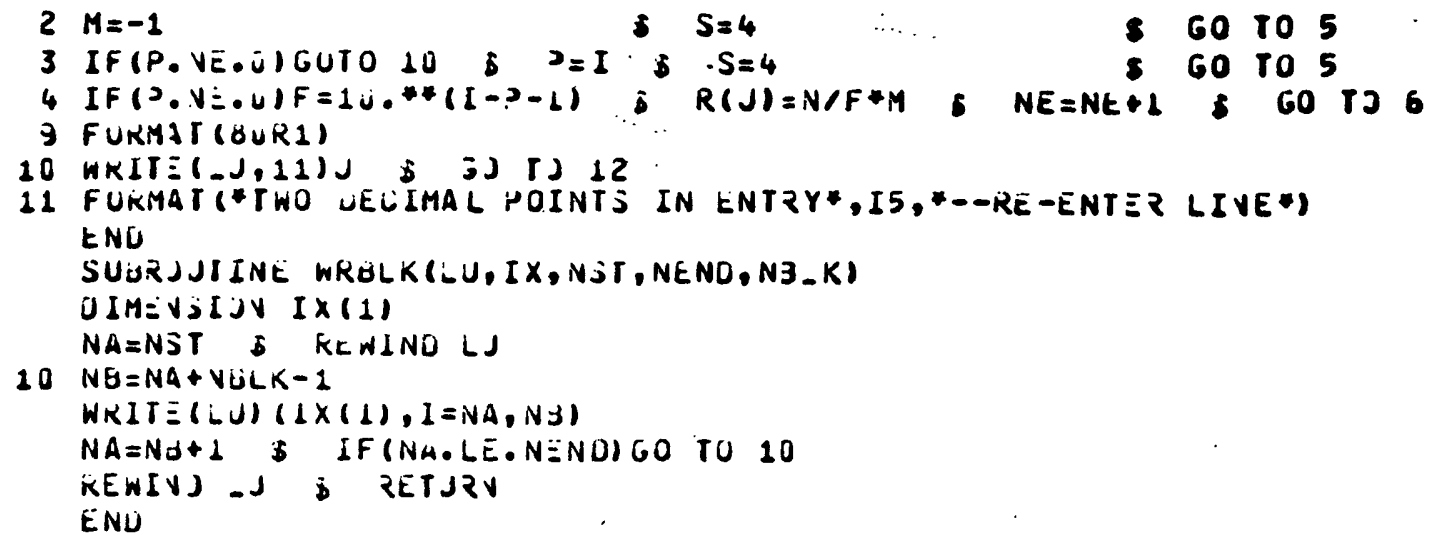


PROGRAM PICK(TAPETTY $=201, F$ ILM $=201$, TAPE $1=$ TAPETTY, OAT 1, UAT2,0AT3, * DAT 4, DAT5, DAT6, DAT7, DAT8, DAT9, OAT10.

- TAPE31 = DAT1, TAPE32= DAT2, TAPE33 = OAT3,

- TAPE3 $4=$ DAT 4, TAPE $35=0 A T 5$, TAPE $36=0 A T 5, T A P E 37=0 A T 7, T A P E 38=0 A T 6$,

- TAPE39= OAT9, TAPE 40= DAT10,

*NOI, RLS, STP, PASS, TAPE $11=$ = OI, TAPE 12=RLS, TAPE 13=STP, TAPE $20=P A S S$.

- PASSA, TAPE 21 = PASSAI

COMMON/TVPOUL /TVPUL ( 8 )

COMMON/TUTUNE/ITUNE (30)

COMMON/JPLOT/XLT, XRT, YLO,YUP, MAJX, MAJY, KX(2), KY (2), LTITL (B), LU,

*LTF,LNLGX, LNLGY, NCL X, NCLY,LTITL 2 (8)

COMMON/PLS/PPP (8)

COMMON/GET/NE

DIMENSION IFET $(8), N C H A N(10), R(8), X(10000), I X(10000), M Y(1000)$

EQUIVALENCE $(X(1), I X(1))$

CALL FET(5LTAPE 1 , IFET, 81

IFET(2) =IFET(2).0R.0000 0010 0000 0000 00008

$\operatorname{IFET}(8)=\operatorname{IFET}(8) \cdot 0 R \cdot 400000000000000000008$

CALL FET (5LTAPE1, IFET, -8)

$L U=1$ \& $K F M T=6 H(16 I 5)$ \&TITL2(1) $=1$

REWINO 20

REAO $(20,103)(N \operatorname{CHAN}(I), I=1,10)$

103 FORMAT (10I7)

REWINO 20

1 WKITE $(1,3)$ \& CALL ENOREC (1)

3 FORMATI*ENTER DIGITIZLR CHANHEL FOR TRACE TO OL DISPLAYËC*)

4 CALL GET (R) \$ NCHL $=I F I X(R(1))$

LUDAT $=N C H L+30$

DO $5 \mathrm{~J}=1,10$

5 IF (NCHAN (J).EQ.NCHL)GO TC 7

WRITE $(1,6)$ \$ CALL ENOREC (1) \$ 30 TO 4

6 FORMAT (*CHANNEL NOT AMONG IHOSE UNPACKED--PICK ANOTHEK*)

7 WRITE $(1,8)$ \& CALL ENOREC (1)

8 FORMAT(*ENTER OIGITIZLR RATE IN SAYP/SLC*)

CALL GET (R) \& NUIG=IFIX(R(1))

NOPPS $=50$ NTH $=$ NOIG/NOFPS $\$$ NTPT $=10000 * N T H-10$

MARLS $=$ NOPPS $/ 12$ I MARAM $=$ NOPPS/17

CALL ELKRO(LUUAT, IX, $1, N T H, N T P T, 5$ UO)

REWIND LUDAT N NPL=NTPT/NTH

DO $100 I=1, N P L$

$100 \times(I)=I \times(I)$

ENCODE $(80,9, L T I T L) N C H L$

9 FORMAT (*RECORD OF JATA FROM DIGITIZER CHANNEL*, I3,45X)

$M S=1000 / N D P P S$

ENCODE $(20,11, K X) M S$

11 FORMA T (*SAMPLES AT*,I4,* MSEC *)

ENCODE $(16,13, K Y)$

13 FORMAT (*DIGITIZER OUTPUT*)

$X L T=1 \quad$ \$ $\quad X R T=N P L$ \& $\quad Y L O=-2000 \$ \quad Y U P=2000$

MAJX $=10$ \& MAJY $=8$ \& LNLGX $=3$ \& LNLEY $=1$

$N C L X=N Z L Y=2$

CALL PLOTS $(X, O U M, 1, N P L)$

21 WRITE $(1,23)$ CALL ENCFEC (1)

23 FORMAT $\left(/, 15 X, *\right.$. IS ID CODE PRESENT?*,2X,* $1=$ YES, $\left.2=N{ }^{*}\right)$

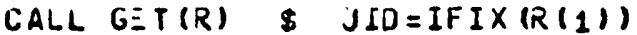

IF (JID.EQ.1) GO IO 25

WRITE $(1,24)$ \$ CALL ENDFEC (1)

24 FORMAT $/ 115 X$, *ENTER STATICN IO NUMBER*)

CALL GETIR) \& IOP=IFIXIR(1)) \& GO TO 29

25 WRITE $(1,27)$ \& CALL ENDKEC (1) 
27 FORMATI/15X, *PICK START (F ID CODE*)

LOOK $=3 H X, Y$

CALL TVFARE (LOOK,EX,WHY,K1,K2)

NID =IFIX (EX)

29 WRITE (1, 31) \$ CALL ENCREC (1)

31 FORMAT $15 X$, *PICK STAET OF SYSTLM NOISE*)

CALL TVFARE (LOOK, CX,WHY,K1,K2)

NOI $=$ IFIX $X(E X)$

IF (JIO.NE. 1$)$ GO TO 33

CALL IOCODE (NOPPS, $X, N I D$, IOP)

WRITE $(1.35)$ IOP 5 CALL ENOREC (1)

35 FORMAT (15X,*TRACE IO IS *,I5)

WRITE $(1,32)$ \$ CALL ENDREC (1)

32 FORMAT $15 X$, *ENTER. ANY CHAR TO CONTINUE*)

CALL GET (R)

33 NSTA $=$ NOI $+2 *$ NDPPS $\$ N E N A=N S T A+7+N D P P S$

$A$ VER $=0$. \$ NATY $=0$

DO 36 IA $=N U I, N S T A$

NATY $=N A T Y+1$

36 AVER=AVER+X(IA)

AVER=A VER/NAT $Y$

DO 37 I $B=N O I, N P L$

$37 \times(I B)=X(I B)-A$ VER

CALL MAXY(X,NSTA,NENA, XMX1, NMX1)

NBK $=N M X_{1} \&$ NSTP $=$ NBK - NDFPS \& FX=XMX1/2.

CALL FINDX $\left(X, N B K, N S T F, F X, X 1, N X_{1}\right)$

NRLS $=N X_{1}-$ MARLS

NST $B=N R L S+7 * N D P P S \& N E N B=N S T B+2 * V D P P S$

CALL MAXY(X,NSTB,NENG,XMX2,NMXZ)

NBK $=N M X 2 \quad N S T P=N B K-N O F P S \& F X=X H X 2 / 2$.

CALL FINOX $(X, N B K, N S T P, F X, X 2, N X C)$

NSTEP $=N X_{2}-$ MARAM

$N I N=N O I * N T H-N O I G$ I $N I P=N I N+30 * N O I G$

CALL BLKRD(LUDAT, IX,NIN, 1,NIP,5OC)

$N X X Y=N I P-N I N+1$

DO $335 I=1, N X X Y$

$335 \times(I)=I X(I)$

REWINO LUDAT

LN=NDIG-1 \& LR=NRLS *NTH-NIN+1 \& LS=NSTEP*NTH-NIN+1

$L N N=L N+N D I G+N D I G / 2$ \& $L N R=L R+7 * N D I . G$

$L N S=L S+15 * N D I G+N O I G / 2$

ENCOOE $(80,41, L T I T L)$ IDP

41 FORMAT (*RECORD OF SYSTEM NOISE FROY STA. NO.*,I5.39X)

CALL TVNEXT \& LTF=0

CALL WHAT $X, N U I G, L N, L N N)$

ENCOCE $(80,43, L T I T L)$ IOP

43 FORMAT (*RECORD OF SEISMOMETER RELEASE TEST FROM STA. NO.*, $5 ., 27 \times$ )

CALL TVNEXT

CALL WHAT $X, Y D I G, L R, L N R)$

ENCOUE $(80,45, L T$ ITL) IUP

45 FORIAT (*RECORD OF AMPLIFIER STLP TEST FROM STA. NO.*, $[5,32 \times 1$

CALL TVNEXT

CALL WHAT $(X, V O I G, L S, L N S)$

$N O O=L N S-L N+1$

DO $47 \mathrm{~J}=1, N D O$

$47 I X(J)=X(J)$

MNOI $=L N N-L N+1$ \& $M K L S=L N R-L R+1$ \& $M S T P=L N S-L S+1$

CALL SCRIB (IX,LN,LNN,16,KFMT, 11)

REWIND 11

CALL SCRIB (IX,LR,LNR,16,KFMT,12)

REWIND 12

CALL S:ORIB (IX,LS,LNS, 16,KFMT, 13) 
REWIND 13

REWIND 21

WRITE $(21,49)$ IDP, NOIG, MNOI, MRLS, MSTP

49 FORMAT $(10 I 7)$

CALL ENDEEC (21) \& REWINO 21

50

STOP

ENO

SUBROUT INE WHAT $X, N O I G, N B G, N N O)$

COMMON J JPLOT /XLT, XRT, YLO, YUP, MAJX, YAJY, KX(2), KY (2) ,LTITL (B), LU

* LTF, LNLGX, LNLGY, NCLX,NCLY

DIMENSICN $X(1), R(8)$

WRITE $(1,10) L T I T L$ \& CALL ENDREC(1)

10 FORMAT (BALO)

11 IF (LTF,EQ.1)WRITE $(1,12)$

WRITE $(1,13)$ \& CALL ENUREC (1)

12 FORMAT $(/ / / / /)$

13 FORMAT $115 x, * 1=P L C T$ ALL, $2=P L O T$ START, $3=$ CHANGE, *

$* 1,15 X, * 4=$ CONT INUE*1

CALL GET(R) \& N=IFIX(R(1))

$N X=1003 / N D I G$ \$ ENCODE $(20,15, K X) N X$

15 FORMAT (* SAMPLES AT *, [3,* MSEC*)

LNLGX $=3$

IF (N.EQ.1) GO TO 20 \$IF (N.EQ.2) GO TO 30

IF (N.EQ.3) GO TO 40 SIF (N.EQ.4) 50 TO $50 \$ 60$ TO 11

20 CALL PLOTS(X,DUM,NBG,NND) \$ LTF=1\$60 TO 11

$30 N N=N B G+100 \$$ CALL PLOTS $(X, D U M, N B O E, N N) \$ L T F=1 \$ 60$ TO 11

40 WRITE $(1.45)$ \& CALL ENDFEC (1)

45 FORMAT (15X,*NEW START POINT*)

CALL PUTIN (NBG)

47 WRITE $(1,48)$ \$ CALL ENUREC (1).

48 FORMAT (15X, *NEK END POINT*)

CALL PJTIN(NND)

LTF $=0 \quad 5 \quad$ GO TO 11

50 LTF $=0$ \$ RETURN

ENO

SUBROUTINE PUTIN(N)

OIMENSION R (10)

5 WRITE $(1,10)$ \& CALL ENOREC(1)

10 FORMAT $115 X, *$ CHOOSE- $1=$ CLRSOR, $2=E N T E R \quad 3=$ NO CHANGE*)

CALL GET (R) I M=IFIX(R (1))

IF $(M . E Q .1)$ GO TO 20 SIF (M.EQ.2) 50 TO 30

IF (M.EQ.3) RETURN $\$$ GO TO 5

$20 \angle O O K=3 H X, Y \$$ CALL TVFAFE (LOUK, $X, Y, K 1, K 2)$

$N=I F I X(X)$ \& RETURN

30 WRITE $(1,40)$ \&ALL ENUREC (1) CALL GET(K)

40 FORMAT (*ENTER SUBSCRIPT NUMBER*)

$N=I F I X(R(1))$ \& RETURN

ENO

SUBRUUTINE MAXY (A, NST, NEN,AMX,NMX)

DIMENS ION A ( 1 )

$A M X=A B S$ ( A (NSTI)

DO $50 \quad I=N S T, N E N$

IF (ABS (A (I)) . LE.ABS $(A M X))$ GO TO 50

50

$A M X=A(I) \& N M X=I$

CONTINUE

RETURN

END

SUBROUTINE FINOX $(A, N S T, N E N, X, A X, N X)$

DIMENSION $A(1)$

$D X=A B S(A(N S T)-X) \& L=1 ; \quad I F(N E N, L T$.NST) $L=-1 ; I=N S T+1$.

$10 I=I+L$ \$ IF(I.EQ.NEN) GC TO 50

$O D X=A B S(A(I)-X)$ 
IF $(D O X . G T \cdot D X)$ GO TO 10

$D X=O U X \& A X=A(I) \& N X=I$

GO TO 10

50 RETURN

ENO

SUBROUTINE IDCODE (NOIG,X,NBEG,IO)

COMMON/PLS/NLH,KLO,NLO,NHL, KHI, NHI, LTHR, MAR

OIMENSION $X(1), R(\theta), I D O(12)$

$\angle T H R=150$ \$SEP $=500 \$$ \$ MAR $=N O I G / 20 \& N P L S=10$

$N S T=N B \equiv G$ \&EN $=N S T+3^{*} N O I G / 2$

NWMIN $=N D I G / 5$ I NWMAX $=N C I G / 3$

DO $100 \quad I=1$, NPLS

CALL PJLSE INST, NEN, $X, L E R R$ )

IF (NL O.LT. MAR)LERR $=1$

IF (NHI D LT.MAR)LERR $=1$

$N W=N H L-N L H$

IF $(N W \cdot L T \cdot N W M I N) L E R R=1$

IF (NW. ST . NWMAX)LERR $=1$

IF (LERR.EQ.0) GO TO 30

21 WRITE $(1,22)$ I CALL ENCREC(1) CALL GET(R)

$N F=I F I X(R(1))$ \$IF (NF,EQ.1) GO TO 24

IF (NF.EQ.2) GO TO 31 GO TO 21

22 FORMATI $15 X, *$ IO COSE BAD AT PULSE *,I2, $/ *$ WHAT NOW?

* $1=S T O P, 2=$ CONT INUE* 1

24 STOP

$30 K D=K H I-K L O \$ I O D(I)=0$

IF $(K O, \because T$.NSEP) IDO $(I)=1$

$N S T=N H L+2 * M A R \quad N E N=N S T+N O I G / 2$

100 NWMIN $=$ NOIG/7

$I O=0$

DO $110 J=1, N P L S$

$110 I D=I 0+I 00(J) * 2 * *(J-1)$

RETURN

31 WRITE $(1,32)$ \$CALL ENCREC(1)

32 FORMATI* ENTER IU COLE NO. OBTAINES BY INSPLCTION*)

CALL GET(R) SID=IFIX(RII)

RETURN

ENU

SUBROUTINE PULSE (NST, NENC, $X, L E R R$ )

COMMON /PLS/NLH, KLO, NLO, NHL, KHI, NHI, LTHR, MAR

DIMENSION $X(1)$

$N B=N S T+1 \$ N=1 \$ M B=I F I X(X(N S T))$

$L E R R=M A V=N i=0$

DO $100 \quad I=N B, N E N D$

IF (LERR.EQ. I) RETURIN

$M A=M B$ \$ $M B=I F I X(X(I))$ \& $M O=M B-M A$ IAD IABS(MC)

GO TO $(40,50,60,70,80), N$

40 IF (MAO.GT.LTHR) GO TO 45

MAV =MAV+MB \& NC=NC+1\$GO 10100

45 IF (NC. LT.MAR)LERR $=1$

IF (MB.-T.MAIGO TO 47

$N=2 \& \quad N L H=I \& \quad K L O=M A V I N C \& N L O=N C \& \quad M A V=N C=0$ GO TO 100

47 MAV $=N C=0$ G GO TO 100

50 IF (MAO.LT.LTHR) GU TO 55

$M A V=N C=0$ \$ 60 TO 1 UO

55 MAV $=M A V+H B$ is $N C=N C+1$

IFINC.GE.MARIN $=3$ S 60 TO 100

60 IF (MAU.GT.LTHR) GO TO US

MAV $=M A V+M B$ \& $N C=N C+1$

GO TO 100

65 IF (MB.LT.MA)GO TO Ó7 


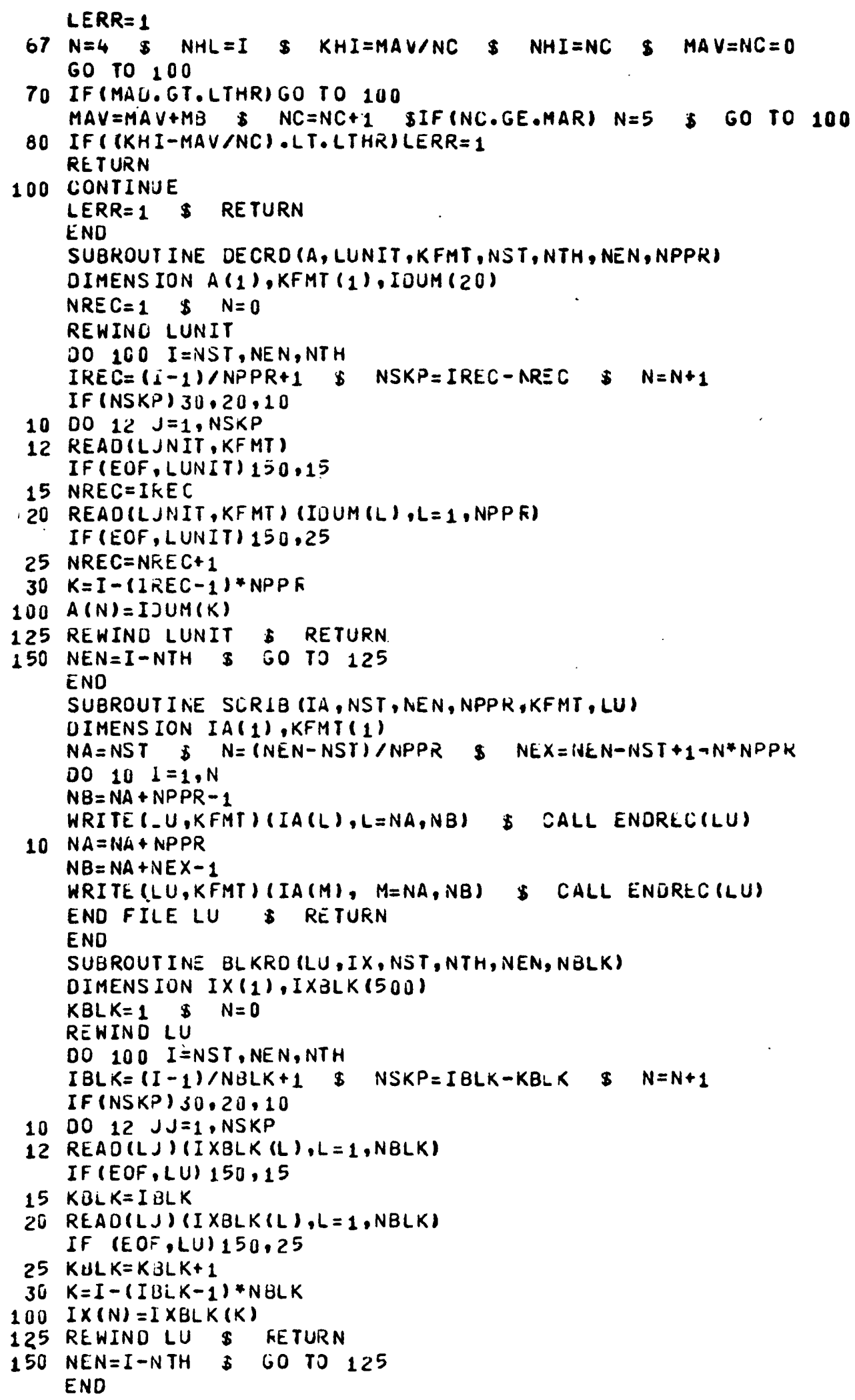


PROGRAM SEISCCN (TAPETTY $=201$,F ILM=201,TAPE1 = TAPETTY,PASSA,

- TAPE3 = PAS S.A, PASSE, TAPE5= PASSB, CONSTS, TAPE6=CONSTS)

COMMON/GET/NE, LU

DIMENSION IFET $(8), \operatorname{CSEIS(10),CPASS}(10), N A(8)$

LU $=1$

CALL FET(5LTAPE1, IFET,8)

IFET (2) =IFET (2).CR.0000 001000000000 0000B

$\operatorname{IFET}(8)=\operatorname{IFET}(8) . C R .400000000000000000008$

CALL FET (5LTAPEI, IFET, -8)

REWIND 3

READ $(3,10) I D, N O I G, N 1, N 2, N 3$

10 FORMAT (10I7)

REWIND 3

CALL DSKCON(IC,CSEIS,KD,NA, I)

$\angle A=0$

CALL TVNEXT

CALL PRINTC (CSEIS,IO,KD,NA)

CALL CHGCICSEIS,KD,NA,LA)

IF (LA.EQ. O)GO TO 20

CALL TVNEXT CALL PRINTC(CSEIS,IO,KD,NA)

20 CALL CALC (CSEIS, CPASS)

CALL PRINTO(CFASS,ID,KD, AA)

REWIND 5

WRITE $(5,60)$ (CPASS $(I), I=1,10),(N A(I), I=1,2), K D$

60 FORMAT (5F $10,5, /, 5 F 10.5,1,3 A 10)$

CALL ENOREC (5)

CALL DSKCON(IC,CSEIS,KO, NA, 2)

REWIND 5

CALL TVNEXT

STOP

END

SUEROUTINE PEIATC(CSEIS, ID,KD,NA)

OIMENSION CSEIS (1), NA (1), K(3)

$K(1)=3 \mathrm{HCH}_{4} \$ K(2)=3 \mathrm{HC} 4 \mathrm{~B} \quad \$ \quad K(3)=3 \mathrm{HC5}$

WRITE (1,30) (NA(I), I=1,2), ID,NA(4) \$ CALL ENOREC(1)

30 FORMAT (*NETHCRK STA.*,2X,2A10,2X,*ID NO.*, I $5,2 X$

* IAstalled *,A10)

HRITE (1,40)KD \$ CALL ENOREC(1)

40 FORMAT (*SEISMCMETER CONSTANTS LAST UPDATED*,2X,A10)

$M=I F I X(C S E I S)$ \& $K K=K(M)$

HRITE (1,50) \$ CALL ENOREC (1)

50 FORMAT $(/ *$ NO.*, 3X,*PARAMETER*, $12 X, * S Y M B O L *, 7 X, * V A L U E *$, * $10 \times, *$ UNITS*)

HRITE (1, 60) KK, (CSEIS (I), I =1,10), NA (3)

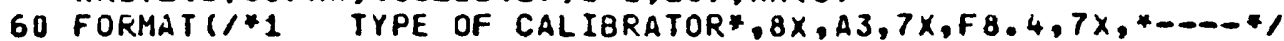

$* * 2$ MASS*, 22X,*M*,9X,F $8,4,7 x, * K G * 1 * 3$ SEIS. MOTOR CONSTANT*.

$* 6 X, * G L *, 8 X, F 8,4,7 X, * N T / A M P * / * 4$ FREE PERIOD*,15X,*T0*,8X,F8.4,

$* 7 x, * S E C * 1 * 5$ OPEN-CIRCUIT DAMPING*,6X,*BETAO*,5X,F $8,4,7 x$,

* *NO UNITS*/*6 SEIS. COIL RESISIANCE*,5x,*RC*,8x,F8,4,7x,

* * ILOHM*1*7 SERIES PAD RESISTAACE*,5X,*T*,9X,F 8,4,7X,*KILOHM*/

$* * 8$ SHUNT PAD RESISTANCE*,6X,*S*,9X,F8.4,7X,*KILGHM*/

$* * 9$ ATTENUATCR SETTING*,8X,*A*,9X,F8.4,7X,*DB*1

* 10 NOMINAL PREAMP GAIN*,7X,*G*,9X,F8.4,7X,*03*1

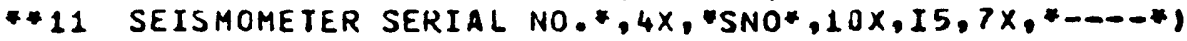

WRITE (1,70) \& CALL ENDREC (1)

70 FORMAT (/*ENTER ANY CHAR TO CONTINUE*)

REAU $(1,35) K X$

35 FORMAT (A1O)

RETURN

ENO

SUBROUTINE CHGC(CSEIS,KD,NA,LA) 
1 HRITE (1,10) \& CALL ENDREC(1)

10 FORMAT (*ALTER TAELE OF SEISMOMETER CONSTANTS? 1=YES, 2=NO*) CALL GETR(R) \$ L=IFIX(R(1))

IF (L.EQ.2)RETURN

15 WRITE $(1,20)$ \&ALL ENDREC(1)

20 FORMATI*TO CHANGE STATION NAME OR INSTALLATION DATE, ENTER 12*/ * TO CHANGE TYPE OF CALIBRATOR. ENTER 1*/

* TO CHANGe OTHEF PARAMETER, ENTER NUMBER OF PARAMETER, */

* Followed bY VAlUE, IN UNITS SHOWN IN TABLE*/

* TO END cHANEES, ENTER O*)

30 IF (LA.EQ. O) GO TO 40

33 WRITE (1,35) \$ CALL ENDREC (1)

35 FORMAT (*EATEF NUPBER, THEN VALUE, OF PARAMETER, OR O TO STOP*)

40 CALL GETR(R) \$ M=IFIX(R(1))

IF (M.NE.O) GC TO 43 \$ IF (LA.NE.O) WHEN=DATE(KD) \$ RETURN

43 IF (M.GE.O.A.M.LE.12) GO TO 50

WRITE (1,45) \$ CALL ENDREC(1) \$ 60 TO 33

45 FORMAT (*NUMBER TCO LARGE - TRY AGAIN*)

50 IF (M.NE.12) GC TO 60 WRITE (1,55) (NA(I), I=1,2),NA(4) \$ CALL ENDREC(1)

55 FORMAT $*$ STATICN*,2X,2A 10, *INSTALLED*,2X,A10/* ENTER NEH NAME, 20 - char or less*) READ (1,57) (NA (I),I=1,2)

57 FORMAT (2A10)

WRITE $(1.58)$ \$CALL ENOREC ( 1$)$

58 FORMAT (* ENTER NEW INSTALLATION DATE*)

READ (1,59) NA(4) \$LA=LA+1 \$60 T0 33

59 FORMAT (A1O)

60 IF (M.NE.1) GO TO 70 WRITE $(1,65)$ \&ALL ENDFEC (1)

CALL GETR(R) \& CSEIS(1)=R(1) \& LA=LA+1 \$ GO TO 33

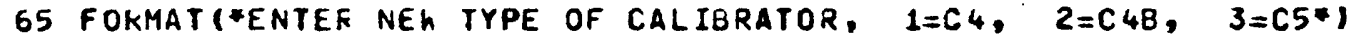

70 IF (M.NE.11) GO TO 71 $N A(3)=R(2) \quad \$ L A=L A+1 \$ G O$ TO 33

$71 \operatorname{CSEIS}(M)=R(2)$ \& $L A=L A+1$ \& 60 TO 33 ENU

SUBROUTINE CALC(CSEIS, CPASS)

DIMENSION CSEIS (1),CPASS (1),R(7),R4(7),R4B(7),R5(7),A (9)

DIMENSION A4(9),A4B(9),A5(9)

DATA $(K 4(I), I=1,7) / 5,6,180,05,6, .15,3 * 0.1$

DATA $(R 4 B(I), I=1,7) / 1.21,91, .5 .6, .15,9,0,1.1, .8 E E /$

DATA (R5 (I) $, I=1,7$ ) $/ .598,20 ., 5.36,0.075,9.31 .0665, .562 /$

DATA (A4II), I $=1,9) / 0 ., 0 ., 0 ., 180, .560 ., 1300, .3000,05600 ., 10000.1$

DATA (A4B(I), I =1.9)/0.,0..0.,91:3,280.,549.,1413.,3000.,5900.)

DATA (ASII), I=1,9)/0.,0.,0.,22.6,68.1,158,.340.,705.,1430./

$X M=\operatorname{CSEIS}(2) \quad \$ \quad G=\operatorname{CSEIS}(3) \quad \& \quad T 0=\operatorname{CSEIS}(4)$

$R C=C S E I S(6)$ \$ $T=C S E I S(7)$ \& $S=C S E I S(8)$

NA $=9-I F I X(C S E I S(9)) / 6 \quad \$ \quad R A=10.0 \quad \$ \quad V=1.34$

$M=I F I X(C S E I S(1))$

$Z S=S *(T+R C) /(S+T+R C)$

$G E F F=G * S * R A /(R A * S+(R A+S) *(T+R C))$

60 TO $(20,50,100), M$

$100012 \quad I=1,7$

$12 R(I)=R 4(I)$

DO $13 \quad I=1,9$

$13 A(I)=A 4(I)$

$A R L S=0.1$

$Z S N=S *(R(1)+1) /(S+R(1)+T)$

- XI $=1000 * V *(R(3)+R(4)) /(A(N A) *(R C+R(3)+R(4))+R(2) *(R(3)+R(4))$

$++R C *(R(2)+R(3)+R(4)))$ 


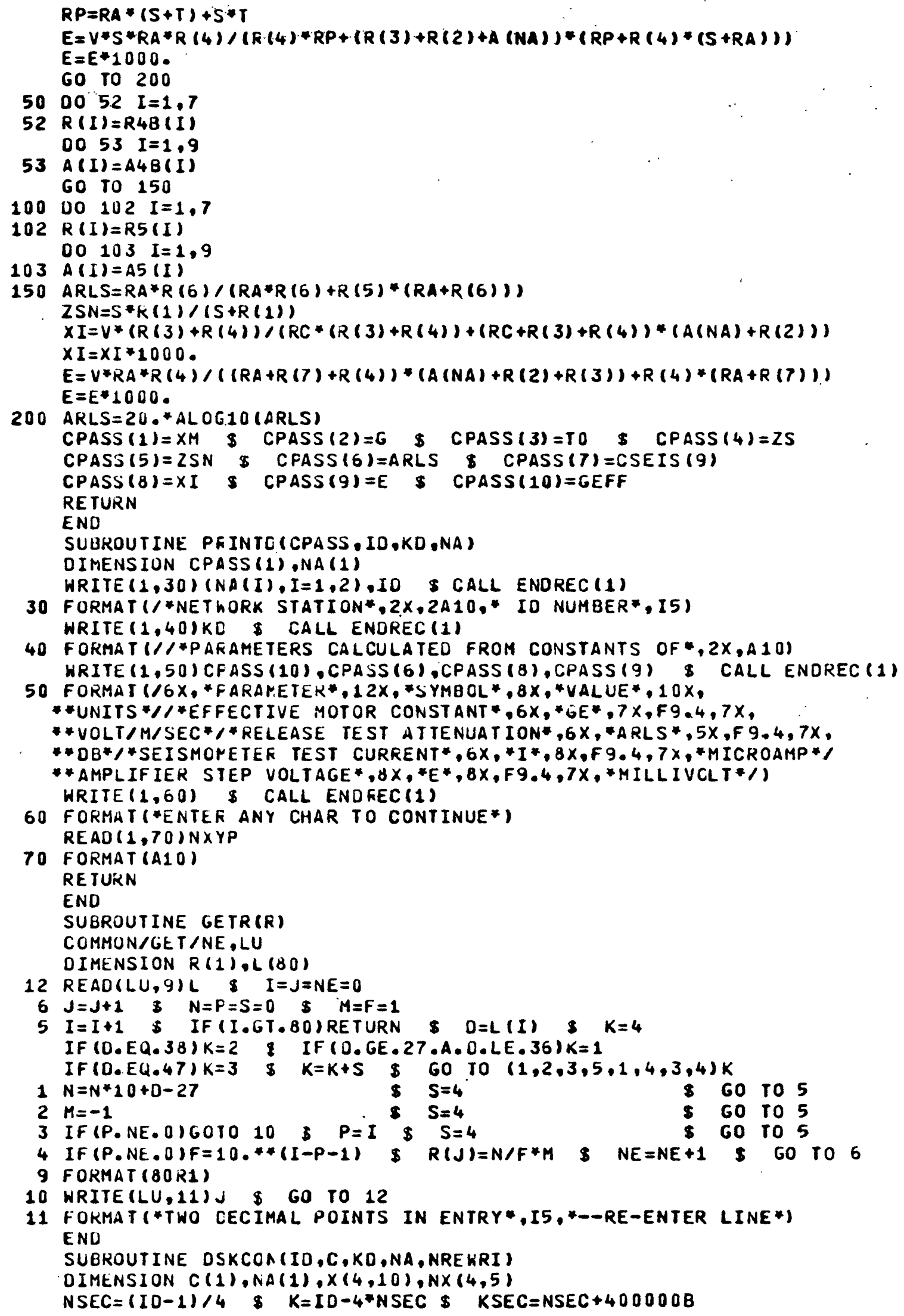


CALL RNOMIO $(6, K S E C)$

IF (NREWRI EEQ.1)GC TO 50

$N X(K, 1)=K D \& N X(K, 2)=N A(1) \& N X(K, 3)=N A(2)$

$N X(K, 4)=N A(3) \quad \$ N X(K, 5)=N A(4)$

$0010 \quad I=1,10$

$10 \quad x(K, I)=C(I)$

WRITE $(6)((X, I, J), J=1,10),(N X(I, L), L=1,5), I=1,4)$

CALL RECALL (6) GO TO 200

$50 \operatorname{READ}(6)((X(I, J), J=1,10),(N X(I, L), L=1,5), I=1,4)$

DO $60 I=1,10$

$60 \quad C(I)=x(K, I)$

$K D=N X(K, 1) \quad N A(1)=N X(K, 2) \quad N A(2)=N X(K, 3)$

$N A(3)=N X(K, 4) \quad$ \$NA $(4)=N \times(K, 5)$

200 CALL RNOMIO $(6,0)$ \$ REWIND 6 \$ RETURN

END 
PROGRAY CALTEM ITAPETTY $=201$, F ILM $=201$,

* TAPE 1 = TAPETTY, RLS, STP, PASSA, NOI, TAPE $8=N O I$,

- TAPE $7=$ TAPETTY, TAPE5 = FLS, TAPE. $20=P A S S A$,

* TAPEG = STP, CONTROL,T TAPET 7 = CONTROL, TPASSB,

- TAPE7 8 = PASSB, RE SP, TAPET 9=RE SP, NRESP, TAPE $80=$ =NRESPI

COMMON D 121001

COMMON/TVPOOL/T VPUL (8)

COMMON/TVTUNE/ITUNE (3O)

COMMON /JPLOT/ XLT, XRT, YLO,YUP, MAJX, MA.JY, KXX(2), K.Y (.2),

-LTITL ( 8 ) ,LU,LTF, LNLGX, LNLGY, NCLX,NCLY, LTITLZ (8)

DIMENS ION AMP $(2100)$, PHASE $(2100)$, TEMP $(2100), T Z(2100), T Y(2100)$

DIMENSION R $(10), A(1600)$, CONS $(10)$, IFET $(8)$, ST $0_{1}(200)$, STO $2(200)$

EQUIVALENCE (D) $(1), H(1))$

COMMON ITITLE/ IQ(d),PI

CALL FET (5LTAPE 1, IFET, 8$)$

IFET $(2)=$ IFET (2).0R.0000 0010 0000 0000 0000B

IFET $(8)=\operatorname{IFET}(8)$. OK. 4000000000000000 ODOUB

CALL FETISLTAPE I, IFET, -8$)$

CALL FET (SLIAPE7, IFET, O)

$\operatorname{IFET}(2)=\operatorname{IFET}(2), 0 R, 00000010000000000000 B$

IFET $(8)=\operatorname{IFET}(8) .0 R .4000$ O0OO 0000000000008

CALL FET(5LTAPE7, IFET, -8)

REWIND 5 \$ REWINU 6 \$ REWIINO 20 SREWINU 8 SREWINO 78

READ $(20,1)$ I COOE, NUIG, NIVUISE, NMFEL, NSTEP

REWINO 20

1 FORMAT (10I7)

READ $(78,106)$ (CONS (I), I $=1,10),(I D(I U), I U=1,2)$, IITT

106 FORMAT $\left(5 F_{10,5,1.5 F 10.5, /, 3 A 10)}\right.$

REWINO 78

CONS $(1)=S E I S H O M E T E R$ MASS IN KGM

CONS $(2)=$ SEISMOMETER MOTUR CONSTANT G (VOLTS/M/SEL)

CONS $(3)=S E I S M C M E T E R$ FREE PERIOC (SEC)

CONS (4) = AMPLIF IER EQUIVALENT SCURCE IMPEJANCE (K-CHMS) LURING NCRIAL OPER

CONS $(5)=A M P L I F I E R$ EQUIVALENT SOURCE IMPEUANCE CUKING NUISE SARPLE

CONS(6) = ATTENUATION RATIO (OB) DURING M.ASS RELEASE

CONS(7) = ACTUAL ATTENUATOR SETTING (DE)

CONS $(B)=$ CURRENT (MICRO AMPS) FCR MASS RELEASE

CONS $(9)=A M P L I F I E R$ STEP VOLTAGE (MILLIVOLTS)

$\operatorname{CONS}(10)=$

$\operatorname{CONS}(6)=10 . * *(\operatorname{CONS}(6) / 20.1$

READ $(80,923)$ JQED

66 JQEU $=0$

IF (E UF, 80$) 66,67$

$67 L U=1$

DIGFACT $=2.5 / 2047$.

C.. 2.5 VOLTS $=2047$ COUNTS ON OIGITILER

$P I=3.14159265358 \subseteq 8$

TWOPI $=? \cdot * P I$

FREQ1 $=0.1$

$\operatorname{ID}(3)=I D(4)=I O(5)=I D(6)=I O(7)=I D(8)=L \operatorname{ITL} 2(8)=10 \mathrm{H}$

$L T I T L(1)=I D(1)$

LTITL (2) $=I O(2)$

WHEN $=$ DATE $(K D)$

ENCOOE (40,2,LTITL2(1)) NUIG, IEUUE, KD

2 FURMAT (I3,* SAMP/SEC ID $=$ *, I 3, * PLOT DATE =*, A 10$)$

SAMP $\perp N T=1 . / N O I E$

FREQ2 =. 5/SAMPINT

86 WRITE $(1,6)$ \$CALL ENOREC(1)

WRITE $(1,26)$ \$CALL ENDREC (1)

WRITE $(1,27)$ SCALL ENOKEC(1) 


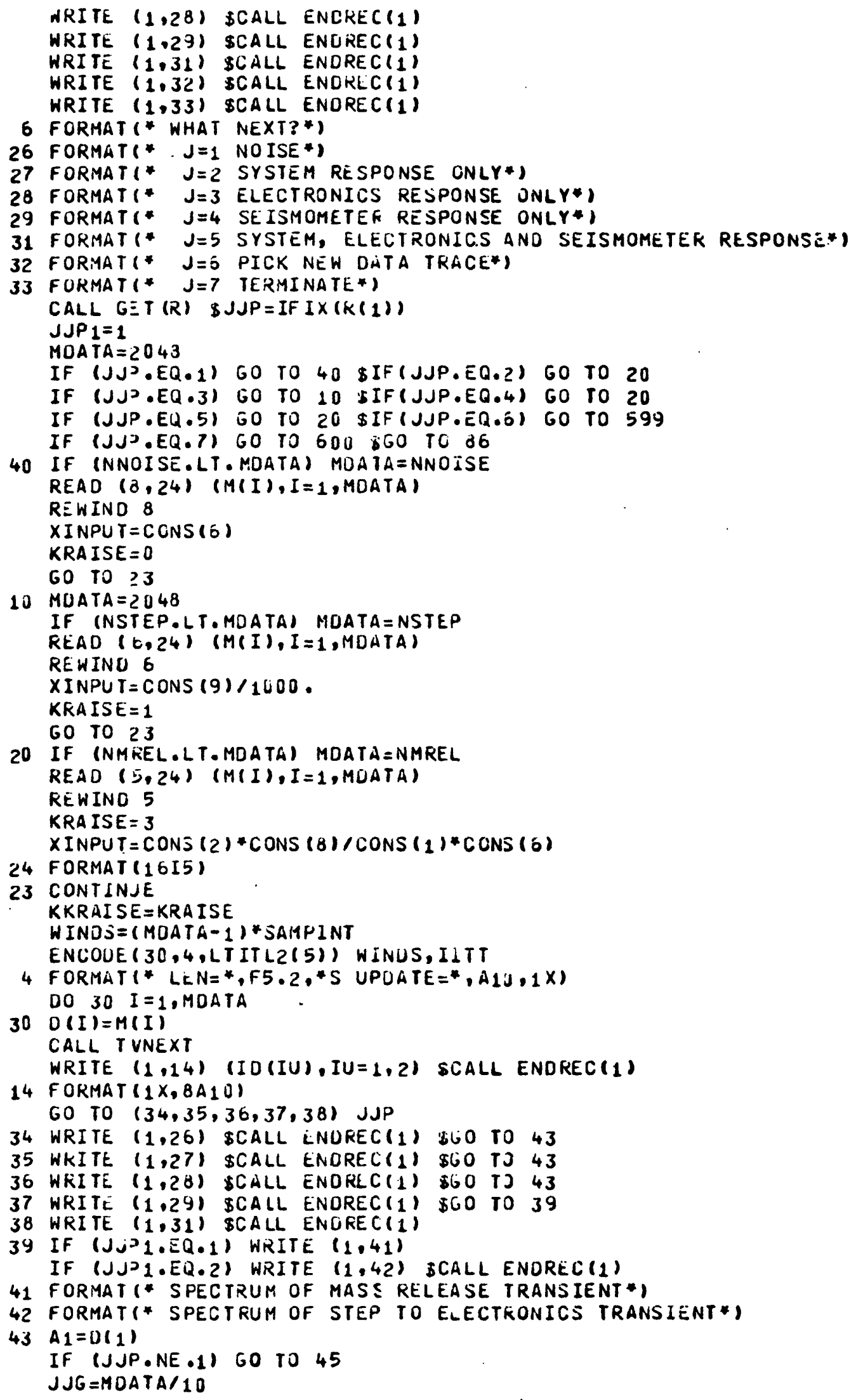


CALL WBWI (1, MODATA,JJG,JJE)

CALL WBAV (1, MDATA,A1)

45 CALL WBSA (1, MDATA,A 1)

IF (MDATA.EQ.256) 10 TO 47

DO $46^{\circ}\lceil 31=1$, MDATA

$46 T \equiv M P(I 31)=0(I 31)$

47 CONTINUE

$N=$ MOA TA

NDI $M=10$

CALL ENLARGE (NOIM, N,EXPAND)

IF (EXPAND.GT.O.) $N=E X P A \cap D * N$

ISI GN $=-1$

IPR INT $=-1$

CALL FFT (N, SAMP INT, FREQ1,FREQZ, OF, T, K1,K2, AMP, PHASE, IS IGN, IPRINTI

IF (MDATA.EQ.256) GO TO 52

DO 51 I $32=1$, MDATA

$51 \mathrm{O}(I 32)=\operatorname{TEMP}(I 32)$

52 CONTINJE

NSUM $=(K 2-K 1) / 2+1$

$\operatorname{TEMP}(1)=\left(K_{1} / 2\right) * D F$

$X F A C T=1$.

IF (KRAISE.NE.3) XFACT=DIGFACT

$\operatorname{AMP}(1)=\operatorname{AMP}(1) * T * X F A C T$

$00300 \mathrm{~J}=2, N S \cup M$

$\operatorname{AMP}(J)=\operatorname{AMP}(J) * T * X F A C T$

$30 G \operatorname{TEMP}(J)=\operatorname{TEMP}(J-1)+D F$

C.. FFT AMPLITUOES MULTIPLIED BY WINLUW LENGTH T TO CORRESPONO TO

C.. DEFN OF FOURIER TRANSFORM (UNITS OF VOLT-SEC) AND UY OIGFACTRTIUITIEEK

C.. VOLTS/COJNT FACTORI

IF (JJP.EQ.1.OR.MOATA.EQ.256) CO TO 401

DO $400 \quad I L=1, N S U M$

400 PHASE $(I L)=$ PHASE $(I L)+P I / 2$

40100402 IL $=1$, NSUM

$402 A M P(I L)=A M P(I L) / X I N P U T *(T E M P(I L) * P I * 2$. )**KKRAISE

IF (JJP.EQ.1) GO TO 509

CALL FASELIN(PHASE, NSUM, NY, NSUM)

IF (KRAISE.NE.3) GO TO 439

DO $430 . I L=1$, NSUM

430 PHASE $(I L)=$ PHASE $(I L)+2.0 * P I$

439 CONTINUE

IF (MDATA.EQ.256) GO TO 481

WRITE $(1,441)$ \$CALL ENOREC (1)

441 FORMAT ( $1 X$, *USE TRANSIENT DERIVATIVE FOR HIGH FREQ RESPONSE?*

$*, 1, *$ ENTER $1=$ YES $2=N O * 1$

CALL GET(R) \$IF (R(1).EQ.2.) 60 TO 486

WRITE $(1,442)$ SCALL ENDREC (1)

442 FORMAT ( $1 X_{*}$ *ENTER MINIMUM FREQ $(H Z)$ FOR RESPONSE FROM OERIVATIVE *

$*, 1, *(5 \mathrm{HZ}$ IS THE NOFMAL MINIMUM $) *$ )

CALL GET(R)

NJOIN $=R(1) / O F$ IIF (NJOIN.GT.200) NJOIN $=200$

$004 \%$ I $33=1$, NJOIN

$S T O_{1}(I 33)=A M P(I 33)$

470 STO2 (I 33$)=$ PHASE $(I 33)$

MOATA $=? 57$

CALL NJ MOERV (MOATA, SAMPINT)

KKRAI SE $=$ KRAISE-1

- RES $=1$ - / (FLOAT (MDATA-1)*SAMPINT)

WRITE $(1,475)$ TEMP(NJOIN), RES SLALL ENCRES( 1 )

475 FORMAT $11 X_{0}$ *RESPONSE FOR FREQ **, F3.1.* FROM DERIVATIVE *

**. RESOLUTION $=*, F 5.2, * H Z * 1$

GO TO 43

481 CONTINJE 
IF (PHASE(3).LE.TWOHI) 6010484

DO 482 I $Y=1$,NSUM

482 PHASE (I Y $)=$ PHASE (IY) - TWOP I

484 CONTINUE

DO 485 I $34=1$, NJOIN

$\operatorname{AMP}(I 34)=S T O_{1}(I 34)$

485 PHASE $(I 34)=S T O 2(I 34)$

$I 341=N J O I N+1$

PHASEOI = ABS (PHASE (I 341) - PHASE (NJOIN) )

IF (PHASEOI.LT.PI) GO TO 487

DO $488 J Q=I 341$, NSUM

488 PHASE $(J Q)=$ PHASE $(J Q)+T W O P I$

487 CONTINUE

486 CONTINJE

IF (JJJ.EQ.2.OK.JJP.EQ.3) GO TO 509

IF (JJP 1.EQ.2) GO TO 502

DO 501 IL $=1$, NSUM

I $Y(I L)=$ PHASE $(I L)$

$301 T Z(I L)=A M P(I L)$

502 CONTINJE

IF (JJP1.EQ.1) GOTO 504

00503 IL $=1$.NSUM

$T Y(I L)=T Y(I L)-P H A S E(I L)$

$503 T Z(I L)=T Z(I L) / A M P(I L)$

504 CONTINUE

509 CONTINJE

WRITE $(1,15)$ BLALL ENOFEC(1)

15 FORMAT (* ENTER ANY CHAR TO CONTINUE*)

REAO $(1,16)$ KJZX

16 FORMAT (A10)

IF (JJP.EQ.4) GO TO 580

CALL PLOTIT (AMP, PHASE, TEMP, NSUM, JJP, JUP I, JQEO)

CALL TVNEXT

IF (JJP.EQ.1.OK.JJP.EQ.2.OK.JJP.EQ.3) GO TO BL

580 CONTINJE

$J J P_{1}=J J P_{1}+1$

IF $\left(J J P_{1} \bullet E Q \cdot 2\right)$ GO TO 10

DO $582 I=1$, NSUM

$582 T Z(I)=T Z(I) * D I$ GFACT

CALL PLOTITITZ,TY,TEMP,NSUM, 11, JJP1, JQEO)

CALL TVNEXT

WRITE $(1.583)$ SCALL ENOREC ( 1$)$

583 FORMAT (///," RESFONSE TC GROUNO ACCELERATION? $1=Y$ Y $2=N O * 1$

CALL GET $(R)$ BNFLAG $=$ IF $I X(R(1))$

IF (NFLAG.EQ.2) GO TO 86

CALL ACCRESP(TEMP, TZ,TY, INSUM)

CALL PLOTITITZ,TY,TEMP,NSUM, 12, JJP1, JQEO)

CALL TVNEXT

GU TO 86

599 REWIND 77

REWINU 80

WRITL $(00.923)$ JQEO

REWINO 80

WRITE $(77,901)$

901 FORMAT (*PIKR, TAPETTY, TAPETTY, *

* SPLGU, TAPETTY, TAPE TTY, *

* CTLGO, TAPETTY, TAPETIY .*1

GO TO 930

600 REWIND 77

IF (JJP.EQ.7)WRITE(1,910) \$ CÁLL ENOREC (1)

910 FORMATI*END OF PROGRAM*I

WKITE $(1,920) J Q E D$ \& CALL ENDREC(1) 


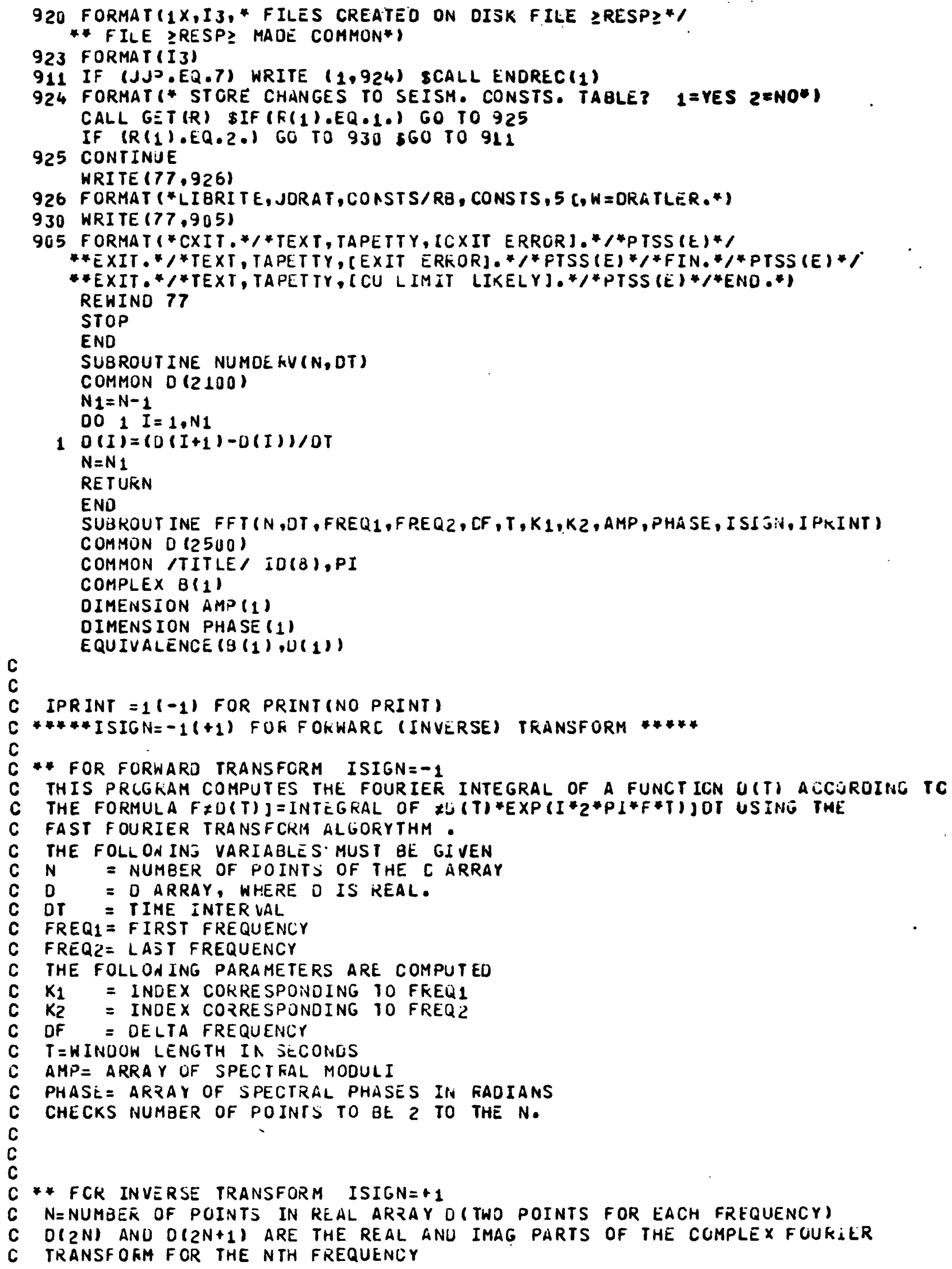


C FOR OT,FREQ1, FREQ2 REAO FREQUENCY INCREMENT,TIME 1, ANO TIMEZ RESPECTIVELY

C $K_{1}$, $K_{2}$, AND DF (TIME INCREMENT) ARE COMPUTEJ

C RËAL (IMAG) TIME SERIES RETUKNED IN AMP(PHASE) ARRAY.

C

IF (ISIGN,EQ,-1) WRITE $(1,1)$

IF (ISIGN.EQ.+1) WRITE $(1,2)$

CALL ENDKEC ( 1$)$

1 FORMAT I FORWARO TRANSFGRYA* )

2 FORMAT I* INVERSE TRANSFORM *

IF (ISIGN.EQ.-1) GO TO 61

$\mathrm{N} 2=\mathrm{N}$

$N=N / 2$

$N_{1}=N-1$

$00112 I=1, N_{1}$

$J=N 2-I$

$112 B(J)=\operatorname{CONJG}(B(I))$

$B(N)=\operatorname{REAL}(B(N))$

$N=N 2-2$

61 CONTINJE

NOP $=8$

$I=2$

$L I=4$

$3 L I=L I+-I$

$I=I+1$

IF(N.LE.8) GO TO 66

$L L=N / L I$

IF (LL.EQ.1) 4,3

$4 N O P=2 * * I$

IF (NOP.EQ.N) GO TO 5

$I=I+1$

$N O P=2 * N O P$

$66 N P=N O P-N$

$N 1=N+1$

DO $6 K=N_{1}$, NOP

$6 D(K)=0$.

WRITE $(1,77)$ NP \& CALL ENOREC (1)

77 FORMAT 1 * NUMBER OF POINTS NOT $=2$ TO THE $N^{*}$

$1,1,1 X_{1}[4, *$ POINTS $=0$ APPENDED*1

$5 N E=I-1$

$N N=N O P / 2$

$F N N=i N N$

$F N O P=N O P$

$D F=1 . /\left(F N O P^{*} D T\right)$

$F N Y Q=0.5 / J T$

$T=F L O A T(N O P) * D T$

WRITE $(1,13)$ NOP, FNYQ,DF \& CALL ENDREC (1)

13 FORMATI* NUMEER OF POINTS $=* 16,1$,

2* NYQUIST FREQUENCY $=* F 8.3, * \mathrm{HZ}, 1$,

3* FRLQJENCY INTERVAL $=* F 7.4, * \mathrm{HZ}^{*} 1$

IF (ISIGN.EQ.-1) GO TO 63

$N E=N E+1$

CALL COCL $(N E, B,+1$,

GO TO 02

63 CONTINUE

CALL RECOOLINE,O,OT)

62 CONTINJE

- $K_{1}=F R E U_{1} / O F+1$

$F K_{1}=K_{1}$

$F R=\left(F K_{1}-2 \cdot\right) * D F$

IF (FREQ2.LT.FNYQ) GO TO 55

$F R E Q 2=F N Y Q$ 
5E CONTINJE

$K 2=F R E Q 2 / O F+1$

$C X=1 . / F N C P / O T$

IF(ISISN.EQ.1) GOTO 64

DO $7 I=K_{1}, K_{2}$

$J J=2^{*} I$

$J=J J-1$

$R=C X * \operatorname{SQRT}(D(J) * O(J)+D(J J) * D(J J))$

$P \quad=A T A N 2(D(J J), D(J))$

$D(J)=R$

$O(J)=P$

7 CONTINJE

64 CONTINJE

IF (ISIJN.EQ.1.ANC.IPRINT.EQ.1) WRITE $(1,14)$

IF (ISISN.EQ.1 . ANC.IPRINT .EQ. I) CALL ENDREC (1)

14 FORIAT I* INDEX *9X*TIME * $9 X$ * REAL * $9 X *$ IMAGINAR $Y * / 1 / 1$

$K P P=0$

$K_{1}=2^{*} K_{1}-1$

$K 2=2^{*} K$ ?

IF (ISIGN.EQ.1) K2=K2*2-4

DO $8 K=K 1, K 2,2$

$K A=K+1$

$F R=F R+D F$

$K P P=K P P+1$

IF (IPR INT.EQ. 1) WRITE $(1,11) K P P, F R, D(K), D(K A)$

IF (IPRINT.EQ.1) CALL ENUFEC(1)

11 FORMAT (I7, F $\left.13,4, F_{1} 6,4, F_{14}, 3\right)$

$A M P(K P P)=D(K)$

PHASE $(K P F)=D(K A)$

8 CONTINJE

RETURN

ENO

SUBROUTINE COOL $(N, X, S I G N I)$

COMPLEX $X, Q, W, H O L O$

DIMENSION $X(1)$, INT $(16), 6(2)$

EQUIVALENCE $(G, W)$

$L X=2 * * V$

$F L X=L X$

$I L=L X$

FLXPI $2=S I G N I * 6.2851853 / F L X$

CO $10 \mathrm{I}=1, \mathrm{~N}$

$I L=I L / 2$

10 INT $(I)=I L$

NBL OKK $=1$

DO 40 - $A Y E R=1, N$

$N B L O C K=N B L O K K$

$N B L O K K=N B L O K K+N E L O K K$

$\angle B L O C K=L X / N B L O C K$

$\angle B H A L F=L B L O C K / 2$

$\mathrm{NW}=0$

DO 40 IBLOCK $=1, N B L O C K$

$\angle S T A R T=\angle B L O C K *(I B L O C K-1)$

$F N W=N W$

$A R G=F N$ N *FLXPI 2

$G(1)=\operatorname{CJS}(A R G)$

$G(2)=S I N(A R G)$

DO $20 \mathrm{I}=1$, LBHALF

$J=I+L S T A R T$

$K=J+L B H A L F$

$Q=X(K) * W$

$x(K)=x(J)-Q$

$20 \quad x(J)=x(J)+Q$ 


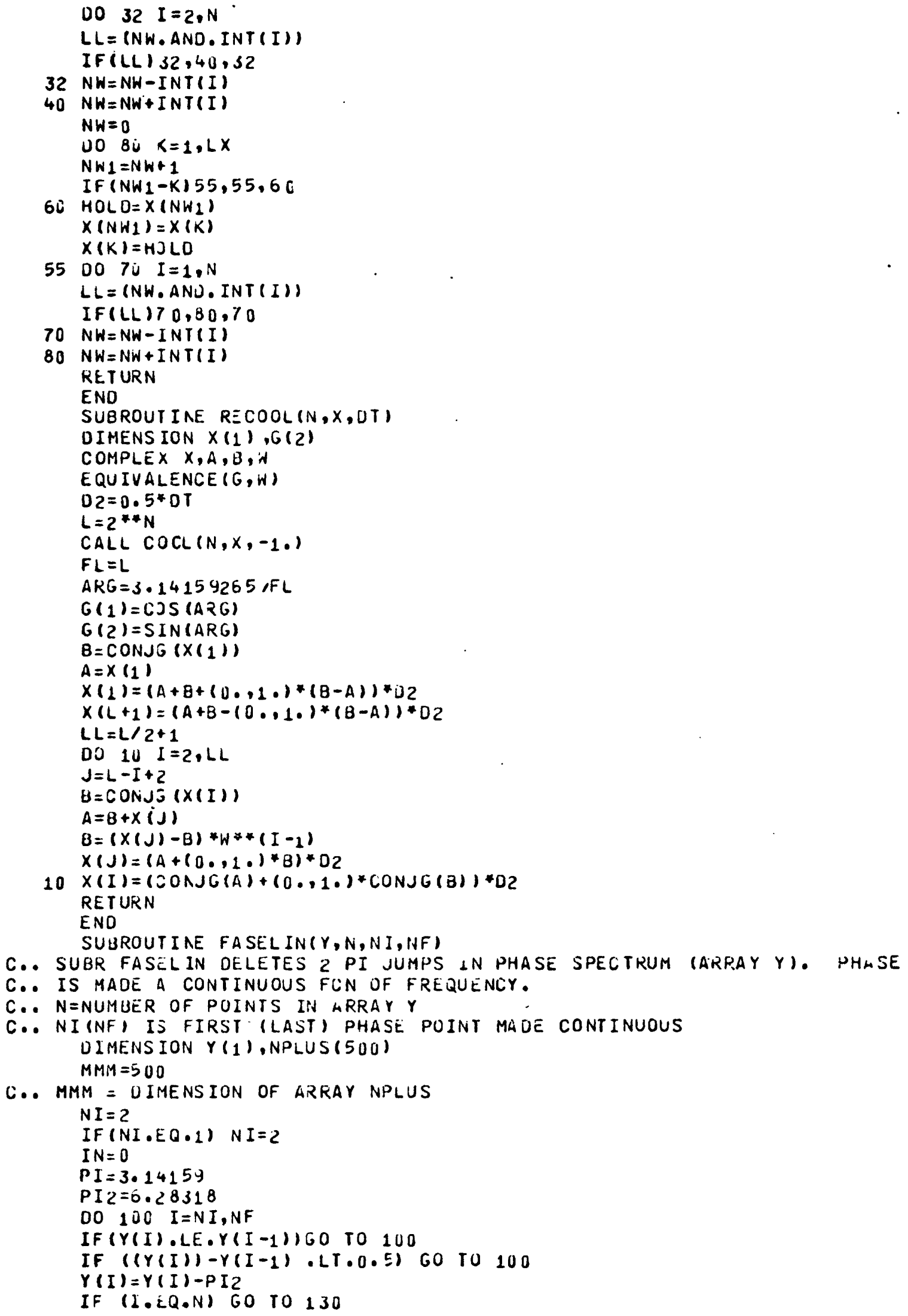




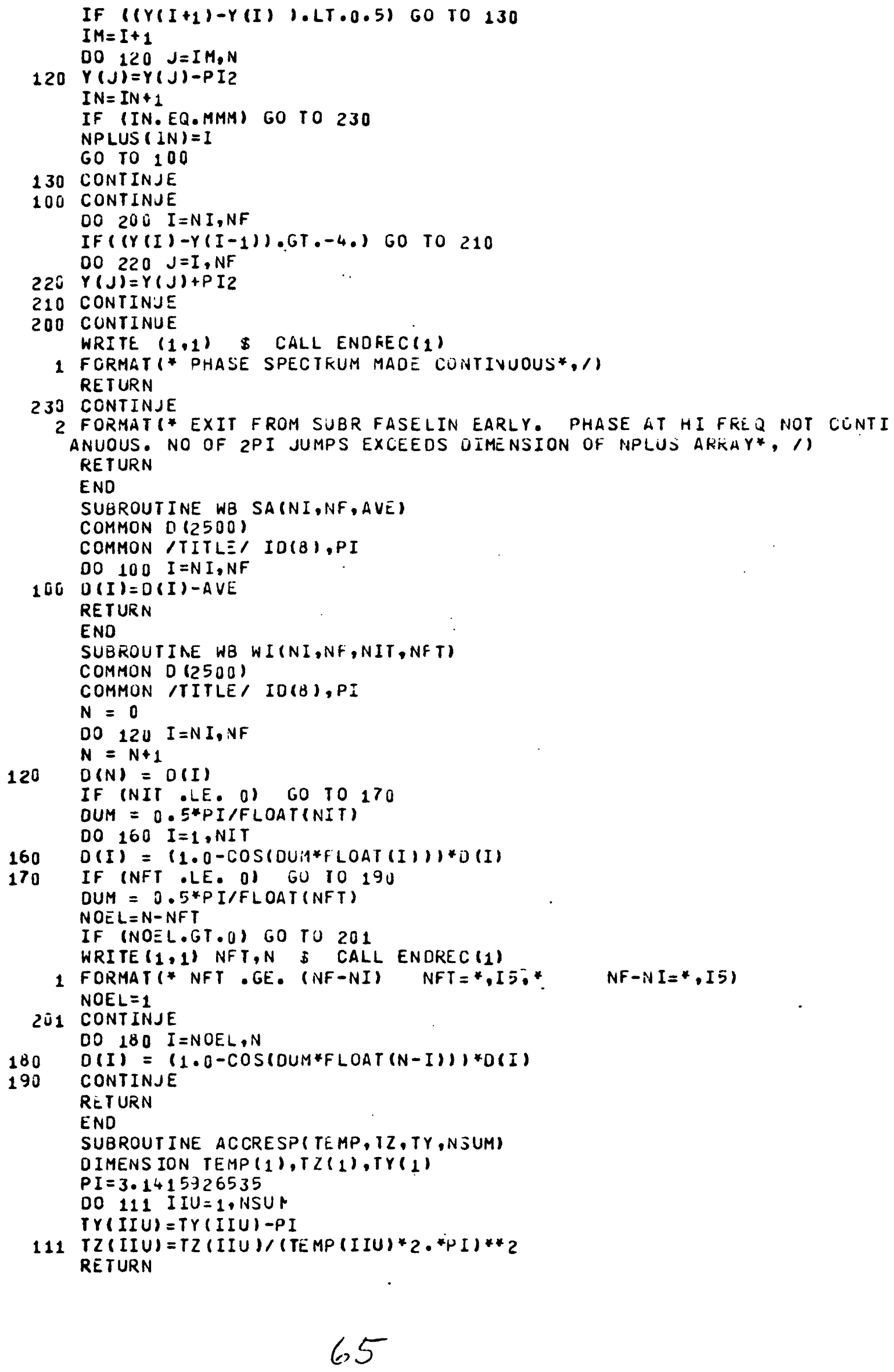




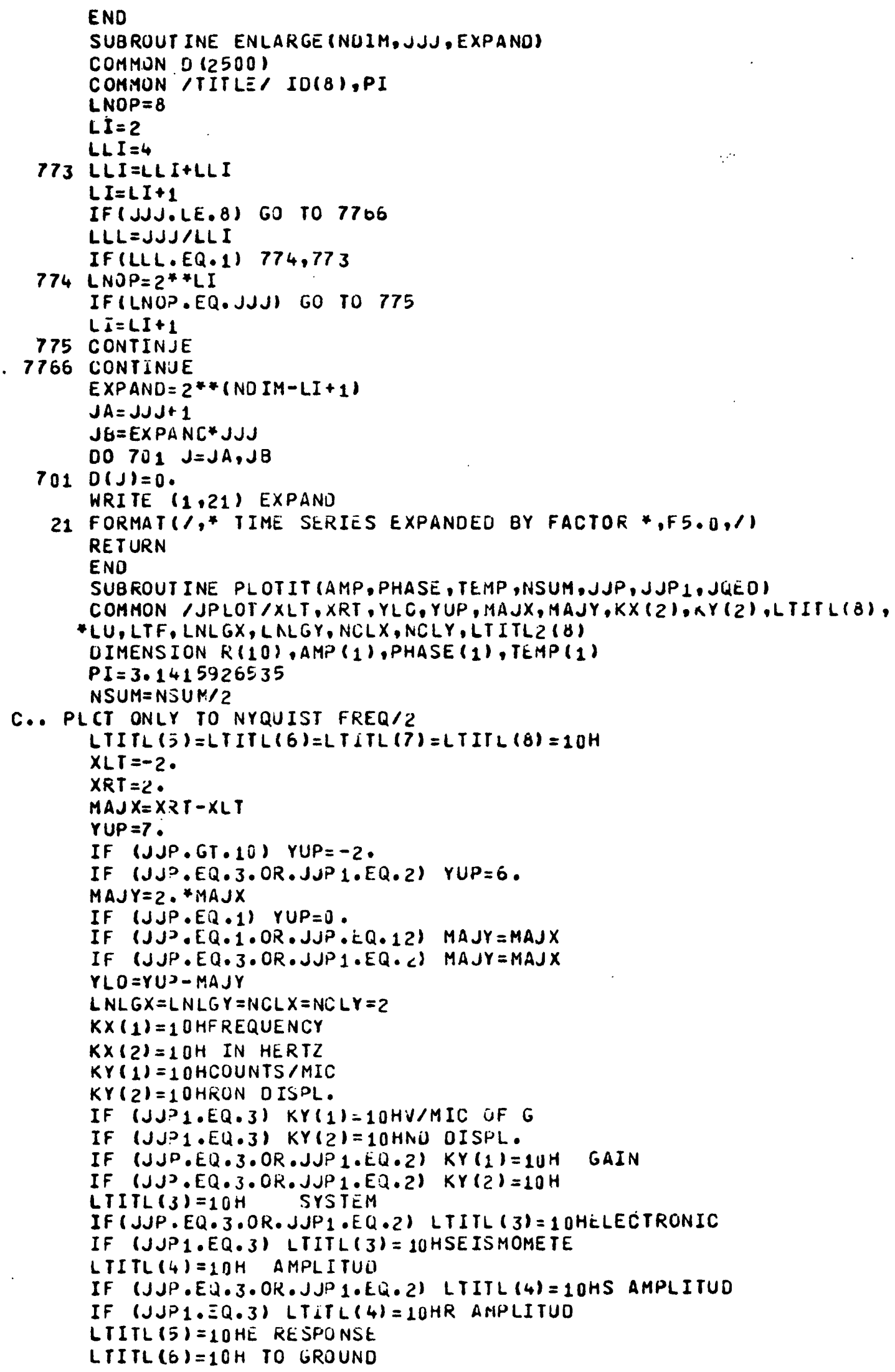


LTITL $(7)=1 O H$ OISPL.

IF (JJP.EQ.3.OR.JJPL,EQ.2) LTITL $(6)=L T I T L(7)=10 H$

IF (JJP.NE. 12) GO TO 4

LTITL (7) $=10 \mathrm{H}$ ACCEL.

$K Y(1)=10 \mathrm{HV} / \mathrm{MIC} / \mathrm{SEC} /$

$K Y(2)=1$ OHSEC

4 CONTINUE

IF (JJP.NE.1) GO TO 5

$K Y(1)=1 O H \vee S E C$

$K Y(2)=10 H$

LIITL(3) $=10 \mathrm{H} \mathrm{NCISE}$

LTITL $(4)=10$ HSPECTRUM

LTITL $(5)=L T I T L(6)=L T I T L(7)=L T I T L(8)=10 \mathrm{H}$

5 CONTINUE

6 CALL PLCTS (AMP, TEMP, 1 , NSUM)

WRITE $(1,31)$ \$CALL ENDREC(1)

31 FORMAT $/ / / /, 15 x,{ }^{*}$ WHAT NEXT ?*,/,15X,*1=CONT INUE *

* * $2=R \equiv P L O T$ WITH NEW YMAX*)

CALL GET(R) SNFLAG = IFIX(R(1))

IF (NFLAG.EQ.1) GO TO 38

WRITE $(1,33)$ \$CALL ENOREC (1)

33 FORMAT $\left(15 X_{0}\right.$ *NEW POWER OF 10 FOR YMAX?*)

CALL GET(R) \$YUP=R(1)

YLO $=$ YUP - MAJY

GO TO 5

38 CONTINUE

IF (JJP.EQ.1) GO TO 101

IF (JJP.NE.12) GO TO 95

WRITE $(1,91)$ \$CALL ENCREC(1)

91 FORMATI/.15X,*PICK PEAK GN SMOOTH PART OF RESPONSE*,

* 15X, *aND TYPE aNY CHAR TO CONT INUE (HO RETURN)*)

$L O O K=3 H X, Y$ SCALL TVFARE (LOOK, $X, Y, K 1, K 2)$

TO $=1.1100^{* *} X$ SWRITE $(1,92)$ TO ICALL ENUREC (1)

92 FORMAT (15X, *SEISMOMETEF FREE PLRIOJ =*,F5.3, *SLC*)

GF IND $=X+A L U G_{1} O(A M P(1))-A L O O_{10}$ (TEMP(1))-Y

GAMMA $=10 . * *(A B S($ GF INC) $) / 2$.

WRITE $(1,93)$ GAMMA \$CALL ENDKEC (1)

93 FORMAT $\left(15 X_{\text {, }}\right.$ SEISMOMETER DAMPING FACTOR = *,FG.s)

GF IND $=X+A L O G 10(A M P(2))-A L O G 10(T \equiv M P(2))-Y$

GAMMA $=10 * *(A B S(G F$ INC $)) / 2$.

WRITE $(1.93)$ GAMMA ECALL ENOREC (1)

GAINS $=100^{*}$ *Y SWRITE $(1,94)$ GAINS $\triangle C A L L$ ENDREC (1)

94 FORMAT $15 X, *$ RESPONSE AT THE FREE PERIOD $=*$, E 15.5,* VOLTS $/ *$

*,1,30X,*MICRON/SËC/SEC*,1,15X,* ENTER ANY CHARACTER TO CONTINUL*I READ $(1,15)$ KJZX

16. FORMAT (A1)

95 CCNTINJE

CALL TVNEXT

WRITE $(1,97)$ \$CALL ENOREC (1)

97 FORMAT ( $/ /, *$ WHAT NEXT? $1=$ CONTINUE $2=P L O T$ PHASE RESPUNSE*)

CALL GET(R) \$NFLAG $=$ IFIXIF(1))

IF (NFLAG.EQ.1) GO TO 101

DO $100 \quad I=1$, NSUM

100 PHA SL $(I)=$ PHASE $(I) / P I$

YUP $=2$.

IF (JJP.EQ.12) YUP $=1$.

$Y L O=-2$

MAJY $=4$.

LNLGY $=1$

IF (JJP.EQ.12) MAJY $=3$.

$K r(1)=10 \mathrm{H}$ PHASE(PI

$K Y(2)=10 \mathrm{H}$ RAOIANS) 
LTITL $(+)=10 H$ PHASE

IF (JJP.EQ.3.OR.JJP 1.EQ.2) LTITL (4) $10 H S$ PHASE

IF (JJP $1 . E Q .3)$ LTITL $(4)=10 H R$ PHASE

LTITL $(5)=10 . H$ RESPONSE

CALL PLOTS (PHASE, TEMP, 1 , NSUMM)

DO $99 I=1$, NSUM

99 PHASE $(I)=$ PHASE $(I) * P I$

101 CONTINJE

CALL TVNEXT

WRITE $(1,102)$ \$CALL ENDREC(1)

102 FORMAT $(/ / 1 / 15 X, *$ DUTPUT TO A UISC FILE? $1=$ YES $2=$ NO*)

CALL GET(R) \$NFLAG $=I F I X(R(1))$

IF (NFLAG.EQ.2) GO TO 104

103 CONTINJE

LTITL $(3)=10 \mathrm{H}$ SYSTEM

LTITL $(4)=10 \mathrm{H}$ RESPONSE

LTITL $(5)=10 \mathrm{H} \quad$ AMP IN

LTITL $(5)=1$ OHCOUNTS/MIC

LIITL $(7)=10 \mathrm{H}$ PHASE IN

LTITL $(8)=10$ HRALIANS

IF (JJP.NE.1)GO TO 106

LIITL $(3)=10 \mathrm{H}$ NCISE

LTITL $(j)=10 \mathrm{H} \vee C L T-S E C$

GO TO 111

106 IF (JJP.NE.3.AND.JJP1.NE.2) GO TO 107

LTITL $(3)=10 \mathrm{HELECTRONIC}$

LTITL $(6)=10 \mathrm{H}$ GAIN

GO TO 111

107 IF (JJP.LT.10) GO TO 111

LTITL $(3)=10 \mathrm{H}$ SEIS.

LTITL $(O)=10 \mathrm{HV} / \mathrm{MICRON}$

IF (JJP.EQ.12) LTITL $(6)=10 \mathrm{H} V / M I C / S / S$

111 CONTINUE

NSUM $=N 5 U H^{*} 2$

WRITE $(79)(1 L T I T L(I), I=1,8),(L T I T L \geq(j), J=1,8), N S U M,(T E M P(K)$,

* AMP $(K), P H A S E(K), K=1, N S U M))$ SEND FILE79

$J Q E D=J Q E D+1$

WRITE $(1,105)$ (LTITL(I),I=1,3), JQED \&CALL ENURECI(1)

105 FORMAT $11 \times, 8$ A $10,1, *$ OUTPU $\}$ TO FILE*, I5,* ON DISC FILE $\geq R E S P \geq *$,

* * ENTER any Char to continue*I

REAO $(1,16)$

104 CONTINUE

RETURN

ENO

SUBROUTINE WAAV(NI, NF, AV)

COMMON O (1)

SUM $=0$.

$00100 \quad I=N I, N F$

100 SUM $=S U M+D(I)$

$A V=S U M / F L O A T(N F-N I+1)$

RETURN

END 
PROGRAM CALFIX ITAPE TTY $=201$, FILM=201, RESP, SY SRESP,

- TAPE $1=$ TAPE TTY, TAPE7 = TAPE TTY, TAPE 79=RESP, TAPE $81=$ SYSRE SP)

COMMON/TVPOOL/TVPUL (8)

COMMON /TENOI NSUMA, NSUMP, NSUMPE

COMMCN/ TVTUNE/ITUNE (30)

COMMON /JPLOT/ XLT,XRT, YLO,YUP, MAJX, MAJY,KX(2),KY $(2)$,

*LTITL(8), LU, LTF, LNLGX,LNLGY, NCLX,NCLY,LTITL2 (8)

DIMENSION R(10), IFET $(8), \operatorname{IO} 9(8)$

OIMENSION F1(1025), SYSAMP (1025), SYSPH (1025)

DIMENSION ELECAMP(1025), ELECPH(1025)

COMMON /TITLE/ IO(8),PI

CALL FET (5LTAPE1, IFET,8)

IFET $(2)=$ IFET $(2), 0 R, 0 C 00 \quad 0 C 10000000000000 B$

$\operatorname{IFET}(8)=\operatorname{IFET}(8) .0 R .40000000000000000000 B$

CALL FET (5LTAPE 1 , IFET, -8$)$

CALL FET (5LTAPET, IFET, 8$)$

IFET $(2)=$ IFET $(2) .0 R .00000010000000000000 B$

IFET $(8)=$ IFET $(8) .0 R .40000000000 C 000000008$

CALL FET (5LTAPE7, IFET, -8)

ISYS $=0$

REHINO 81

LU $=1$

1 WRITE $(1,2)$ \$CALL ENDREC (1)

2 FORMAT (///. * ENTER FILE NO OF SYSTEY RESPONSE*)

CALL READ1 (LTITL,LTITL2,NSUM,F1, SYSAMP, SYSPH, R)

DO $3 \mathrm{IO}=1,8$

$3 I O g(I O)=L T I T L(I 0)$

IF(R(1),EQ.777) GO TO 1

NSUMA $=N$ SUMPE $=$ NSUMP $=$ NSUM

CALL PLS(F1,SYSAMP, SYSPH, NSUM,1)

101 HRITE (1.102) \$CALL ENDFEC (1)

102 FORMAT $\left(/ / /{ }^{*}\right.$ ENTER FILE NO OF ELECTRONICS RESPONSE*)

CALL READI (LTITL,LTITL2, KSUM, F1, ELECAMP, ELECPH, R)

IF (R(1).EQ.777) GO TO 101

CALL PLS (F1, ELECAMP, ELECPH, KSUM, 2)

$F 1 H Z=1$.

DO $180 \quad I=1$, NSUM

180 CONTINUE

IF (FIHZ.LE,F I(I)) GO TO 181

181 CONTINUE

NNSTAR $=I$

DO $200 \mathrm{~J}=\mathrm{N} N S T A R_{1}, N S U M$

$200 \operatorname{SYSAMP}(J)=\operatorname{SYSAMP}(J)$ *ELECAMP $(J) / E L E C A M P(N N S T A R)$

$X T I E=S Y S P H$ (NSUMP) /ELECPH (NSUMP)

DO $201 \mathrm{~J}=$ NSUMP, NSUMPE

$201 \operatorname{SYSPH}(J)=E L E C P H(J) * X T I E$

NSUMP $=$ N.SUMPE

WRITE $(1,202)$ \$CALL ENDFEC(1)

202 FORMAT I* WHAT NEXT? $1=$ CONTINUE $2=$ PLOT SMOOTHED RESPONSES*1

DO $205 \mathrm{KL}=1,8$

$205 L T I T L(K L)=I 09(X L)$

CALL GET(R) \$IF(R(1),EQ.2.) CALL PLS(F1,SYSAMP,SYSPH, NSUM,3)

ISYS $=$ ISYS +1

WRITE ( 81$)$ ( $(L T I T L(I), I=1,8)$, NSUM,NSUMA,NSUMP, $(F 1(K), \operatorname{SYSAMP}(K)$,

* SYSPH(K),K=1, NSUM) \$ENCF ILE 81

WRITE $(1,301)$ (LTITL(I), I=1,8), ISYS, F1(NSJMA), F1 (NSUMP)

CALL ENDREC (1)

301 FORMAT $11 \times, 8$ A10, $/ 0^{*}$ OUTPUT TO FILE *, I5,* ON OISC FILE $\geq S Y S R E S P \geq *$

$* * /, 1 X, *$ MAX FREQ OF AMPLITUOE (PHASE) RESPONSE $=*, F 5.1, * 1 *, F 5.1$,

**) $\left.H Z^{*}\right)$

WRITE $(1,302)$ \$CALL ENDREC(1) 
302 FORMAT ( $1 X$, *HHAT NEXT? $-1=$ STOP $2=F I X$ ANOTHER SYSTEM RESPONSE*) CALL GET (R) SIF (R(1).EQ.2.) GO TO 1.

STOP

END

SUBROUT INE REAO1 (IO1,ID2,NSUM,F, $A, P, R)$

DIMENSION IOI(1), ID $2(1), F(1), A(1), P(1), R(1)$

CALL GET(R) DIFF $=R(1)-1$

REHINO 79

CALL SK IPFIL 179 , IFF)

READ (79) ( (IOI (I),I=1,8), (ID2(J),J =1,8),NSUM, $(F(K)$,

* $A(K), P(K), K=1, N S U M)$

REWIND 79

WRITE $(1,4)$ (IJI(I),I=1,8) \$CALL ENOREC(1)

WRITE $(1,4)$ (ID2 (I), I=1,8) \$CALL ENDREC(1)

4 FORMAT $(1 X, 8 A 10)$

WRITE $(1,7)$ DSALL ENDREC(1)

7 FORMAT $(1 /$, * ENTER 777 IF WRONG FILE ANY OTHER CHAF IF OK*). CALL GET(R)

RETURN

END

SUBROUTINE PLS (F,A,P,NSUR, KKKK)

COMMON /TEND/NSUMA, NSUMP, NSUMPE

COMMON/ JPLOTIXLT, XRT, YLO, YUP, MAJX, MAJY, KX(2), KY (2), LTITL(B),

*LU, LTF, LNLGX, LNLGY, NCL X, NCLY, LTITL2 (8)

OIMENSION $R(10), A(1), P(1), F(1)$

$\operatorname{LTIL2}(1)=1$

$\operatorname{LTITL}(5)=\operatorname{LITL}(6)=\operatorname{LTTL}(7)=\operatorname{LTITL}(8)=10 \mathrm{H}$

$P I=3.1415926535$

NNFLAS $=1$

$X L T=-2$.

$X R T=2$.

MAJX $=X R T-X L T$

YUP $=7$.

MAJY $=2$. * MAJX

LNLGX $=L N L G Y=N C L X=N C L Y=2$

$K X(1)=10$ HFREQUENCY

$K \times(2)=10 H$ IN HERTZ

$K Y(1)=10 H C O U N T S /$ Y.IC

$K Y(2)=10 H R O N D$ ISPL.

IF (KKKK.NE.2) GO TO 5

$Y U P=6$. $\$ M A J Y=M A J X$

$K Y(1)=10 H \quad$ GAIN $\quad \$ K Y(2)=10 H$

5 CONTINJE

YLO $=$ YUP - NAJY

6 CALL PLOTS $(A, F, 1, N S U M A)$

WRITE $(1,31)$ \$CALL ENDREC(1)

31 FORMAT $\left(/ / / /, 15 X_{*}^{*}\right.$ WHAT NEXT?*,/,15X,*1=CONTINUE *

** 2=REPLOT WITH NEW YMA $\times * 1$.

CALL GET(R) BNFLAG =IFIX(R(1))

IF (NFLAG.EQ.1) GO TO 38

WRITE $(1,33)$ \$CALL ENDREC(1)

33 FORMAT (15X,* NEW POWER OF 10 FOR YMAX?*)

CALL GET $(R)$ SYUP=R(1)

$Y L O=Y U D-M A J Y$

GO TO 5

38 CONTINUE

IF (KKKK.EQ.3) GO TO 99

WRITE $(1.51)$ \$CALL ENDREC(1)

51 FORMAT (15X,*PICK HIGH FREQ LIMIT OF SMOOTH RESPONSE*.

* $1.15 X_{*}$ * ANO TYPE ANY CHAR (NO RETURN) *)

LOOK $=3,4 X, Y$

CALL TVFARE (LOOK, $X, Y, K 1, K 2)$ 
$6 \times 0=10 . * X \quad \$ \times 0=X \quad \$ Y 0=Y$

HRITE $(1,52)$ GXO CCALL ENDREC(1)

52 FORMAT $\left(15 X, * F R E Q\right.$ SELECTED $\left.=*, F 5.2, * H Z^{*}\right)$

IF (KKKK.EQ.1) GO TO 94

53 WRITE $(1,64)$ SCALL ENDREC (1)

64 FORMAT (15X, *PICK HIGH FREQ EXTRAPOLATION POINT*,

* $1,15 X_{0}$ *ANO TYPE ANY CHAR (NO RETURN) *)

$L O O K=3+X, Y \quad \$ C A L L$ TVFARE (LOOK, $X, Y, K 1, K 2)$

GX1=10.*XX \$X1 =X \$Y $1=Y$

HRITE $(1,52)$ GX1 SCALL ENDREC(1)

$X M=\left(Y_{1}-Y_{0}\right) /\left(X_{1}-X_{0}\right)$

CALL POI ( $F, 1, N S U M, G \times O$, NNSTAR)

$X J I=A L O G 10(F(N A S T A R))$

CALL POI (F, NNSTAR, NSUM, GX1, NNEND)

DO $69 \mathrm{~J}=$ NNSTAR, NNEND

$P O W=A L O G 10(A(N A S T A R))+X M *(A L O G 10(F(J))-X J I)$

$69 A(J)=10$ * *POW

IF (NNFLAS.EQ.2) GO TO 71

WRITE (1,70) \$CALL ENDREC (1)

70 FORMAT $115 X_{0}$ *EXTRAP TO $1=$ INTERMEDIATE FREQ*, 1,

- $25 X_{0} * 2=$ MAX FREQ OF RELIABLE RESPONSE*)

$X O=X 1 \quad \$ Y O=Y 1 \quad \$ G \times O=G \times 1$

CALL GET (R) SNNFLAS=IFIX(R(1)) \$GO TO 53

71 NSUMA $=$ NNEND

WRITE $(1,15)$ \$CALL ENDREC(1)

READ $(1,16) \mathrm{KJGH}$

CALL PLOTS $(A, F, 1, N S U M A)$

GO 1096

94 CONTINJE

WRITE $(1,15)$ SCALL ENOREC(1).

READ $(1,16) \mathrm{KJGH}$

CALL POI $(F+1, N S U M, G \times O$, NNSTAR)

DO $97 J=N N S T A R, N S U M$

$97 A(J)=A(N N S T A R)$ * $F(J) / F$ (NNSTAR)

CALL PLOTS (A,F, $1, N S U M A)$

96 NNFLAS $=1$

$9900100 \quad I=1$, NSUM

$100 P(I)=P(I) / P I$

YUP=2. \$YLO $=-1 . \quad$ SMAJY $=3$. \$LNLGY $=1$

$K Y(1)=10 \mathrm{H}$ PHASE (PI $\$ K Y(2)=10 H$ RADIANS)

101 NPLOG=NSUM \$IF (KKKK.EQ.3) NPLOG=NSUMPE

CALL PLOTS $(P, F, 1, N P L O G)$

WRITE $(1,31)$ SCALL ENDREC(1)

CALL GET (R) \$VFLAG $=I F I X(R(1))$

IF (NFLAG.EQ.1) GO TO 104

WRITE $(1,102)$ \$CALL ENDFEC(1)

102 FORMAT $(15 X$, *ENTER NEW YMAX*)

CALL GET(R) SYUP=R(1)

YLO $=$ YUP - Y.AJY

GO TO 101

104 CONTINUE

IF (KKKK.EQ.3) GO TO 151

WRITE $(1,105)$ \$CALL ENDREC(1)

105 FORMAT $(/ / /)$

WRITE $(1,51)$ \$CALL ENOREC (1)

LOOK $=3 H X, Y$ SCALL TVFARE (LOOK, X, Y,K1,K2)

GXO $=10 . * * X \quad \$ \times 0=X \quad \$ Y O=Y$

WRITE. $(1,52)$ GXO \$CALL ENOREC (1)

106. WRITE $(1,64)$ SCALL ENDREC(1)

LOOK $=3 H X, Y$ SCALL TVFARE (LOOK, X, Y, K1, K2)

GX1=10:* $\quad \$ X 1=X \quad$ SY1 $=Y$

HRITE $(1,52)$ GX1 \$CALL ENDREC(1) 
$X M=(Y 1-Y 0) /(X 1-X 0)$

CALL POI (F, 1, NSUM,GXO, NNSTAR)

$X J I=A L O G 10$ (F (NASTAR))

CALL POI (F, NNSTAR,NSUM, GX1, NNEND)

DO $107 J=N N S T A R$, NNEND

$107 P(J)=P(N N S T A Z)+X M *(A L O G 10(F(J))-X J I)$

IF (NNFLAS.EQ.2) GO TO 108

WRITE $(1,70)$ \$CALL. ENDREC (1)

$X O=X 1$ \&YO $=Y 1 \quad \$ G \times O=6 \times 1$

CALL GET(R) \$NNFLAS=IFIX (R(1)) \$60 TO 106

GO TO $10 E$

108 CONTINJE

WRITE $(1,15)$ SCALL ENDREC(1)

READ $(1,16) \mathrm{KJGH}$

CALL PLOTS $(P, F, 1, N N E N D)$

DO 140 IT $=1$, NSUM

$140 P(I T)=P(I T) * P I$

IF (KKKK.EQ.1) NSUMP = NNEND

IF (KKKK.EQ.2) NSUMPE $=$ NNEND

151 CONTINJE

CALL TVNEXT

15 FORMAT (15X,*ENTER ANY CHAR TO CONTINUE*)

16 FORMAT (A10)

RETURN

END

SUBROUTINE POI ( $F, N I, N F, A, N 1)$

C.. SUBR POI RETURNS N1 = THE NC. OF THE SMALLEST $F(I)$

C.. SUCH THAT $F(I)>A$ AND NI $<N 1<N F$.

DIMENSION $F(1)$

DO $1 I=N I$, NF

IF (A.LE.F(I)) GO TO 2

1 CONTINUE

2 CONTINJE

N1 = I

RETURN

ENO 
APPENDIX C. Further results from the Oroville net

Calibration signals generated on 10 Sept. 75 and 16 Sept. 75 by the automatic daily calibration system (ADCS) were digitized (200 samples/sec; 10 channels multiplexed) from telemetered data recorded on the "B" tape recorder (i.e., non-dub). Digitized calibration signals for some of the stations are attached as figure $\mathrm{Cl}$. Abrupt termination of a calibration is due to error in the specification of the digitization start and stop time rather than ADCS malfunction. Error in start/stop time specification was due, at least in part, to the somewhat random time of occurrence of the calibration signals. Efficient analysis of the calibration signals depends on the suite of calibration signals being nearly simultaneous, (i.e., start times within a $30 \mathrm{sec}$ interval).

System amplitude and phase response functions for stations OTAB, OKAT, ORAT, OLON, OCAM and OHON obtained from the mass release transients are shown in figures C2 and C3. The "system" includes all components from the seismometer through the digitizer.

The jittery character of the system amplitude response at high frequency is due to a poor signal-to-noise ratio for the calibration signal (see discussion in section). The system amplitude responses have nearly identical shapes at low frequencies. The response at $1 \mathrm{~Hz}$ is $8 \times 10^{2}$ digitizer units / micron ground displacement for stations OHON, OTAB, and ORAT and is $1.9 \times 10^{3}$ digitizer units/micron for stations OLON, OCAM, and OKAT. These values depend upon measured parameters of the particular seismometer and the amplifier attenuator setting (see figure $\mathrm{C} 4$ for the entries from the seismometer constants table). Note that the attenuator setting for stations OHON, OTAB and ORAT is $18 \mathrm{db}$ and 
$12 \mathrm{db}$ for stations OLON, OCAM, and OKAT. It thus appears feasible to assume that, as designed, the system amplitude response for any one of the six stations can be obtained from a single reference amplitude response function if the reference response is scaled according to the nominal electronics gain implied by the amplifier attenuator setting noted in the field installation log for the station. Each of the system amplitude and phase response functions shows a "glitch" at $7 \frac{1}{2}$ to $8 \mathrm{~Hz}$. The glitch in the response reflects a real "non-ideal" behavior of a component common to the six systems. A likely culprit is the tape recorder or the tape playback drive. There is a $7 \frac{1}{2}$ to $8 \mathrm{~Hz}$ flutter in the tape systems, the effect of which will be minimized via the soon-tobe-operational tape speed compensation (J. Eaton, oral communication).

Phase response for the six systems (see figure $(3)$ are not as easily compared. Differences in the automatic picking of the mass release transient onset would generate significant differences in the phase response functions. (A time delay $\Delta t$ is transformed in the frequency domain to an increment in phase linearly proportional to frequency.

The electronics voltage step transient was also analyzed for stations OCAM, OTAB and ORAT to obtain the electronics transfer functions (see figure $\mathrm{C5}$ ). As for the system transfer functions, there is a "glitch" in the responses near $7 \frac{1}{2}$ to $8 \mathrm{~Hz}$.

The digitized seismogram recorded at station Campbell Hill (OCAM) for the $M=110$ Sept. 751216 GMT Oroville aftershock (hypocentral coords: $\left.39^{\circ} 29.5^{\prime} \mathrm{N}, 121^{\circ} 30.0^{\prime} \mathrm{W}, \mathrm{h}=5.6 \mathrm{~km}\right)$ is shown in figure $\mathrm{C} 6$. The great circle azimuth to OCAM, $=11 \mathrm{~km}$, lies $\sim 12^{\circ}$ off the $\mathrm{P}$-wave fault plane solution nodal plane obtained from the sense of first motion (C.B. Raleigh, 
oral communication). A $10 \%$ Hanning window was applied to 4.385 seconds of the OCAM seismogram to obtain the signal shown in figure $C 7$. The amplitude spectrum of the signal shown in $\mathrm{C7}$ is displayed in $\mathrm{C8}$.

The OCAM ground displacement spectrum were computed using the Boggs Mountain (BGG) system response functions shown in figures 7.12 and 7.13. System response functions for stations OCAM and BGG are interchangeable; the $B G G$ phase response is reliably determined for the 10 second to $30+\mathrm{Hz}$ band). The ground displacement amplitude spectrum is shown in figure $C 9$. Ground displacement, velocity, and acceleration for the signal shown in figure $\mathrm{C} 7$ were computed by transforming back into the time domain. The results are shown in figures $\mathrm{C} 10, \mathrm{Cl1}$, and $\mathrm{C} 12$ respectively. (Note that the signals shown in figures $\mathrm{C} 10, \mathrm{Cl}$, and $\mathrm{Cl} 2$ are band limited $(.29 \mathrm{~Hz}$ to $30.7 \mathrm{~Hz}))$. 


\section{REFERENCES}

Bracewe11, R. M. "The Fourier transform and its applications,"

McGraw-Hi11, Inc., New York, N.Y., 381 pp., 1965.

Dratler, J., Jr. "Theoretical transfer functions for stations in the central California seismographic network," U.S. Geol. Survey Open-File Report, in preparation, 1975.

Espinosa, A. F., G. H. Sutton, and H. J. Miller, S.J., "A transient technique for seismograph calibration," Bul1. Seism. Soc. Am., 52, 767-779, 1962.

Jarosch, H. and A. R. Curtis, "A note on the calibration of the electromagnetic seismograph," Bul1. Seism. Soc. Am., 63, 1145-1155, 1973. Mitche17, B. J. and M. Landisman, "Electromagnetic seismograph constants by least-squares inversion," Bull. Seism. Soc. Am., 모, 1335-.]348, 1969.

Papoulis, A. "The Fourier integral and its applications," McGraw-Hill, Inc., New York, N.Y., 318 pp., 1962.

Wood, R.V., Jr., and R. A. Guillette, "LASA sensor calibration experiments," Seismic discrimination SATS, Lincoln Laboratory, M.I.T., (30 June 1966) ESD-TR-66-250, 21-24, 1966.

Ziolkowski, A., "LASA short-period instrument responses," Seismic Discrimination SATS, Lincoln Laboratory, M.I.T., (30 June 1972) ESD-TR-72-187, 37-48, 1972. 


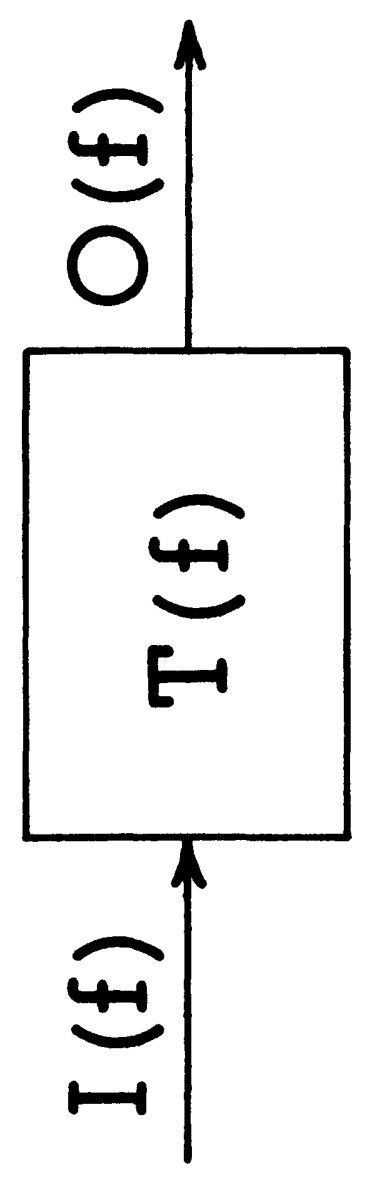

돈

这

过 蒙

फ.

กิ

s

$\stackrel{n}{n} \cdot r$

t)

4

ธำ

달유

뒁

$4 \sum=$

बै $\overrightarrow{~ ज े ~}$

o 0 年

it n

蒫 立

平

NF.r

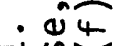

$\because 气 \frac{1}{=}$

ल

4 气ัँ

ว

iv 


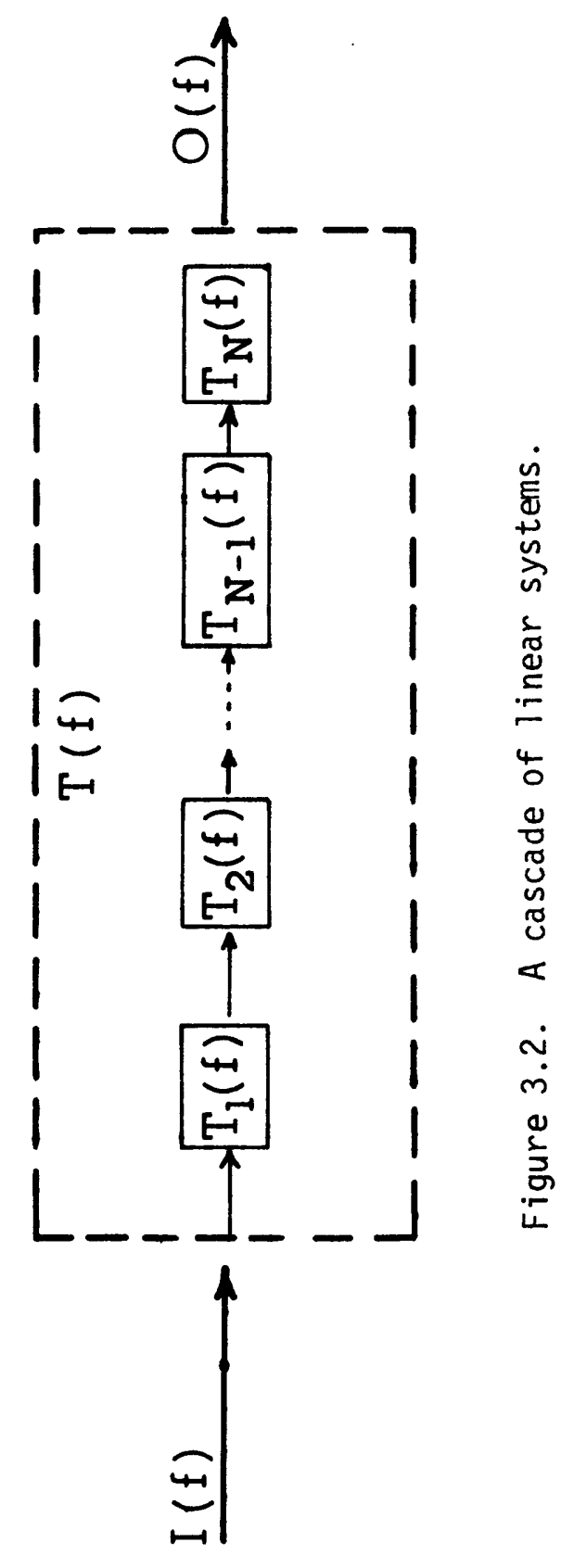




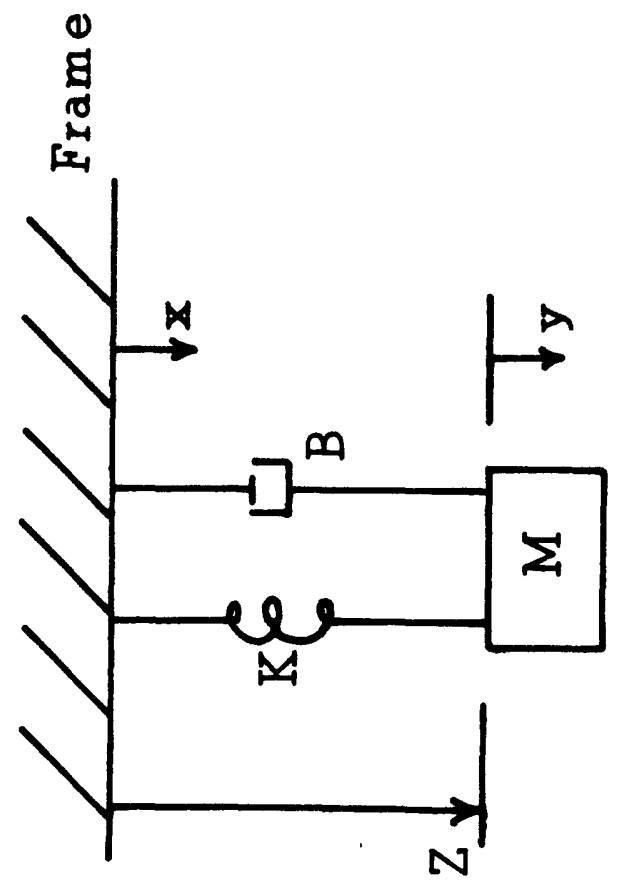

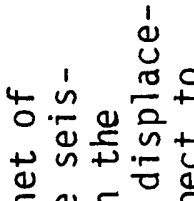

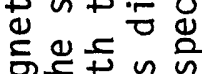

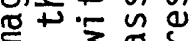
E

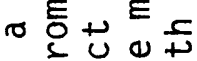
ज4 $\mathbb{C}^{2}+\underline{C}$

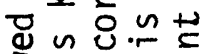

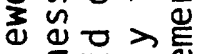
$5=$ $>\frac{4}{4} \cdot \pi+5$

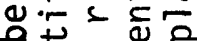

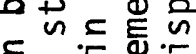
ᄃ․․

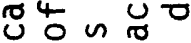
cor

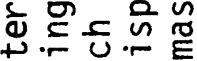

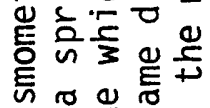

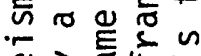

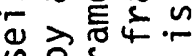
ง \& - 등 $\backsim 1$

- 㟔必 $m$ in $x$ m

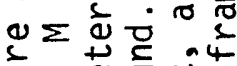
引n岂

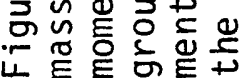




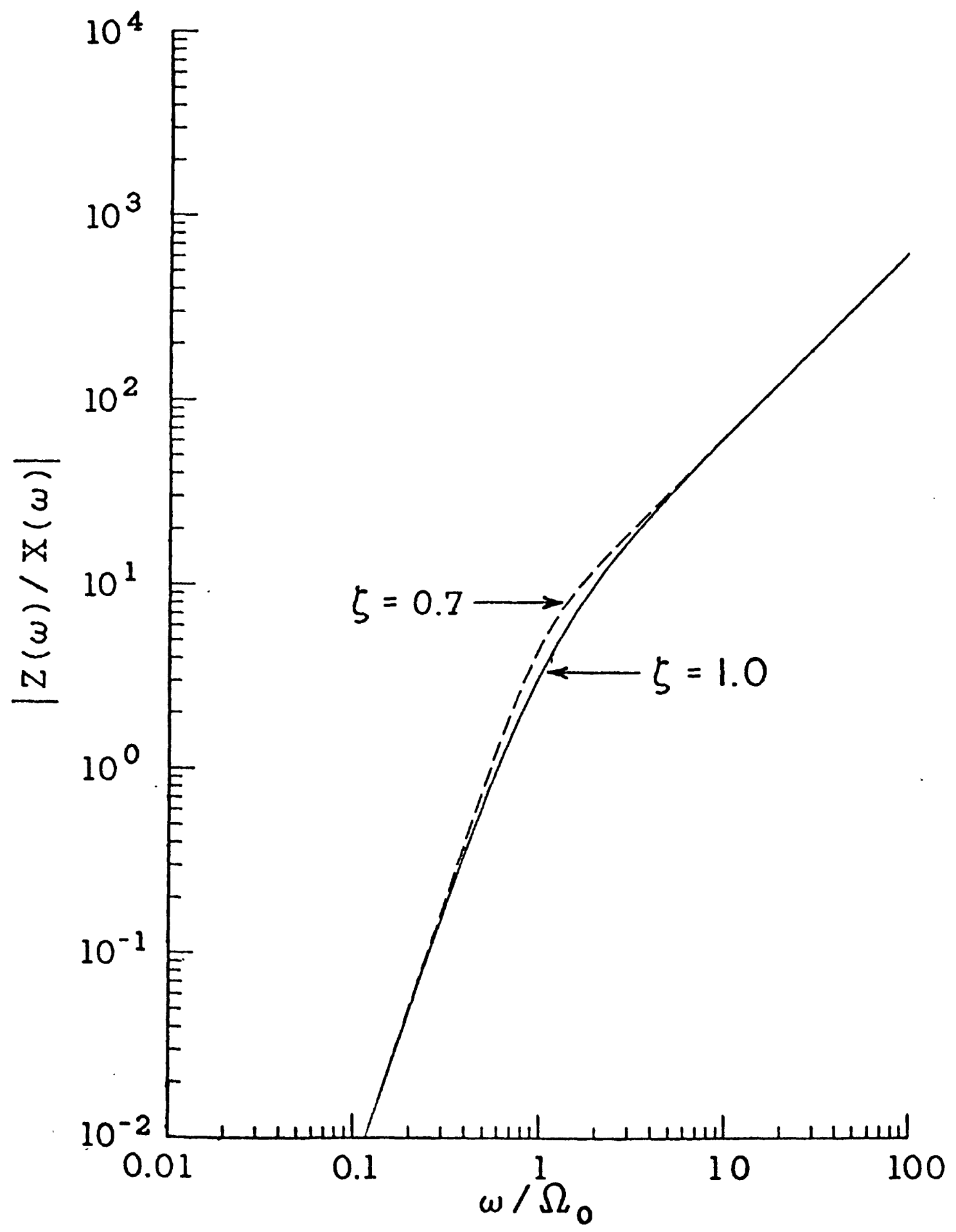

Figure 3.4. Amplitude response of a velocity-transducer seismometer to displacement for damping factors $J^{\prime}=0.7$ and 1.0 . The ordinate and abscissa are nomalized to the seismometer generator constant $G$ and the seismometer resonant frequency respectively. 


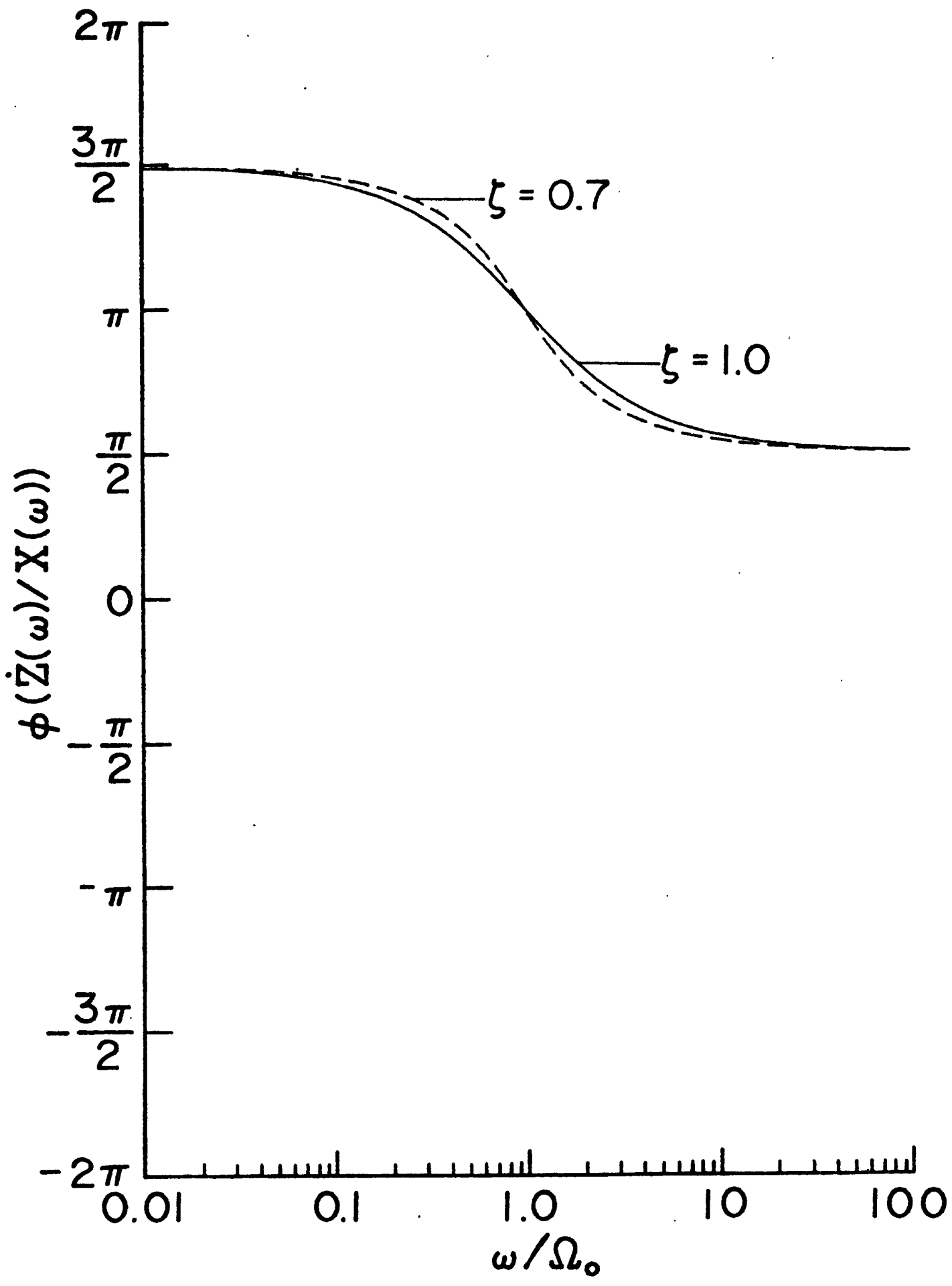

Figure 3.5. Phase response of a velocity-transducer seismometer to displacement for damping factors $S=0.7$ and 1.0 . 


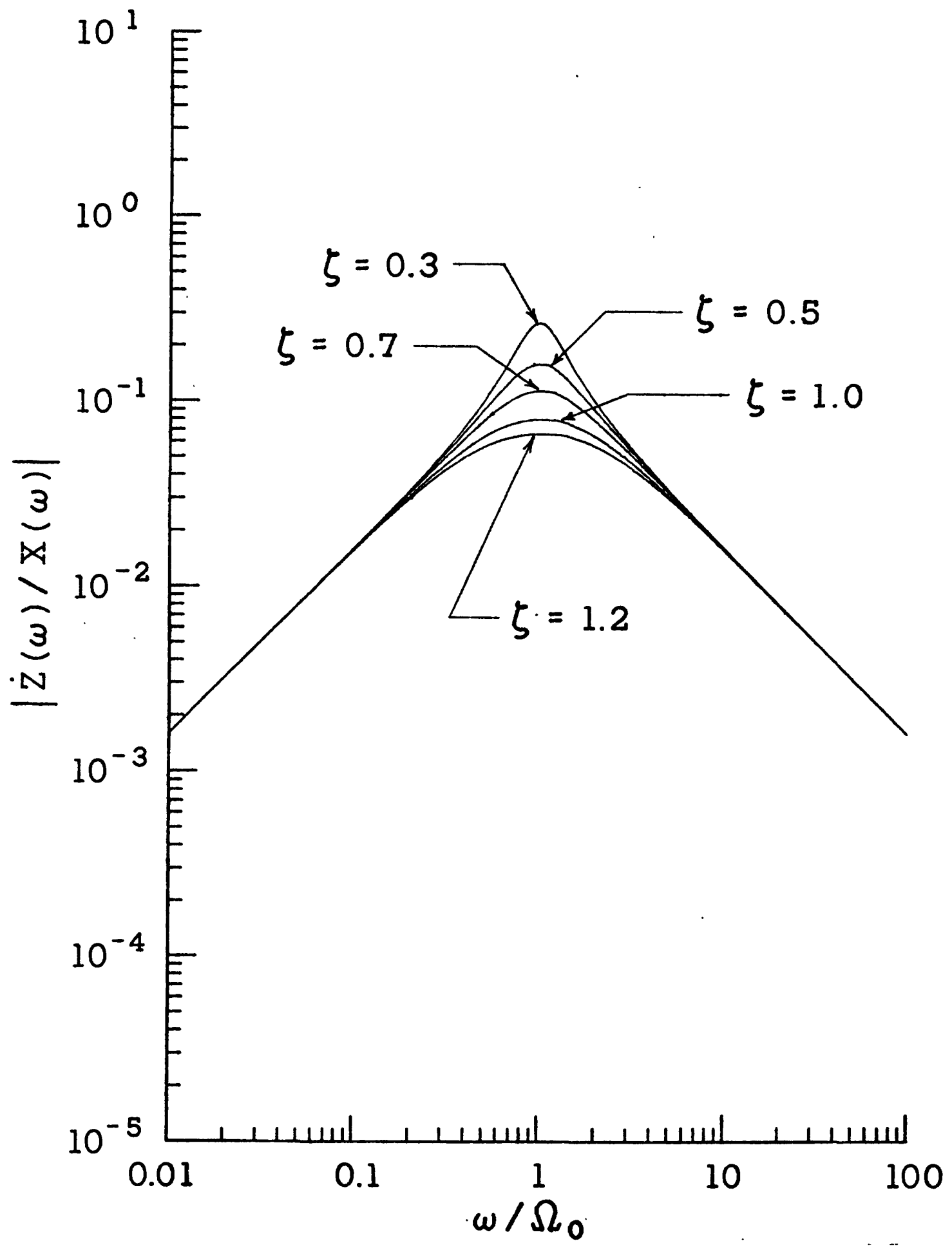

Figure 3६6. Amplitude response of a velocity-transducer seismometer to acceleration for a range of damping factors $\%$. The ordinate and abscissa are normalized to the seismometer generator constant and the seismometer resonant frequency respectively. 


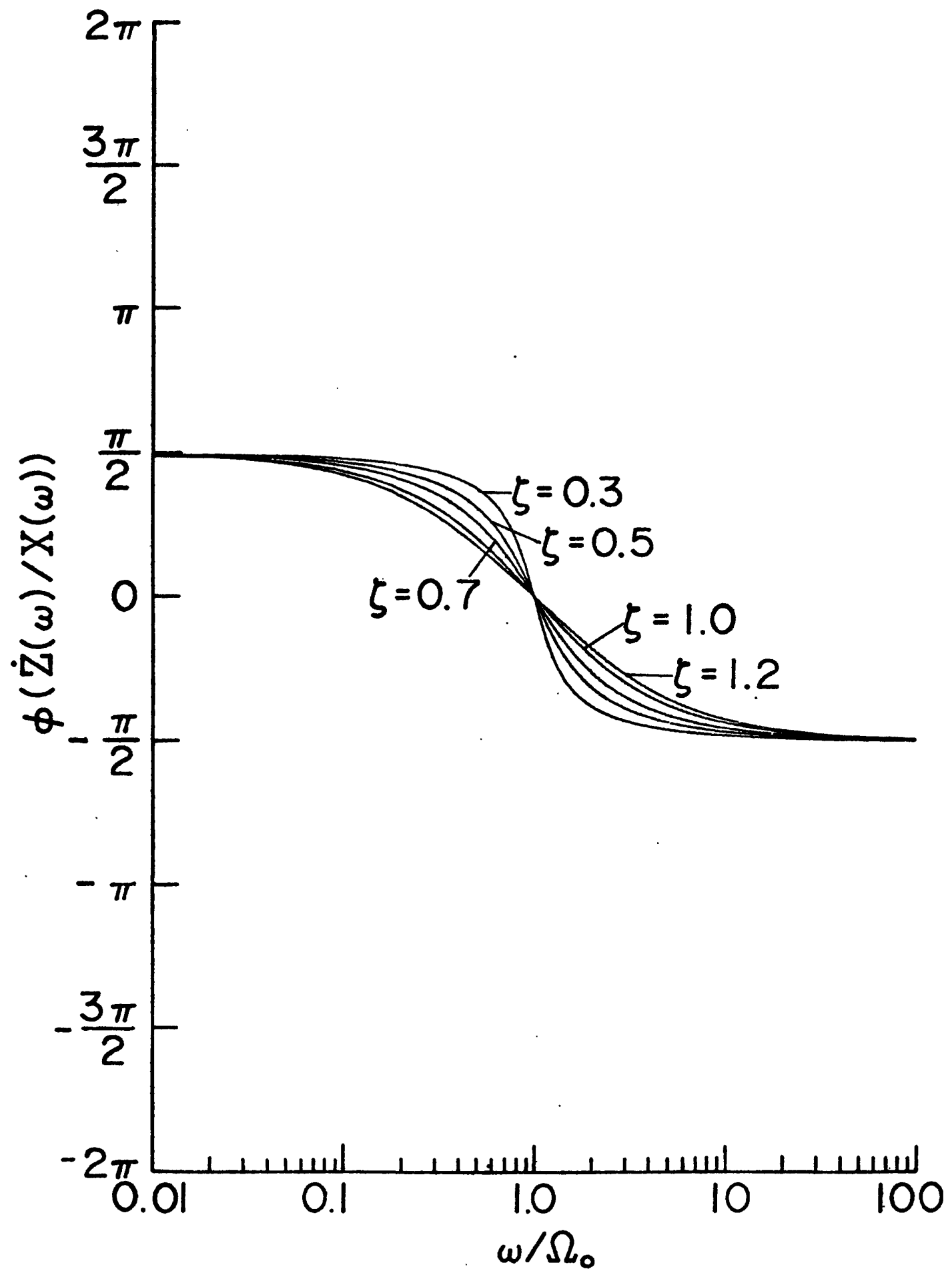

Figure 3.7. Phase response of a velocity-transducer seismometer to acceleration for a range of damping factors $\mathrm{J}$. 


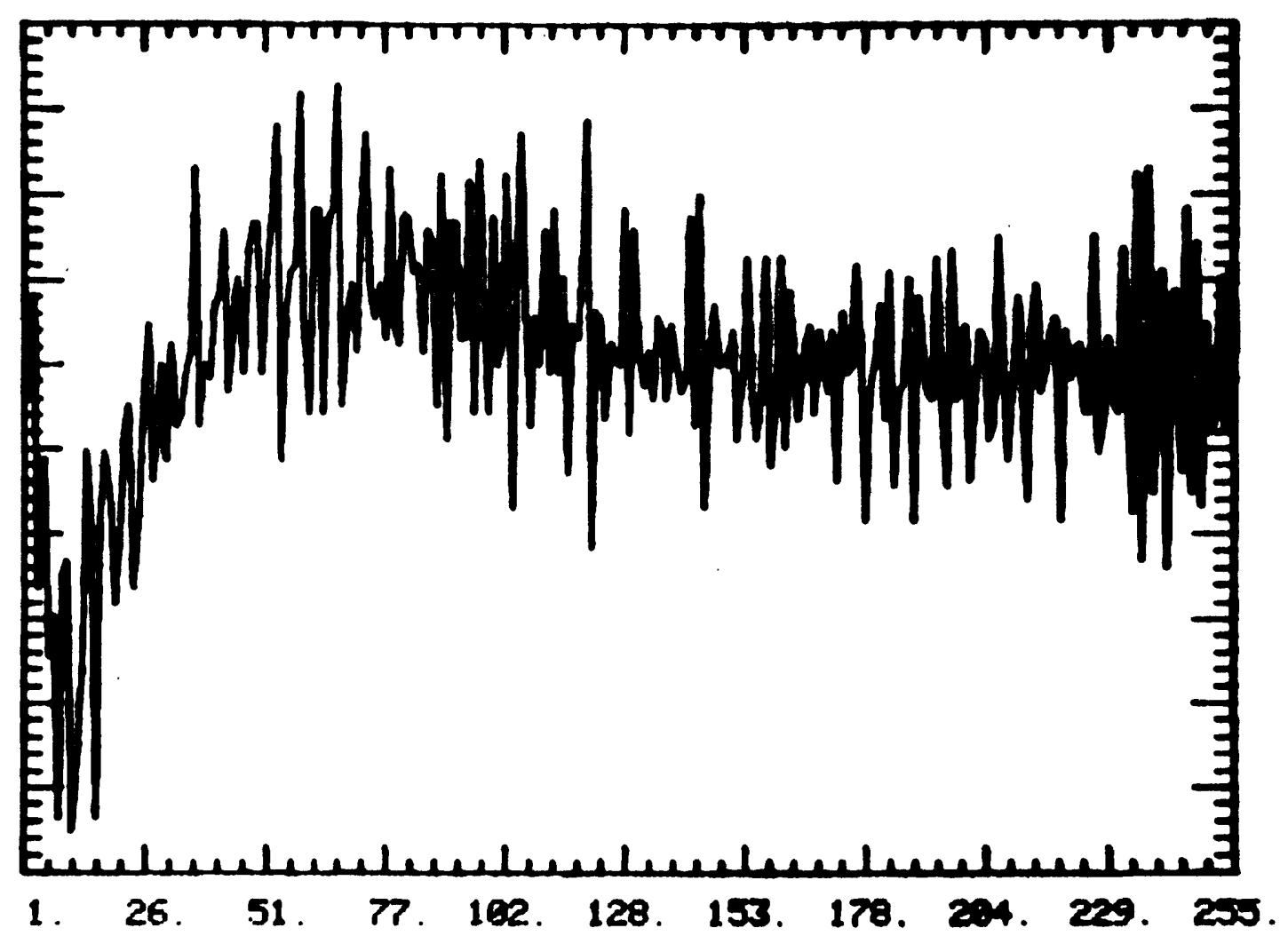

Figure 3.8 10 June 75 differentiated mass release transient at station BGG. $\Delta \tau=.005 \mathrm{sec}$ so that window length $=1.28 \mathrm{sec}$. 


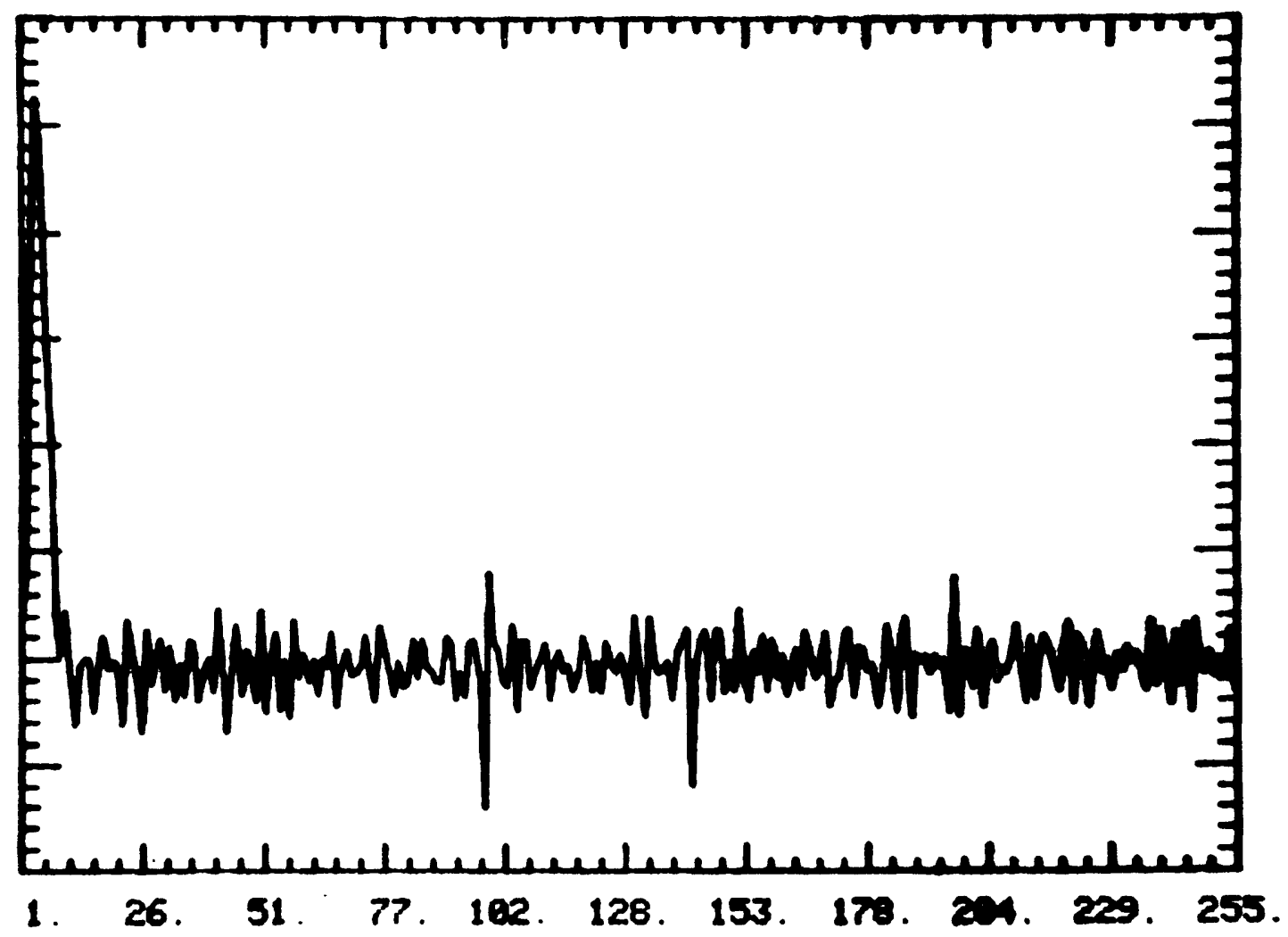

Figure 3.9. 10 June 75 differentiated electronics step transient $u$ : station BGG. $\Delta \tau=0.005 \mathrm{sec}$ so that window length $=1.28 \mathrm{sec}$. 


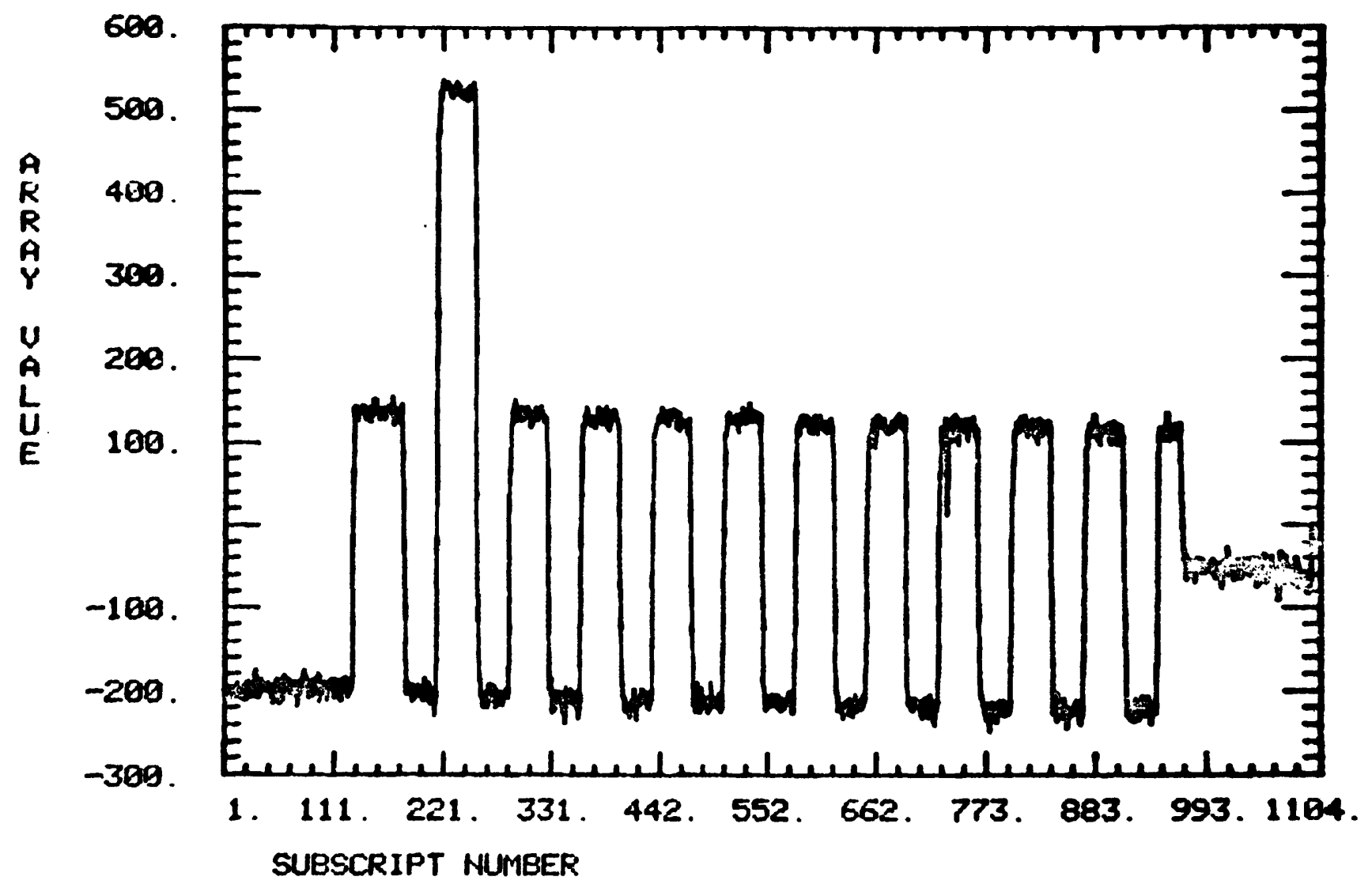

Figure 4.1. Structure of the ID code for station \#2. 


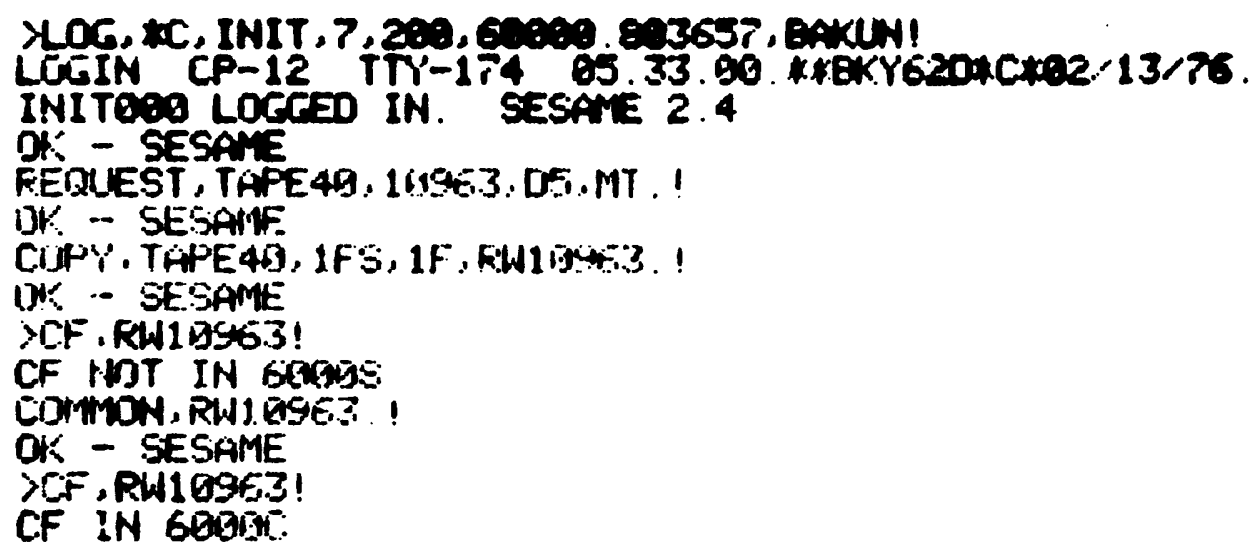

Figure 6.0. Logaing onto the $C$ machine, and creating a common file "RW 10963" from the second file on LBL tape \#10963. 


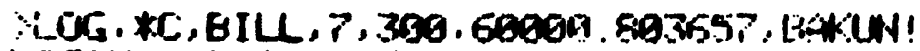

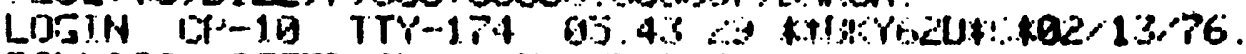

BILLGQ2 LOTRESU IN SESAME 2.4

OK - SESAME

XF. RWIG 1963 !

CF iN GOABu:

A.LOAO, CALIS, JRATT!

LOANS CIMPIETE: ENTEKING ERIJT

Q OF - AEIT

FIUN!

ENTER NAME OF CAK.IEPATIONA TMTA COMHN FILE (FORMAT AP)

RWI ESTS.3!

EHTIR MUMEER OF CHANELS LIIGITIMEO

4 !

ENTER AUMBER OF SCANS TO EE STIPPILII

6900 !

ENTER CHPWEL NUHEERS OF SEIECTEL CHWHEIS. IN OAOER

$1,2,3,4 !$

ENTER DIGITIZER CHANEL FIRR TROME TII EE OSSPLAYED

2 !

EHTER OIGITIZER. RATE IN SAM BHAC

260

Figure 6.1. Initial sequence of commands: Logging onto the $C$ machine, verifying that common file RW 10963 exists on the $C$ machine, loading the program "CALIB" from library "JDRAT", executing via $\uparrow R U N$, and interactively entering the input information described in section VIA. 
A!

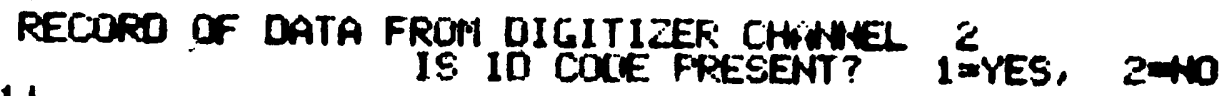

1 !

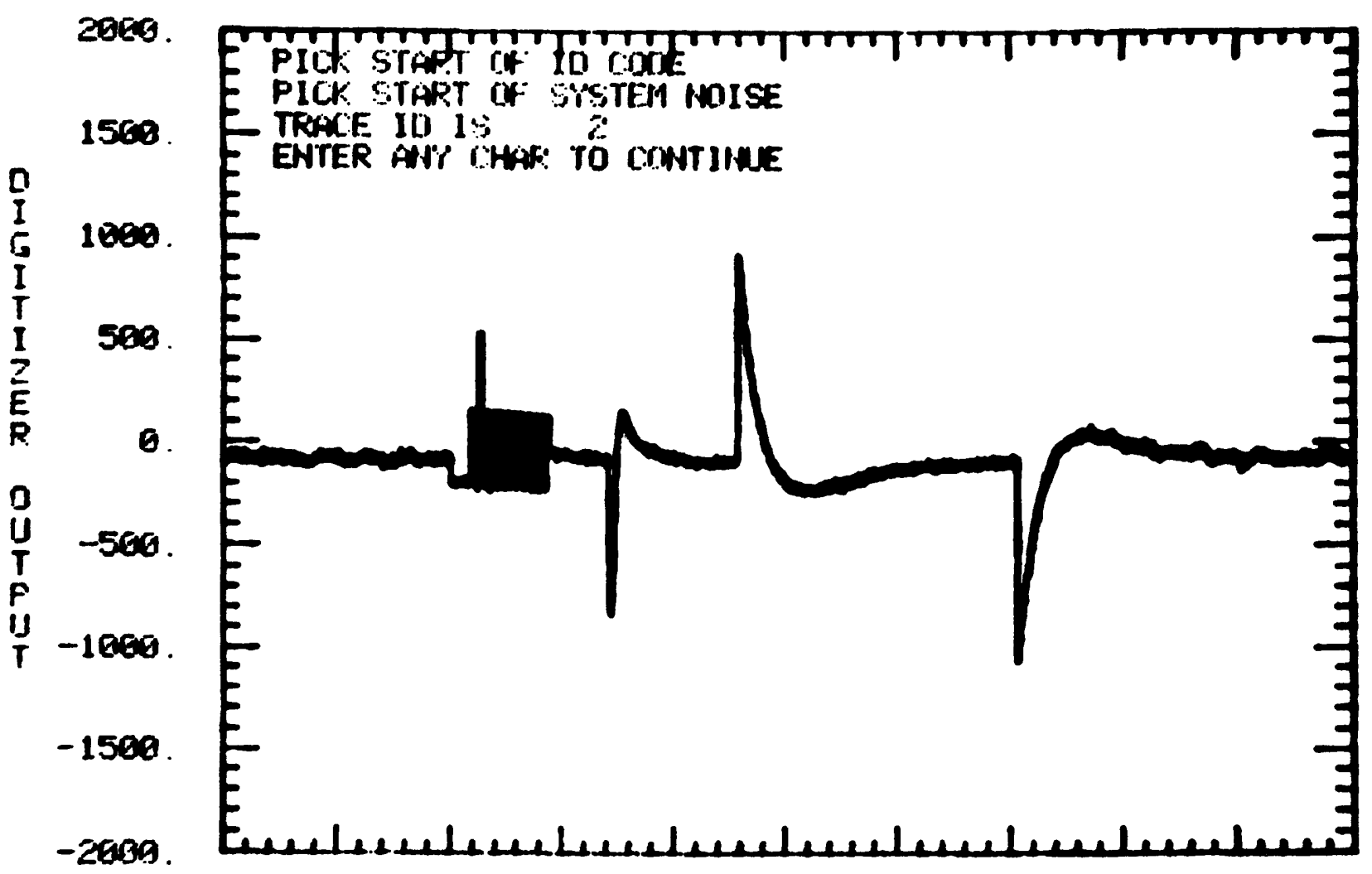

1. 306.664 .5010 .1210 .1500 .1799 .2099 .2399 .2699 .2999$. SAMFLES AT 2U MEFO

Figure 6.2. Sequence of calibration signals for channel \#2. 
$1 !$

Recoivo of SYSTIM MDISE FRXM STA. NU. 2

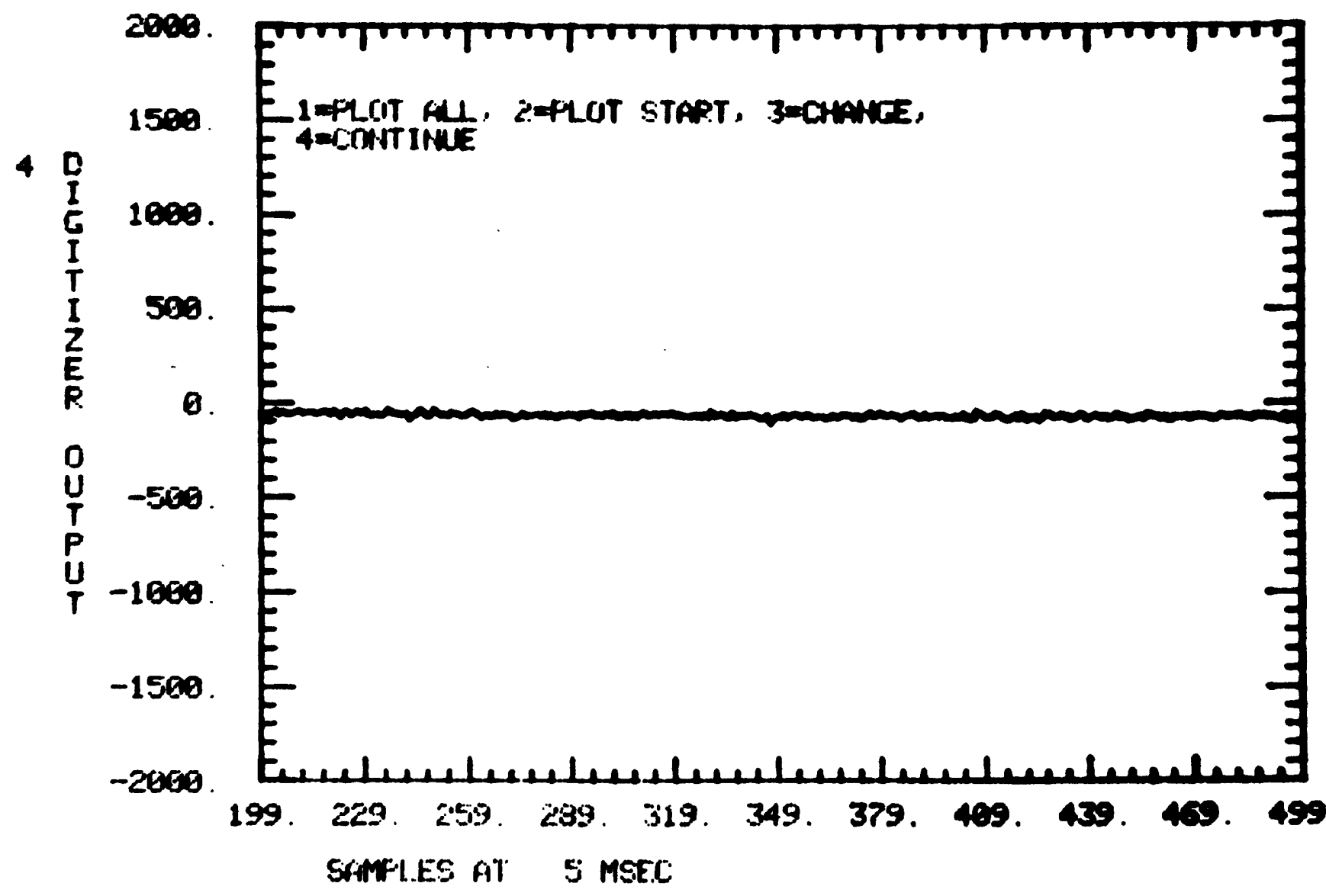

Figure 6.3. System noise signal for station with ID code \#2. 
${ }^{1}$ KECORD OF SEISMOMETEP. PELLASE TEST FROM STA. NO. 2

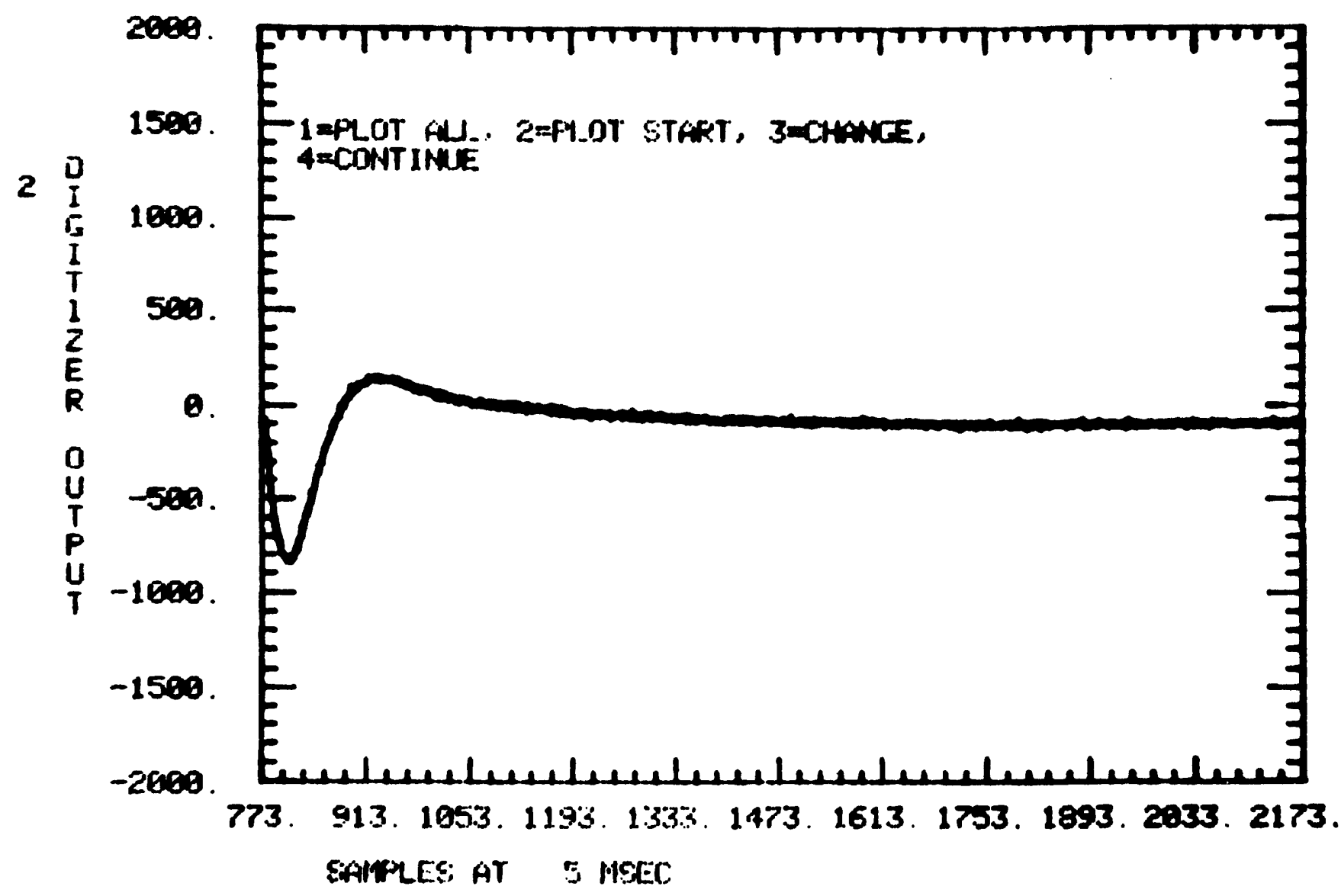

Figure 6.4. Seismometer mass release transient for station with ID code \#2. 
$1 !$

RECCRD OF SEISMDMETER. RELEASE TEST FRUM STA. NU. 2

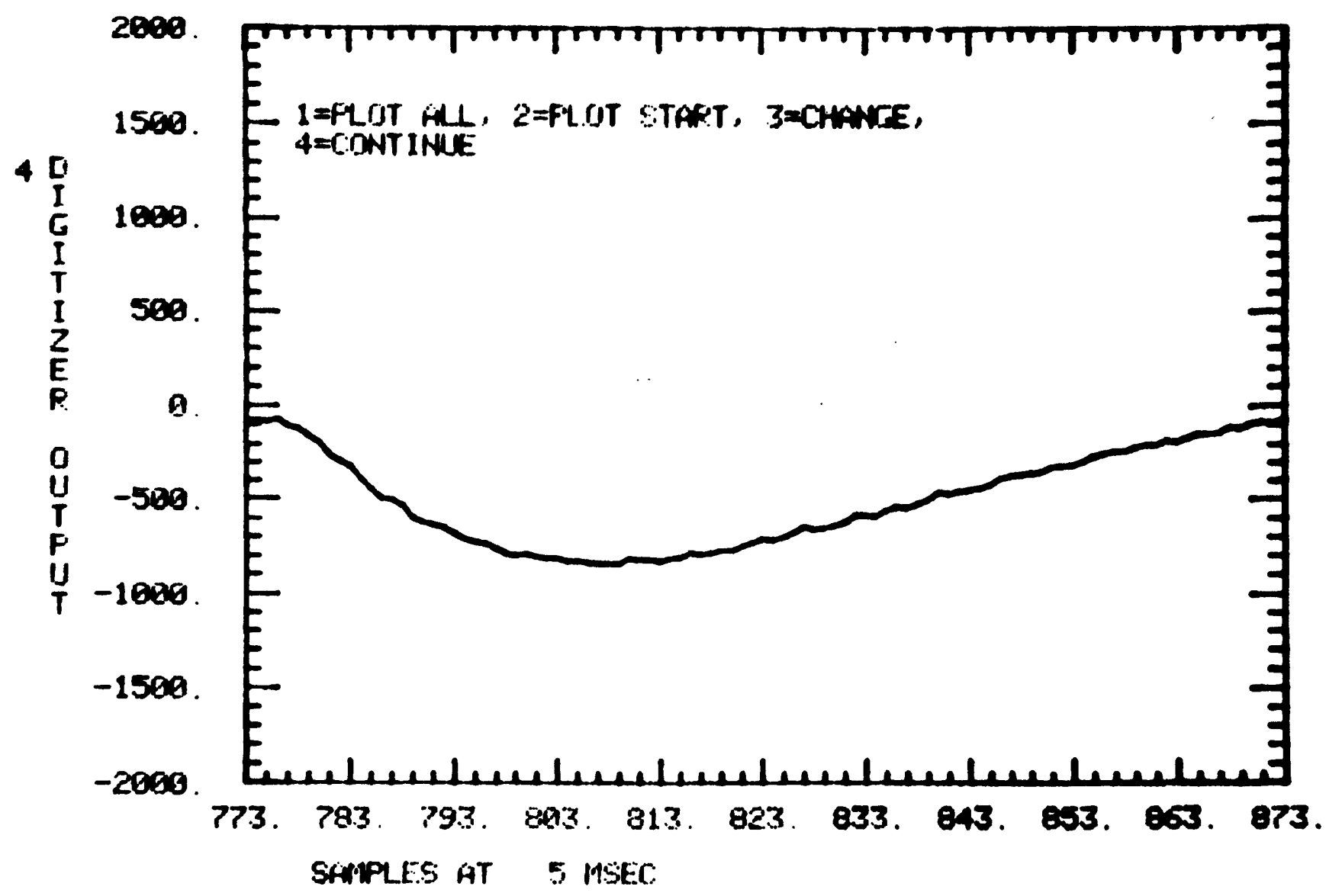

Figure 6.5. "Blowup" of the beginning of the seismometer mass release transient for station with ID code \#2. 
L!

RECOPO OF PMPLIFIER STEP TEST FFOM STA. NO. 2

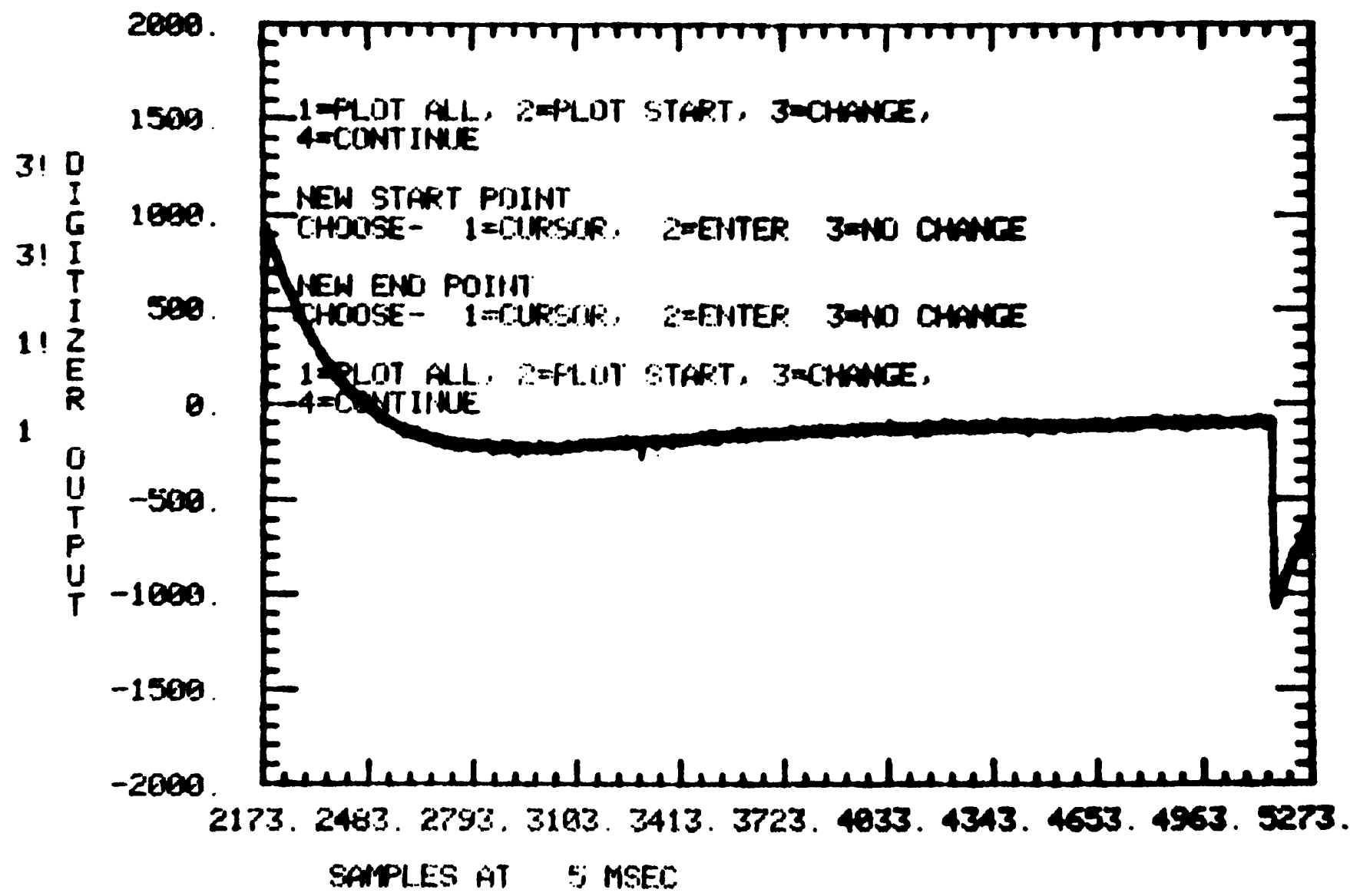

Figure 6.6. Amplifier step test transient for station with ID code \#2. 
$1 !$

PECOND OF AMFLIFIER STEP TEST FROM STA. ND. 2

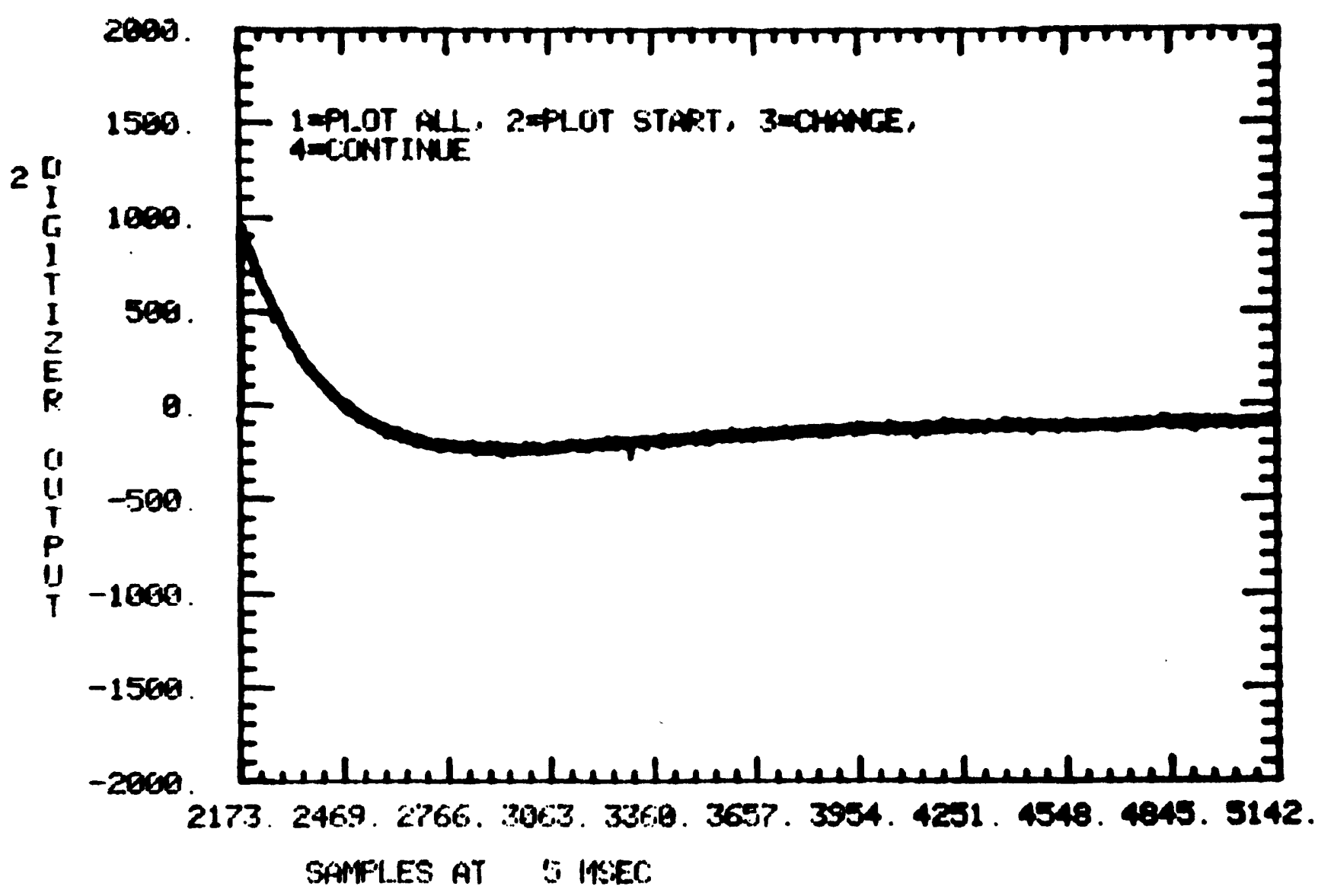

Figure 6.7. "Rewindowed" amplifler step test transient for station with ID code \#2. 
1 RECORD OF AMPLIFIER STEP TEST FROM STA. NO. 2

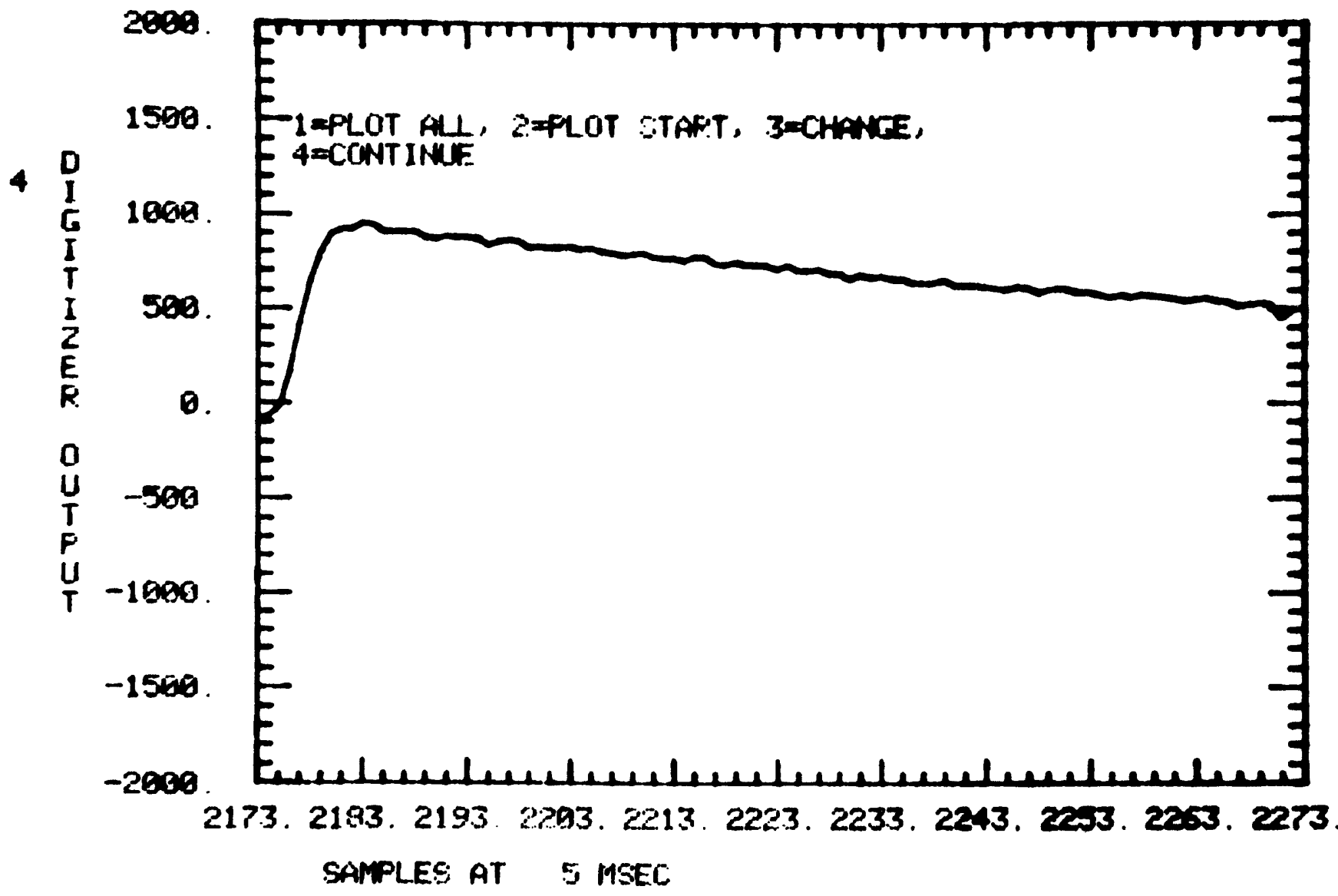

Figure 6.8. "Blowup" of the beginning of the "rewindowed" amplifier step test transient. 
METWORK STA. BCG BOCLS MTN SEISMOMETER CONSTANTS LAST UPDATED

IO NO. 2 INSTALLEO 29 MAY 75 NO. PARAMETER SYMBOL UALUE UNITS

1 TYFE OF CALIERATOR Z MASS

3 SEIS. MOTOR CONSTANT

4 FREE PERICO

5 OPEN-CIRCUIT DAMPING

6 SEIS. COIL RESISTANICE

7 SERIES PAD RESISTANCE

8 SHWWT PAD RESISTANCE

9 ATTEMUATOR SETTING

10 NOMINAL PRESMMP GAIN

11 SEISMOMETER SERIAL NO.

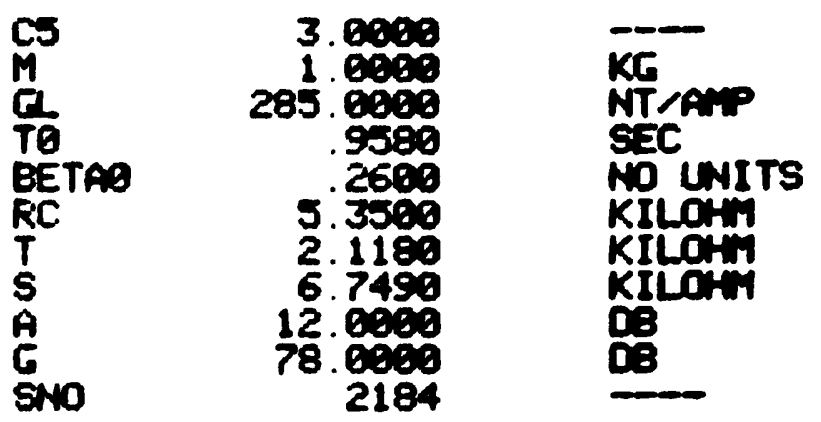

ENTER ANY CHAR TO CONTIMUE D!

ALTER TPBLE OF SEISMOMETER CONSTANTS? 1=rES, 2MD 2 !

NETHOOK STATION BCG BOCGS MTN

ID MUNESR 2

PARAMETERS CALCLLATED FROM CONSTANTS OF 12 SEP 75

PARPMETER

EFFECTIUE MOTOR CONSTANT

RELEASE TEST ATTENUATION

SEISMOMETER TEST CURRENT

AMPLIFIER STEP LOL TACE

ENTER ANY CABR TO CONTINUE
SYMeOL

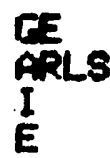

verus

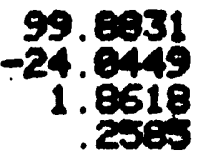

WNIT

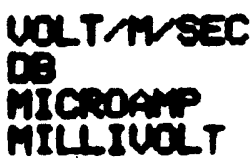

Figure 6.9. (top) Seismometer constants, etc. for BGG, the seismographic station with ID code \#2. (bottom) Seismograph parameters calculated from the constants (top) and the C3 calibrator unit circuitry. 


\section{BIGG BOGGS MTN \\ $J=1$ HDISE \\ TIME SERIES EXPANOED BY FACTOR \\ FORWARD TRAWEFFORM \\ HHMEER OF POINTS NOT $=2$ TO THE $N$ \\ 844 FOINTS $=9$ APPERIDED \\ NUMEER OF POIHTS $=2048$ \\ HYQUIST FREQUENCY = $109.009 \mathrm{HZ}$ \\ FREQLENICY INTERIJAL $=0.0977 \mathrm{HZ}$ \\ ENTER ANY CHAR TO CONTINUEE}

4

Figure 6.10. Results of operations on system noise signal for station $B G G$. 
PEG BDGGS MTN NOISE SPECTRLM

260 SAMP SEC IO= 2 PLOT DATE $=16$ OCT 75 LEN 1.505 UPOATE $=12$ SEP 75

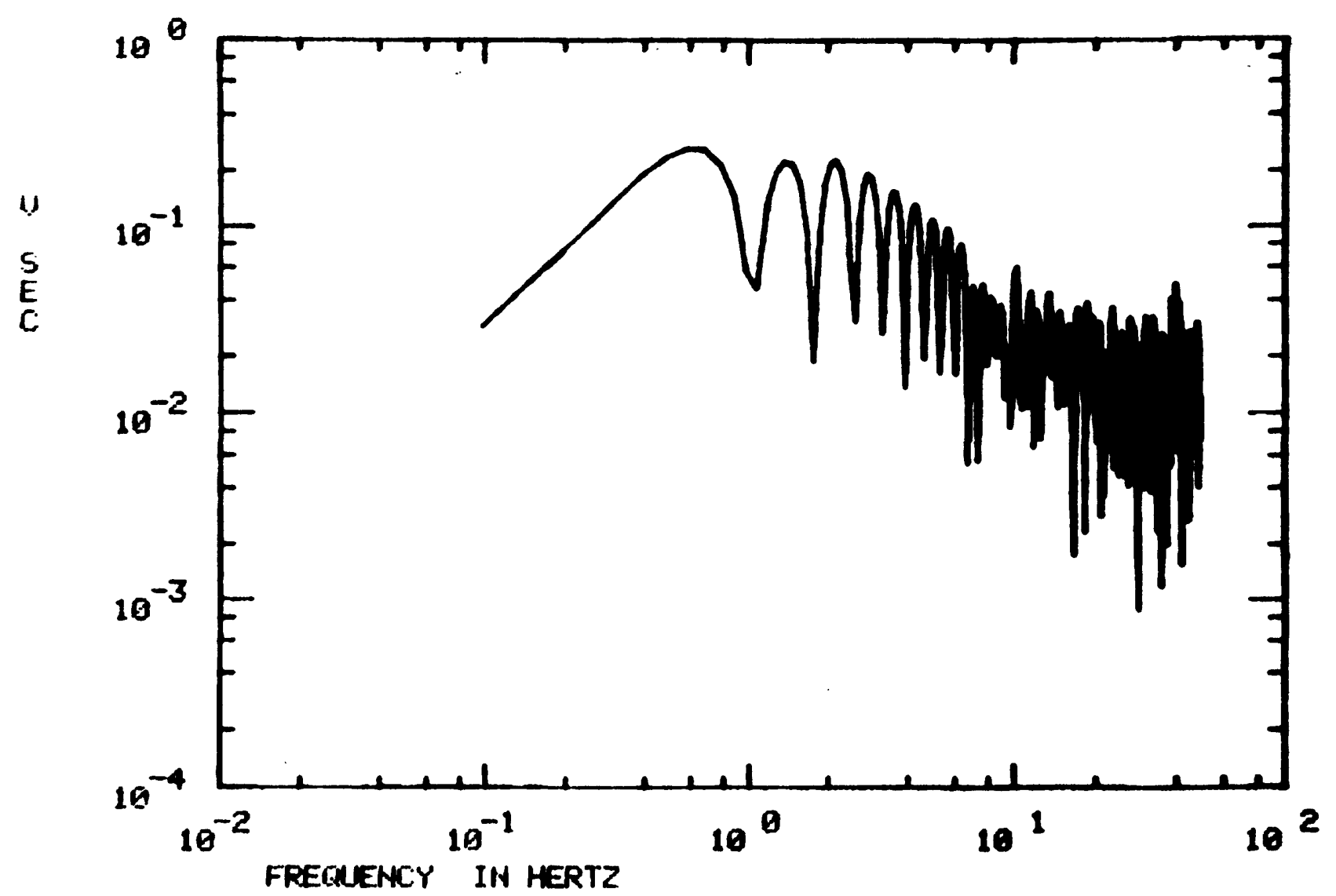

Figure 6.11. Noise amplitude spectrum for station BGG. 


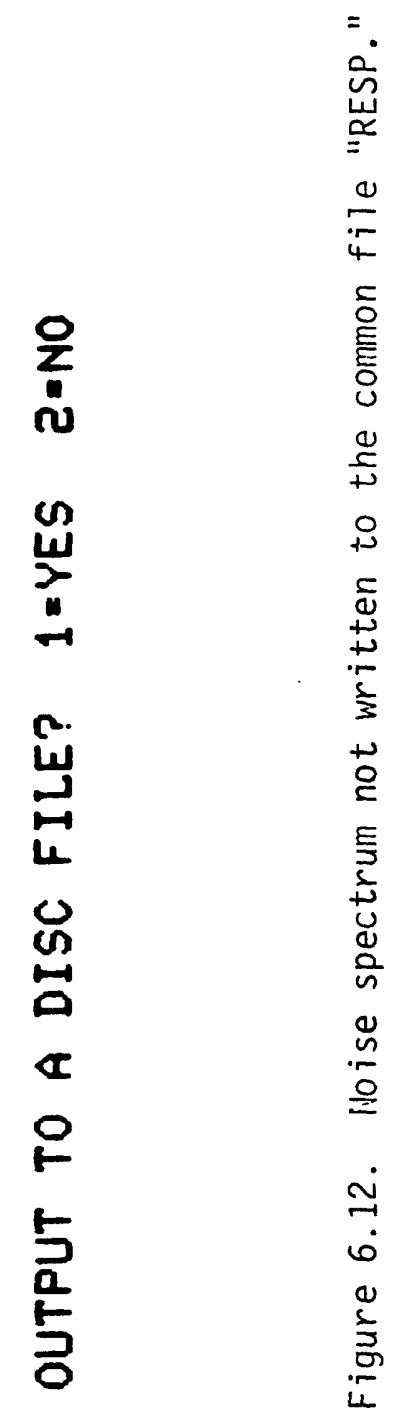


PIj; BITGGS MTN

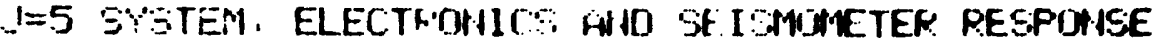

BFET:TRIMM OF MASS PELEAHE TRAHSIEHT

TIHE SERIES EXFAHWED FY FANTOK: 1

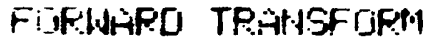

HAHEEF OF POIHTS HIT $=2$ TU THE: H

547 FOIHT: $=\bar{C}$ APFERHED

TIIMEFE: IF FOIITTS = 20148

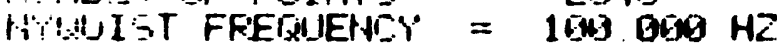

FFFIIIEENT I INTEPUAL = $1997 \mathrm{HZ}$

FHASE SPEITFIJM MACIE CRATIMUIJS

IIEE TFANSIENT DERIUATIUE FOR HISH FPES! RESPONSE?

EHTEF $\quad I=I E S \quad Z=H J$

11

EHTEF MIHIMUM FFEIIHE, FIIP FESFOHIE FPOM DEPIUATIUE

$65 \mathrm{H}$ ¿ IS THE HOFMAL MINIMIINA

51

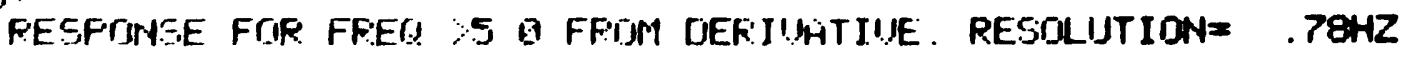

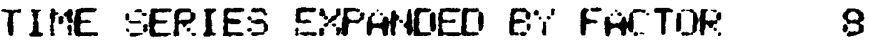

FULULATEO TRAHISFORTH

HIHEEF IJF POINTS = $244:$

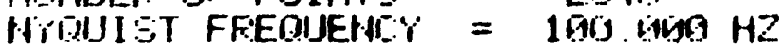

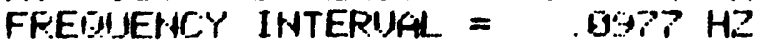

FHASE GFELTPIJM MALIE COJHTIHIOUS

ENTEF: AHY CHAP TO COUHT IHHE:

Figure 6.13. Results of operations on the seismometer mass release transient for station $B G G$. 
F! BGG EOTES MTN SYSTEM AMPITUDE RESPONSE TO COOWN DISPL. 209 SAMP/SEC IO= 2 PLOT DATE= 16 OCT 75 LEN 7.605 UPOATE 12 SEP 75

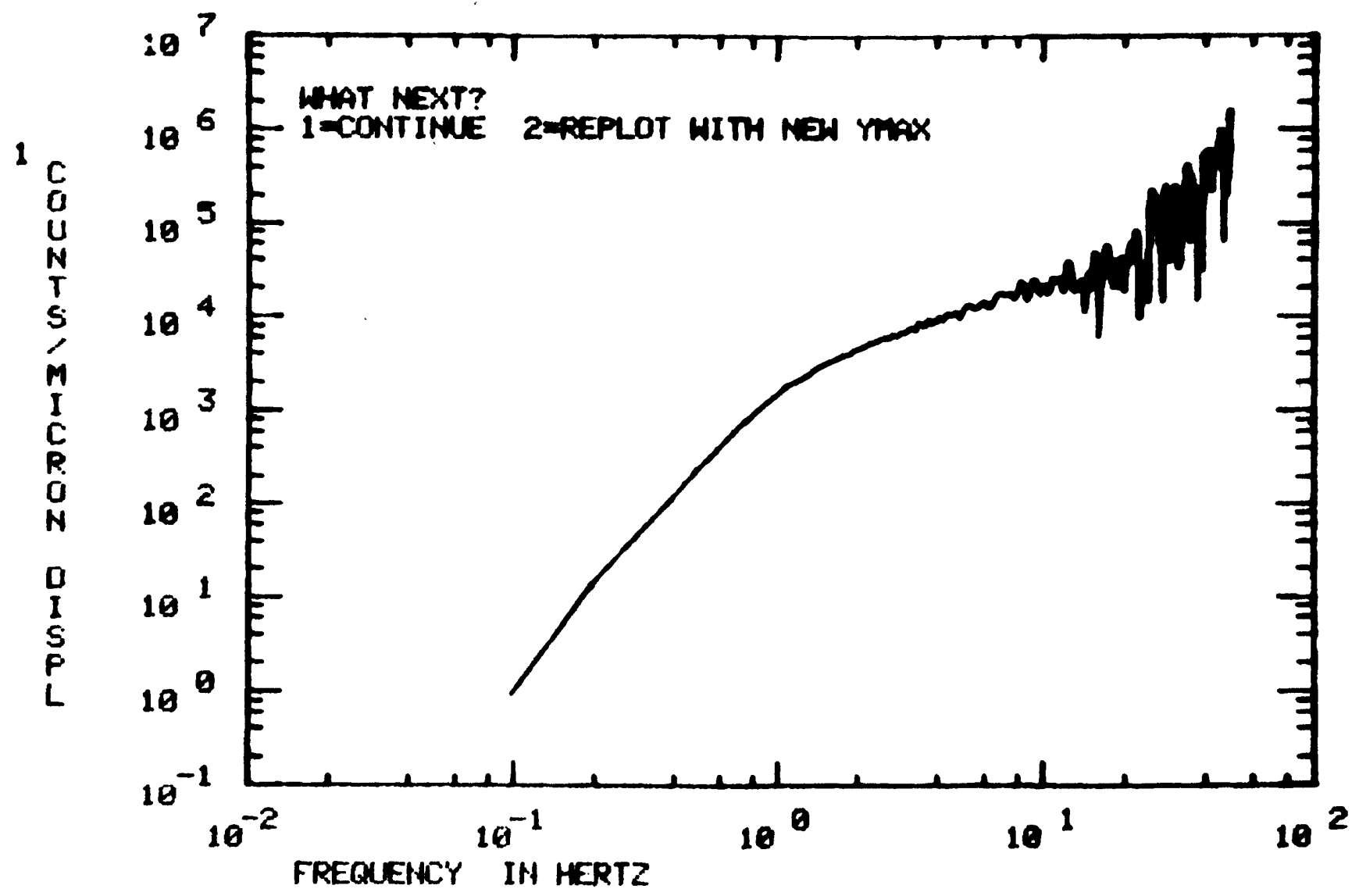

Figure 6.14. Amplitude response for seismographic station BGG. 


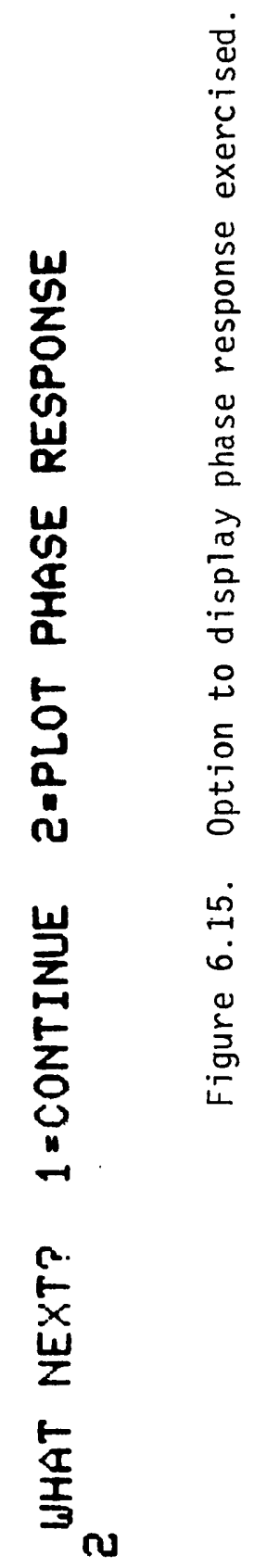


ETG ERTES MTN

SYSTEN PHASE RESPONEE TO CROUND DISPL.

200 SAMP. SEC ID $=2$ PLOT DATE $=04$ MAP $7 E$ LEN $=7.0 B S$ IPPOATE $=12$ SEP 75

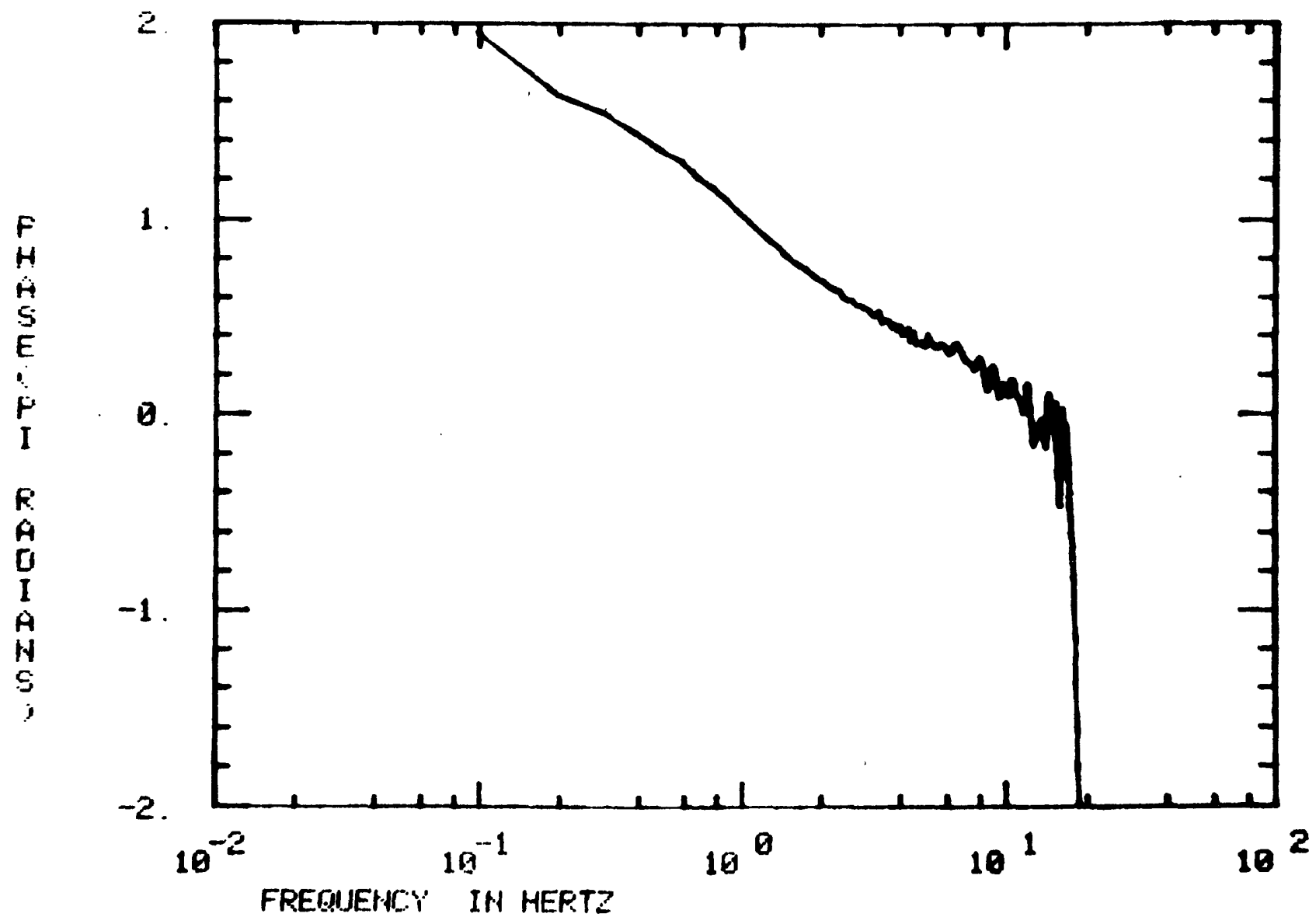

Figure 6.16. Phase response for seismographic station BGG. 


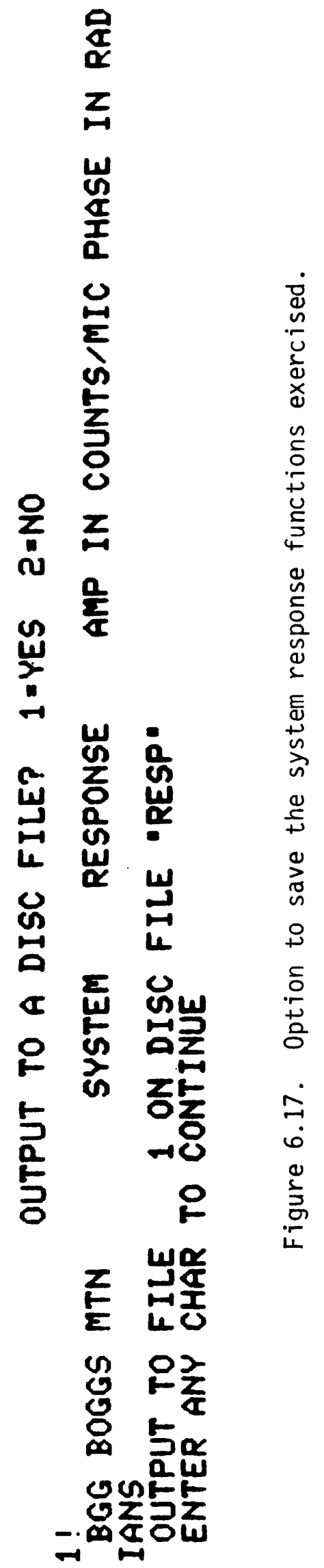




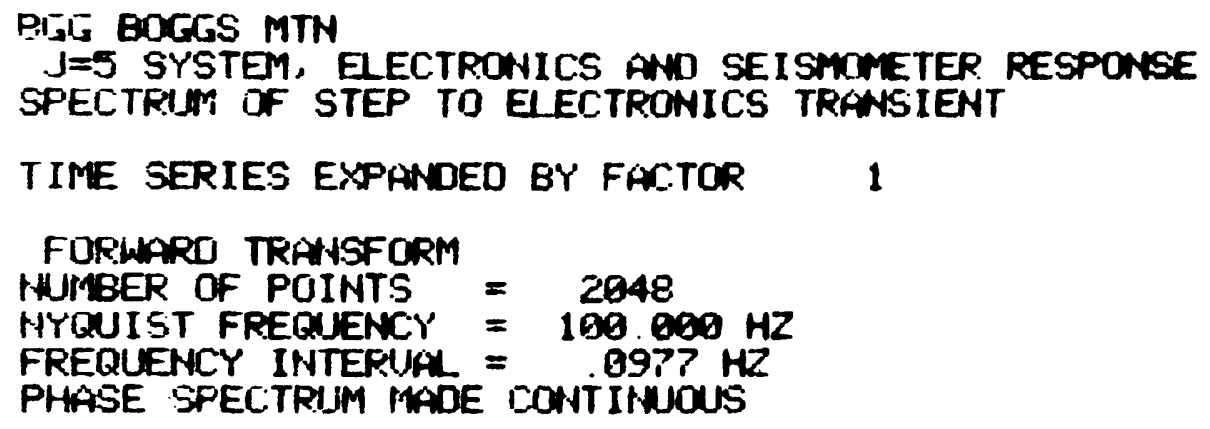

Figure 6.18. Results of operations on the amplifier step test transient for station BGG. 
Q!

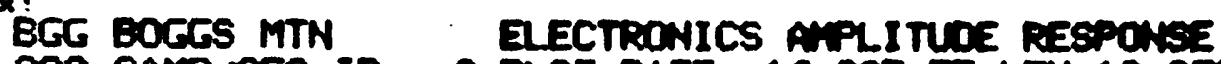

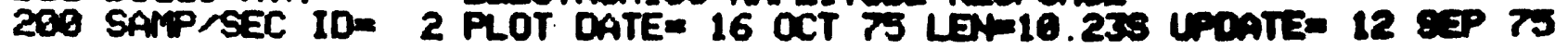

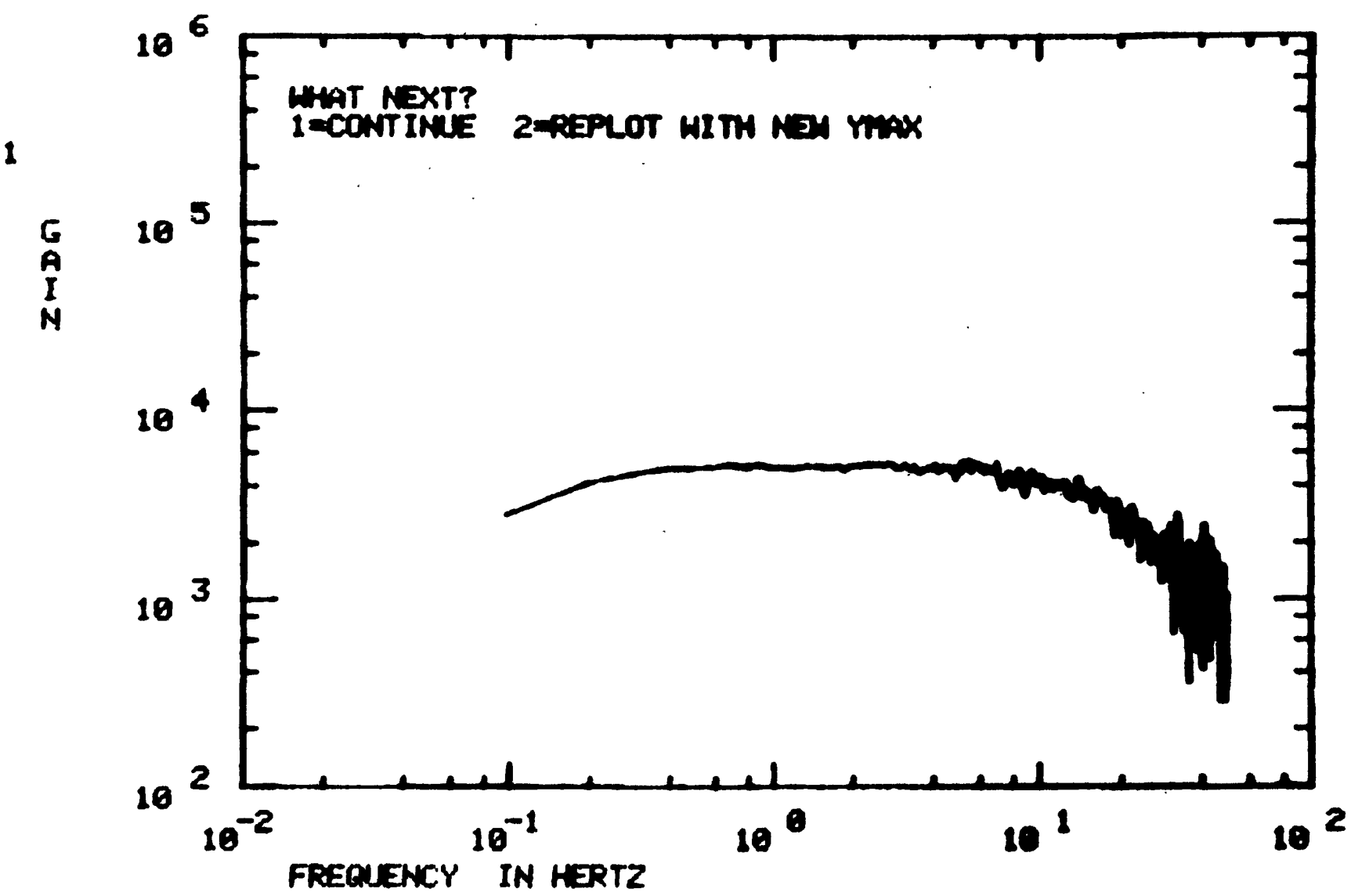

Figure 6.19. Amplitude response for the electronics for seismographic station BGG. 
BGG BOGGS MTN

200 SAMP/SEC ID $=2$ PLOT DATE $=16$ DCT 75 LEN=10.235 UPDATE= 12 SEP 75

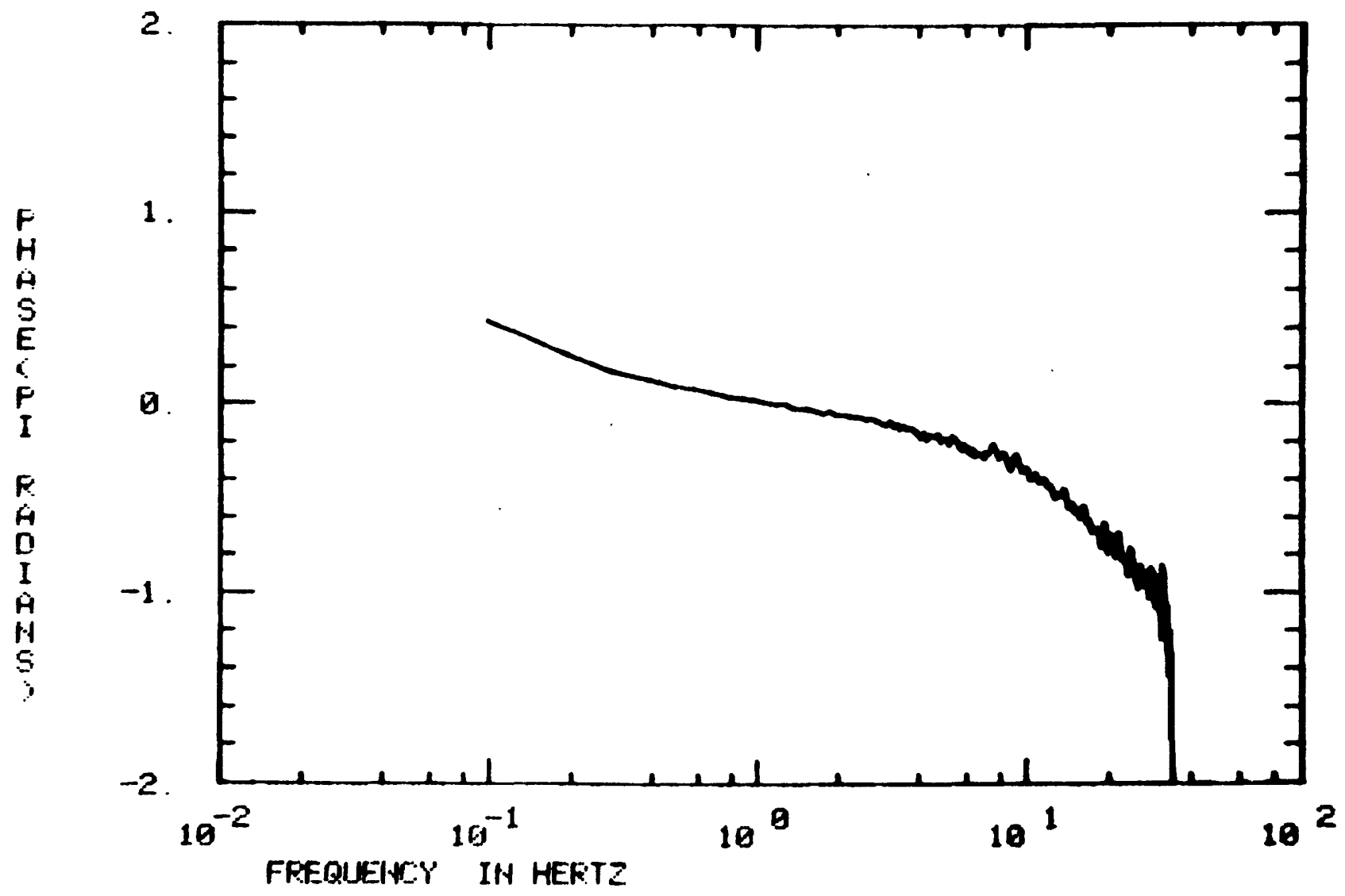

Figure 6.20. Phase response for the electronics for seismographic station BGG. 

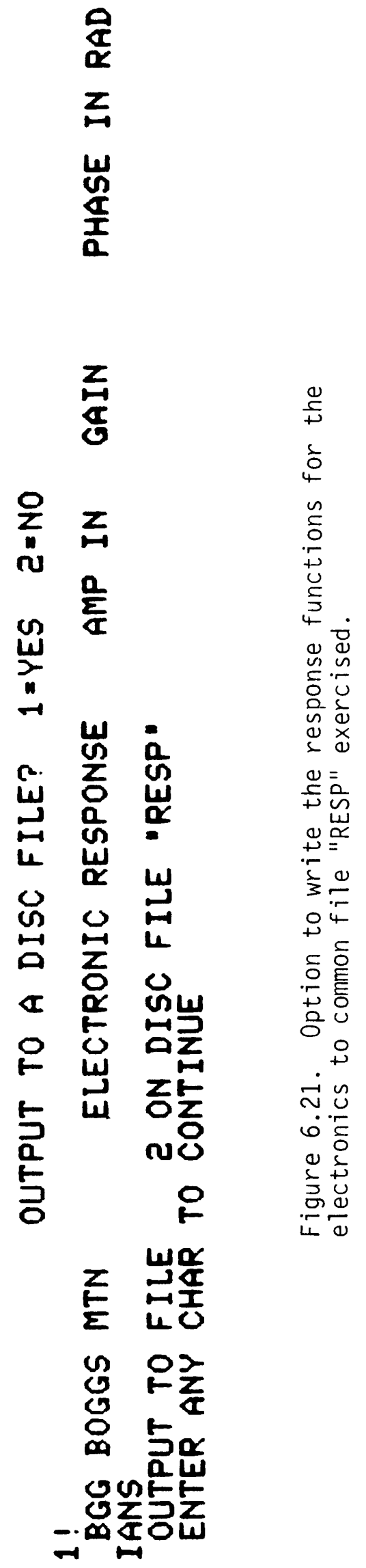
F!

BGG BOGGS MTN SEISMUMETER PMPLITUOE RESPONSE TO GROND DISPL.

290 SANP $/$ SEC ID $=2$ PLOT DATE $=16$ OCT 75 LEN=10.235 UPDATE 12 SEP 75

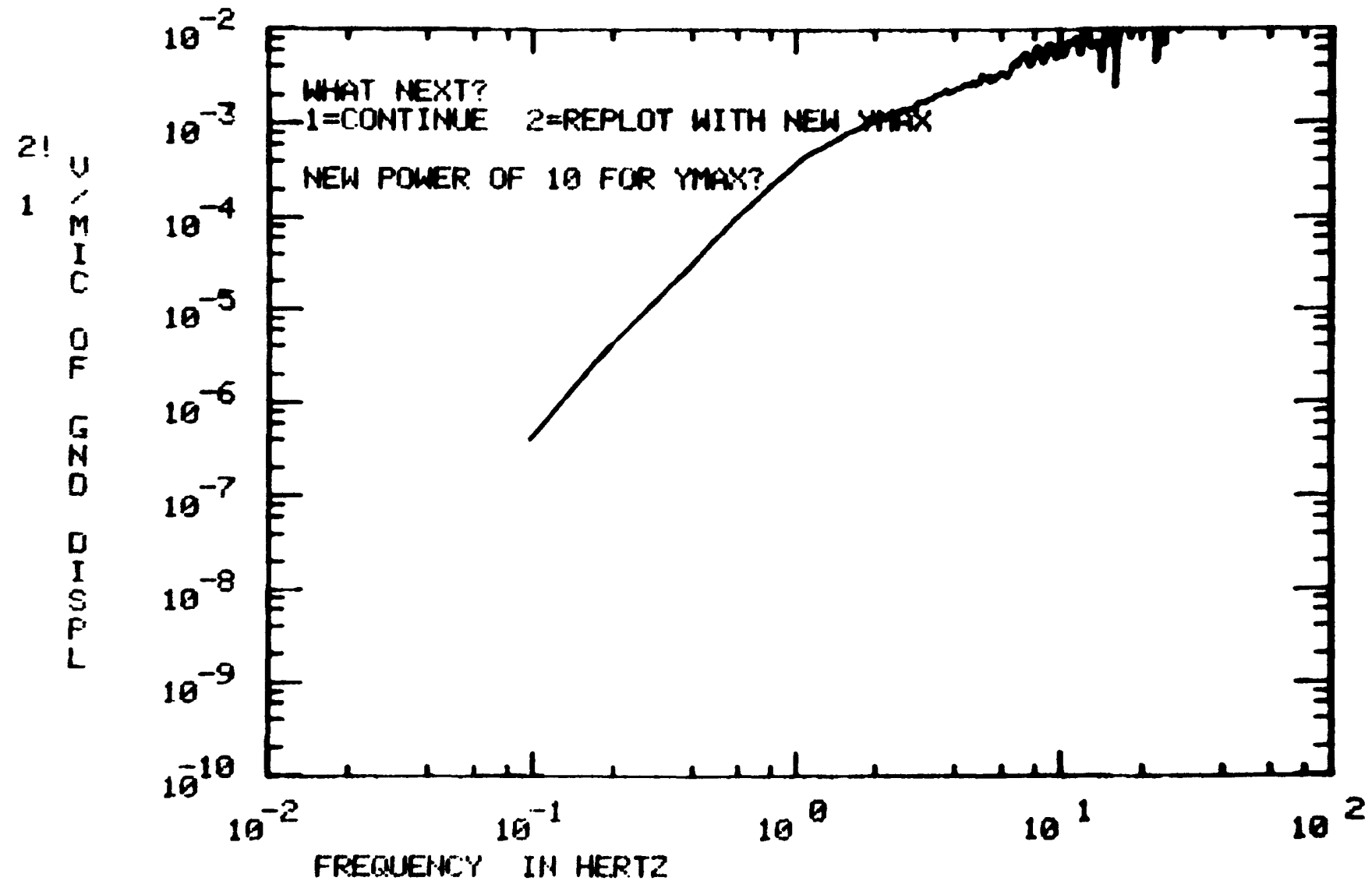

Figure 6.22. Amplitude response of the seismometer at station BGG. 
5 !

BCG BOCGS MTN SEISMOMETER AMPLITUDE RESPONSE TO COXUD DISPL.

290 SAMP $S E C$ ID 2 PLOT DATE 16 OCT 75 LEN=16.235 UFDATE 12 STP 75

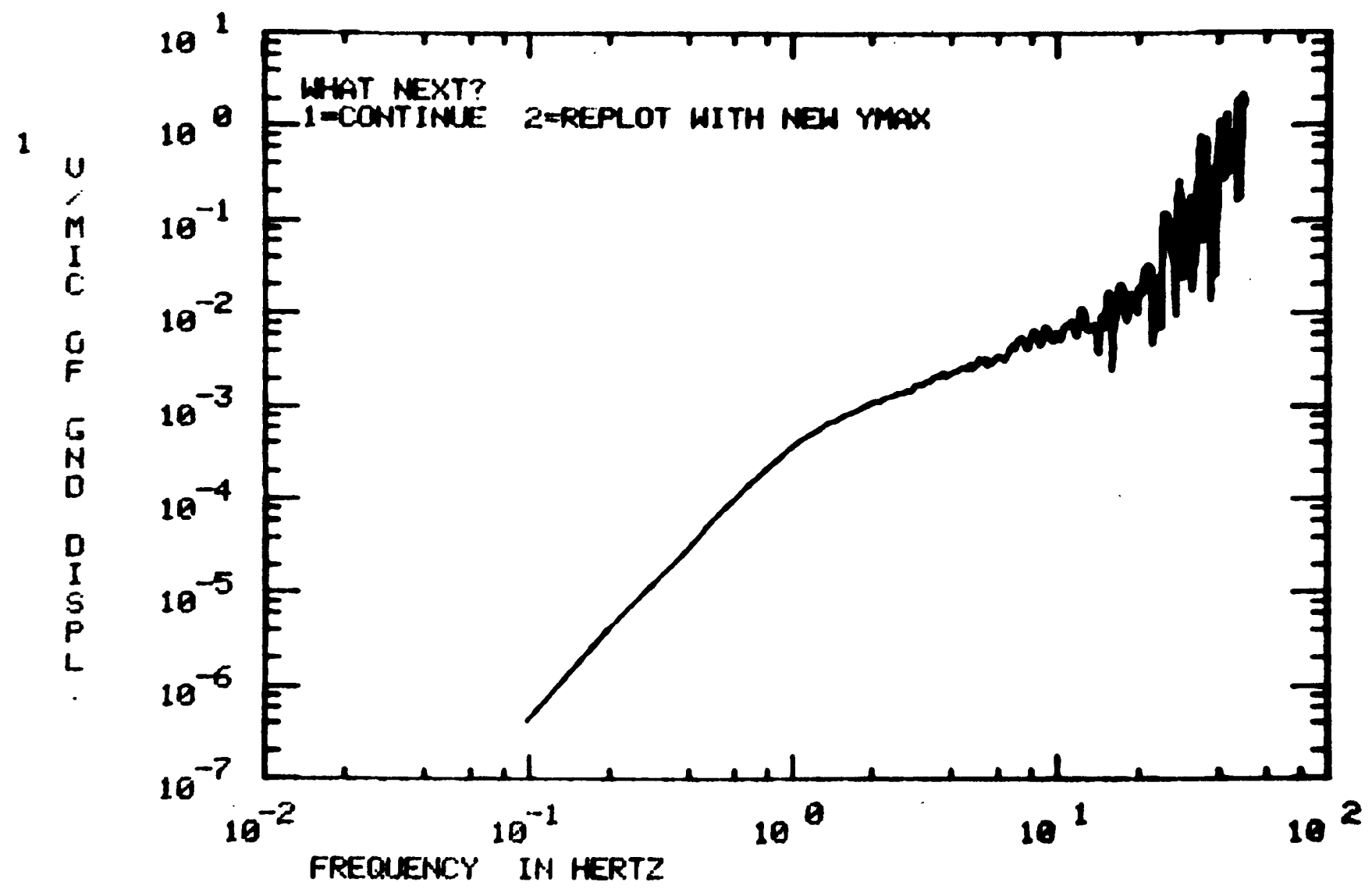

Figure 6.23. Amplitude response of the seismometer at BGG (replotted with new YMAX). 
BGG BOGGS MTN SEIGMOMETEP PHASE PESPFONSE TO CROUNO OISPL. 200 SAMP/SEC ID $=2$ PLOT DATE $=04$ MAF 76 LEH $=10.235$ LPDATE $=12$ SEP 75

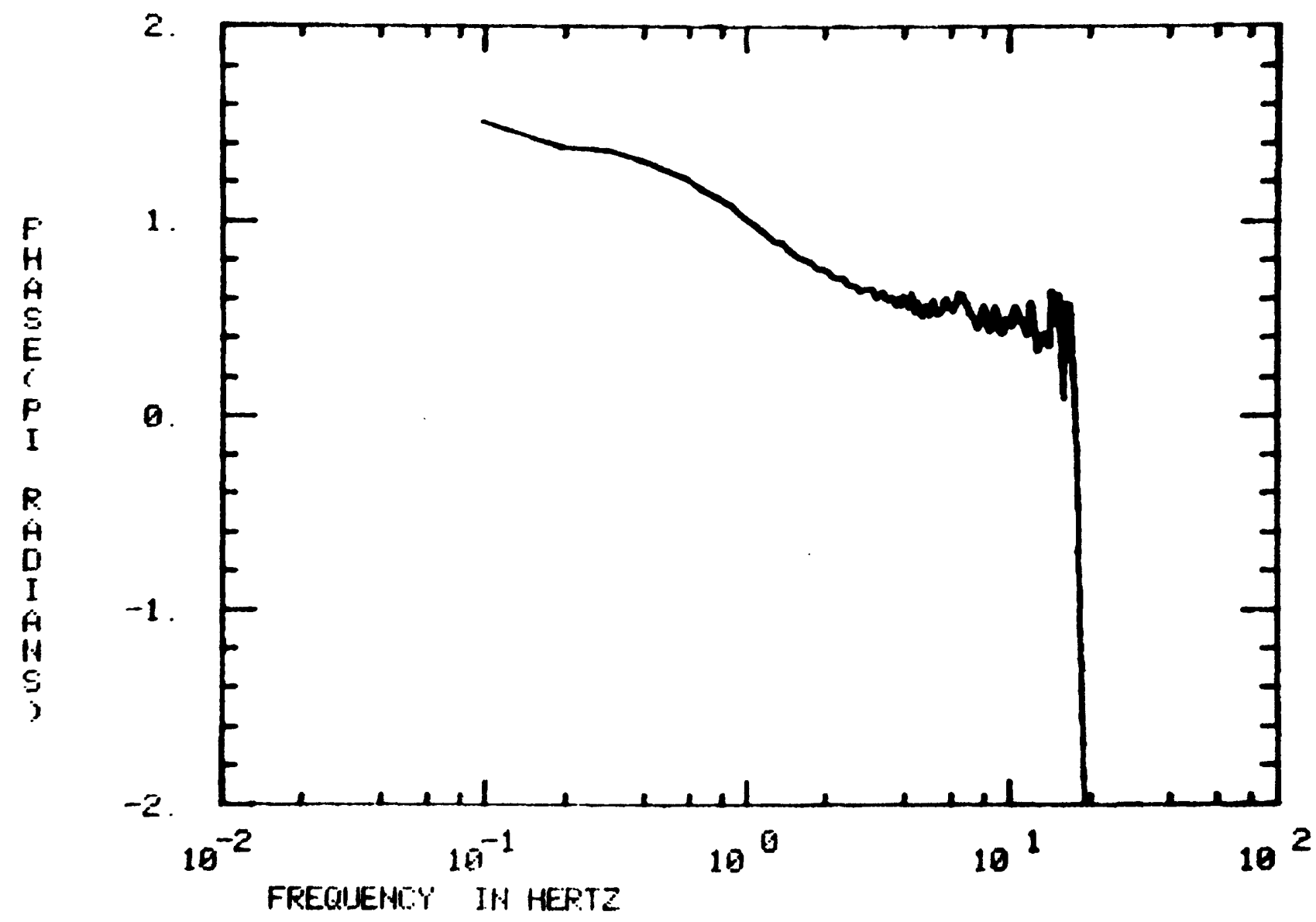

Figure 6.24 Phase response of the seismometer at station BGG. 


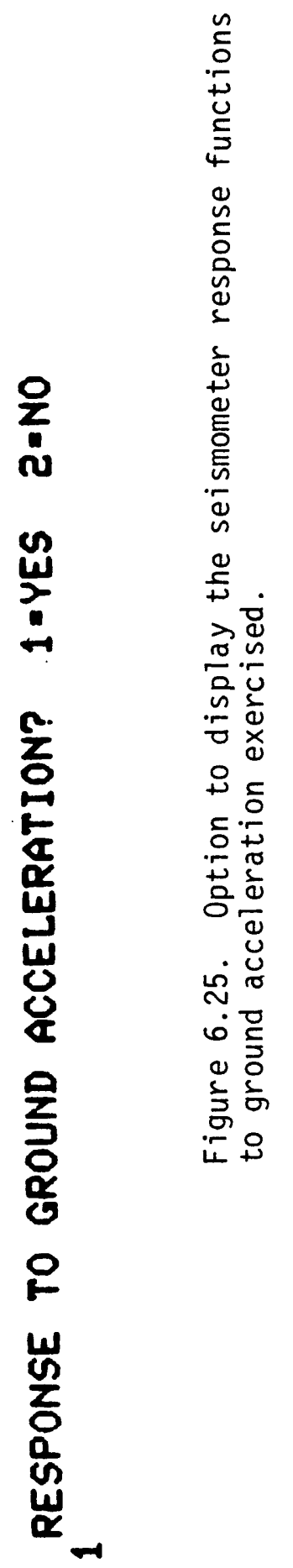


51

BGG EOGGS MTN SEISMOMETER AMPLITUOE RESPONSE TO GMOMD ACCDL. 209 SAMP $/$ SEC ID 2 PLOT DATE $=16$ OCT 75 LEN=16.235 UPOATE 12 SSP. TS

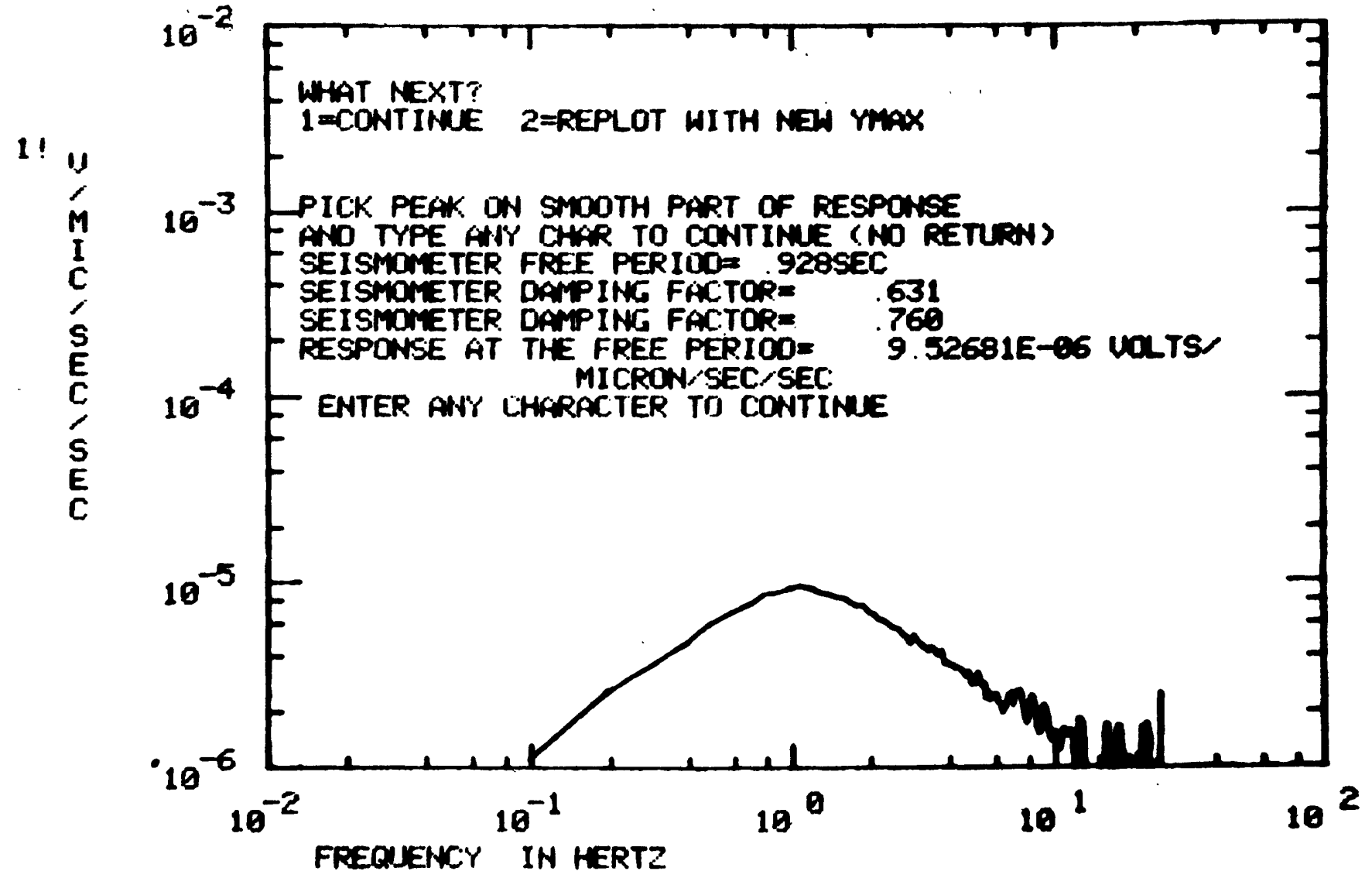

Figure 6.26. Amplitude response of the seismometer to ground acceleration. 
BGG BOGGS MTN SEISTMMETER PHASE RESPDISE TO GROND ACCE.

209 SAMP $/$ SEC ID $=2$ PLOT DATE $=94$ MAR $7 E$ LEN $=19.235$ UPOATE $=12$ SEP 73

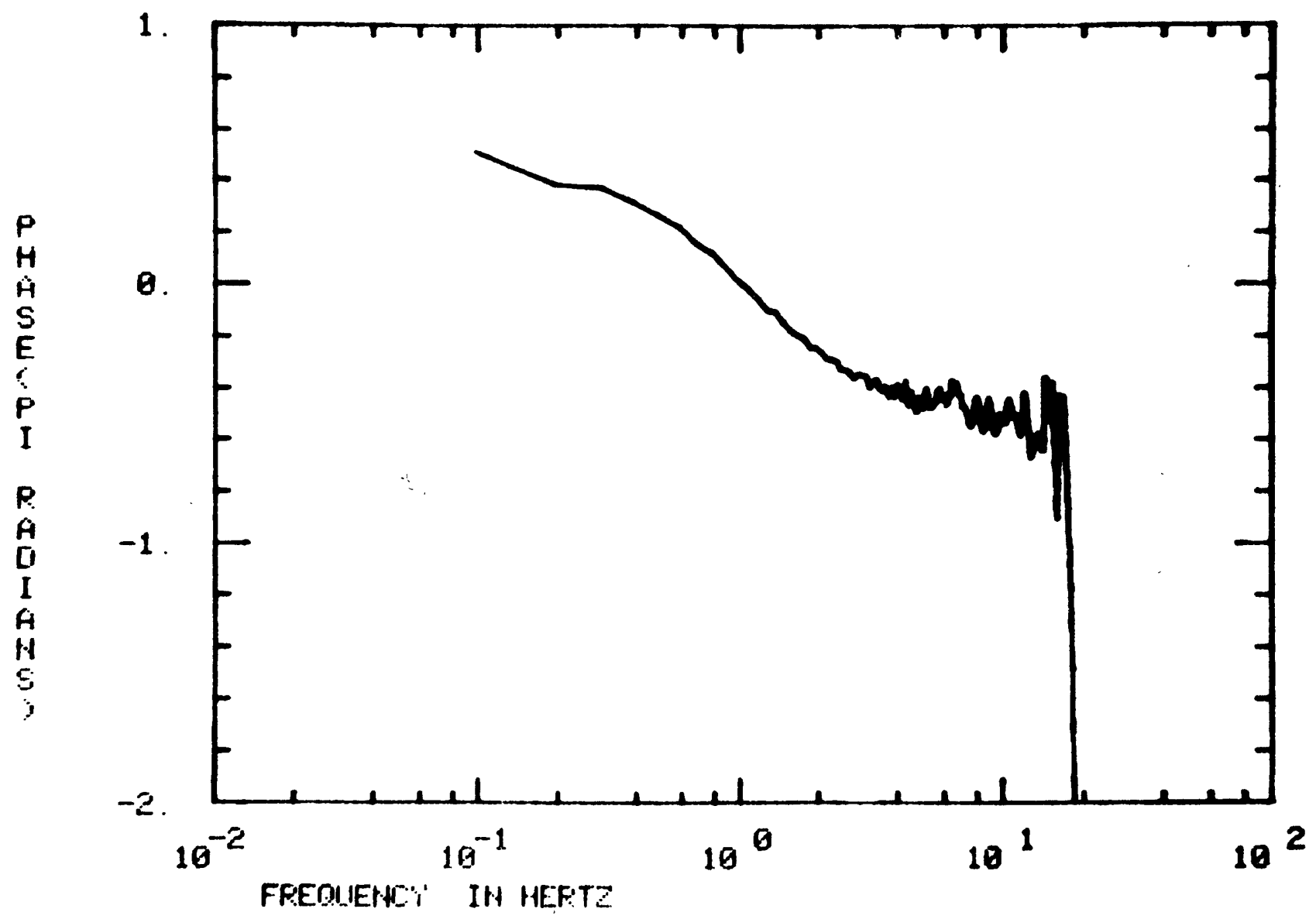

Figure 6.27. Phase response of the seismometer to ground acceleration. 


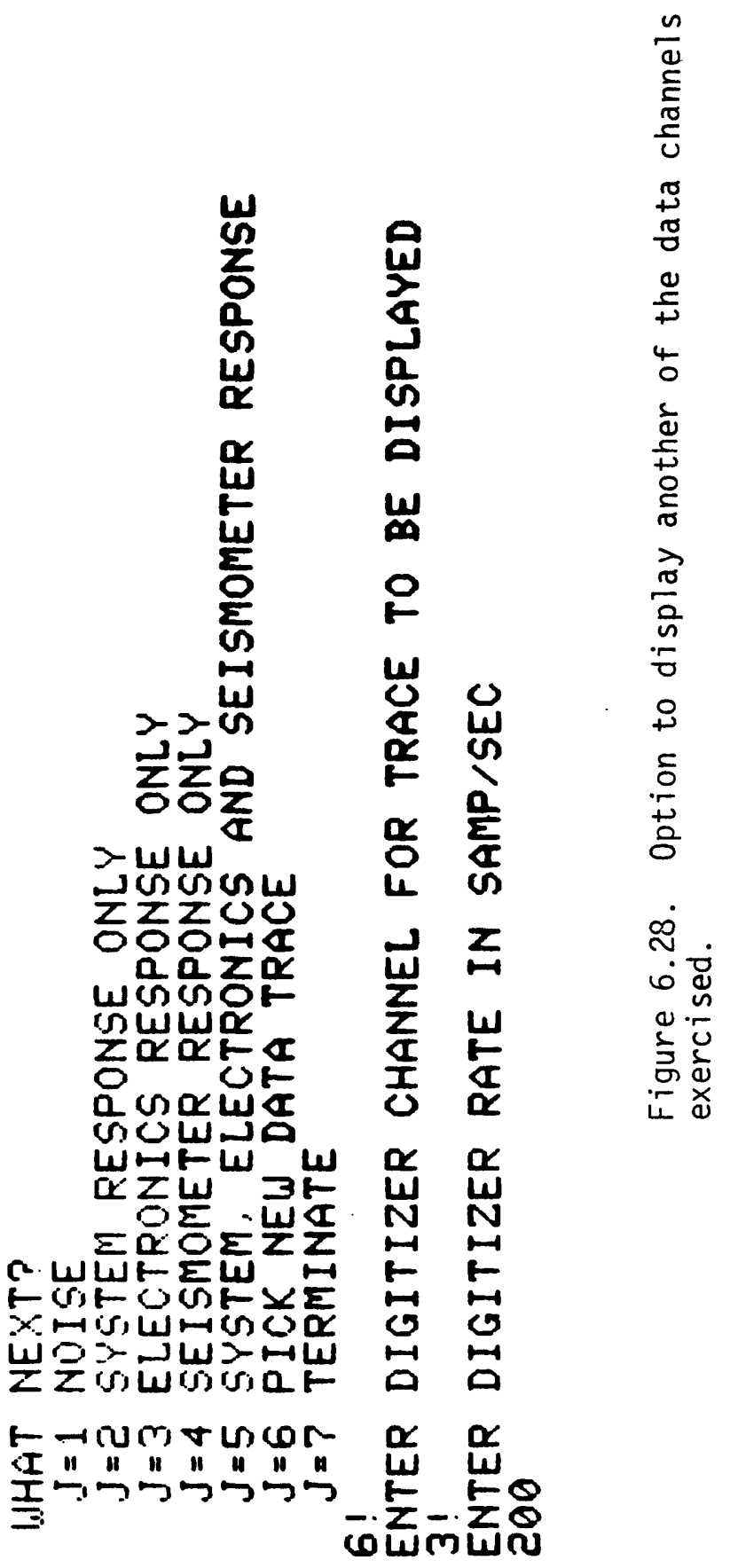




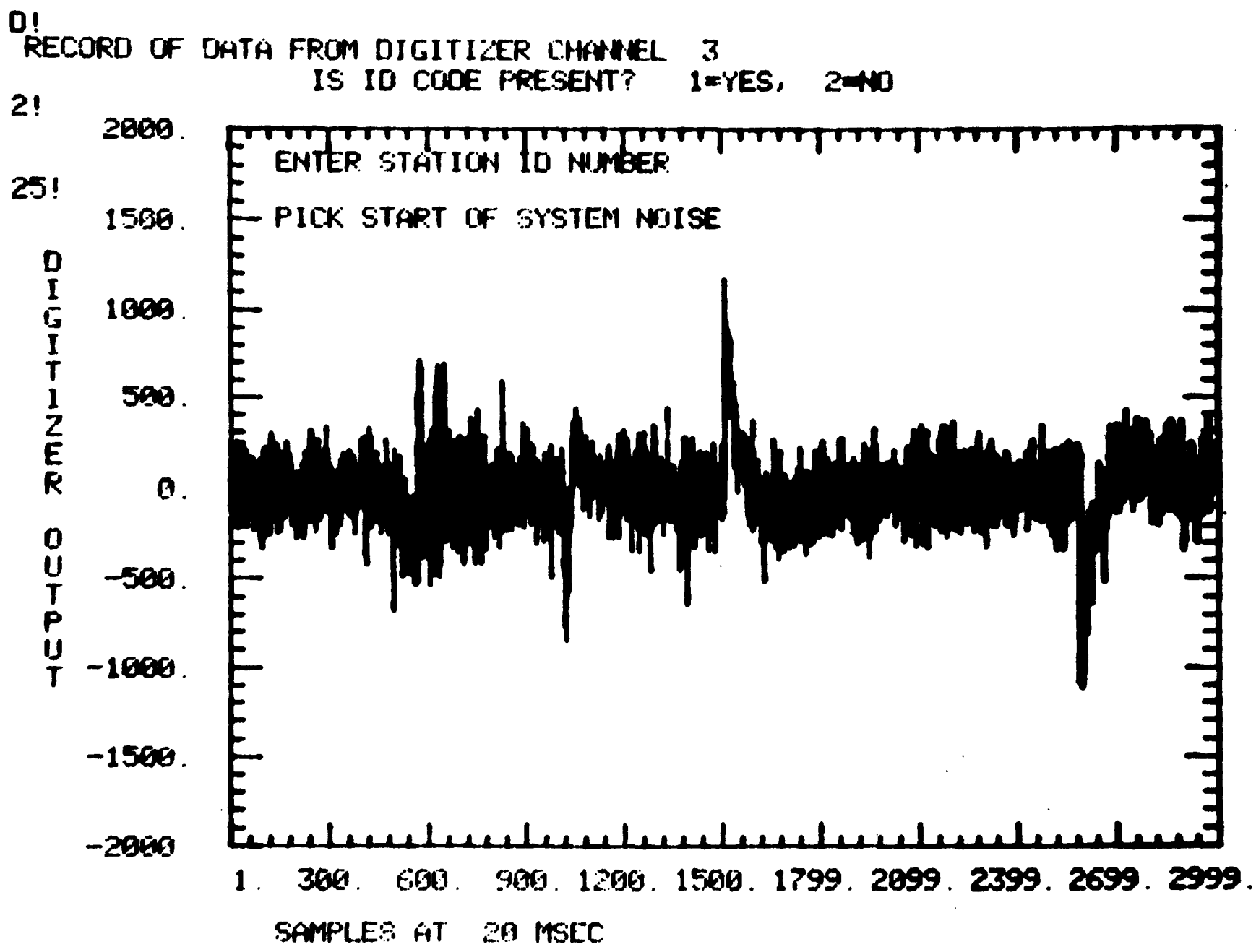

Figure 6.29. Sequence of calibration signals for channel \#3. 
E!

RECORO OF SISTEM NOISE FPCM STA. NO.

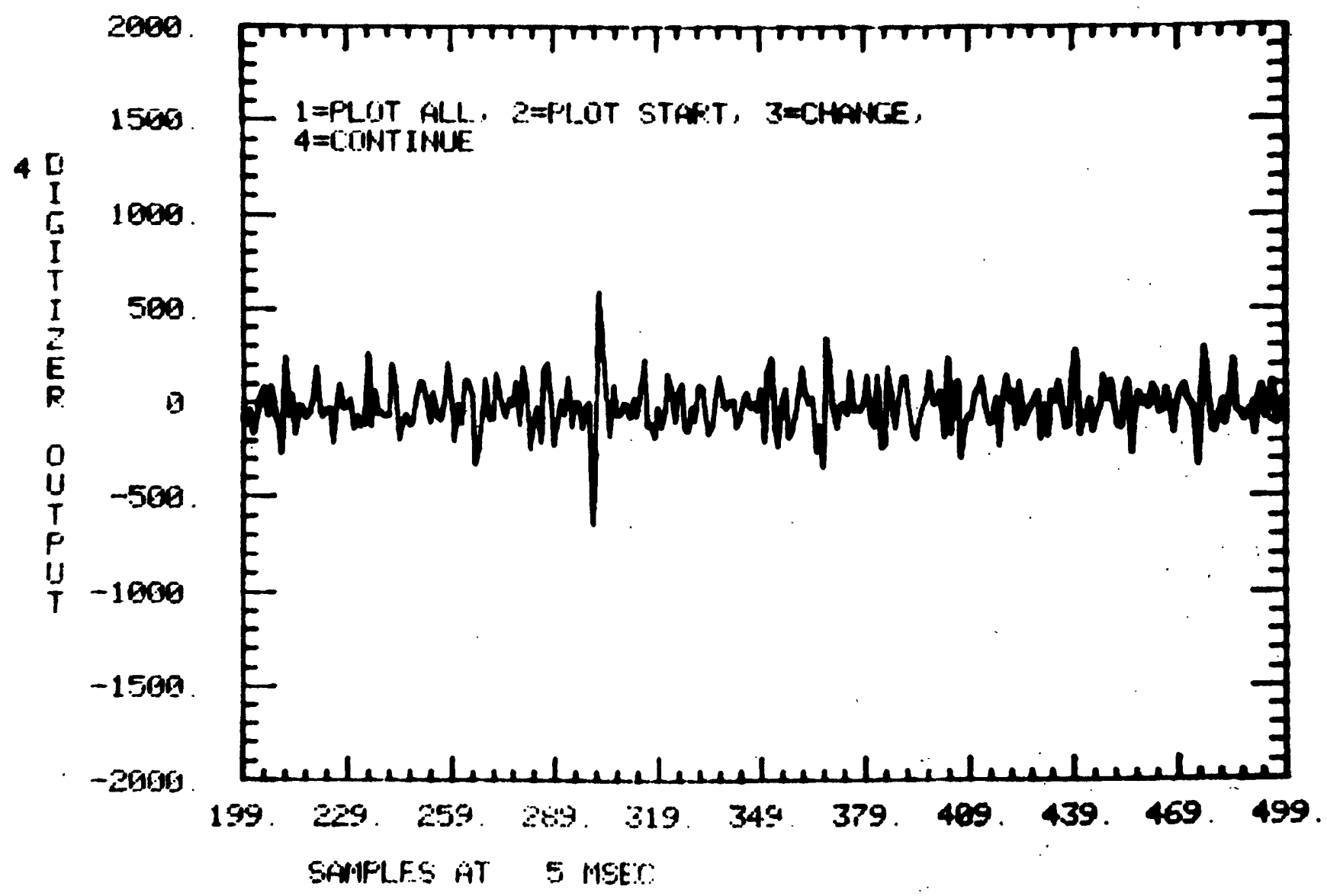

Figure 6.30. System noise signal for station with ID code \#25. 
SkECORD of SEISMOMETER RELEASE TEST FROM STA. MO. 25

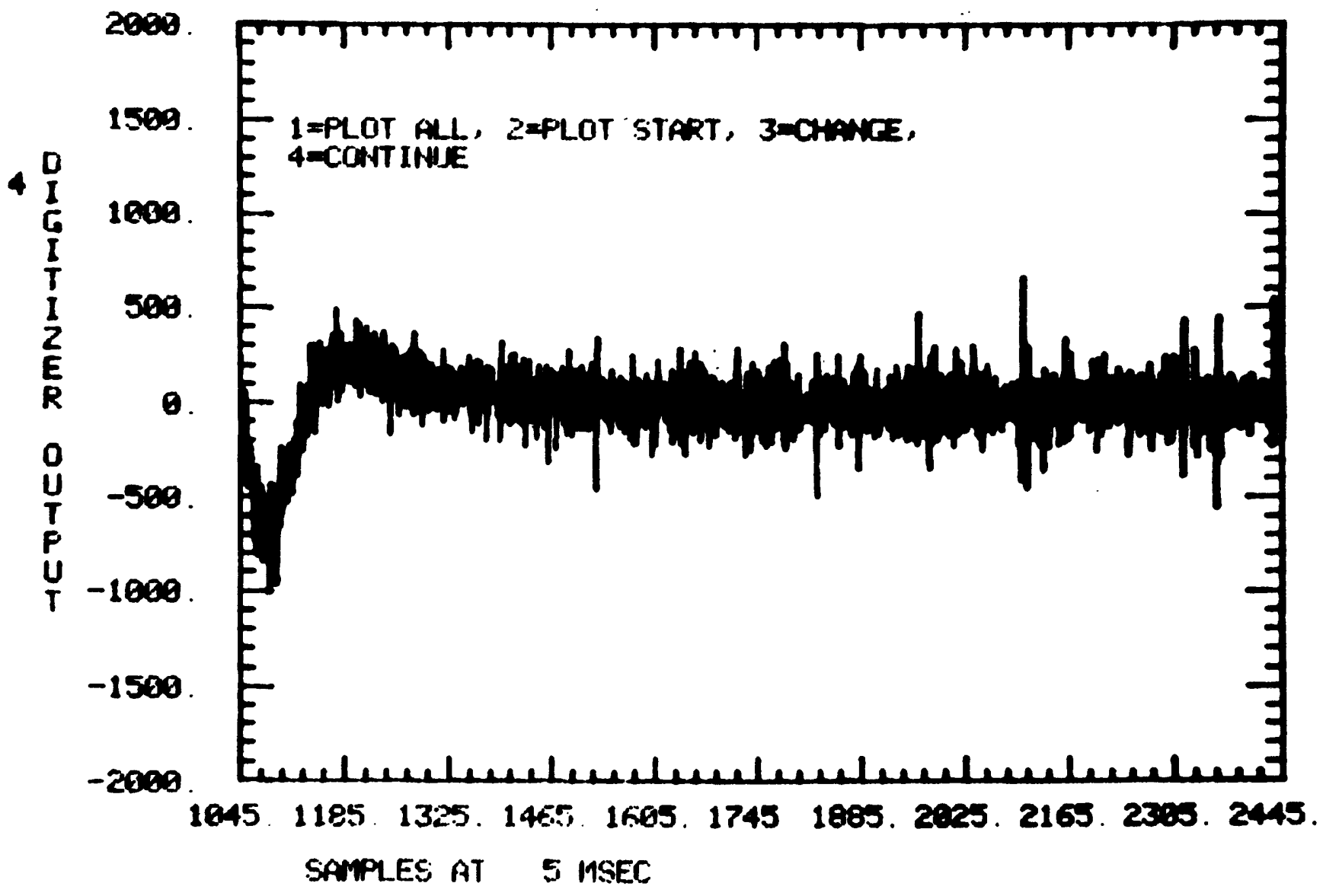

Fiqure 6.31. Seismometer mass release transient for station with ID code \#25. 
GECORD OF AMPLIFIER STEP TEST FRCM STA. NO. 25

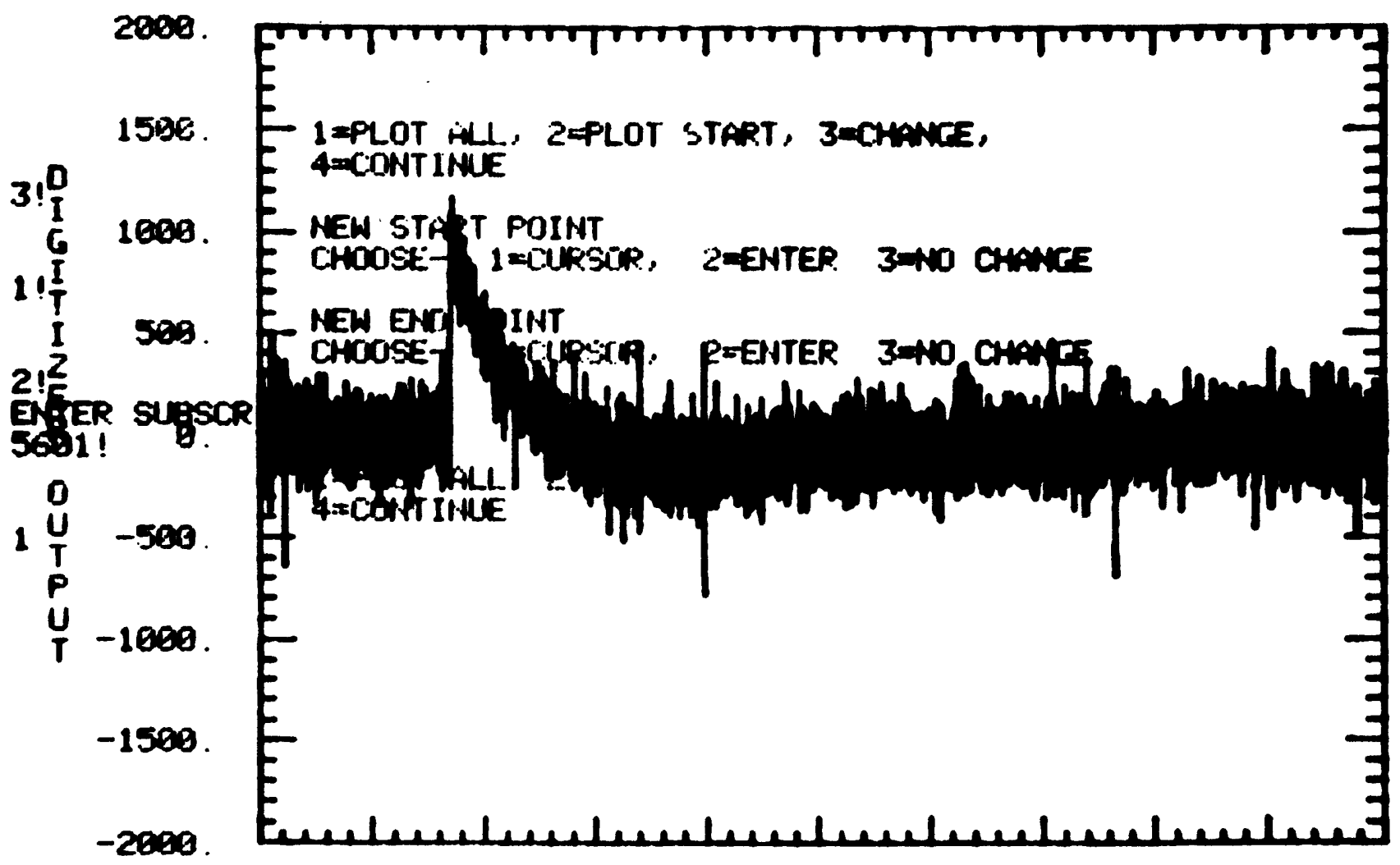

2501.2811 .31213431 .3741 .4951 .4361 .4671 .4901 .5291 . S601. SAMPLES AT 5 MSEC

Figure 6.32. Amplifier step test transient for station with ID code \#25. 
S!

RECORO DF AMPLIFIEP STEP TEST FPOM STA. NO. 25

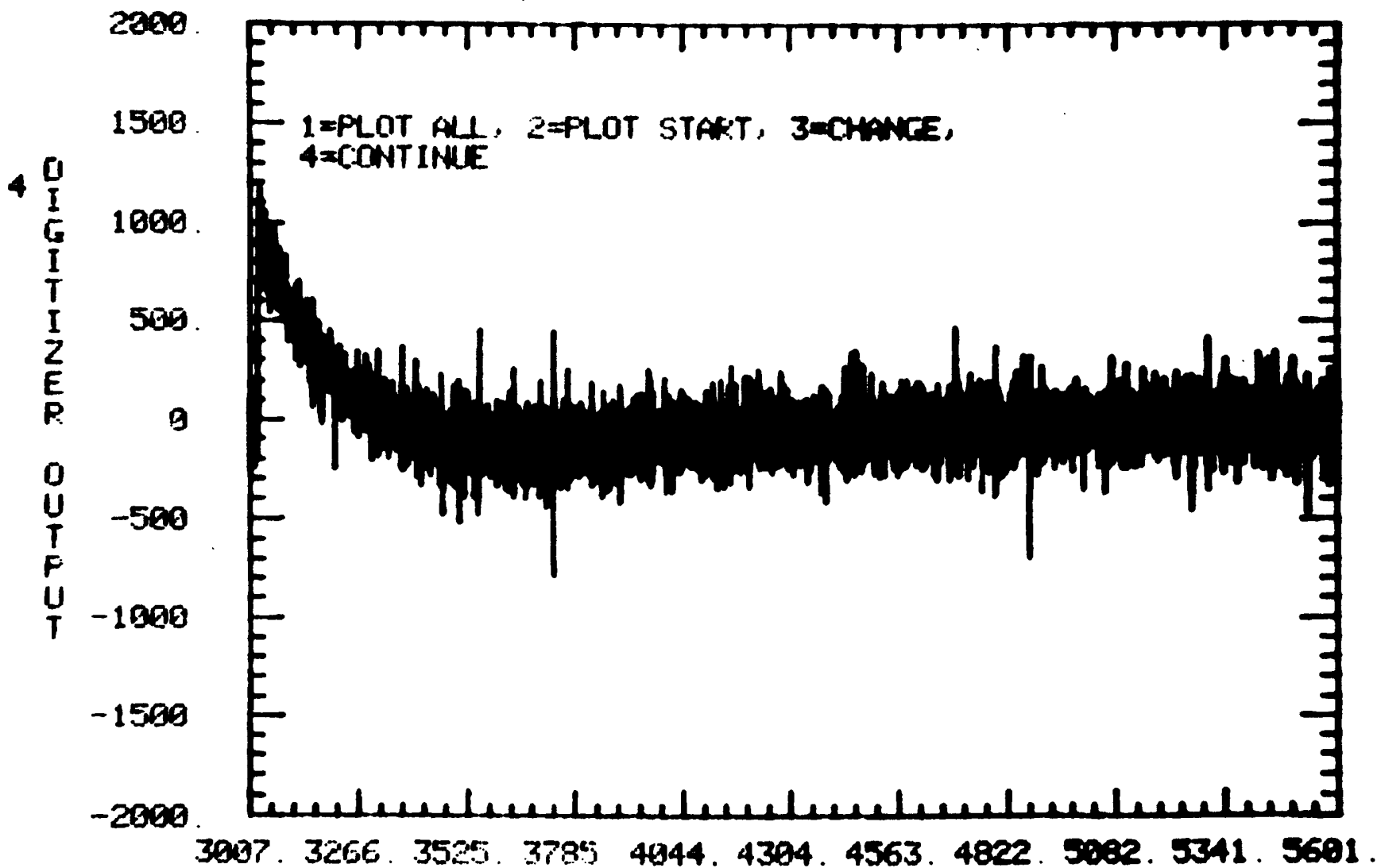
SAMPLES AT 5 MSEC

Figure 6.33. "Rewindowed" amplifier step test transient for station with ID code \#25. 


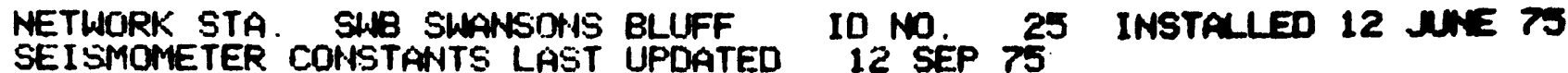
NO FARAMETER.

SYMBOL

UAUE

UNITS

1 TYPE OF CALIBRATOR

$\frac{2}{3}$

4

5

6

7

8 MASS

SEIS. MOTOR CONSTANT FREE PERIOD

CS
$M$
$G L$
To
EETAO
$R C$
$T$
$S$
$A$
$G$
$G N O$

$$
\begin{array}{r}
3.6000 \\
283.6000
\end{array}
$$

OPEN-CIRCUIT DAMPING

SEIS. COIL RESISTANCE

SERIES PAD RESISTANCE

SHUNT PAO RESISTANCE

ATTEMUATDR SETTING

10 NOMINAL FREAMP GAIN

11 SEISMOMETER SERIFL NO.

SNO

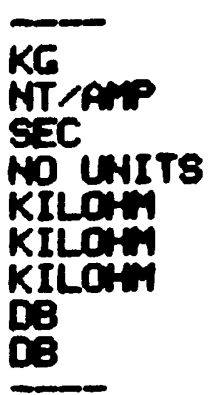

ENTER ANY CHAP TO CONTINUE

D! 2 ! TER TABLE OF SEISMOMETER CONSTANTS? 1=YES, $2=10$

NETWORK STATION SWB SWANSONS BLLFF ID MUMEER 25

PARAMETERS CALCLLATED FROM CONSTANTS DF 12 SEP 75

PARAMETER

EFFECTIUE MOTOR CONSTANT

RELEASE TEST ATTENUATION

SEI BMOMETER TEST CURRENT

AMPLIFIER STEP NOL TACE
SYMBOL

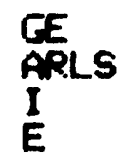

UALUE

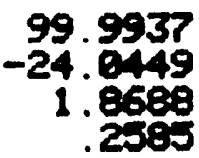

UNITS

VOLT/MSEC

Do

MICROAMP.

ENTER AWY CHAR TO CONTINUE

Figure 6.34. (top) Seismometer constants, etc. for SWB, the seismographic station with ID code \#25. (bottom) Seismograph parameters calculated from the constants and the $\mathrm{C5}$ calibrator unit circuitry. 
SWE SWANONS BLUFF NOISE SPECTRUM

200 SAMP /SEC ID $=25$ PLOT DATE $=16$ OCT 75 LEN 1.505 UPOATE= 12 SUP 75

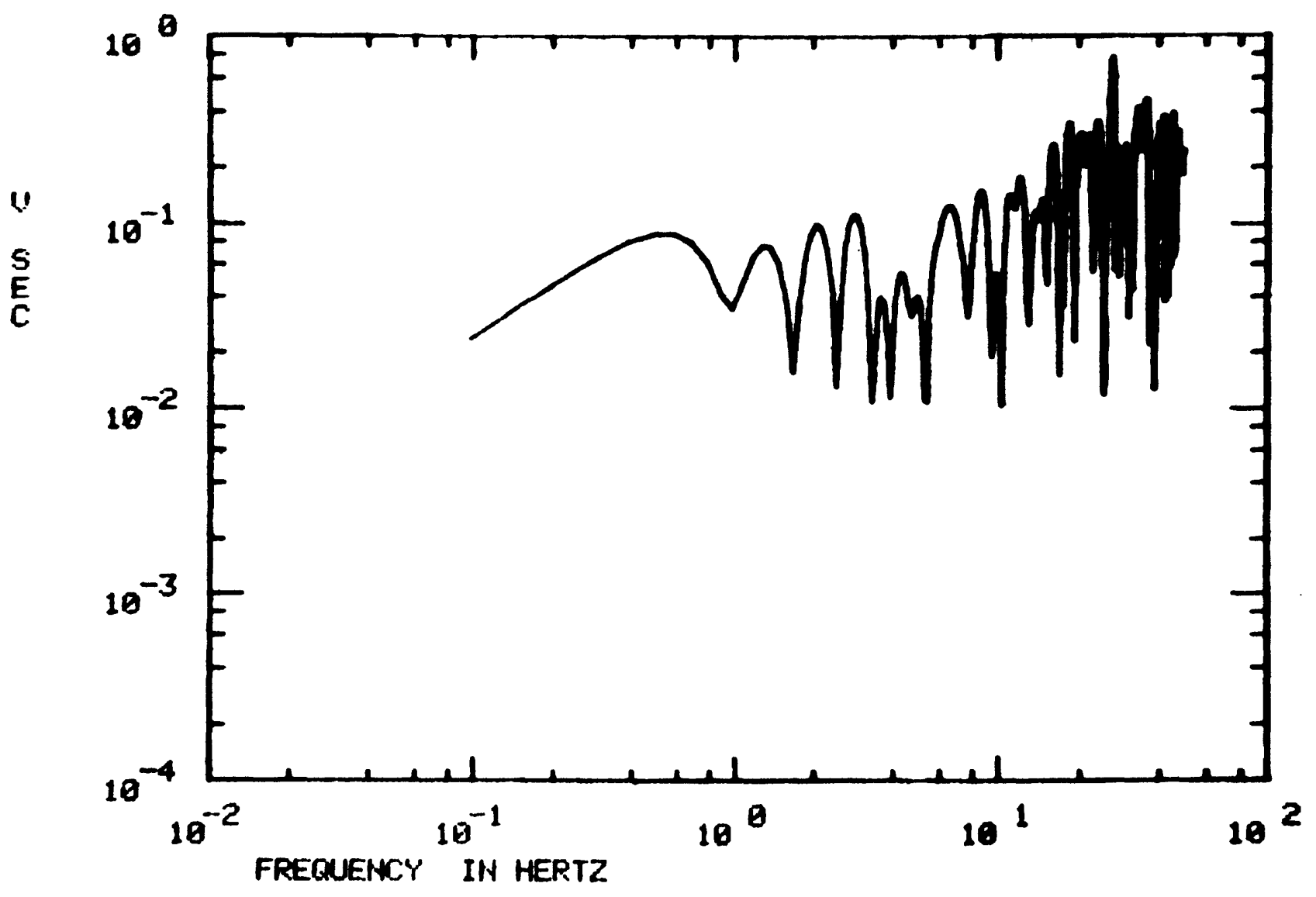

Figure 6.35. System noise amplitude spectrum for station SWB. 
SWB SWANSONS ELUFF SYSTEM AMFITUDE RESPONBE TO GOOND DIEPL. 200 SAMP/SEC ID $=25$ PLOT DATE $=16$ OCT 75 LEN 7.606 UPOATE 12 SIP 75

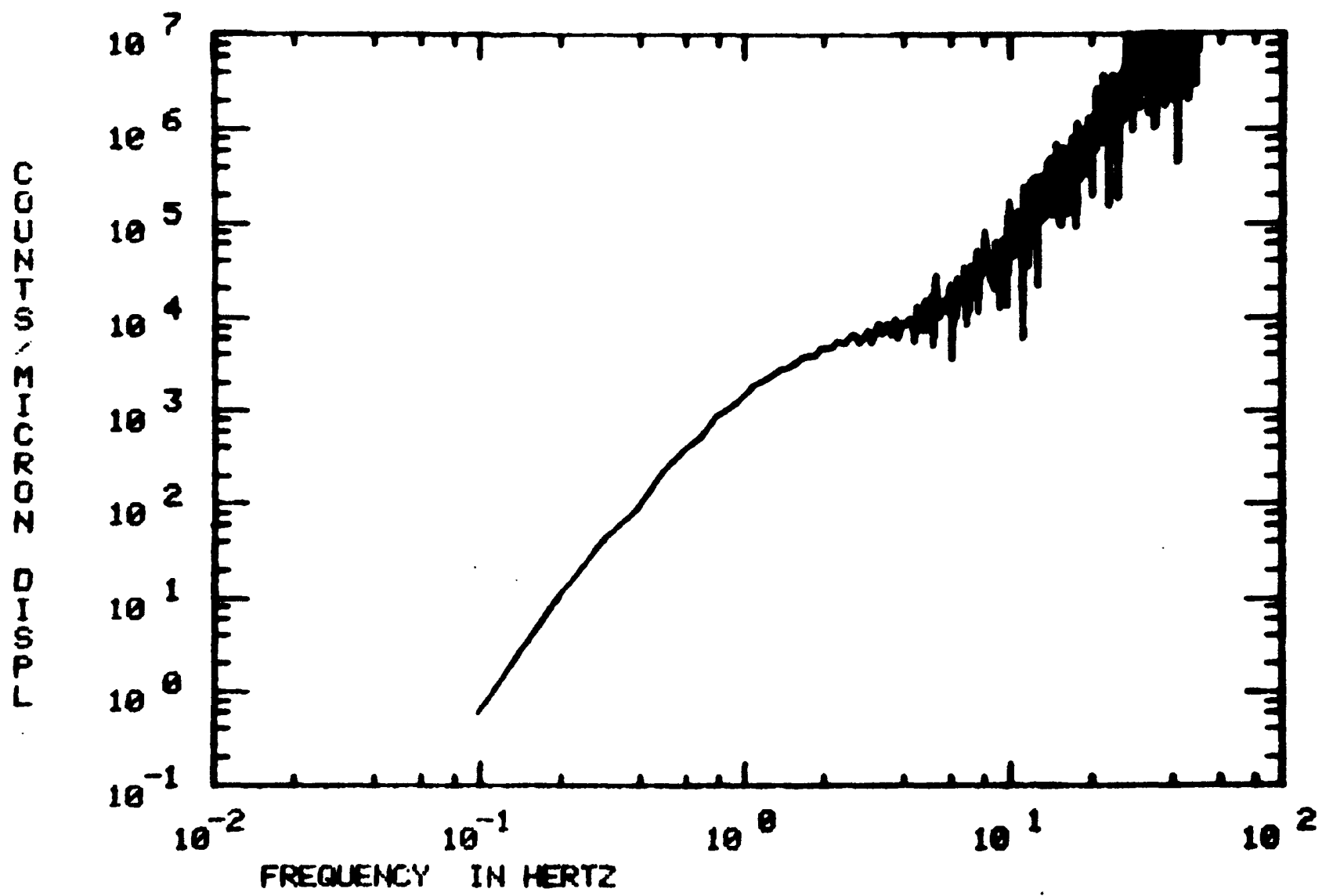

Figure 6.36. Amplitude response for seismographic station SWB. 
SWB SWHWSONS BLIFF

SYSTEM PHASE

RESPDNSE TO EROUND DISPL.

200 SAMP, SEC ID $=25$ FLOT DATE $=64$ MAR 76 LEN= 7.065 UPDATE 12 SEP 75

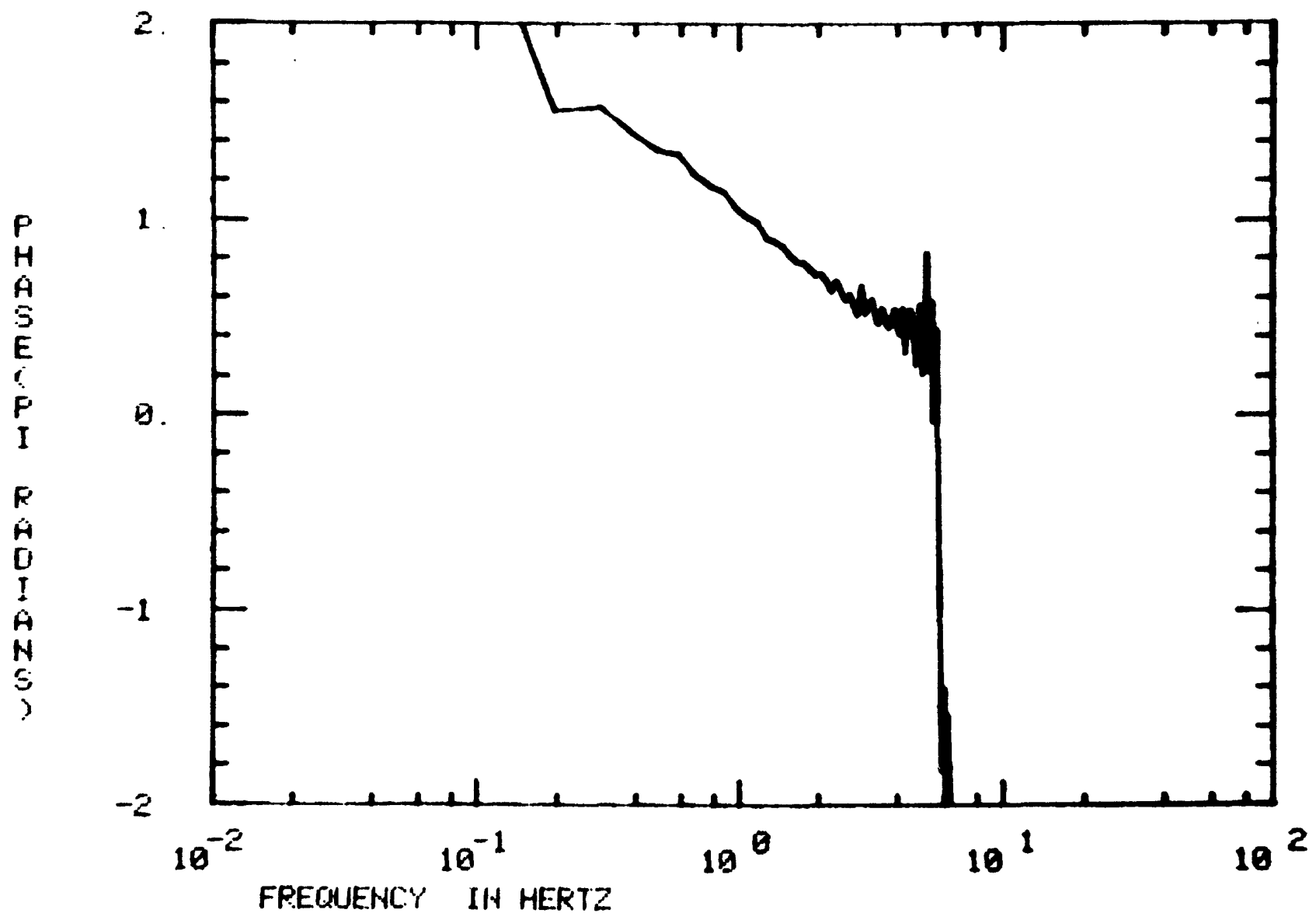

Figure 6.37. Phase response of the seismographic station SWB. 
SHB SHANSONS BLUFF ELECTRONICS AMPLITUDE RIEPang:

200 SAMP/SEC ID= 25 PLOT DATE 16 OCT 7J LINM19.239 UPAATE= 12 SIP 75

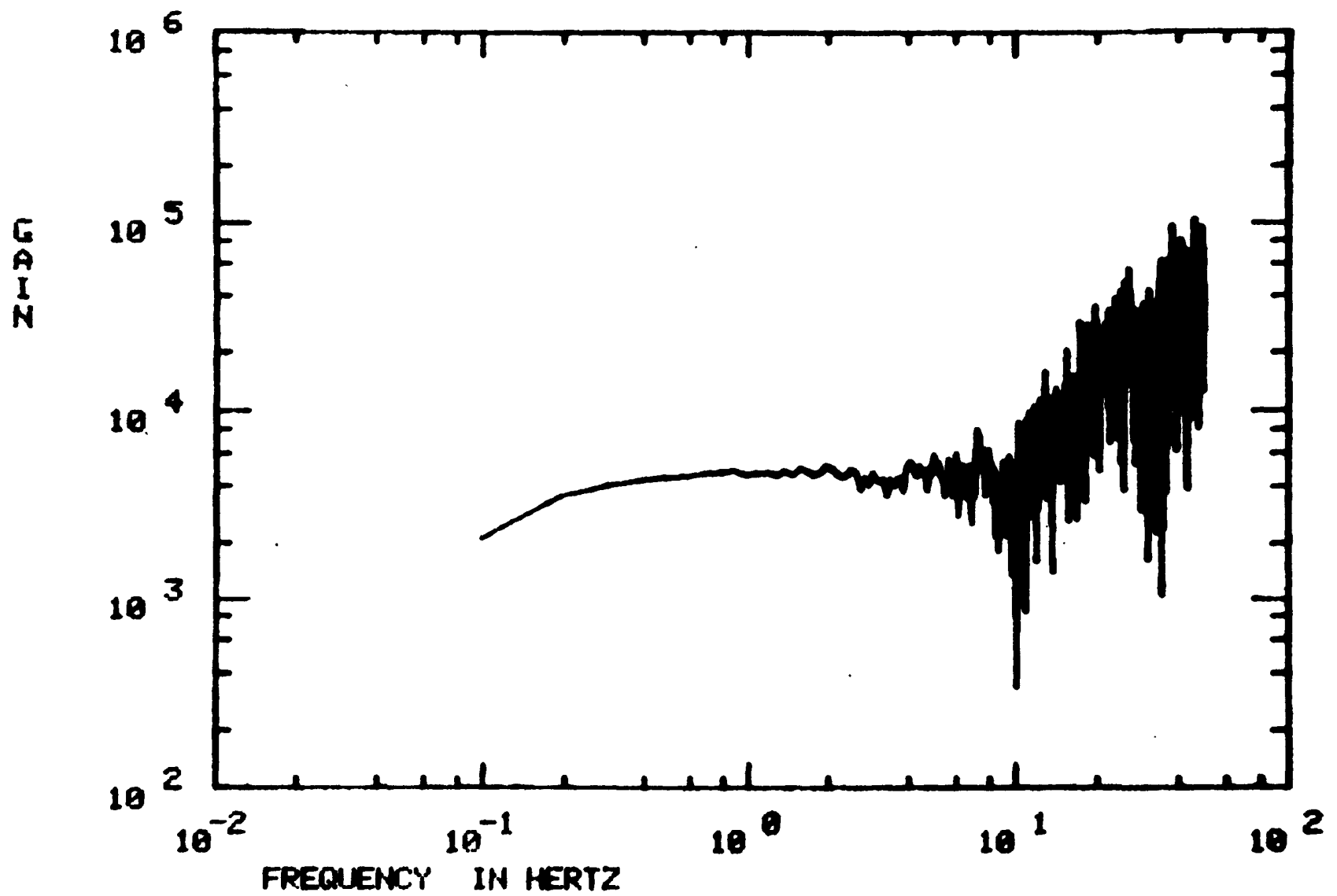

Figure 6.38. Amplitude response for the electronics at station SWB. 


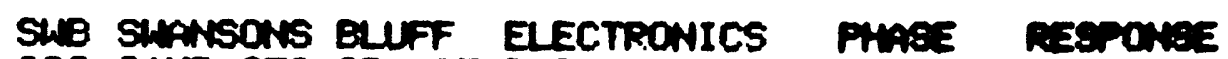

200 SAMP/SEC IO= 25 PLOT DATE= 16 OCT TS LDR10.235 UPOATEN 12 gaP 75

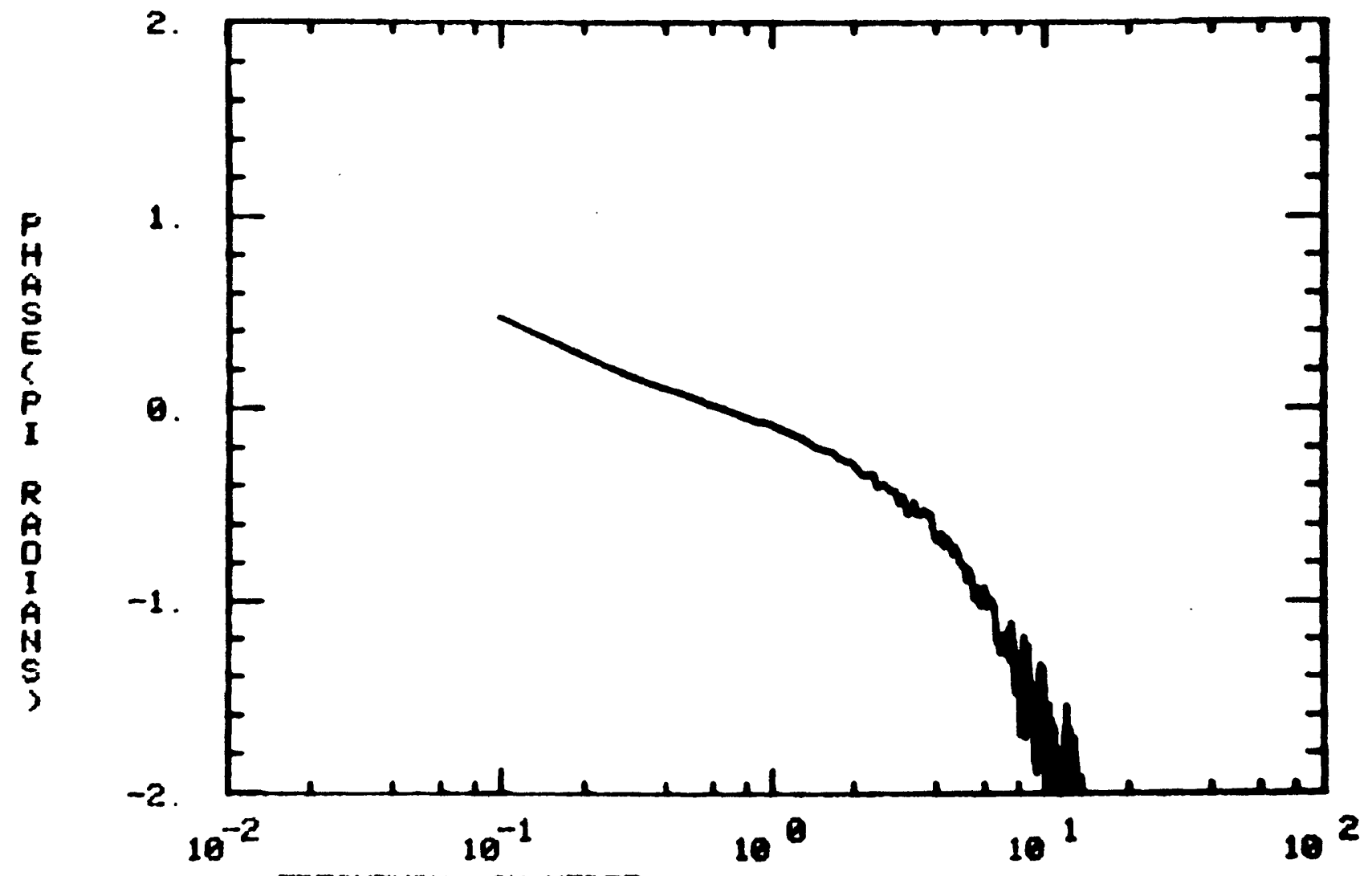

FREQUENCY IN HERTZ

Figure 6.39. Phase response for the electronics at station SWB. 
SWB SWANSONS QLUFF SEISMOMETER AMFLITUDE RESPONSE TO CROUND DIEPL. 209 SAMP SEC ID $=25$ PLOT DATE $=16$ OCT 75 LEN-10.235 UPDATE $=12$ SבP 75

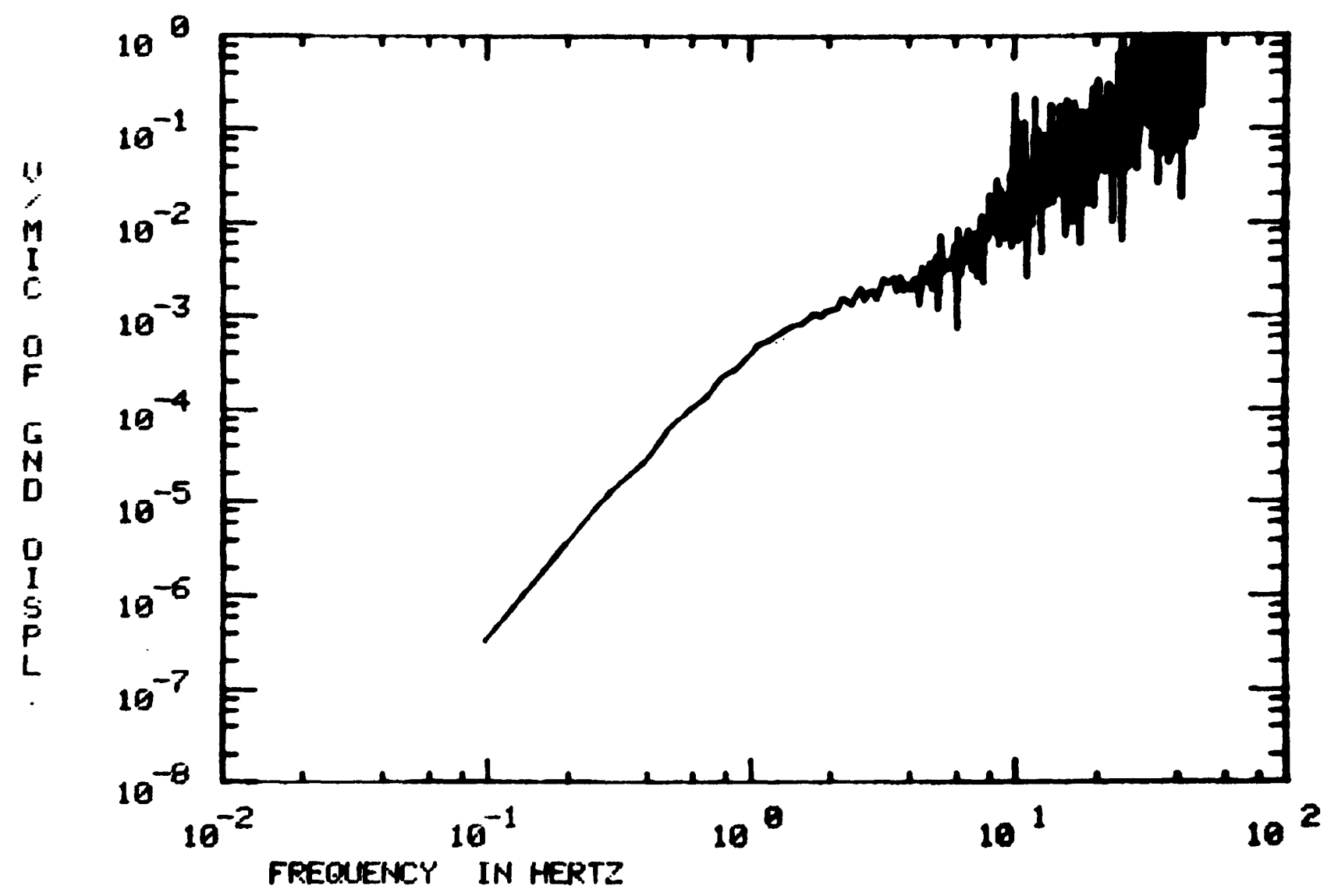

Figure 6.40. Amplitude response of the seismometer at station SWB. 
SHA SHAHSONS RLIFF SEISMOMETER PHASE PESPONSE TO CROUND DISPL.

290 SAMP $/ S E C$ III $=25$ FLOT CIATE $=04$ MAP $7 E$ LEN $=10.235$ LPDATE $=12$ SEP 75

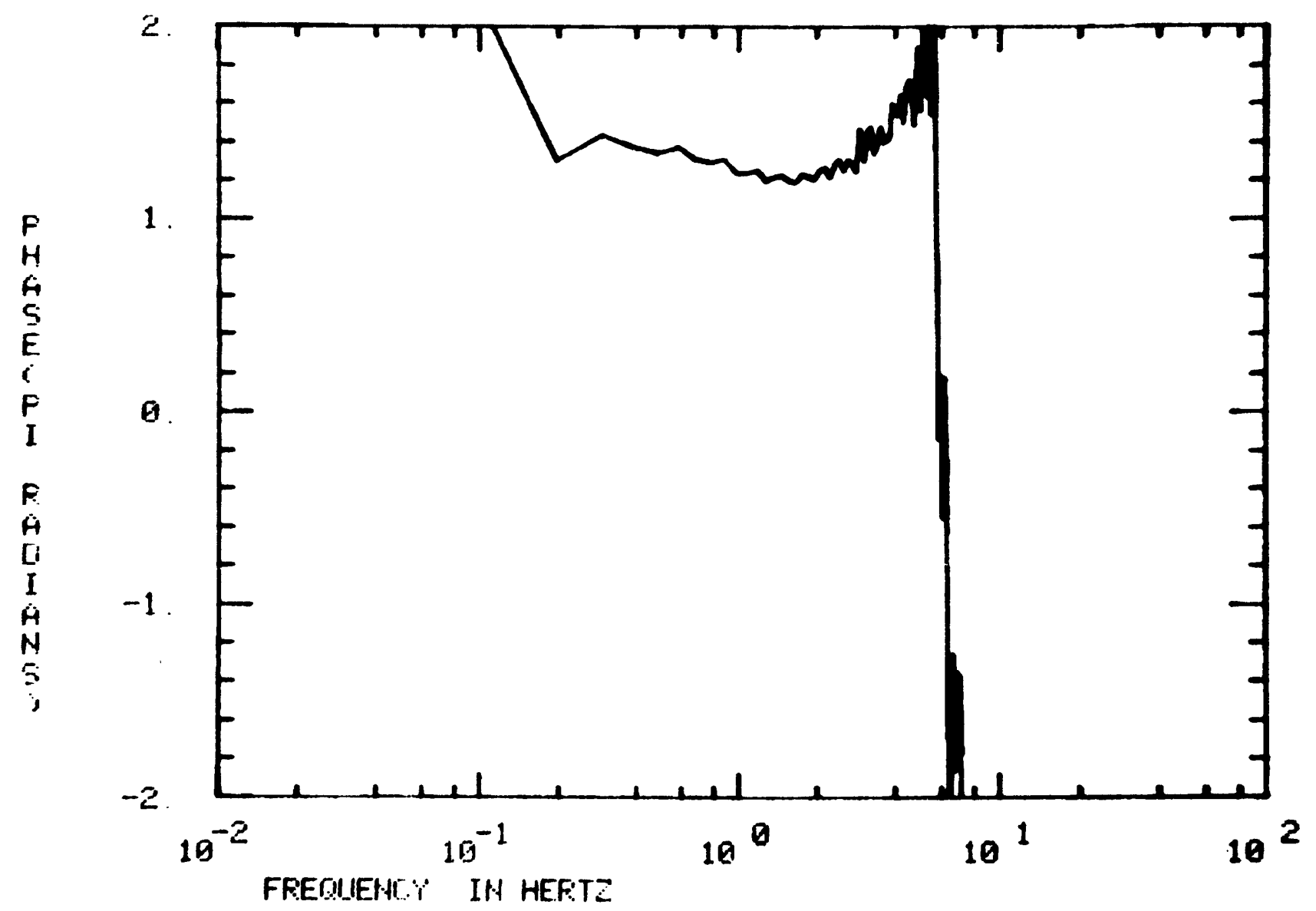

Figure 6.41. Phase response of the seismometer at station SWB. 
D!

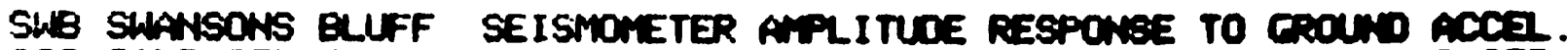
200 SAMP/SEC ID $=25$ PLOT DATE = 16 OCT 75 LON=16.235 UPOATE 12 EDP 73

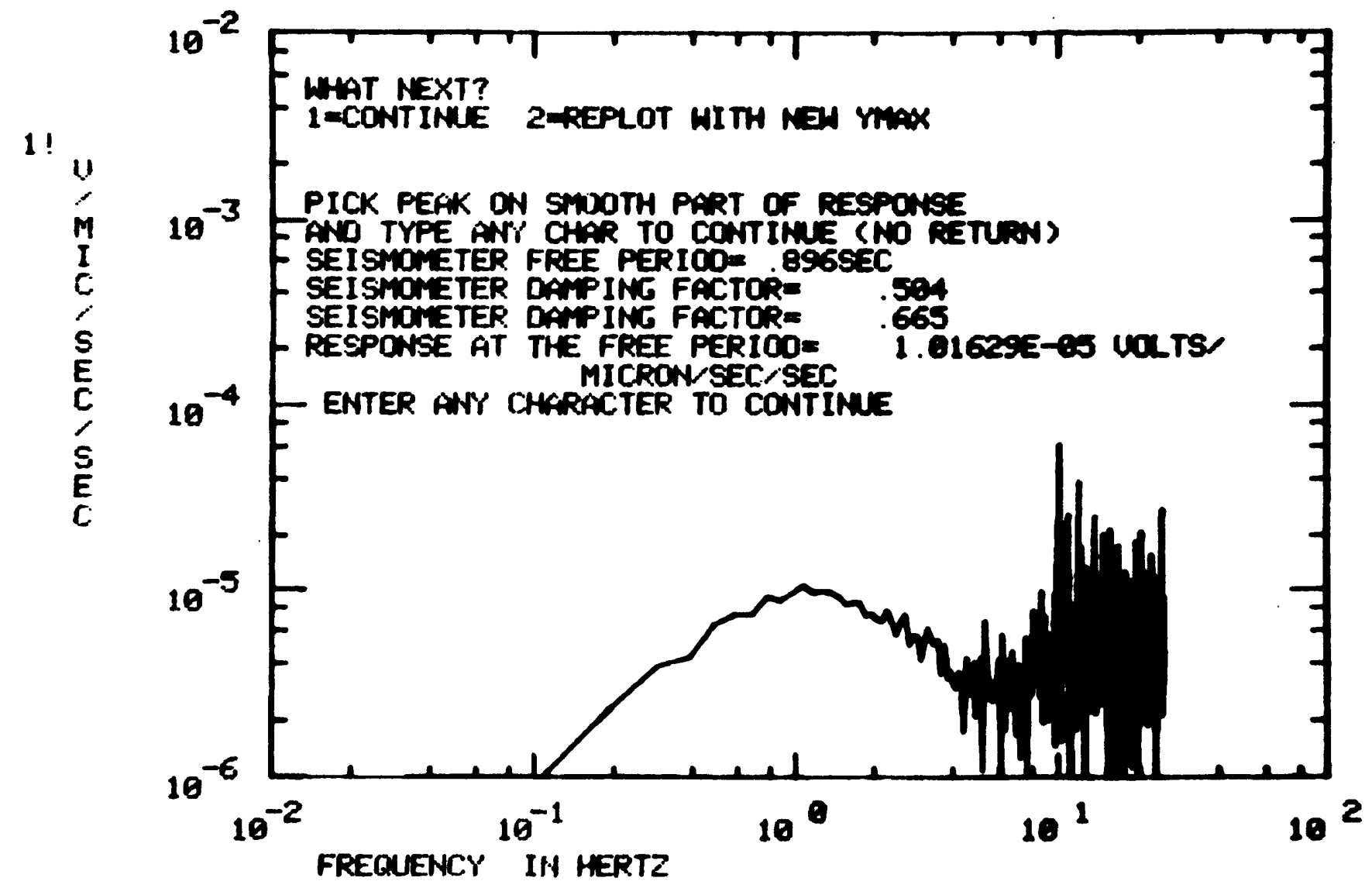

Figure 6.42. Amplitude response of the seismometer at station SWB to ground acceleration. 
OHE SWHNOHS BLUFF SEIGHOMETER PHASE RESPONSE TO CROUND ACCEL.

2 UD SAIP. SEC ID = 25 PLOT LATE= 04 MAR 7E LEN=10.235 IJPDATE= 12 SEP 75

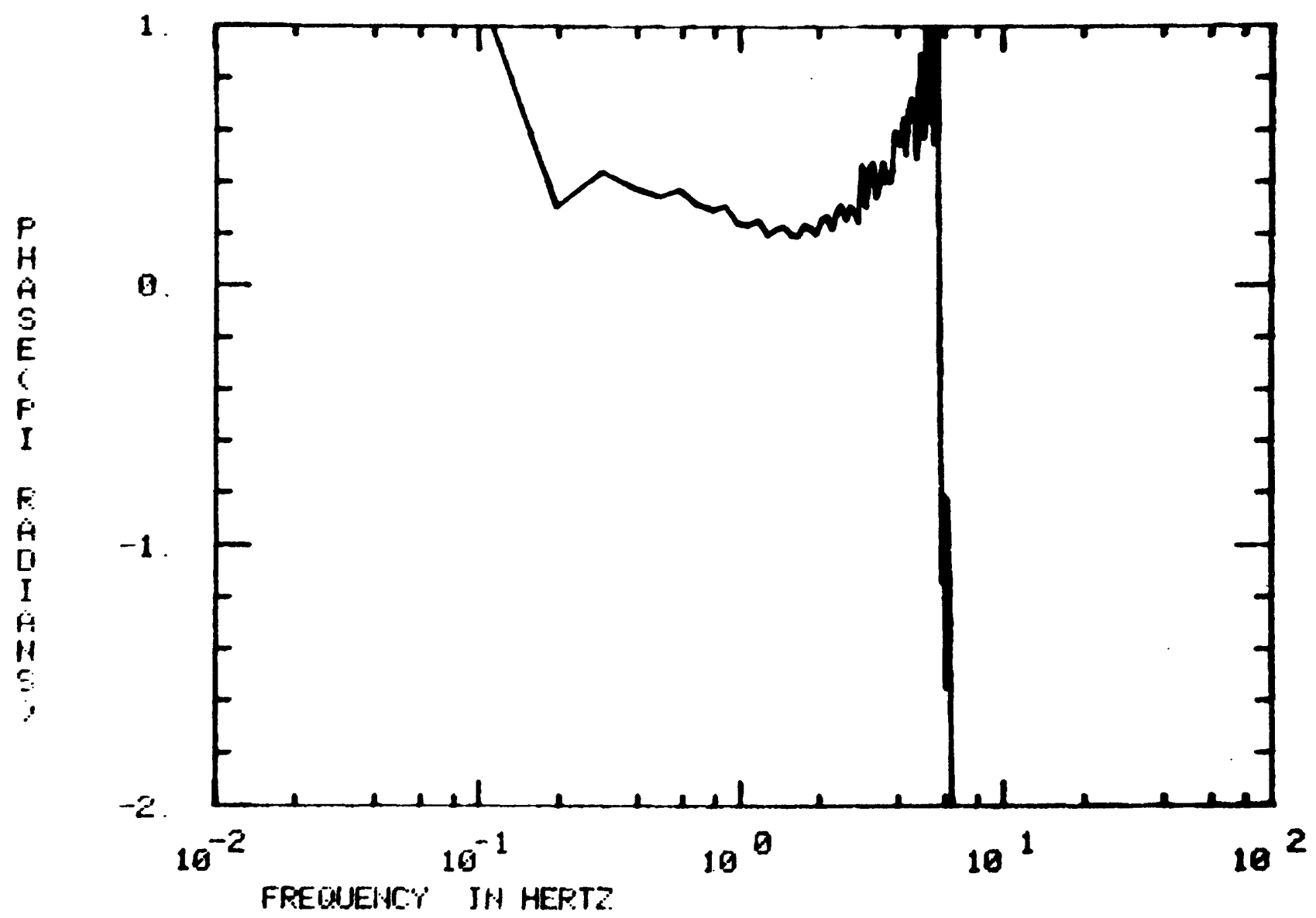

Figure 0.43 . Phase response of the seismometer at station SwB to ground acceleration. 


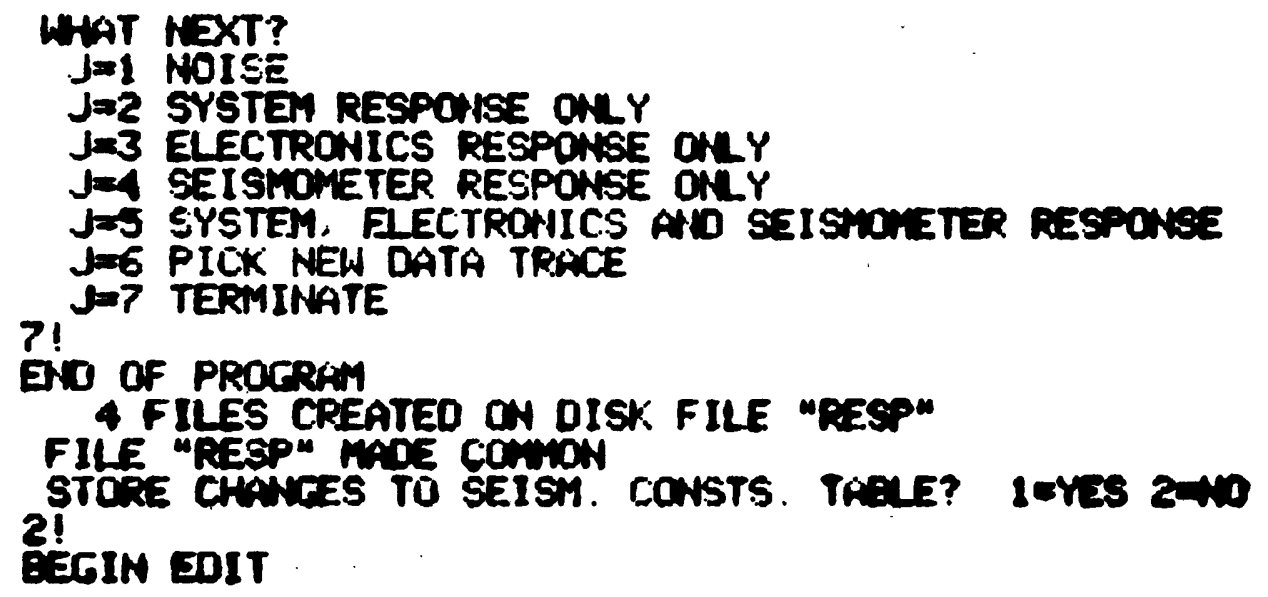

4 FILES CREATED ON DISK FILE "RESP"

FILE "RESP" MADE COMNON

$2 !$

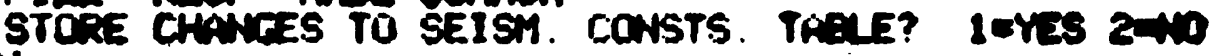

EESIN EDIT

Figure 6.44. Program terminated normally. 
$>$ LUIS, $* C, B I L, ?, 180,500009.803657$, BAKUN!

LOTIH CF-11 TTY-1QR 09.53 55. **EKY61 J*C*11/15/75.

ETLLAZG LOGGED IN. SESAME 2.3

DK - SESAME

ALGAD, CALSMO WBSOURCE!

LOACI COMPLETE, ENTERING AEIT

OK - AEOIT

L!

1. DELETE, CXLGO, L.IFWLST.

2 LIBCOPY, JORAT, NPLCOU RR, IPLCO.

3. LIECOPY, JCRAT , TXLCO RR, TXLCO

4. LIBLOFY, HBSOUKCE, RESF/RR, RESP

S LIECOPY, WESOUFCE, SM CO KR, SH CO

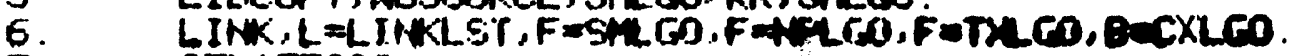

7 SF $(35000)$

8 CXLGO, TAFETTY, TAPETTY

OR: - AEUIT

ATUt

Figure 7.1. Initial sequence of commands: logging onto the $C$ machine, loading program CALSHO from data call library WBSOURCE, listing CALSMO and executing via $\uparrow$ RUN. 


\section{ENTER FILE NO OF SYSTEM RESPONSE \\ 11 \\ BCG BOCGS MTN \\ SYSTEM RESPOMEE \\ AMP IN COUNTSMIC PMABE IN RA \\ SAMP ESC ID= 2 PLOT OATE= 03 OCT 75 LEN 7.093 UPOATE= 12 EבP 75}

8

INTER 777 IF WRONG FILE ANY OTHER CWAR IF OK

Figure 7.2. Interactively entering file number on local file RESP of system response and verifying the ertry after examining the identification text(arrays LTITL and LTITLZ) from the file. 
L'GG BOGGS MTN

SYSTEM RESPONEE

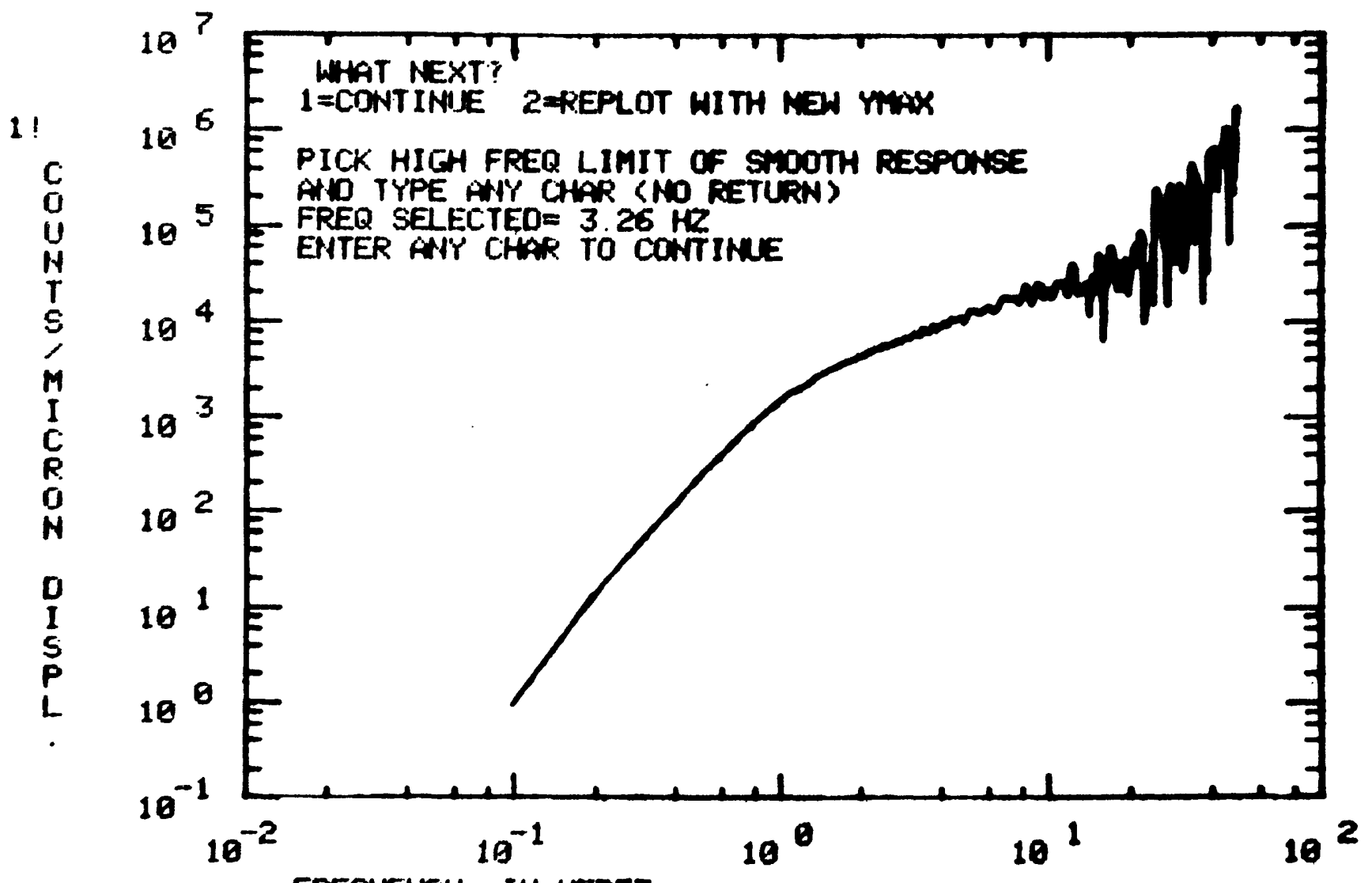

FREQUENTY IN HERTZ.

Figure 7.3. System amplitude response for station BGG. The user has selected, via the cursor, the point on the response where noticeable jitter begins. 
SYSTEM RESPONSE

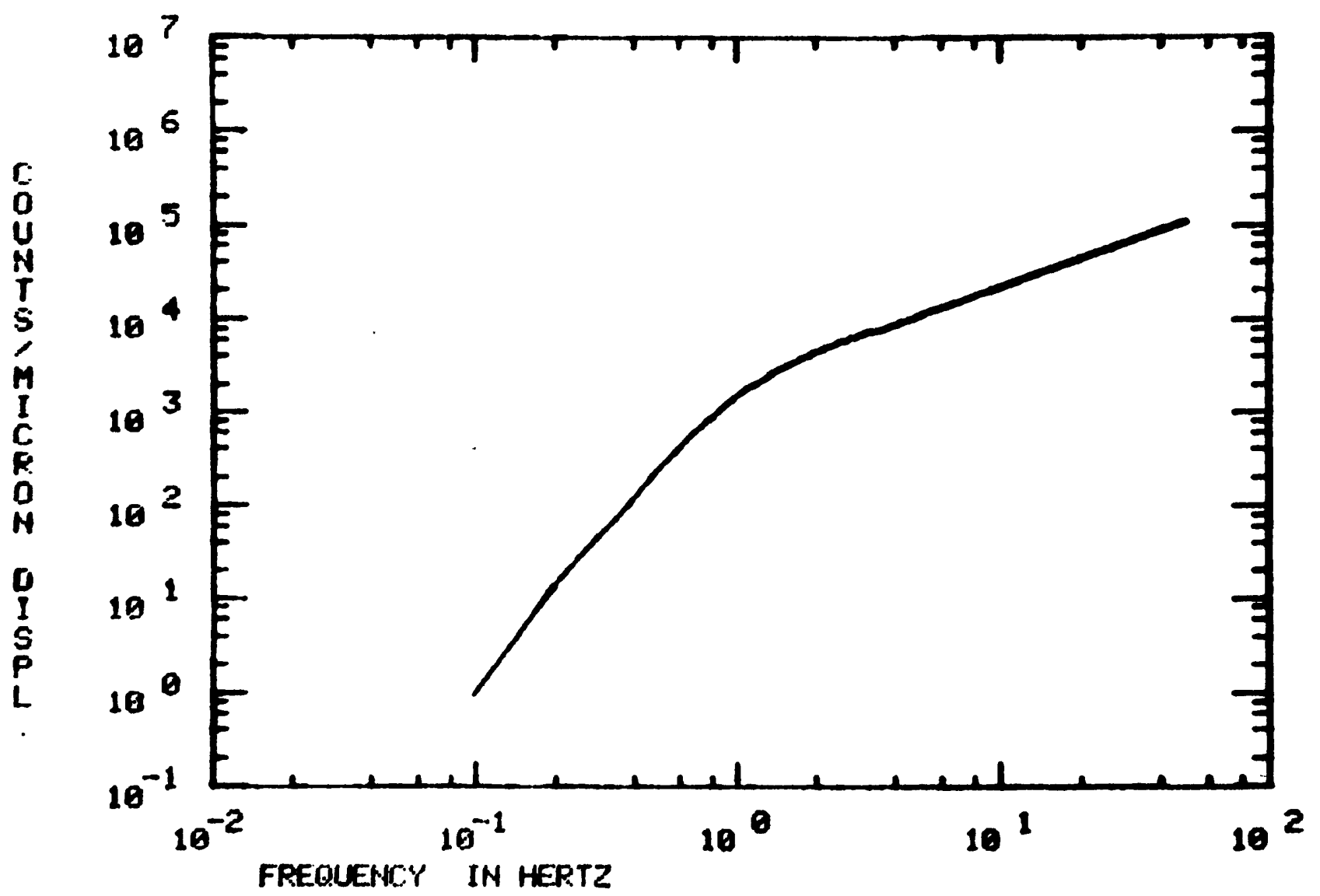

Figure 7.4. Pseudo-system amplitude response for station BGG. Empirical response for frequencies less than $3.26 \mathrm{~Hz}$; theoretical seismometer response for frequencies greater than $3.26 \mathrm{~Hz}$. 
$5:$

BGT BDrGS MTN

SYSTE.M

PESPONEE

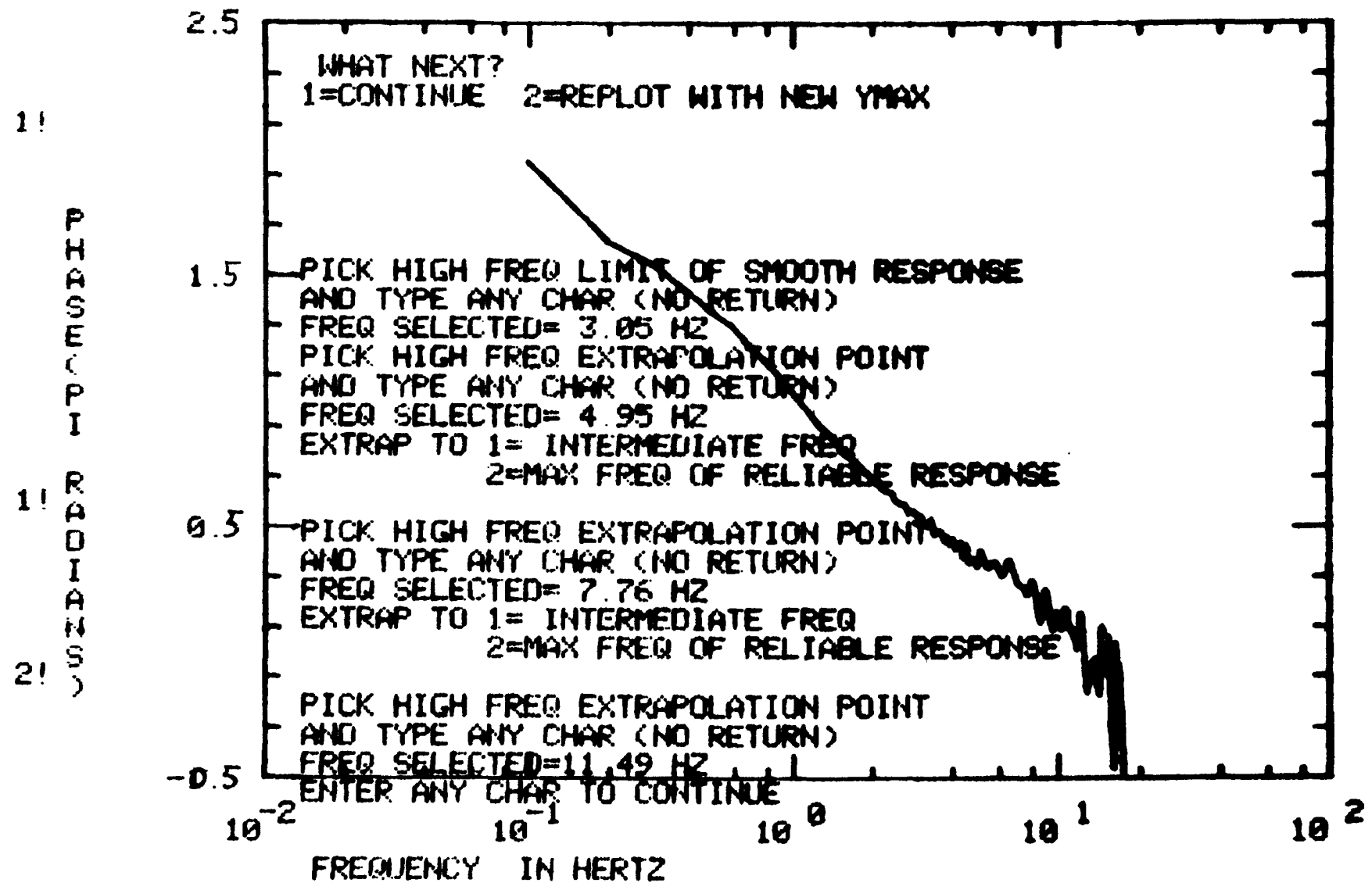

Figure 7.5. System phase response for seismographic station BGG. Superimposed text is the interactive dialogue by which the user selects points on the response for interpolation. 


\section{BGG BOCGS MTN SYSTEM RESPOMBE}

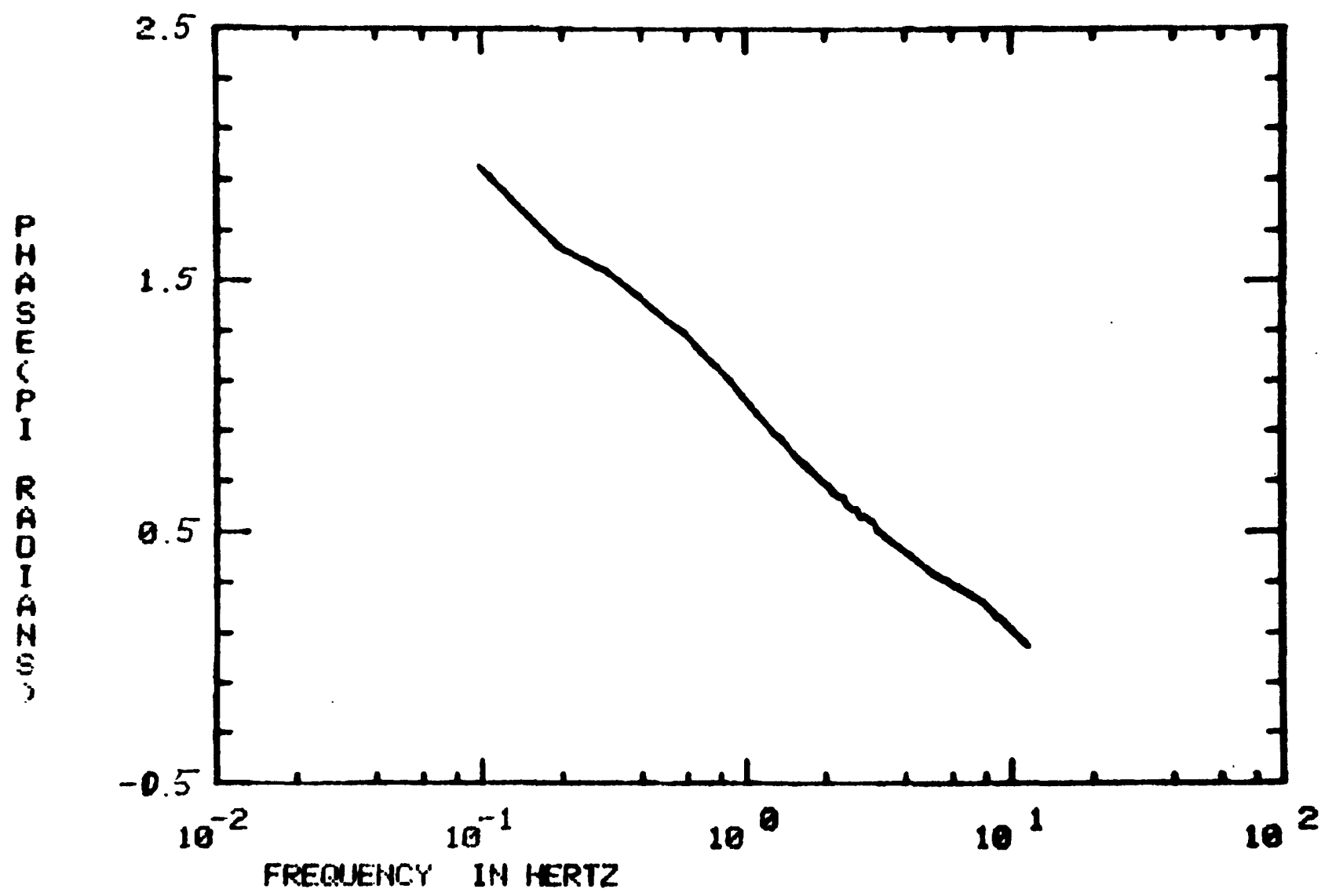

Figure 7.6. Smooth system phase response for station BGG. 
2 !

ENTER FILE NO OF ELECTRONICS RESPONSE

BCG BOCES MTN

ELECTRONIC RESPONSE

AMP IN CAIN

PHASE IN RW

IPNS

SAMP $/ S E C$ ID- 2 PLOT OATE= 03 OCT 73 LEM10.238 UPOATEN 12 SEP 75

ENTER 777 IF HRONG FILE ANY OTKER CWAR IF OK

s

Figure 7.7. Electronics response is the second file of local file "RESP"; after examining the titles from the second file, an " $S$ " is entered to proceed. 
D!

BCG BOCES MTI

ELECTKCHIC KESPONSE

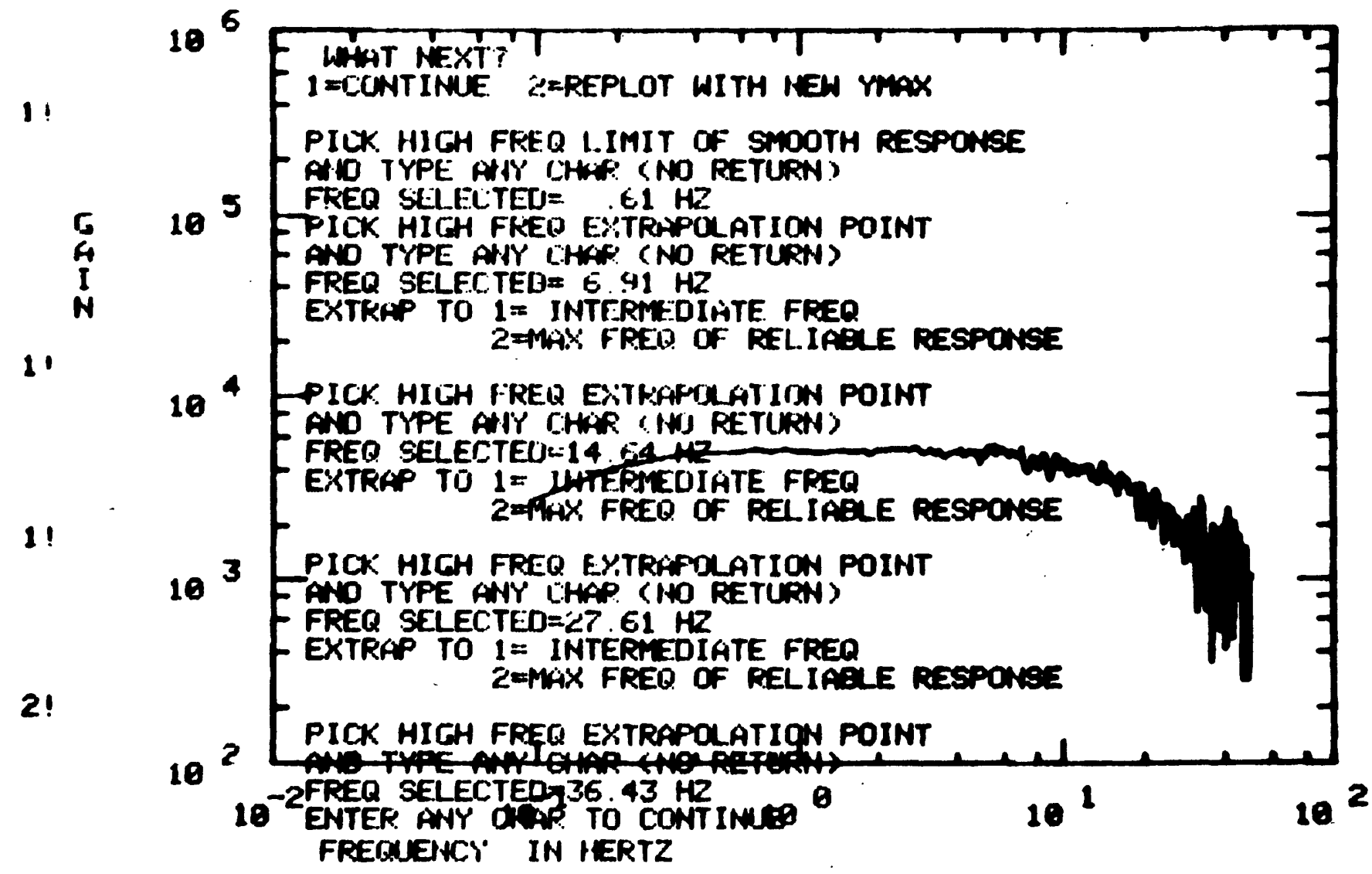

Figure 7.8. Empirical amplitude response of the electronics at station BGG. Superimposed text is the interactive dialogue by which the user selects points on the response for interpolation. 


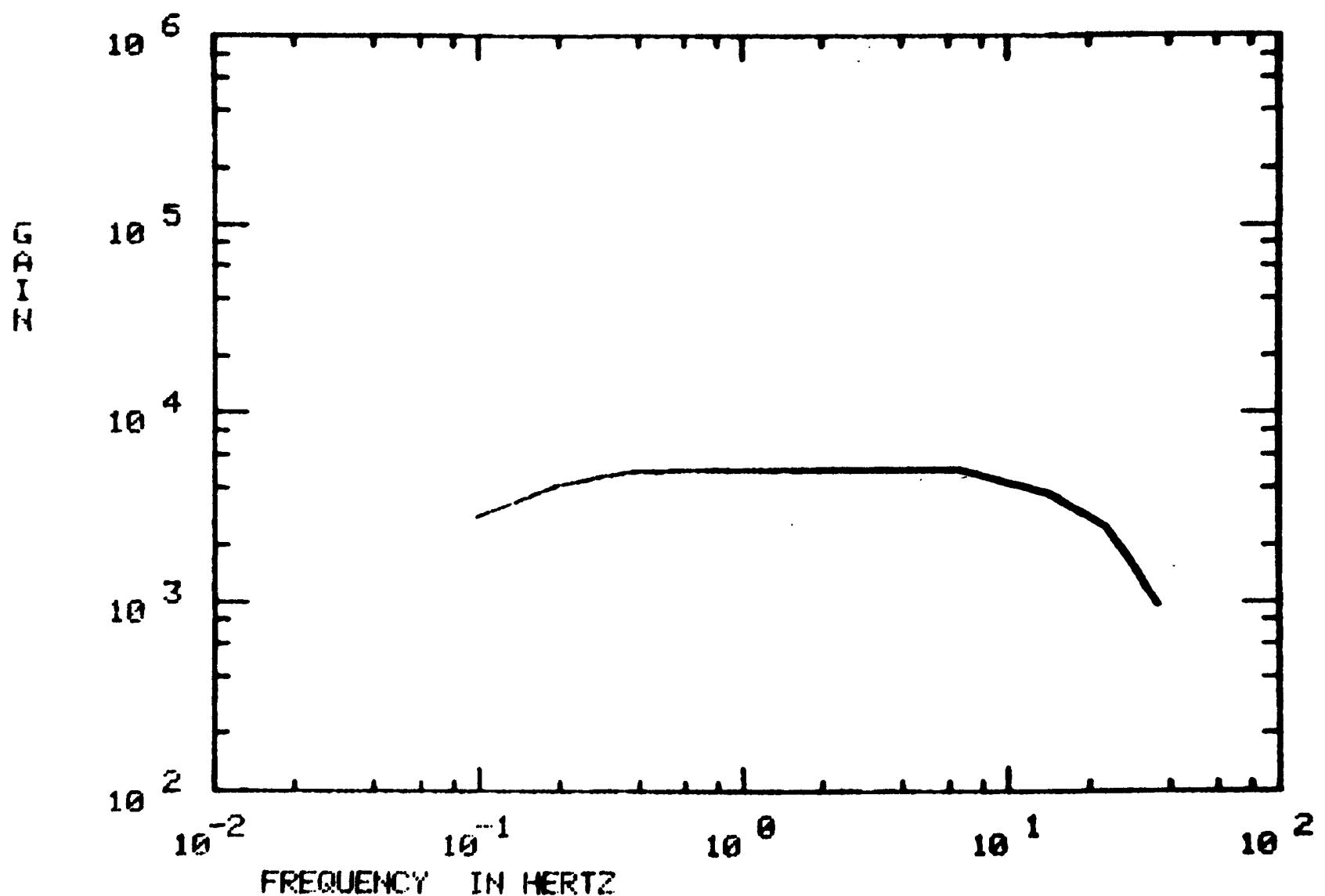

Figure 7.9. Smooth electronics amplitude response obtained by interpolation through the high frequency jitter of the empirical electronics amplitude response (see figure 7.8). 


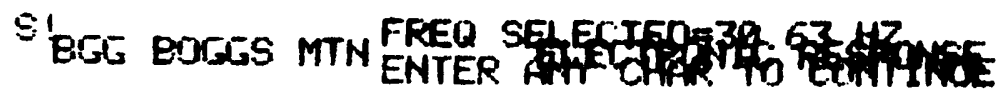

11

1.

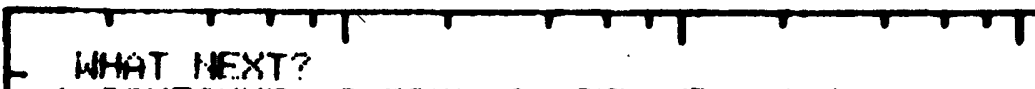

$1=$ COHTIHUE $2=$ FEPLOT WITH NEM YMAXX

0.

$P$
$H$
$A$
$S$
$E$
$⿱$
$P$
$I$

$P$
$H$
$A$
$S$
$E$
$⿱$
$P$
$I$

$P$
$H$
$A$
5
$E$
$\dot{P}$
$I$

$P$
$H$
$A$
5
$E$
$\dot{P}$
$I$

$P$
$H$
$A$
$S$
$E$
$\dot{P}$
$I$

$1 . \stackrel{F}{A}$

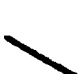

PICK HICH FEEO LIMIT OP

AND TVPE AN'Y LHAP (NDO RETLPN)

FRED SELECTED $=6.09 \mathrm{HZ}$

PICK HIGH FREQ EXTRPAOLATION POINT

AND TYPE ANY CHAR (NO RETLRN)

FREO SELECTEU:= $9.77 \mathrm{HZ}$

EXTRAF TO $1=$ INTERTAOIATE FREQ

$Z=$ MW: FREQ (f REI IAQLE RESPONSE

$-1$

(t)

CK. HIGH FFEG EXTRAPOLATION POINT

AHD TYPE AN'Y CHAK (NO RETUPN)

FRED? SELECTED $=13.98 \mathrm{HZ}$

EXTRAP TO $1=$ IHTERTEOIATE FREQ

2=MAN FREQ OF REL IAELE RESPONSE

$1 ! 3$

$2 !$

PICK HIGH FREQ EXTRAPOLATION POINT

ANO TYPE AN'Y CHAP? (HO RETURN)

-2 . $10^{-2}$

FREQ SELECTED $=25,18 \mathrm{H}^{\circ}$

EXIRAP TO $1=$ INTERTEOTATE FliEQ

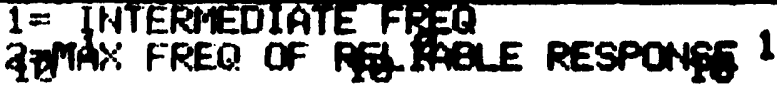

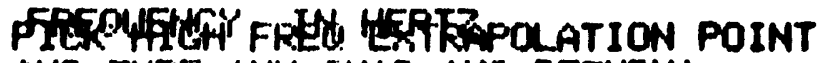

AND TYFE ANIY OHAP (NO RETURN)

Figure 7.10. Empirical phase response of the electronics at station BGG. Superimposed text is the interactive dialogue by which the user selects points on the response for interpolation. 
ELECTRONIC RESPONSE

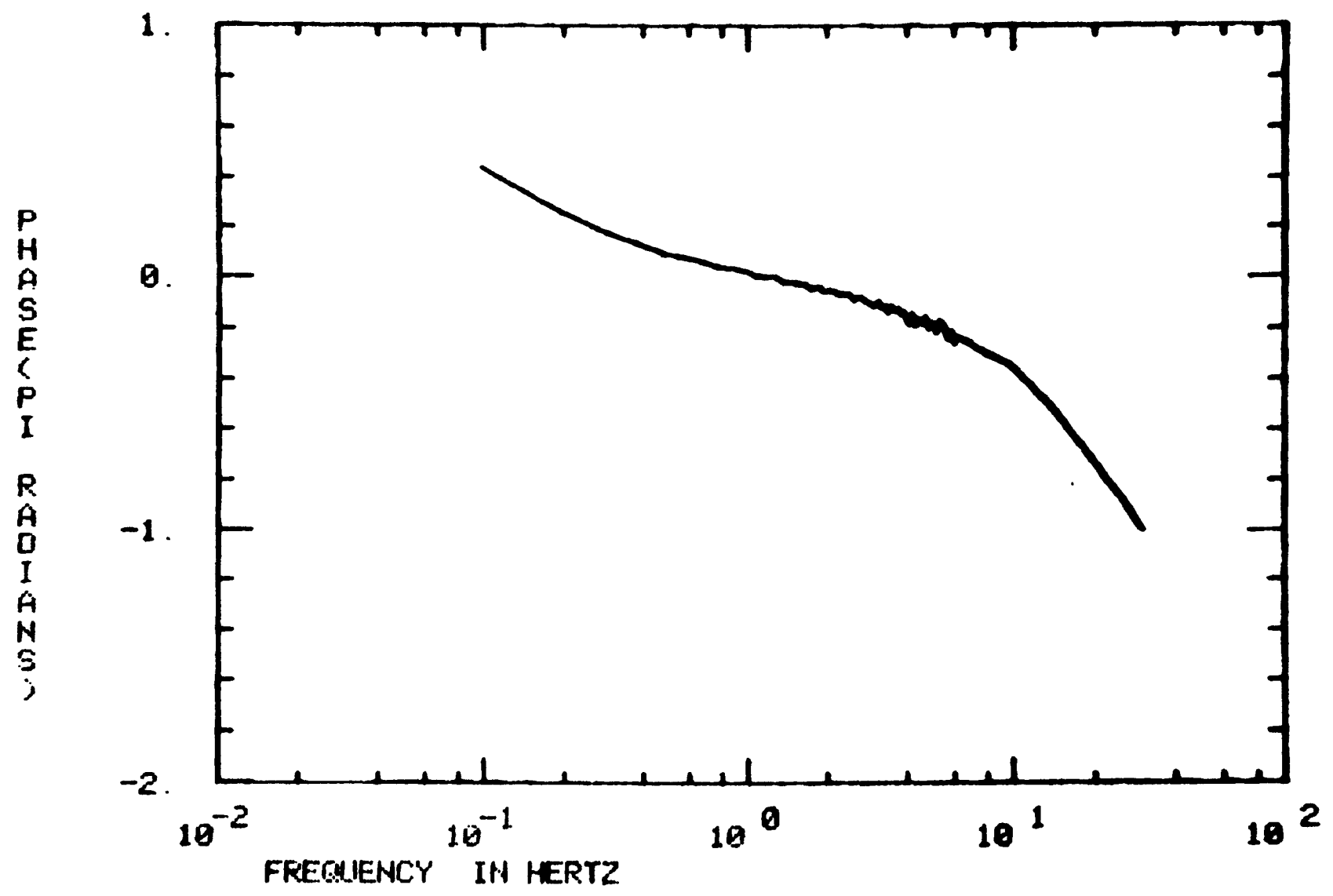

Figure 7.11. Smooth electronics phase response obtained by interpolation through the high frequency jitter on the empirical electronics phase response (see figure 7.10 ). 
BGG BOGGS MTM

SYSTEM RESPONSE

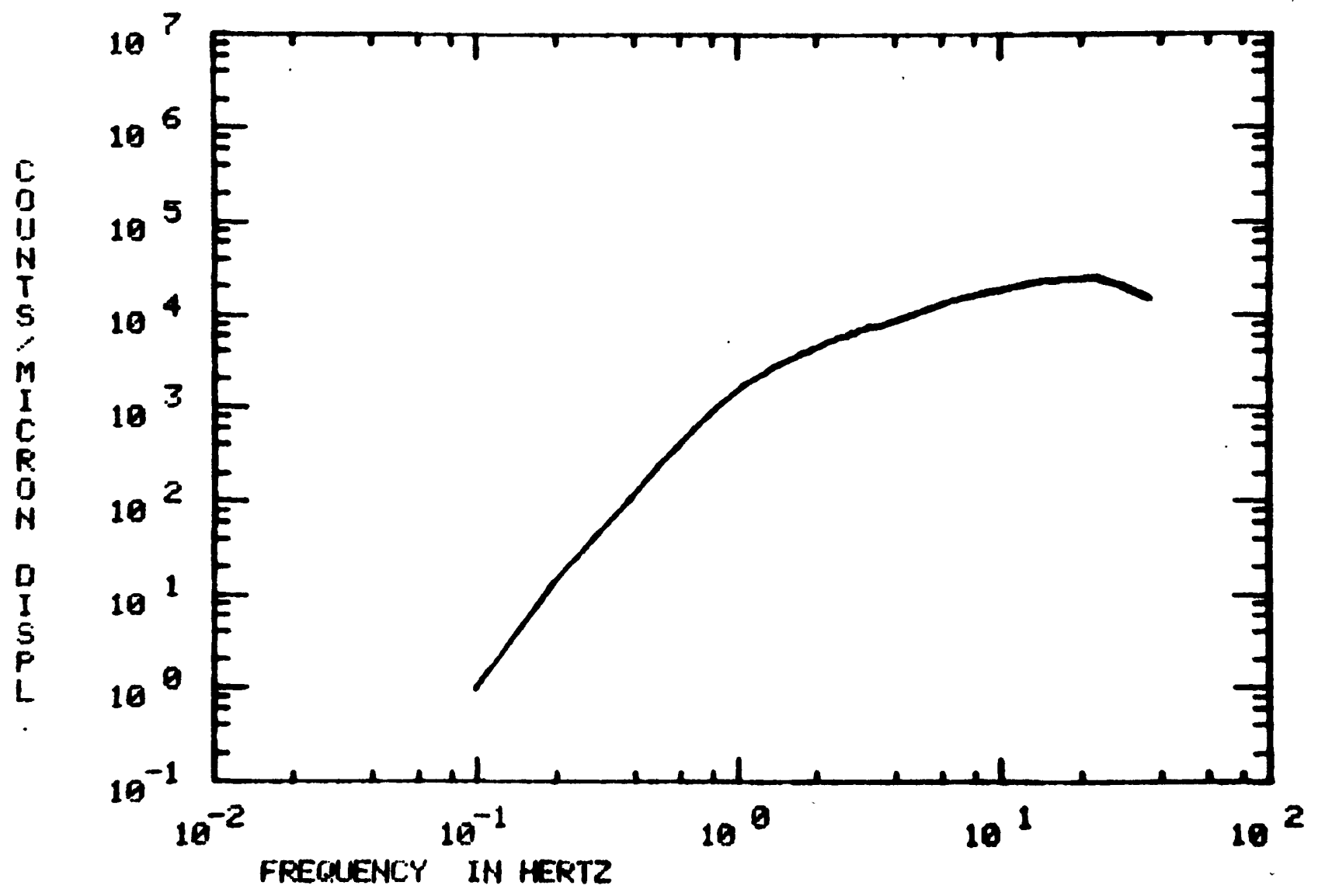

Figure 7.12. Smooth system amplitude response for seismographic station BGG. 
BISG EOTSGS MTN SYSTEM RESPONSE

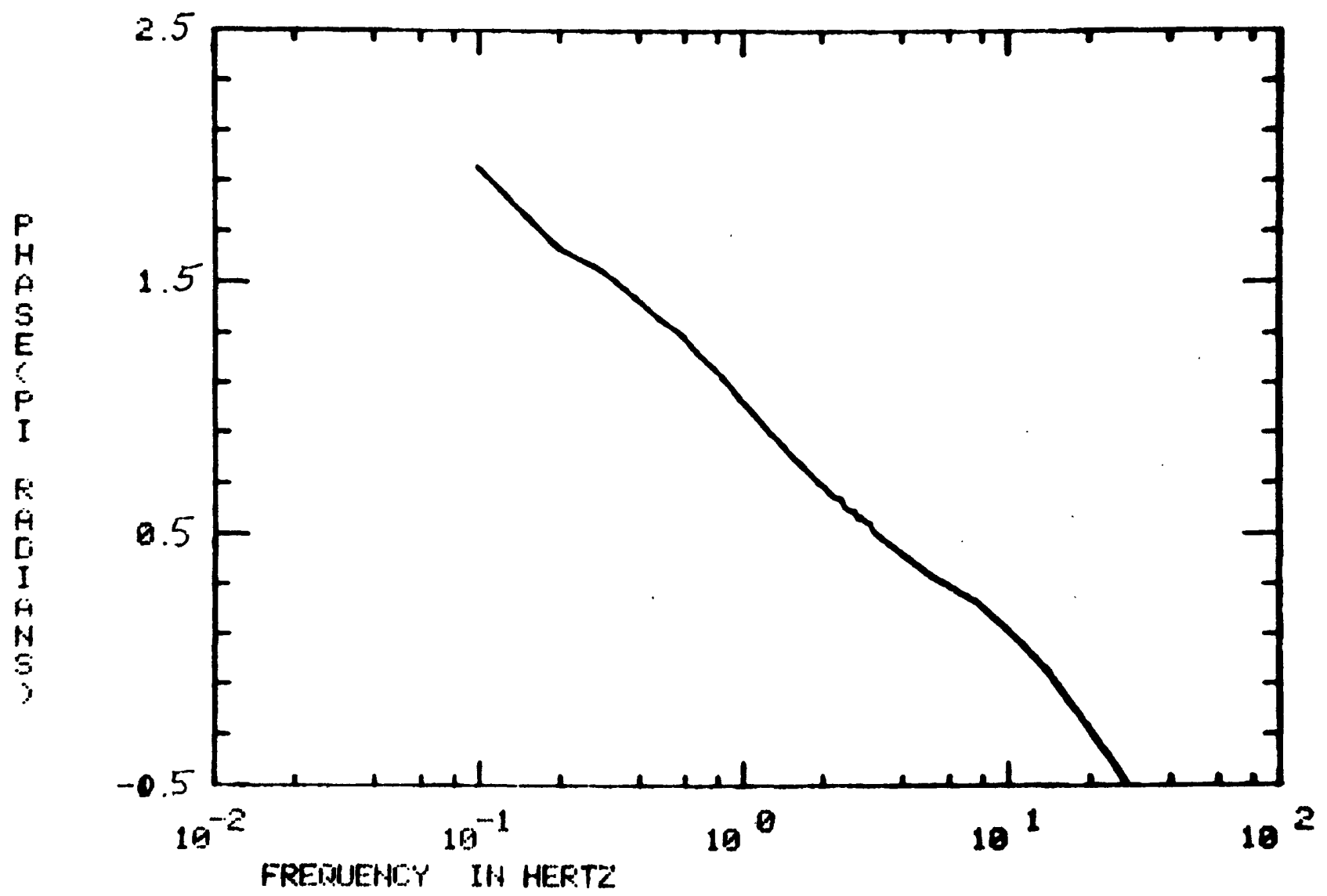
Figure $7 \dot{1}^{13}$ Smooth system phase response
for seismographic station $B G G$. 


\section{BIGG BOGSS MTN SYSTEM RESPONSE \\ DUTPUT TO FILE 1 ON DISC FILE "SYSFESP" \\ MAN FREQ OF AMFL ITUOE( PHASE) RESPONSE $=36.4(39.7) \mathrm{HZ}$ \\ WHAT NEXT? $1=S T O P$ 2=FIX AMOTHER SYSTEM RESPONSE \\ 1 ! \\ OK - NEDIT}

Figure 7.14. Smooth system responses written to disc file SYSRESP. Option to terminate execution or smooth another empirical system response on file RESP. 

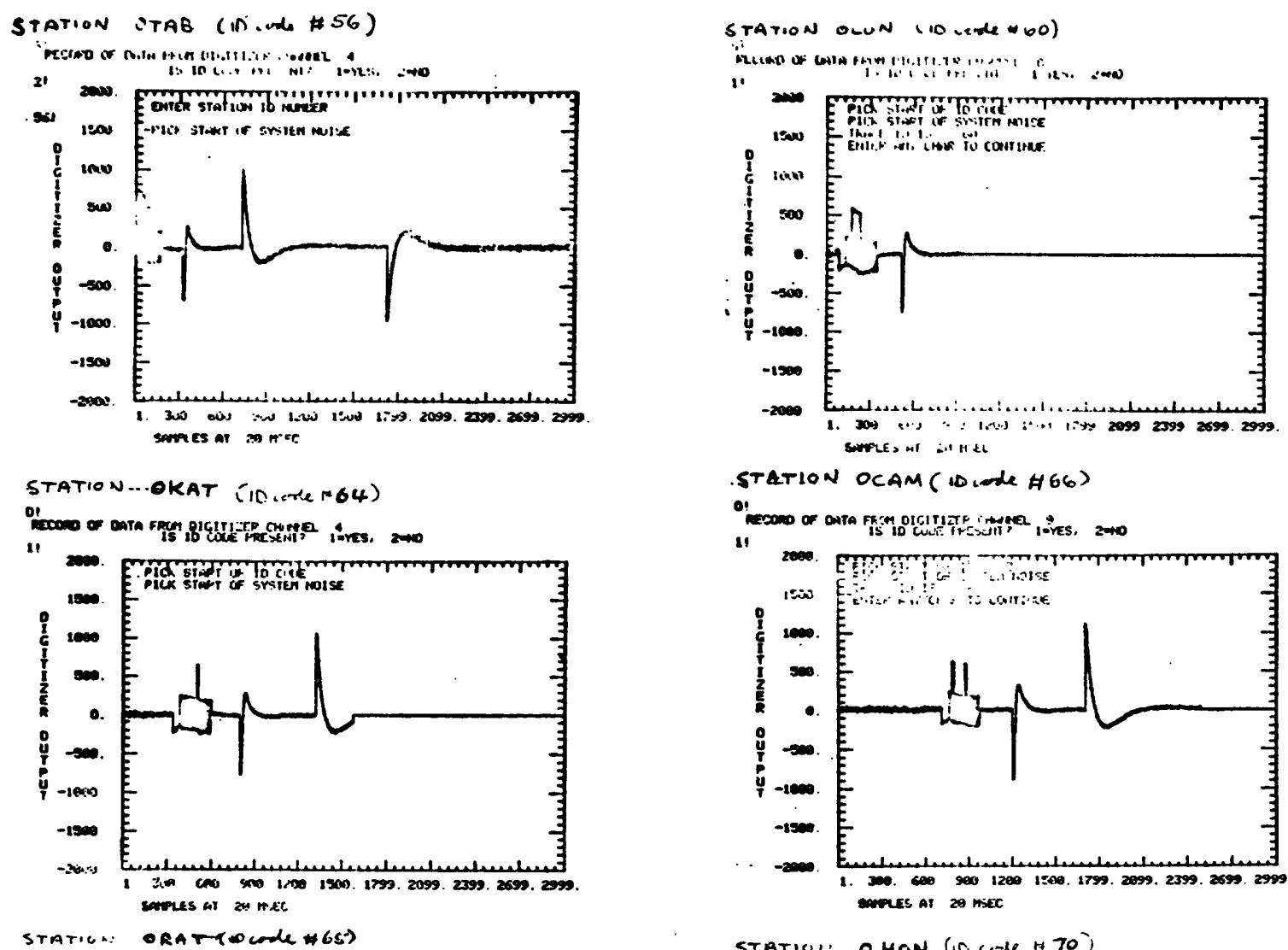

STATION OCAM ( 10 Lade $H 66)$

$$
\text { o! }
$$

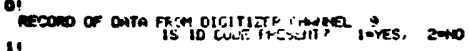
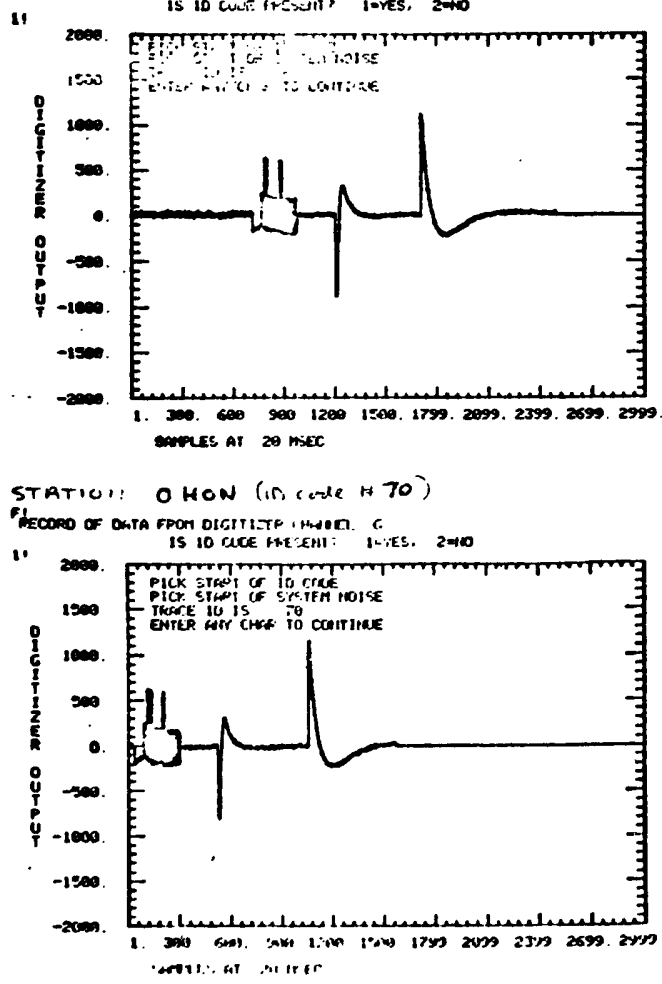

Figure $\mathrm{Cl}$. Digitized calibration signals from the Oroville net. 

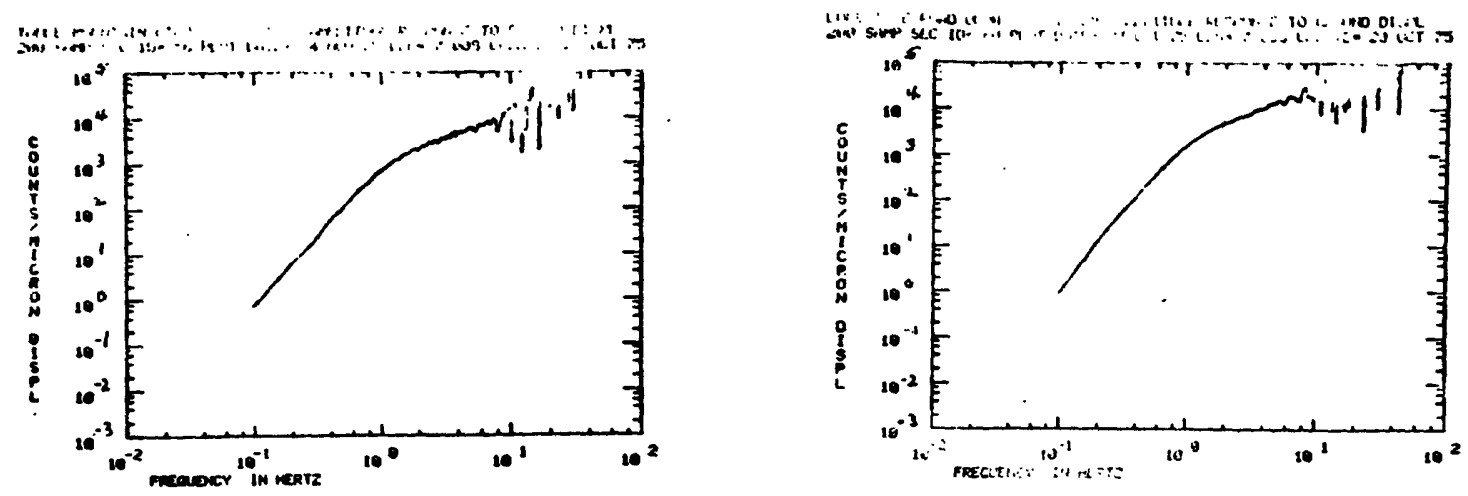

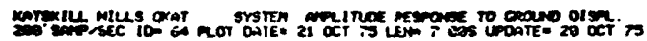

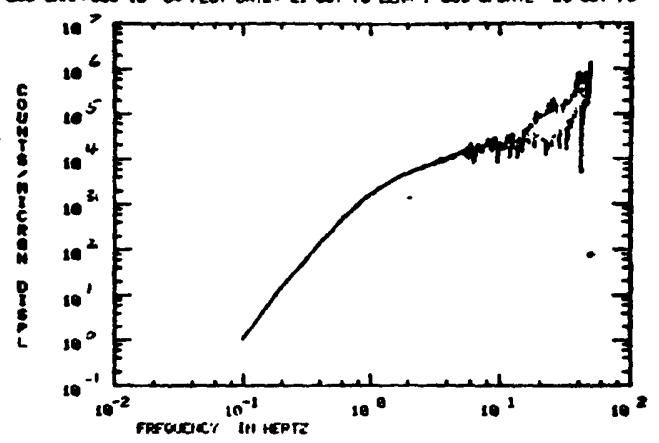

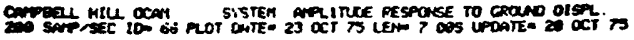
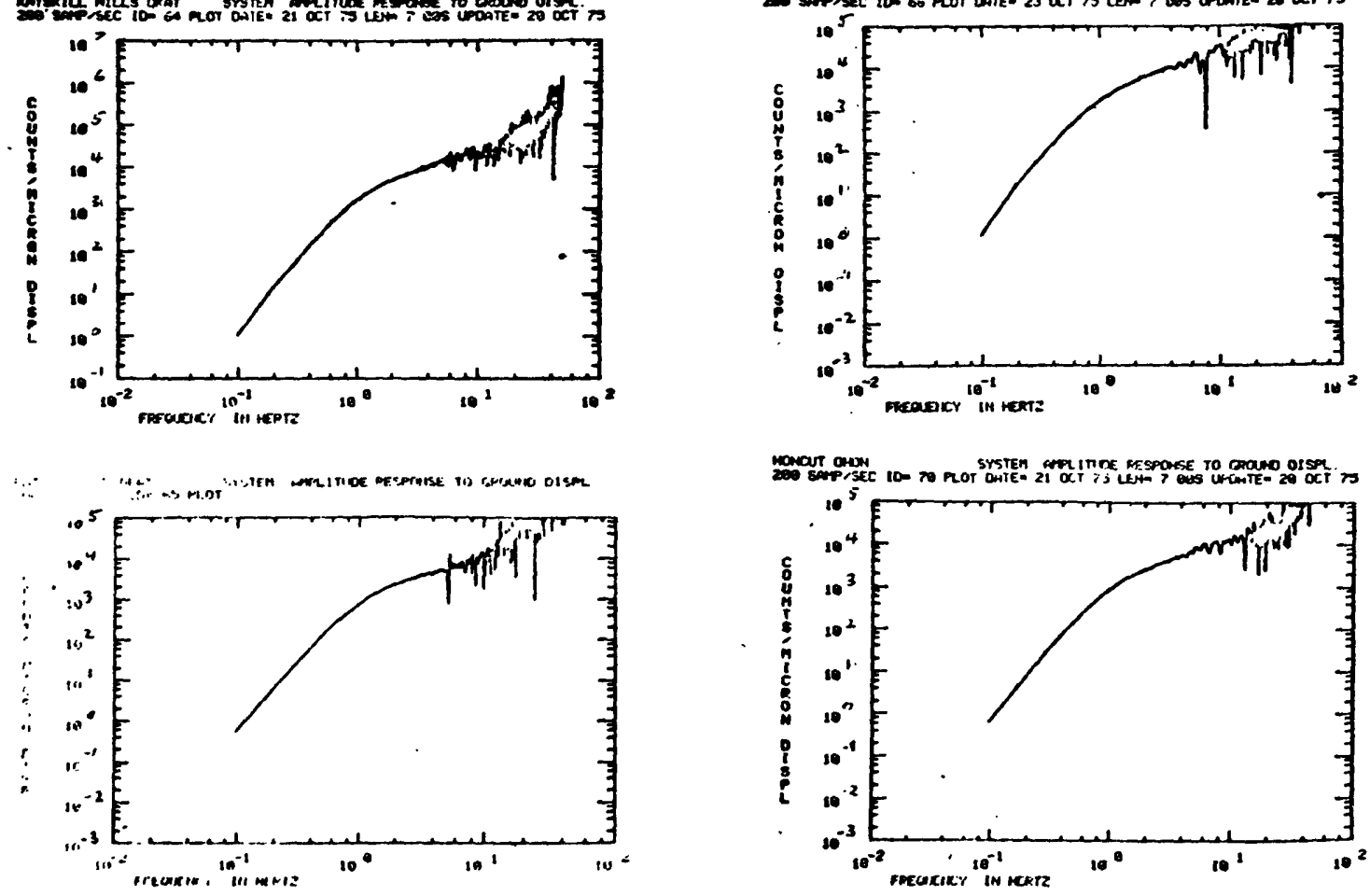

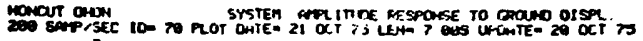

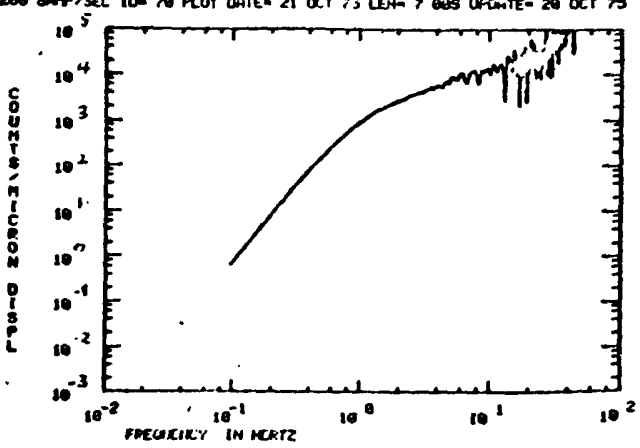

Figure C2. System amplitude response functions for stations in the Oroville net. 


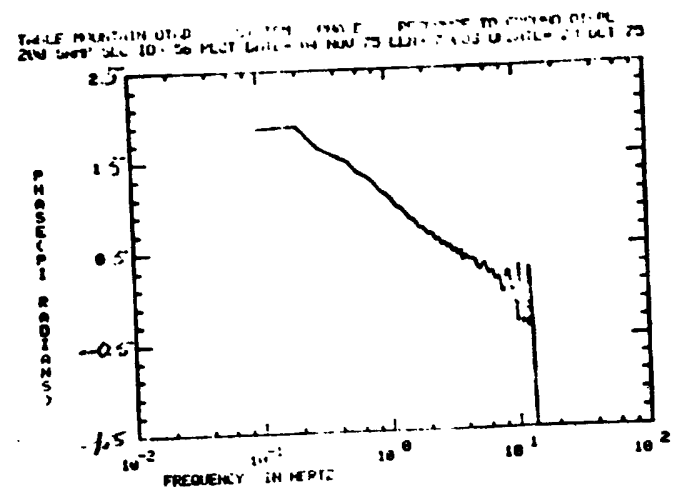

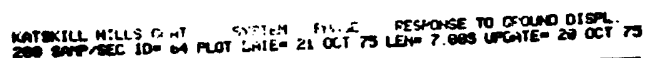

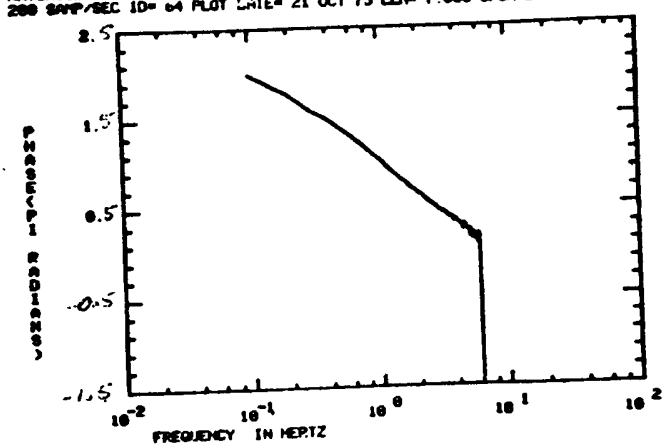

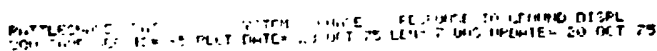

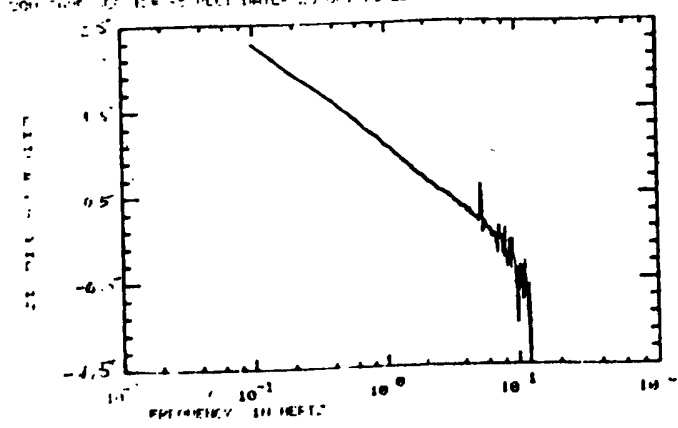

$\therefore$ ar.

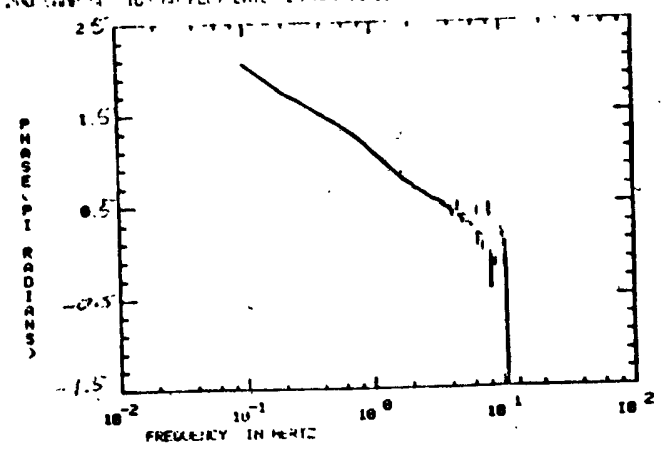

civy

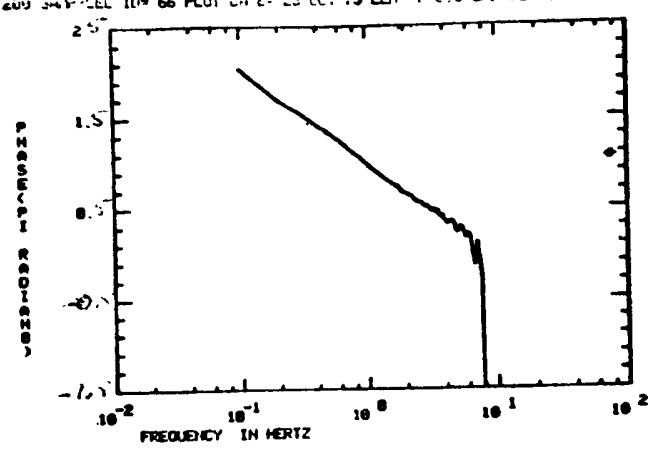

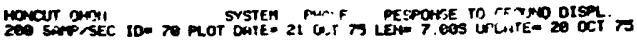

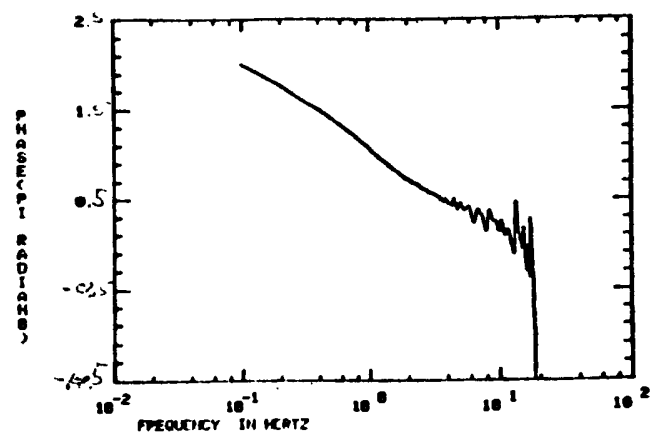

Figure 13 . System phase response functions for stations in the Oroville net. 


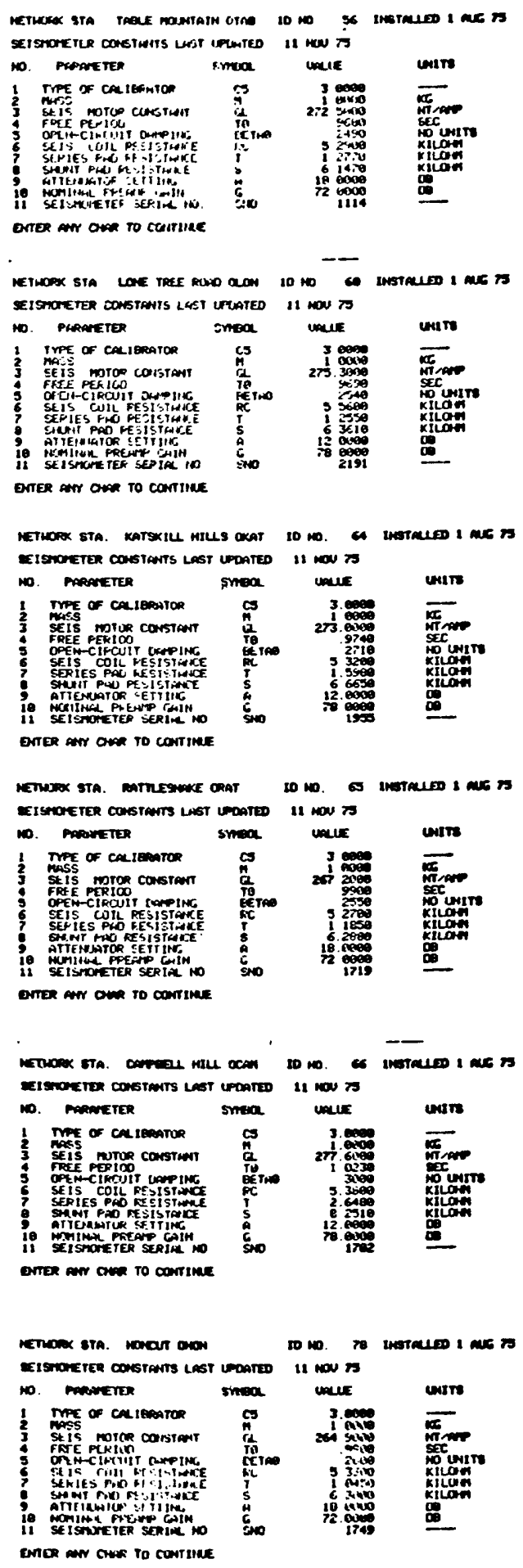

Figure C4. Seismogràph constants from the seismometer constants table for stations in the Oroville net. 


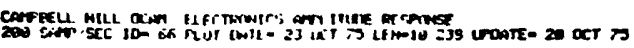

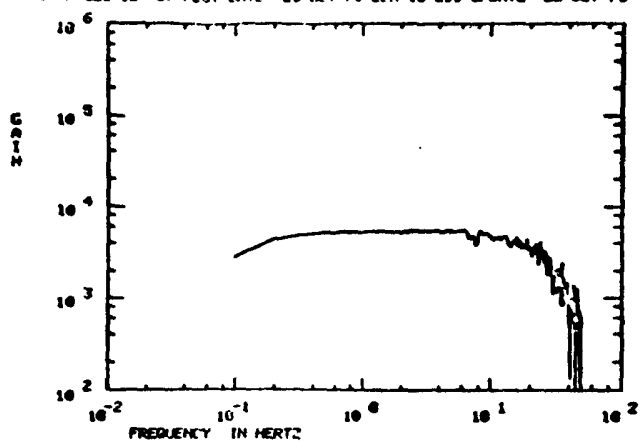

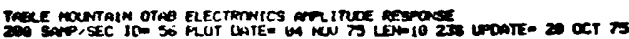

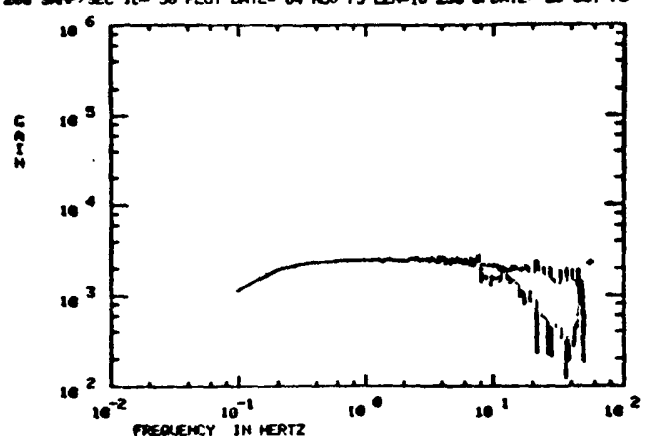

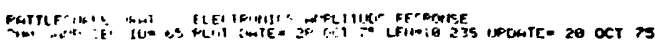

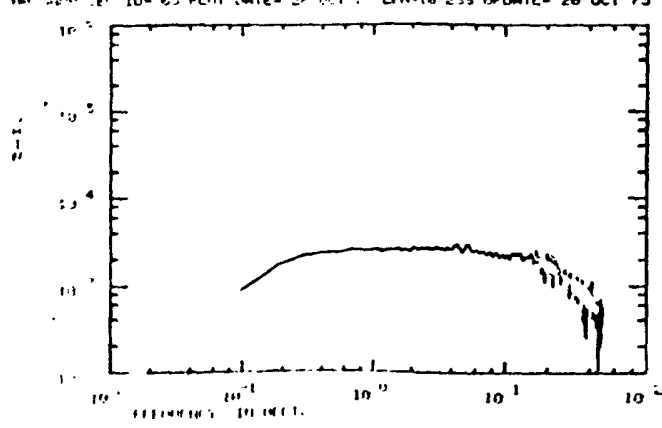

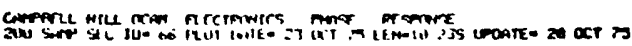

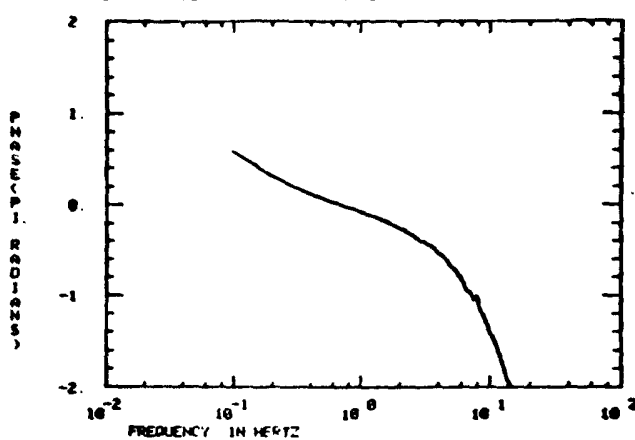

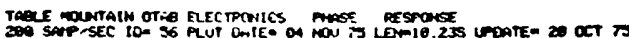

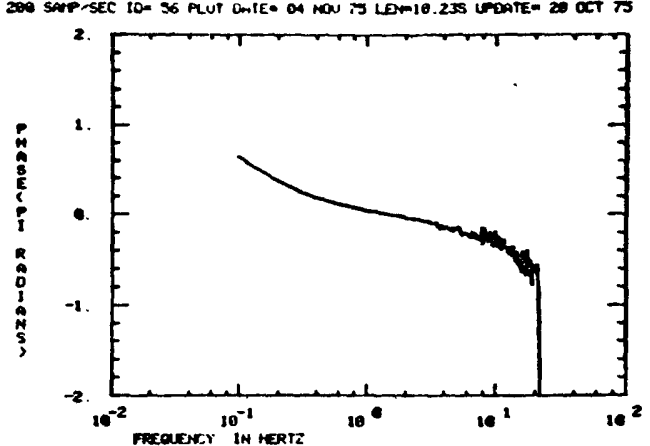

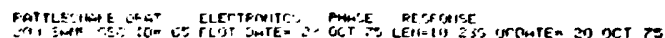

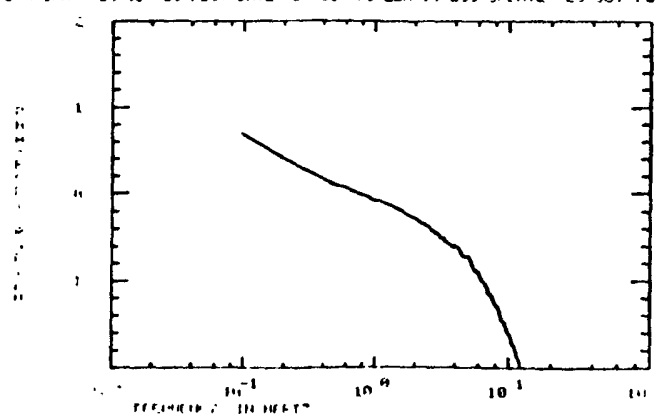

Figure C5. Electronics response functions for stations in the Oroville net. 
$P$ WAUE AT OCAM 10 SEPT 75 1215CMT

1.9995EC MANOR DIU. MIKDON LEK=19.995SEC

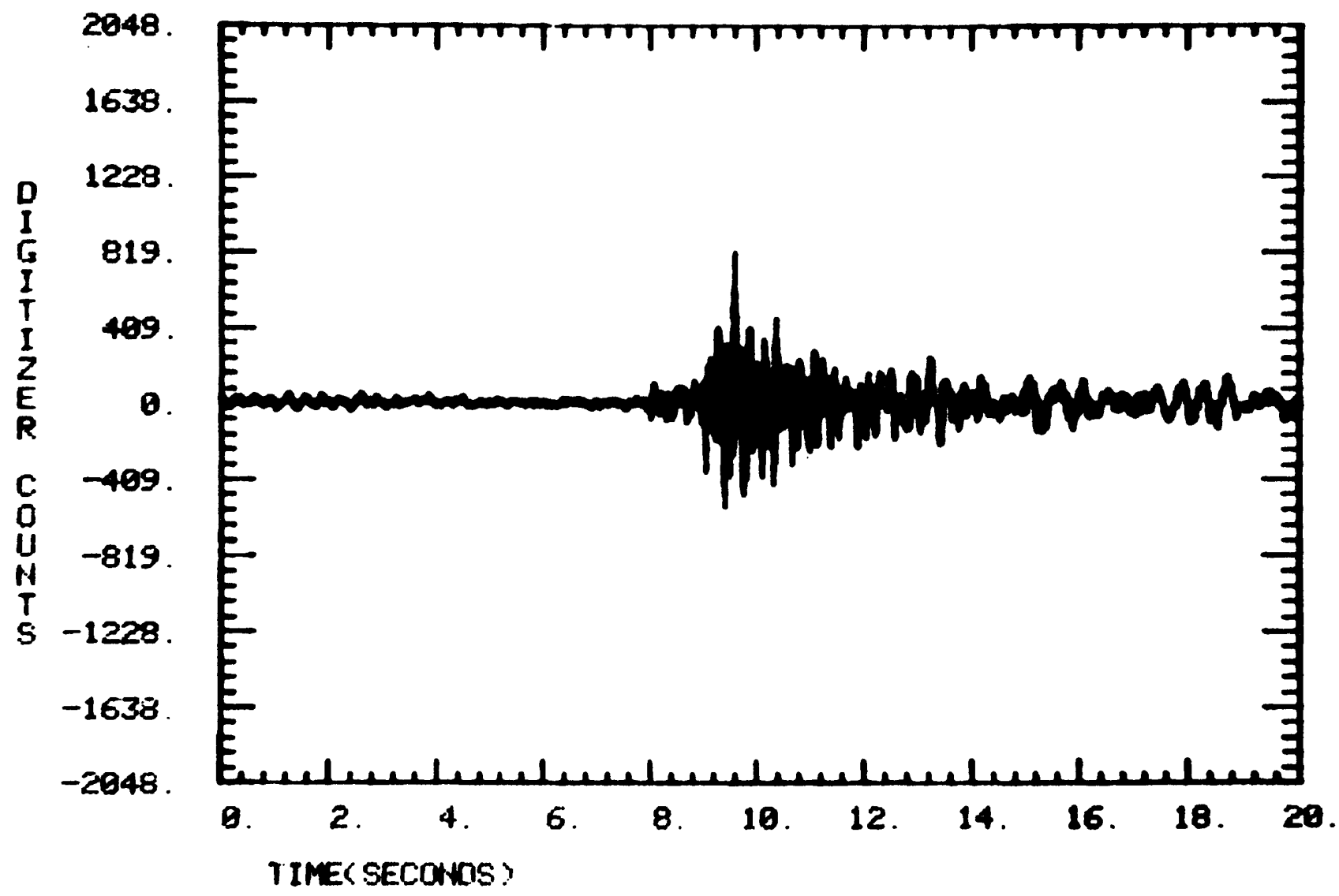

Figure C6. OCAM seismogram (Z) for the $M=110$ Sept. 75 OT $=1216$ GHTT Oroville aftershock. 
10 SEPT TS 12160MT AT STA. OCAM

HINDON LEN $4.43055 C$

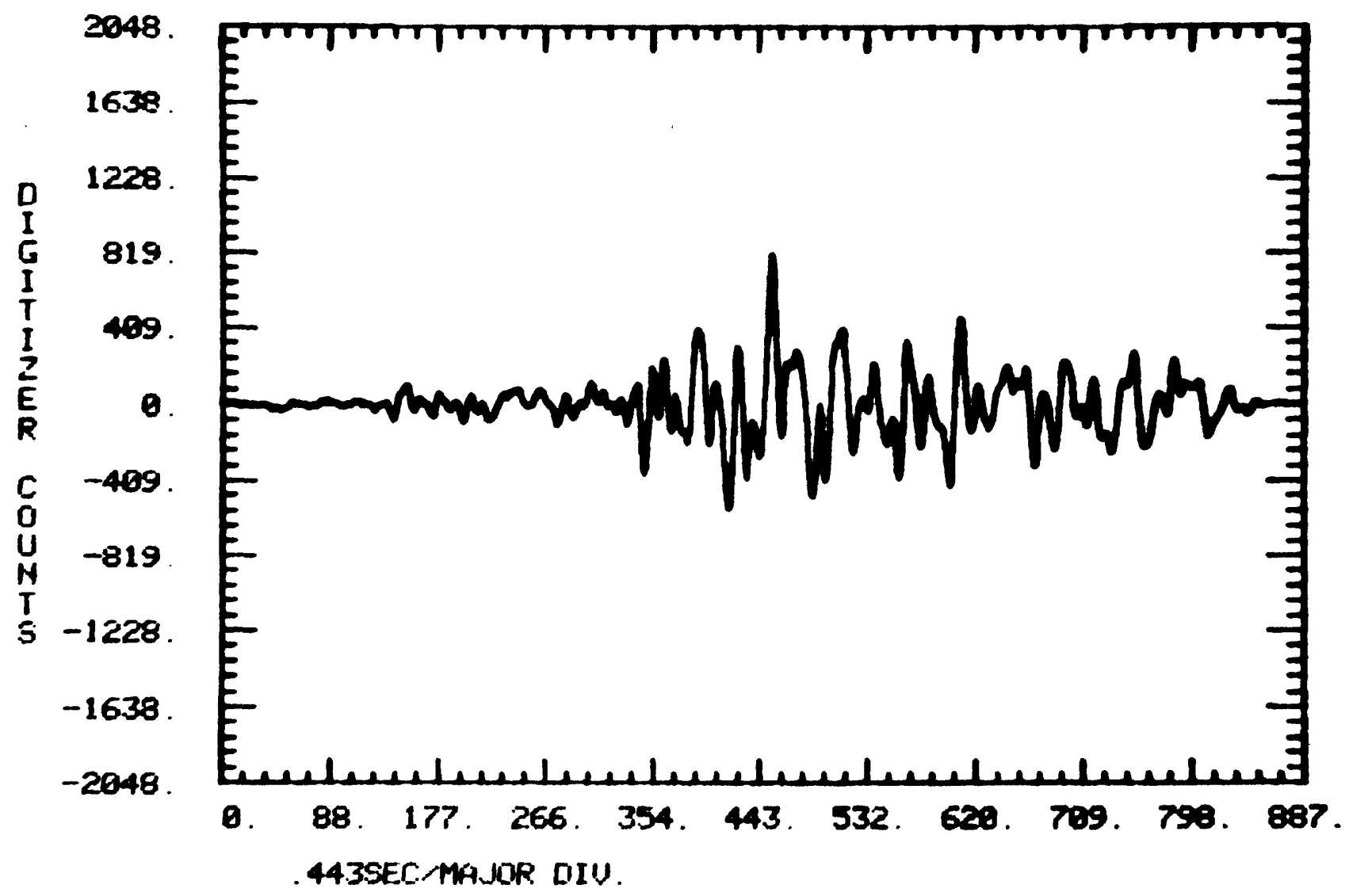

Figure C7. A 4.435 second segment of the OCAli seismogram ( $Z$ ) for the 10 Sept. 75 OT $=1216$ GMT Oroville aftershock. A $10 \%$ Hanning window has been applied to the end of the segment. 
SYSTEM AMPL I TUOE(PAHSE) RESPONSE RELIAELE TO 36.430 .7 ) HZ

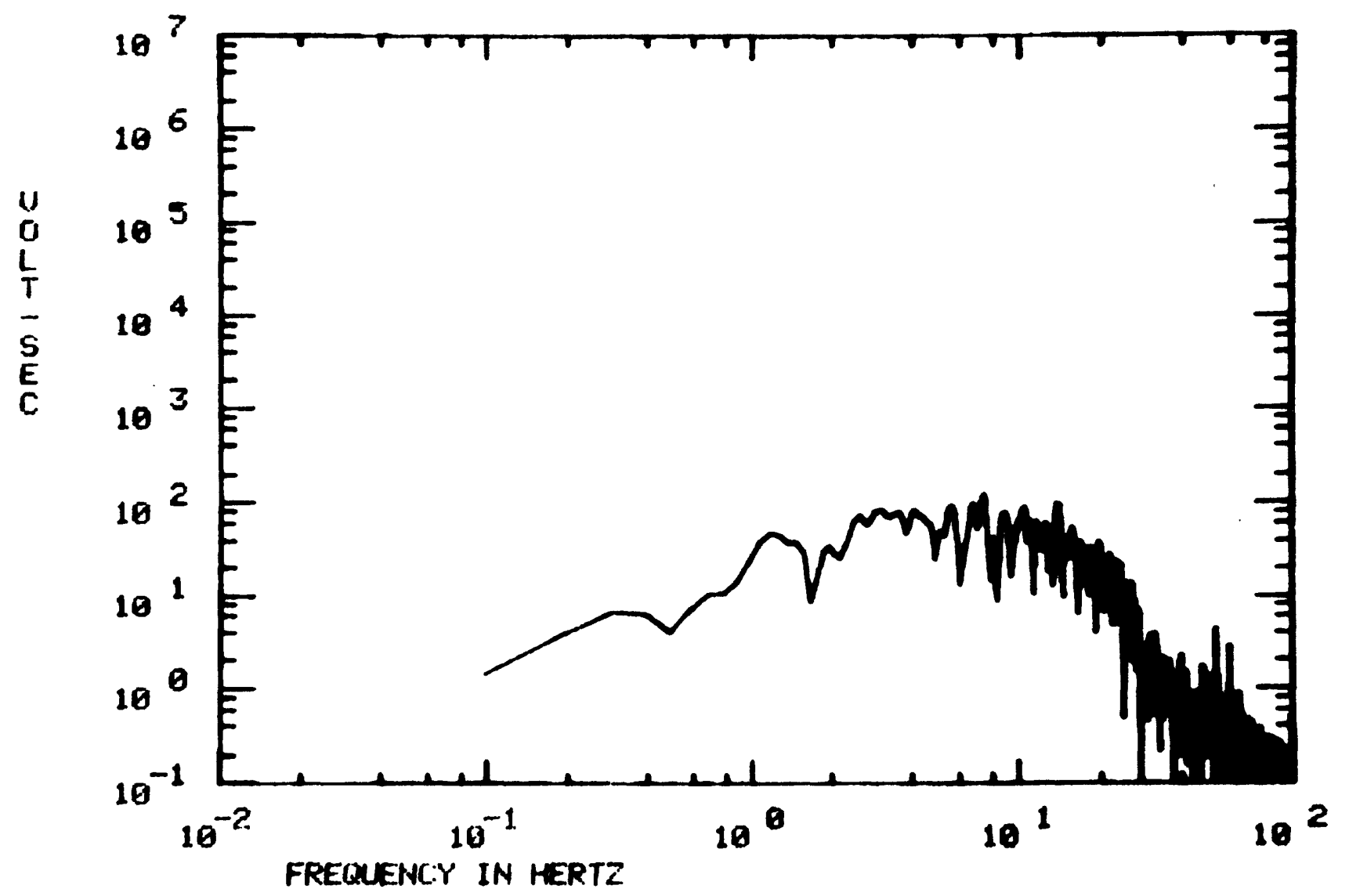

Figure c8. Fourier amplitude spectrum for the signal shown in Figure $\mathrm{C7}$. 
10 SEPT 75 121ECMT AT STA. OCAM

STSTEM AMPL I TUDE (PHASE) RESPONSE REL IFELE TO 36.430 .7 ) HZ

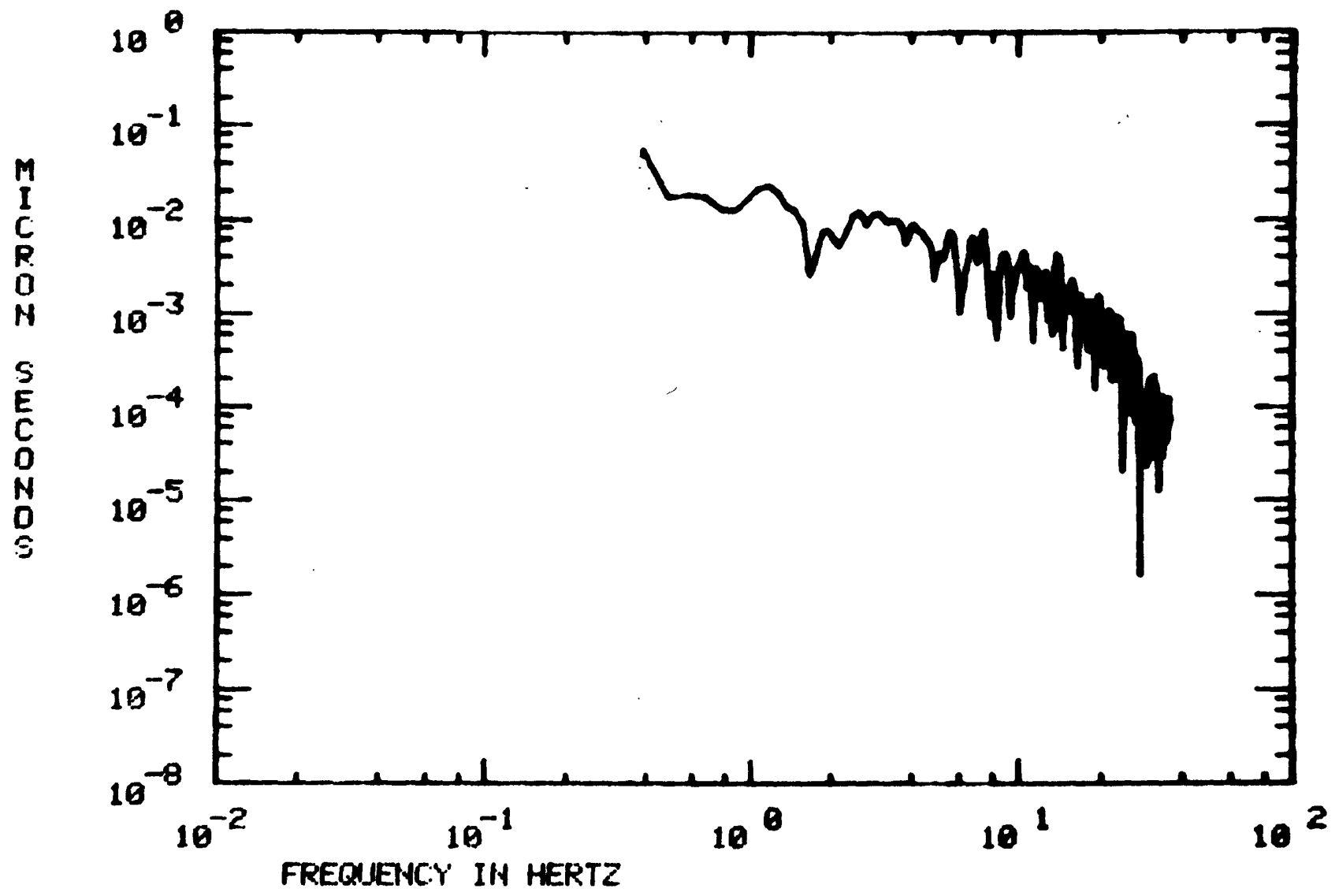

Figure C9. Ground displacement spectrum at station OCAM for the 10 Sept. 751216 GMT Oroville aftershock. 
18 SEPT 75 1216CMT AT STA. OCAM

OISPLACEMJT

FOR THE .29-30.66 HZ BAND

HIMboh LeN $4.4305 x$

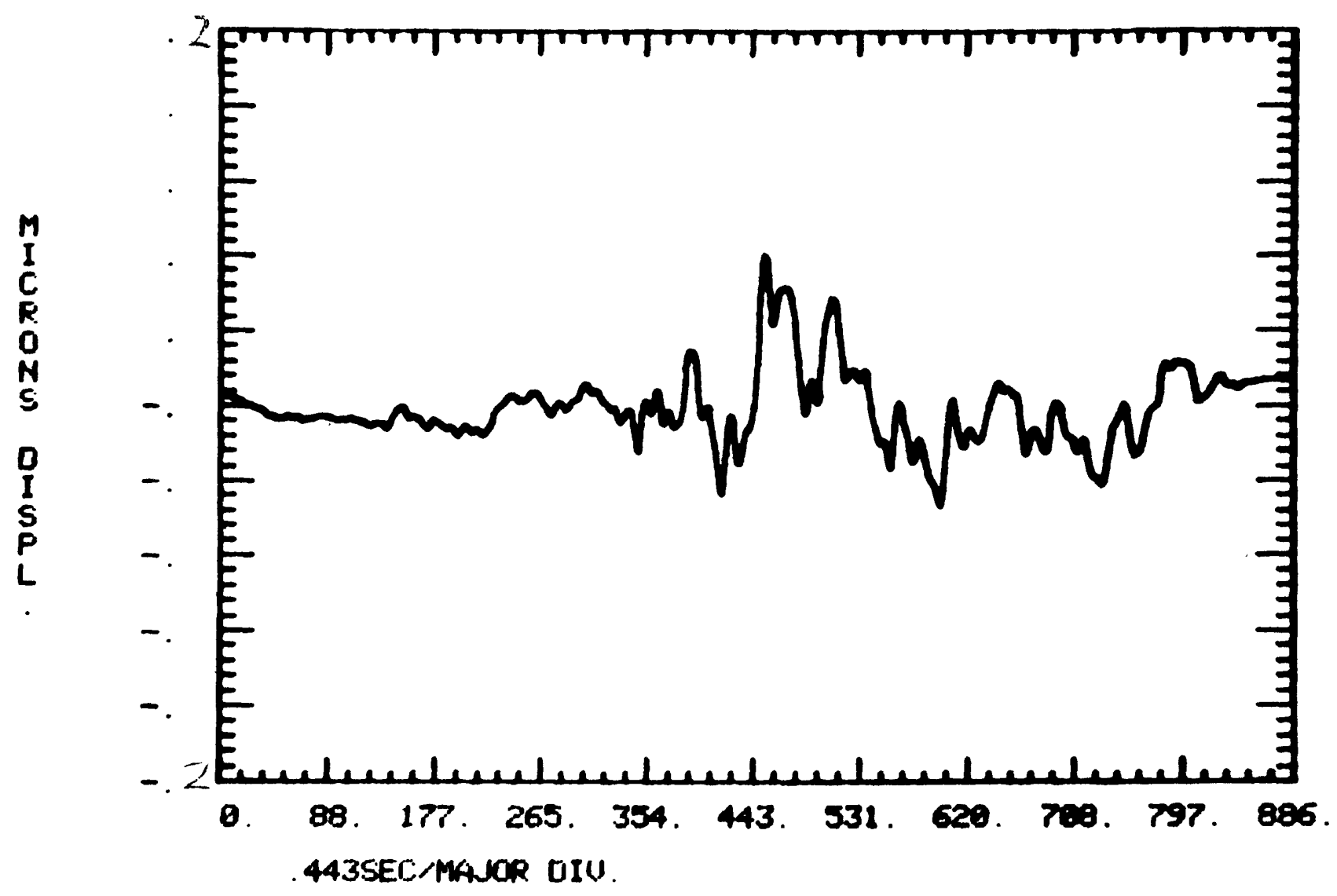

Firura C1C. Displacement trace criresponding to the signai shown in figure $\mathrm{C7}$. Linear ordinate scale (+0.2 micron) vs. Iinea:- abscissa scáie (0 to 4.43 seconds). 
FCR THE 29-30.66 HE BAND MIKDON LEN 4. 430SESC

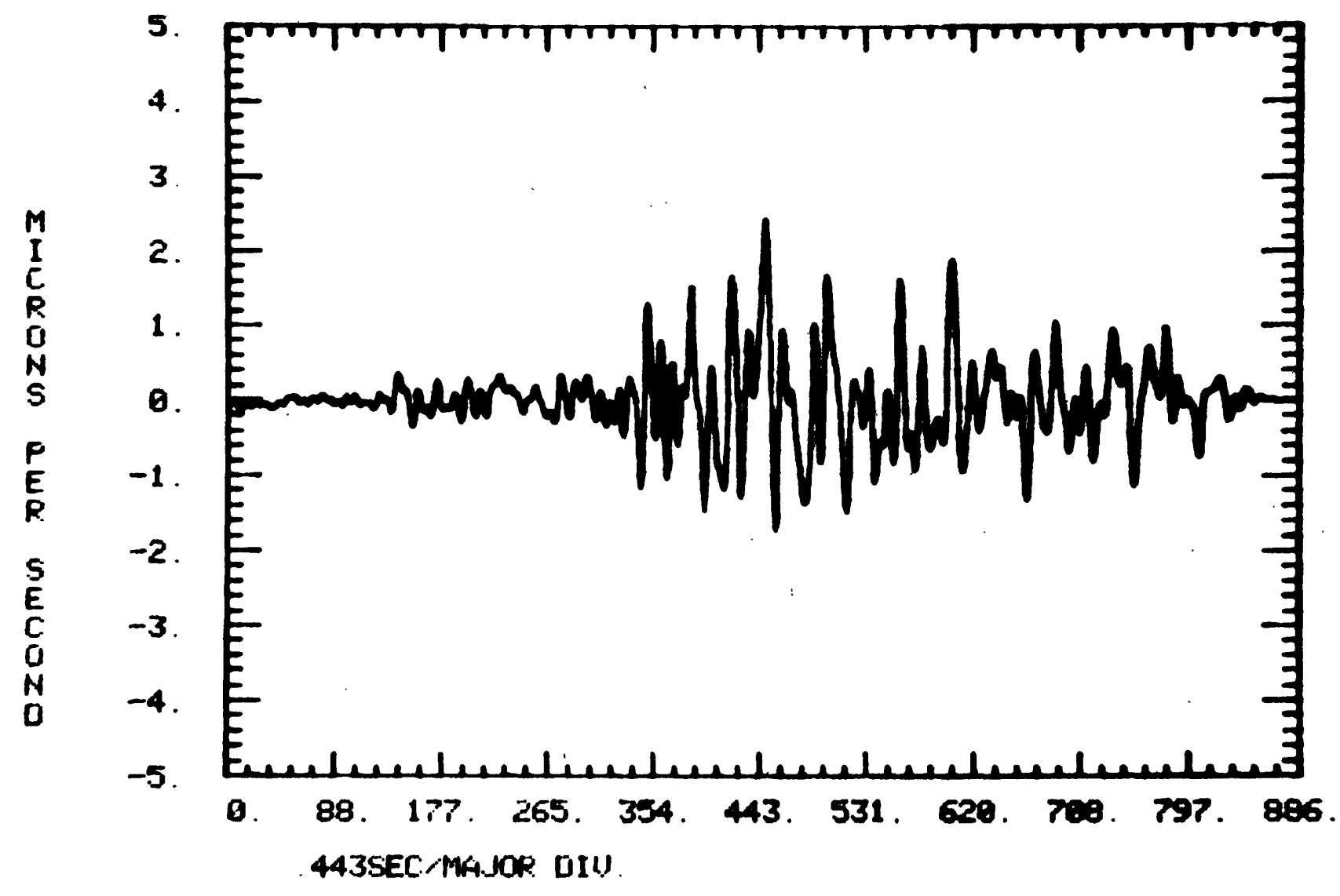

Figure $\mathrm{Cll}$. Velocity trace corresponding to the signal shown in Figure $\mathrm{C} 7$. 


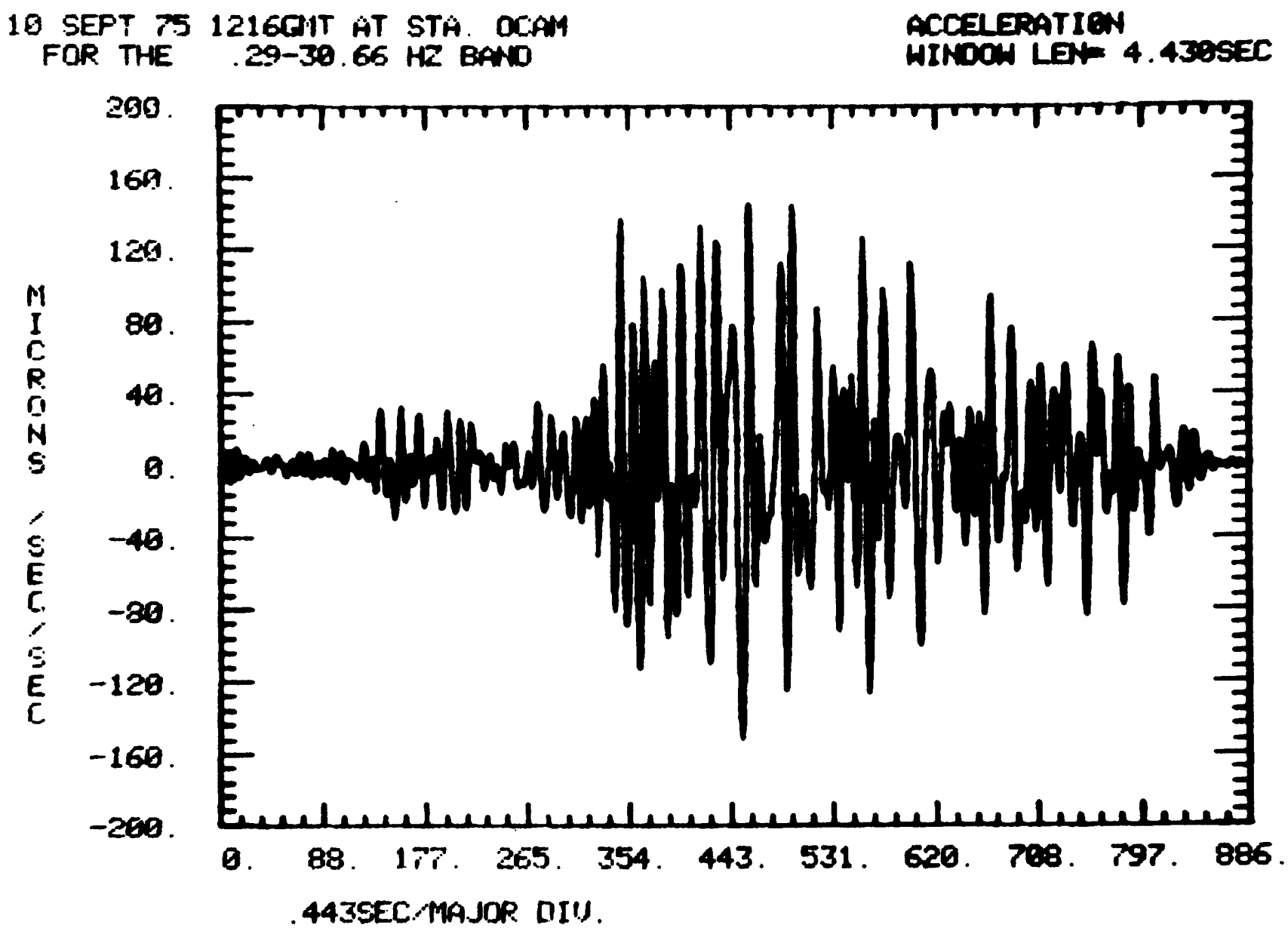

Figure $\mathrm{C12}$. Acceleration trace corresponding to the signal shown in figure $\mathrm{C} 7$. 